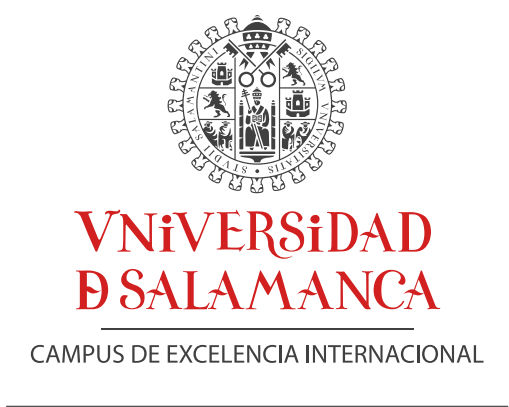

FACULTAD DE BIOLOGÍA

DPTO. DE BIOLOGÍA ANIMAL, PARASITOLOGÍA, ECOLOGÍA, EDAFOLOGÍA Y QUÍMICA AGRÍCOLA

TESIS DOCTORAL

\title{
AVIFAUNA DEL PLEISTOCENO SUPERIOR-HOLOCENO DE LAS PITIUSAS: PASSERIFORMES Y SUS DEPREDADORES
}

\author{
Memoria presentada por Carmen Guerra Rodríguez \\ para optar al título de Doctor en Ciencias Biológicas
}

V.B. del Director

Dr. Josep Antoni Alcover Tomàs, IMEDEA (CSIC-UIB) 

a mi familia 



\section{AGRADECIMIENTOS}

Quisiera dar las gracias a toda la gente que ha estado a mi lado durante la realización de este trabajo.

En primer lugar, quisiera agradecer a mi director, el Dr. Josep Antoni Alcover, la oportunidad para realizar esta Tesis doctoral. Sin su ayuda, su paciencia, su consejo y su apoyo, este trabajo nunca habría sido posible.

También quiero dar las gracias a mis compañeros de despacho y de otros departamentos. Anna Díaz ha hecho posible que todo el material de éste y otros trabajos se encuentre disponible en internet, una gran labor, una inestimable ayuda para mí y un recurso disponible para todos. Sámer Al-Ismail me prestó su ayuda con el "Corvus bromax" y al igual que Anna, ha sido la mejor compañía de despacho que se puede tener. Gracias también a Pere Bover por su ayuda. Gracias a Miquel Gomila y a Juanjo Ensenyat por su disponibilidad, su ayuda y su atención a mis llamadas de socorro. Gracias a Clara Vignolo por las fotos de los huesos, a Miguel McMinn por el trabajo previo y a todas las personas que participaron en las campañas de excavación de es Pouàs.

A Ima Ferri y Jaume Marco por cederme un trocito de su talento. Todo el trabajo de maquetación y el diseño de la portada son obra de estos grandes profesionales del diseño gráfico. ¡Mil gracias!.

Gracias también a Juanjo Ensenyat por las fotografías de la portada, entre otras, y por la ilustración del cráneo de Corvus corax. ¡Artista!.

De la Universidad de Salamanca, quiero agradecer a Valentín Pérez-Mellado, a Teresa González y a Sonia Mediavilla su ayuda con los trámites para la presentación de esta Tesis.

Gracias al Dr. Jelle W.F. Reumer (Natuurhistorisch Museum Rotterdam, Holanda) y a la Dra. Joanne H. Cooper (Natural History Museum at Tring, Reino Unido) por acogerme durante mis estancias y darme la oportunidad de trabajar con las colecciones de dichos museos. Mil gracias a André de Baerdemaeker por su hospitalidad en Rotterdam.

Respecto al trabajo de la dieta de Tyto alba, quiero dar las gracias a Dani Oro y a Juan Carlos Rando por sus comentarios. A R. Barone y F. Siverio por la bibliografía. A Valentín Pérez-Mellado por los datos sobre pesos de anfibios y reptiles. A las autoridades del Parc Natural de ses Salines d'Eivissa i Formentera por el apoyo logístico y la autorización para la recolección de material. A Alex Villa y Miquel Vericad por su ayuda durante el trabajo de campo. A D. Jaume y A. Bonner por la revisión del texto en inglés.

En este periodo de tiempo en Mallorca he tenido la suerte de conocer y pasar grandes ratos con grandes amigos. A mis amigos palmesanos de adopción (forasters): Elsa, Encarni, Labra y Sergi. Mil gracias por la ayuda logística, por todos los ratos de playa, conciertos, verbenas, torradas... Es una suerte teneros en sa Roqueta. A los esporlerins: Maruchi, Tomeu, Juan, Ima, Asier, Raquel, Clarita, Inés, Albert, Lorena por los café-passeig, los mojitos, las paellas, las partidas de ping-pong, los Sant Pere, los foguerons, los carnavales, los Banyalbujazz, los Eres Negre, etc. Sois los responsables de que no me quiera ir de este pueblo. Y a mis amigos de siempre, a pesar de habernos visto menos durante estos años.

A todos los imedeos con los que he compartido los descansos en el ágora, excursiones, cumpleaños, conciertos, fiestas, Escola de Natura... Es estimulante estar rodeada de gente con tantos "pájaros" en la cabeza como para querer dedicarse a la ciencia teniendo en cuenta la situación actual.

A mi padre, a mi hermana y en general, a mi familia. Por un millón de cosas, entre otras, por su apoyo y ayuda constantes, por mimarme en mis visitas a la península y por entender y aguantar que esté lejos de casa.

A Álex, necesitaría otras diez páginas para agradecerle, además de su gran ayuda en esta Tesis (campañas, traducciones, estancias, etc.) su apoyo y su compañía, entre un millón de cosas más.

Esta Tesis se ha realizado gracias a la financiación de la beca FPI asociada al proyecto del Ministerio de Economía y competitividad: CGL 2012-38087 "Cambios holocénicos en la biodiversidad animal de las islas de la Macaronesia y de las Baleares". 


\section{ÍNDICE}

Agradecimientos

Resumen ○8

$1 \quad$ INTRODUCCIÓN 13

1.1 Origen del material fósil

1.2 Descripción del yacimiento

2.1 Dataciones

2.2 Estudio y conservación

2.3 Osteometría y estadística

2.4 Definición de las medidas utilizadas

2.5 Otras abreviaturas utilizadas

2.6 Taxonomía y nomenclatura

2.7 Presentación del texto

3 ESTUDIO TAXONÓMICO DE LOS PASSERIFORMES DE ES POUÀS

Familia Alaudidae

Familia Hirundinidae

Familia Motacillidae

Familia Bombycillidae

Familia Prunellidae

Familia Turdidae

Familia Sylviidae

Familia Muscicapidae

Familia Paridae

Familia Oriolidae

Familia Laniidae

Familia Corvidae

Familia Sturnidae

Familia Passeridae 
4.1 Comparación con la ornitofauna fósil de áreas próximas

4.1.2 Mediterráneo continental adyacente

4.2 Comparación con la ornitofauna actual de Baleares

4.3 Indicaciones paleo-ecológicas generales del Pleistoceno superior-Holoceno $\quad 144$ de las Pitiusas

4.3.1 Origen del depósito

4.3.2 Paleo-ambiente

4.3.3 Indicaciones paleo-climáticas

4.3.4 Efectos de la llegada del hombre sobre la ornitofauna

6 ESTUDIO DEL COMPORTAMIENTO ALIMENTICIO DE LA LECHUZA (Tyto alba) EN ISLOTES DE LAS PITIUSAS

6.1 Introducción

6.2 Publicación 


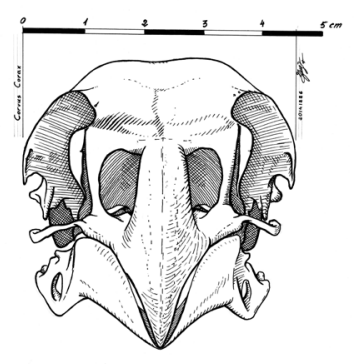

\section{RESUMEN}

Esta Tesis es el resultado de la identificación y estudio de una parte de las comunidades orníticas del Pleistoceno Superior y el Holoceno de las islas Pitiusas (Ibiza y Formentera), en concreto, de las aves paseriformes (Passeriformes) y sus potenciales depredadores (Falconiformes y Strigiformes).

Todos los fósiles objeto de este estudio proceden de un único yacimiento, es Pouàs (Sant Antoni de Portmany, Ibiza). La riqueza paleornitológica de este yacimiento es única entre las islas mediterráneas. La gran abundancia de aves obtenida en es Pouàs, se relaciona con la ausencia de mamíferos terrestres en el Pleistoceno superior y Holoceno de Ibiza.

La identificación de la avifauna de es Pouàs se ha realizado a partir de la selección y el estudio de miles de restos fósiles obtenidos en las campañas de excavación realizadas entre 1988 y 1994. La identificación de los fósiles se ha llevado a cabo utilizando caracteres diagnósticos, tanto inéditos, obtenidos a partir de materiales de comparación, como procedentes de la literatura científica.

Se han identificado 16.262 fósiles pertenecientes a 16 familias de Passeriformes y a tres familias de los órdenes Falconiformes (s.l.) y Strigiformes. De un total de 73 taxones identificados a nivel específico o genérico, 6o corresponden a Passeriformes, nueve a Falconiformes y cuatro a Strigiformes. Cinco especies de rapaces y 40 de paseriformes se incluyen por primera vez en el registro de este yacimiento, y 24 especies de Passeriformes y seis de Falconiformes y Strigiformes constituyen nuevas incorporaciones al registro fósil del Pleistoceno superior-Holoceno de las Baleares. Así mismo se han identificado 28 especies de paseriformes que no se encuentran en el registro fósil del área continental cercana a Ibiza. 
Además del estudio de las aves paseriformes y rapaces fósiles, se ha comparado la fauna de es Pouàs con la ornitofauna actual de las Pitiusas y con la fauna actual y fósil de aves del área adyacente. El gremio de aves depredadoras es objeto de un capítulo en el que se valora tanto su papel bio-acumulador como su singularidad.

Se ha realizado una aproximación a la significación paleo-ecológica y paleo-climática del conjunto ornítico estudiado. El hábitat que ocupan en la actualidad las especies identificadas, permite conocer, a grandes rasgos, el paisaje del Pleistoceno superior de las Pitiusas. La identificación de especies de distribución actual septentrional indica la existencia de un clima más frío en el Pleistoceno superior. Se analizan las posibles causas de la desaparición local de algunas especies y de la ausencia de otras en el registro. Se documentan casos de cambios morfológicos relacionados con procesos de evolución insular (e.g., Bubo sp., Corvus corax).

Se ha incorporado el estudio de la dieta de Tyto alba en la actualidad en las Pitiusas menores. Dicho estudio ha permitido evaluar algunos de los efectos de la llegada del hombre a estas islas, y proporciona un ejemplo de la utilidad de los estudios paleo-ecológicos en la interpretación de las comunidades actuales. 


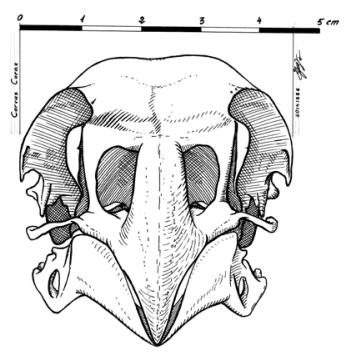

\section{ABSTRACT}

This Thesis is the result of the identification and study of part of the bird communities of the Upper Pleistocene and Holocene of the Pityusic Islands (Eivissa and Formentera) specifically, Passeriformes and their potential predators (Falconiformes and Strigiformes).

All fossils studied come from a single site, es Pouàs (Sant Antoni de Portmany, Eivissa). The paleontological richness of this site is unique among the Mediterranean islands. The abundance of birds obtained in es Pouàs is related to the absence of terrestrial mammals in the Upper Pleistocene and Holocene of Eivissa.

Identifying bird fauna in es Pouàs was possible through the study and selection of thousands of fossils obtained in the excavation campaigns conducted between 1988 and 1994. Fossil identification was carried out using diagnostic features, both unpublished and obtained from comparison materials, as well as from scientific literature.

16,262 fossils have been identified belonging to 16 families of Passeriformes and 3 families of the orders Falconiformes and Strigiformes. Of a total of 73 taxa identified at a specific or generic level, 6o correspond to Passeriformes, 9 to Falconiformes and 4 to Strigiformes. Five species of raptors and 40 species of Passeriformes are included for the first time in this site. There are 24 species of Passeriformes and six Falconiformes and Strigiformes which are new additions to the fossil record of the upper Pleistocene-Holocene of the Balearic Islands. We also have identified 28 species of Passeriformes not found in the continental fossil record near Eivissa. 
In addition to studying the fossils of raptors and Passeriformes, the fossil fauna of es Pouàs was compared with the current ornithofauna of the Pityusic Islands as well as the current and fossil fauna of the adjacent area. The guild of birds of prey is the subject of a chapter in which both its bio-accumulator role as its uniqueness is valued.

The paleoecological and paleoclimatical significance of the bird fauna was studied.

The habitats that the identified species currently occupy allows us to better understand the environment of the Upper Pleistocene of the Pityusic Islands.

The presence of species with current northern distribution indicates the existence of a cooler climate in the Upper Pleistocene. Possible causes of local disappearances of some species and the absence of others from the fossil record are discussed. There are documented cases of morphological changes related to processes of insular evolution (e.g., Bubo sp., Corvus corax).

The study of the current diet of Tyto alba in the lesser Pityusic Islands was included. This study has allowed the evaluation of some of the effects of human arrival on these islands and provides an example of the usefulness of paleoecological studies in the interpretation of current communities. 



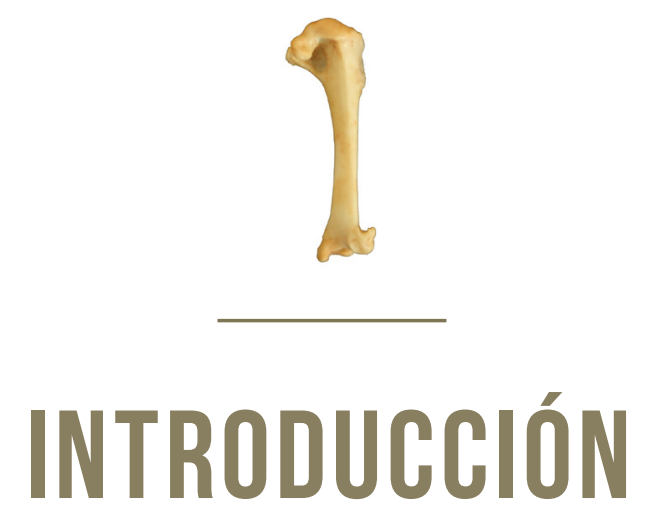




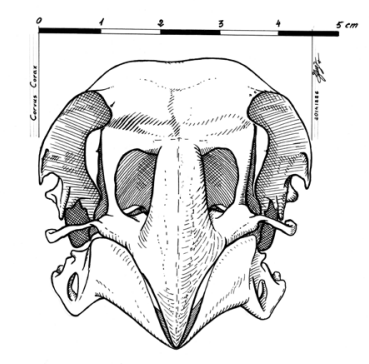

\section{1 - INTRODUCCIÓN}

El estudio de las faunas fósiles aporta una valiosa información no sólo sobre las especies estudiadas y sus paleo-distribuciones, sino también sobre diferentes características de los ecosistemas del pasado, tales como la estructura de las comunidades faunísticas, la vegetación, la climatología y las redes tróficas. Por otro lado, también permite valorar las consecuencias de la expansión humana en los diferentes ecosistemas (e.g., Grayson 2001; Steadman y Martin 2003; Willis et al. 2007; Turvey 2009).

Estas consecuencias son particularmente importantes en las islas, donde el impacto de la llegada de los humanos se traduce en cambios en los ecosistemas insulares (más frágiles que los continentales), introducción de especies alóctonas y extinción de especies autóctonas (Diamond 1985; Steadman y Martin 2003; Kirch 2005).

El grupo de vertebrados que ha sufrido una mayor tasa de extinción tras la irrupción humana en las islas es, sin duda, el de las aves. Johnson y Stattersfield (1991) estiman que alrededor de un $90 \%$ de las extinciones de aves que se han producido en época histórica se han dado en islas, a pesar de que se calcula que menos de un $20 \%$ de las especies de aves del mundo son especies insulares.

Desde mediados del siglo XIX, comenzando con los trabajos de Darwin y Wallace, se ha documentado que las condiciones de aislamiento que se dan en las islas constituyen un motor para la evolución de las especies. El estudio de las faunas fósiles insulares ha permitido el descubrimiento de un gran número de especies nuevas para la ciencia, endémicas de las islas, que constituyen una documentación especialmente relevante en el estudio de la evolución (e.g., Worthy y Holdaway 2002; Steadman 2006; Van der Geer et al. 2010). Los patrones y procesos evolutivos que se dan en las comunidades faunísticas de las islas oceánicas son singulares (Gillespie 2007; Whittaker et al. 2008), sobre todo en las más aisladas geográficamente. Así mismo, en un grado diferente, estos patrones y procesos evolutivos se han observado también en islas de origen no volcánico más cercanas al continente, tales como las Antillas, las islas mediterráneas y las islas de la Wallacea.

Las Islas Baleares presentan faunas con algunas características similares a las de las islas oceánicas (Alcover et al. 1998): hasta la llegada de los humanos albergaban una fauna pobre, poco equilibrada y sumamente rica en endemismos. Estas tres características 
(pobreza faunística, falta de armonía faunística y riqueza en endemismos), propias de las islas oceánicas, en el caso de las Baleares se deben a que, a pesar de haber estado unidas al continente, su unión fue breve (menos de trescientos mil años) y muy lejana en el tiempo (en el Mesiniense).

Las Baleares constituyen el archipiélago más aislado del Mediterráneo, y están compuestas a su vez por dos archipiélagos, las Gimnesias (Mallorca y Menorca) y las Pitiusas (Ibiza, cuyo nombre oficial es Eivissa, Formentera y más de 60 islotes circundantes [Kuhbier 1984]). Ibiza es la isla más grande de las Pitiusas, con $541 \mathrm{~km}^{2}$ de extensión. Está situada a 90 km de la Península Ibérica y a unos 80 km de Mallorca.

Desde el final de la desecación mesiniense del Mediterráneo (esto es, desde hace 5,35 $\mathrm{Ma})$, las Baleares han permanecido aisladas, sufriendo además los efectos de oscilaciones del nivel del mar durante la alternancia de los periodos glaciales e interglaciales de los últimos 2,58 millones de años (Haug y Tiedemann 1998). Estas glaciaciones han influido enormemente sobre la evolución y la composición faunística, uniformizando las faunas de cada archipiélago (Gimnesias y Pitiusas) y manteniendo las diferencias entre ambos. El análisis de las faunas endémicas actuales de las Gimnesias y de las Pitiusas refleja la antigüedad de su origen (Palmer et al. 1999).

Por lo que se refiere al estudio de las faunas fósiles del Cuaternario de ambos archipiélagos, el conocimiento de la fauna vertebrada de las Gimnesias se inició mucho antes que el de las Pitiusas. La exploración paleontológica en busca de vertebrados fósiles en las Pitiusas comenzó a principios del siglo XX (Bate 1914), sin resultados. A mediados de los setenta, R. Daams localizó una brecha en ses Fontanelles que contenía dientes de gerbílido (Alcover et al. 1981).

En septiembre de 1981 se encontraron nuevos depósitos fosilíferos, cuyas faunas han permitido caracterizar cuatro episodios faunísticos en las islas Pitiusas. El episodio más antiguo, del Mioceno superior (Mesiniense)/Plioceno inferior, corresponde a la fauna de ses Fontanelles e incluye dos bóvidos de talla pequeña, un lepórido, dos roedores, una musaraña, una tortuga y un lacértido (Moyà-Solà et al. 1984 a, b; Agustí y Moyà-Solà 1990; Alcover 2000; Bover et al. 2008; Quintana y Moncunill 2014). El segundo episodio, atribuido tentativamente al Plioceno superior-Pleistoceno inferior, incluye dos especies de glíridos, así como especies características de gasterópodos, abundantes restos de lagartijas y una tortuga gigante (Cheirogaster sp.) (Bover et al. 2008). Es posible que este periodo se extienda hasta el Pleistoceno medio. El tercer episodio, del Pleistoceno superior-Holoceno, corresponde a una fauna mayoritariamente ornítica, con lagartijas y carente de mamíferos terrestres. El último episodio corresponde a las faunas coetáneas a los humanos, incluidas las especies introducidas (Alcover 2003; Alcover et al. 1994). Las especies de aves identificadas en este trabajo a partir de los fósiles obtenidos en es Pouàs, forman parte del tercer episodio faunístico mencionado anteriormente.

La identificación taxonómica de los restos fósiles de Passeriformes conlleva una dificultad superior respecto al estudio de otros grupos de aves. Se trata de un orden que incluye gran cantidad de taxones de pequeño tamaño y morfología relativamente similar, por lo 
que es difícil establecer criterios de discriminación en base a sus elementos óseos. Por otra parte, la mayor fragilidad de sus restos respecto a los de otros grupos de aves de talla superior hace que normalmente los restos fósiles de paseriformes tiendan a obtenerse en peor estado de conservación.

Los estudios publicados sobre discriminación osteológica entre las diferentes categorías taxonómicas de Passeriformes son escasos, sobre todo a nivel de especie. Por este motivo ha sido necesario establecer en este trabajo nuevos criterios de discriminación osteológica.

\subsection{Origen del material fósil}

Los materiales objeto del presente trabajo proceden de un único depósito, es Pouàs y corresponden a niveles del Pleistoceno superior y del Holoceno. El yacimiento de es Pouàs es el depósito de vertebrados cuaternarios que ha proporcionado un mayor número de restos fósiles en las Baleares. Así mismo, es el depósito ornítico más rico que se conoce en las islas mediterráneas y uno de los más ricos de toda el área mediterránea (Alcover y McMinn 1992). Durante decenas de miles de años, es Pouàs actuó como una trampa sedimentaria que incorporó huesos y otros restos animales proporcionando una enorme cantidad de fósiles.

La composición faunística del yacimiento es extremadamente peculiar, debido a la ausencia de mamíferos terrestres previa a la llegada del hombre a Ibiza hace alrededor de 4150-4350 años (Alcover 2008). Las Pitiusas constituyeron, al menos durante el Pleistoceno superior y el Holoceno, el mayor territorio no desértico de la región mediterránea carente de mamíferos terrestres (Florit et al. 1989). La ausencia de mamíferos constituye la anomalía faunística más importante del Mediterráneo durante el Pleistoceno superior. Esta anomalía condicionó el desarrollo de unas comunidades sumamente peculiares en las Pitiusas, cuyas faunas orníticas originales presentan similitudes ecológicas con la ornitofauna prehumana de las islas Hawái (Seguí y Alcover 1999).

Se han publicado algunos estudios preliminares sobre la avifauna de es Pouàs. Florit et al. (1989) realizaron un estudio general en el que se dieron a conocer 21 especies de aves, entre las que figuraba la extinta Grus primigenia, descrita por Milne-Edwards en el año 1869 y actualmente sinonimizada con Grus grus (Stewart 2007). Posteriormente, se publicó un estudio sobre la presencia del pigargo europeo (Haliaeetus albicilla) en es Pouàs (Alcover y McMinn 1992) y su significado ecológico. En 1995, Sondaar et al. publicaron un listado de la ornitofauna fósil de las Pitiusas, basado principalmente en la identificación de aves de es Pouàs, a pesar de no estar indicado en el trabajo (Alcover, com. pers.). Por otra parte, en base a materiales fósiles de este yacimiento, se ha descrito una especie nueva para la ciencia, Rallus eivissensis (McMinn et al. 2005), extinguida presumiblemente tras la llegada de los humanos a Ibiza. Recientemente, dentro del marco de los trabajos efectuados para la realización de esta Tesis, se ha publicado un estudio sobre el gremio de aves depredadoras de la fauna prehumana de las Pitiusas (Guerra et al. 2013). 


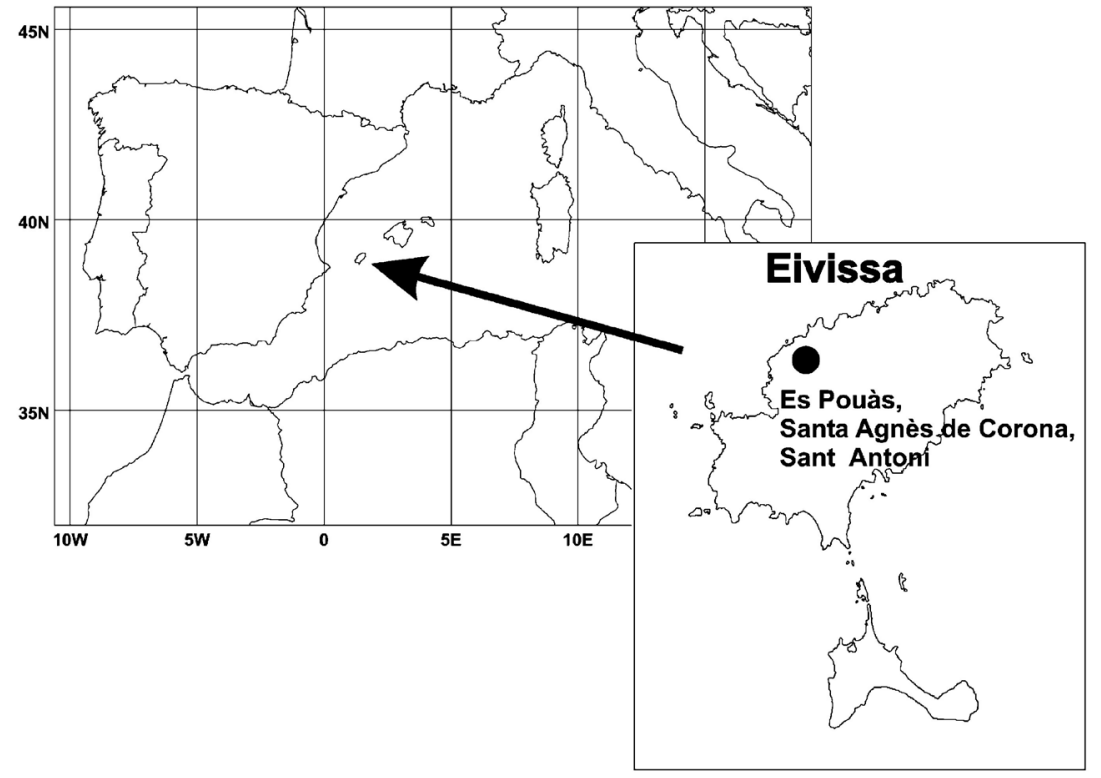

Figura 1. Localización del yacimiento de es Pouàs.

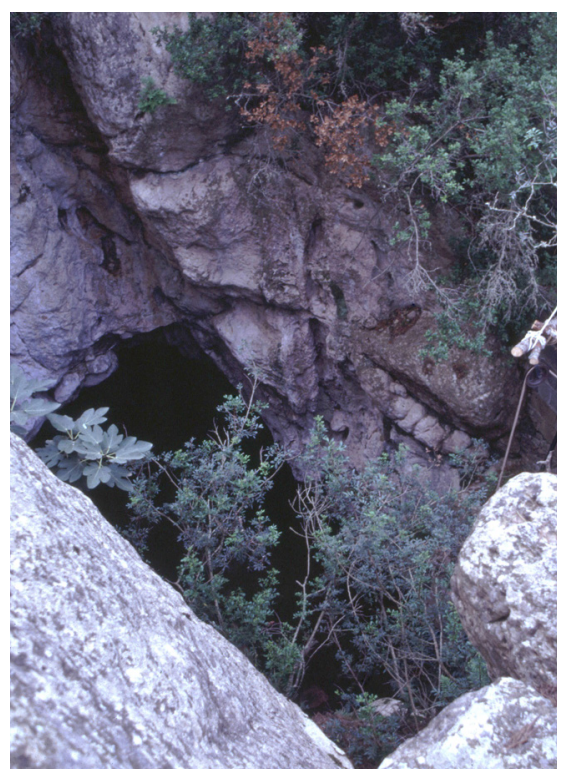

Figura 3. Entrada a es Pouàs.

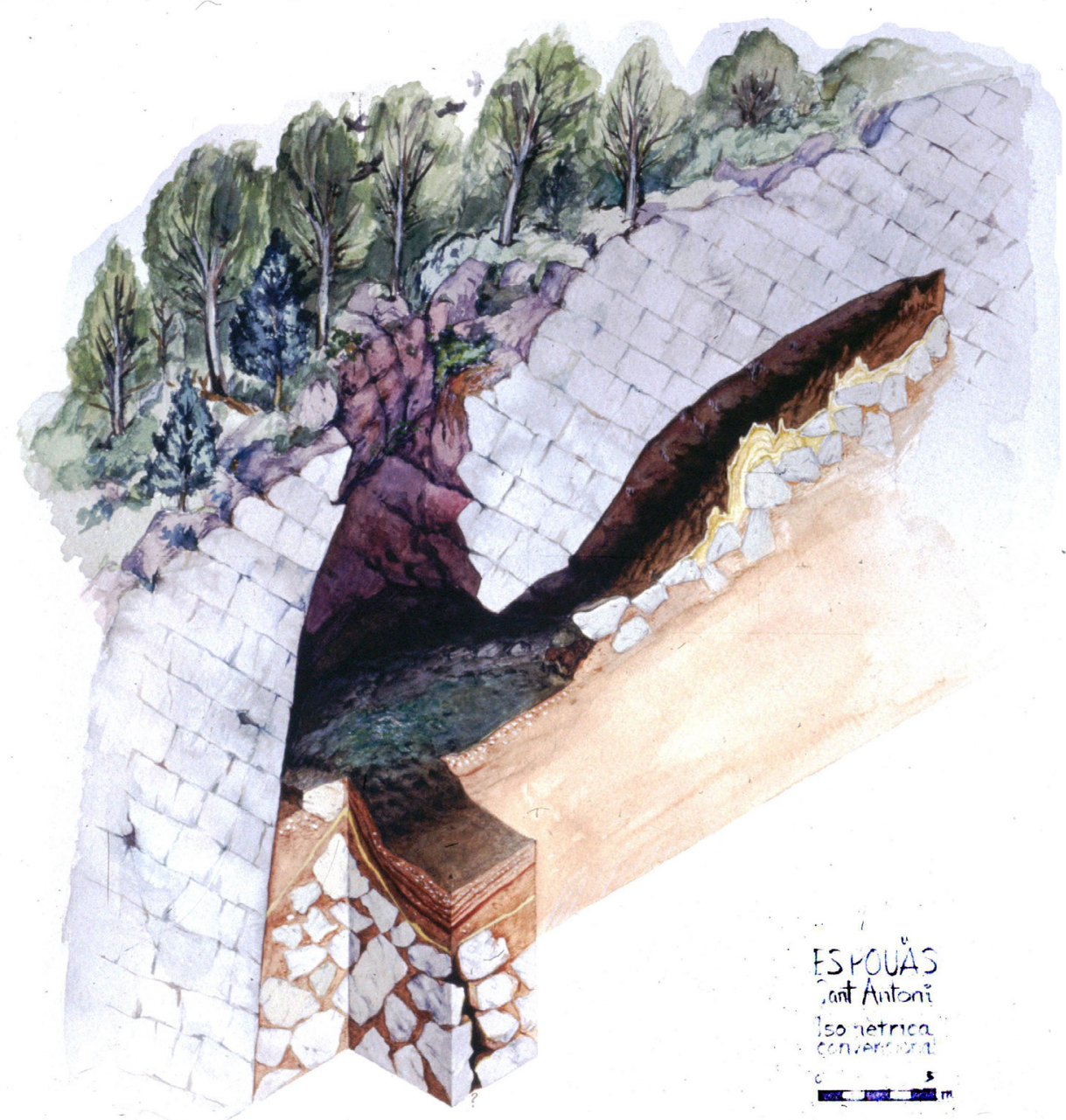

Figura 2. Representación tridimensional de es Pouàs. Ilustración de Miquel Trias. 
El rango de tallas de las aves procedentes de este depósito abarca desde las especies de aves más grandes, como la avutarda, el pigargo europeo o las grullas, hasta las más pequeñas, como la curruca cabecinegra, el verdecillo o los mosquiteros. Esta diversidad de tallas refleja la eficacia de la metodología empleada en la obtención de restos del depósito.

\subsection{Descripción del yacimiento}

El yacimiento de es Pouàs está situado en una colina en el municipio de Santa Agnès de Corona, a $265 \mathrm{~m}$ sobre el nivel del mar, en el noroeste de la isla de Ibiza (coordenadas UTM: 37222.92, 4321971.66).

Se trata de una sima de hundimiento cuya boca está abierta en un área de calizas urgonianas. El pozo, de siete metros de diámetro, comunica con una sala de 32 x $15 \mathrm{~m}$ de planta que presenta una forma alargada irregular y que transcurre en sentido E-O. El suelo de la cueva está formado por una mezcla de materiales clásticos pequeños y arcillas y tiene una profundidad total de 19 m (Thomas y Montoriol 1953; Ginés y Ginés 1971; Trias 1982; Trias 1983). El relleno sedimentario es muy homogéneo y su compactación se debe al propio peso de las capas superiores. Al no existir mamíferos terrestres que pudiesen compactar los diferentes niveles mediante el pisoteo del terreno, las discontinuidades estratigráficas son difíciles de seguir en el paquete sedimentario excavado. La homogeneidad del sedimento constituyó una dificultad para la separación de unidades estratigráficas durante la excavación.

En el interior de la cueva existía un depósito arqueológico pre-púnico del que en la actualidad tan sólo se conservan algunos restos en las paredes de la sala. El resto de dicho depósito fue destruido por los propietarios del terreno, que vaciaron parte de los sedimentos para llevar a cabo el proyecto de construcción de una discoteca dentro de la cavidad (Florit et al. 1989).

Hasta el momento, el yacimiento paleontológico subyacente al arqueológico ha proporcionado más de 120.000 huesos, además de numerosos restos de invertebrados (gasterópodos y miriápodos). Se ha obtenido una enorme cantidad de restos de aves, lagartijas y gasterópodos y, en menor proporción, murciélagos y miriápodos. Así mismo, en niveles inferiores, anteriores al Pleistoceno superior, se han obtenido los restos fósiles de una especie de tortuga gigante (Cheirogaster sp.). Probablemente corresponden a algún descendiente de la descrita por Bour (1985) en base a los restos del yacimiento ibicenco de la Cova de Ca Na Reia. Tres de los cuatro episodios faunísticos registrados en Ibiza están representados en es Pouàs: todos, excepto el primero, el de la fauna de ses Fontanelles. 
1 - INTRODUCCIÓN 



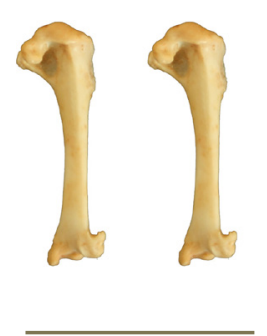

MATERIAL Y MÉTODOS 


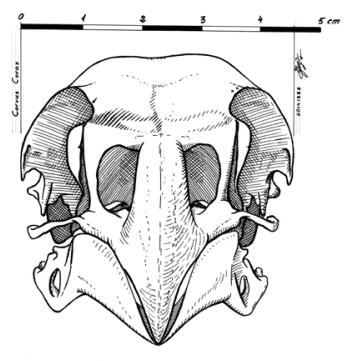

\section{2 - MATERIAL Y MÉTODOS}

Se han obtenido decenas de miles de restos fósiles de aves. Entre estos se han seleccionado 13.868 huesos corresponden a los Passeriformes y 2394 a sus depredadores potenciales (Falconiformes y Strigiformes), que constituyen el objeto de estudio de este trabajo. En el caso de Falconiformes, Strigiformes y la familia Corvidae, se han identificado los huesos principales de los miembros, del torso y de la cabeza. Sin embargo, en el resto de los Passeriformes, se ha incidido principalmente en la determinación de los cráneos, mandíbulas, húmeros y tarsometatarsos. Esto se debe a que dichos elementos son los que presentan más y mejores caracteres diagnósticos y, por tanto, permiten un diagnóstico taxonómico más preciso.

Las campañas de excavación paleontológica (figura 5) del yacimiento de es Pouàs se llevaron a cabo durante seis meses, entre 1988 y 1994. La excavación se inició en la cuadrícula A1 (ver figuras 8 y 9) siguiendo niveles horizontales artificiales de $20 \mathrm{~cm}$ y al llegar a una gran roca que dificultaba la excavación, se continuó excavando la cuadrícula A2 con el mismo criterio. La excavación de la cuadrícula A2 proporcionó un corte (A3/ A2, ver figuras 6 y 7) que permitió visualizar la disposición estratigráfica en la cuadrícula adyacente $\left(\mathrm{A}_{3}\right)$ y, a partir de las pequeñas discontinuidades más aparentes, definir una serie de niveles. Con el mismo objetivo se excavaron la cuadrícula A4 y la mitad contigua de la cuadrícula B4. Esto permitió visualizar ambos lados de la cuadrícula A3 en la que se definieron ocho niveles sedimentarios, que posteriormente se excavaron. 
El primer nivel es superficial e incluye especies introducidas por el hombre, y el segundo es una lámina que contiene abundantes gasterópodos endémicos de la superfamilia Trochoidea. Estos dos primeros niveles presentaban alteraciones debido a las actuaciones por parte de los propietarios del terreno. Del tercer nivel en adelante la deposición es continua y dentro de cada nivel se observa una serie de subniveles procedentes de esa sucesión de deposiciones (Alcover 2003).
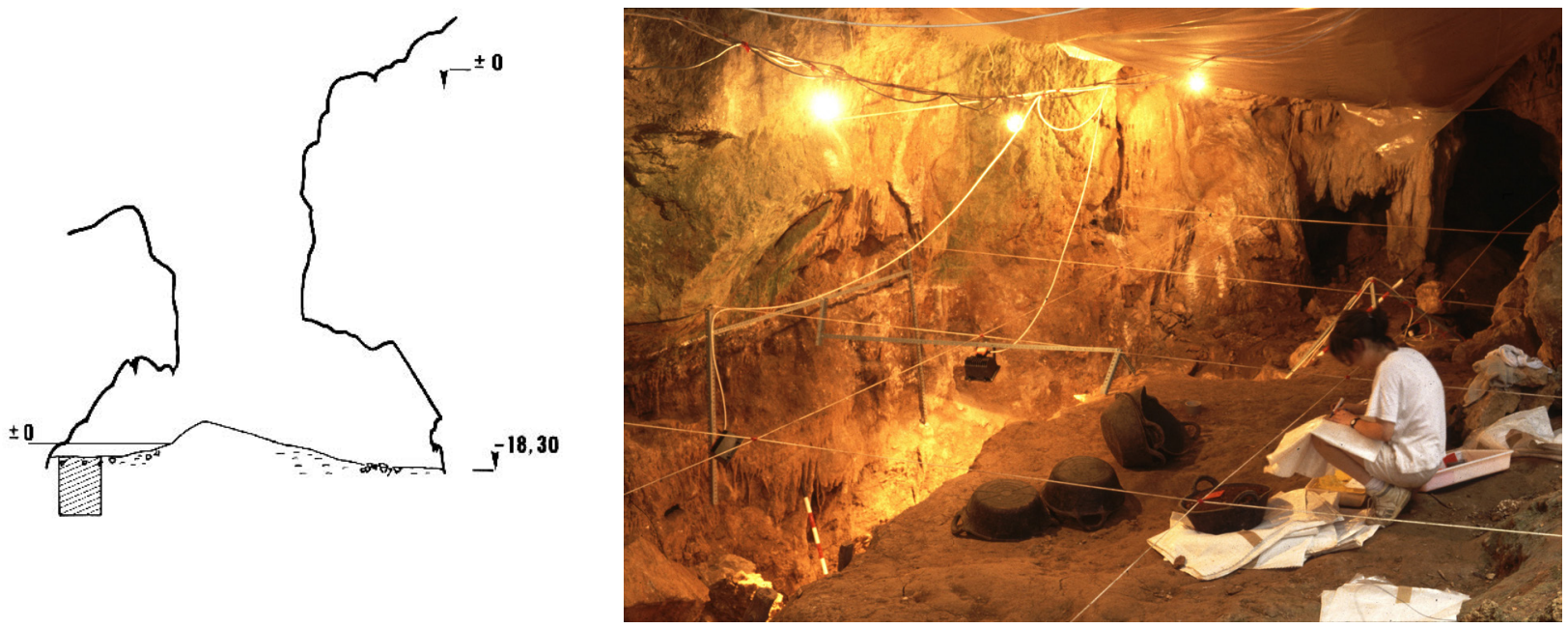

Figura 4. Sección de es Pouàs

Figura 5. Excavación de es Pouàs, campaña de 1990.

donde se aprecia la cota o y la zona

excavada.
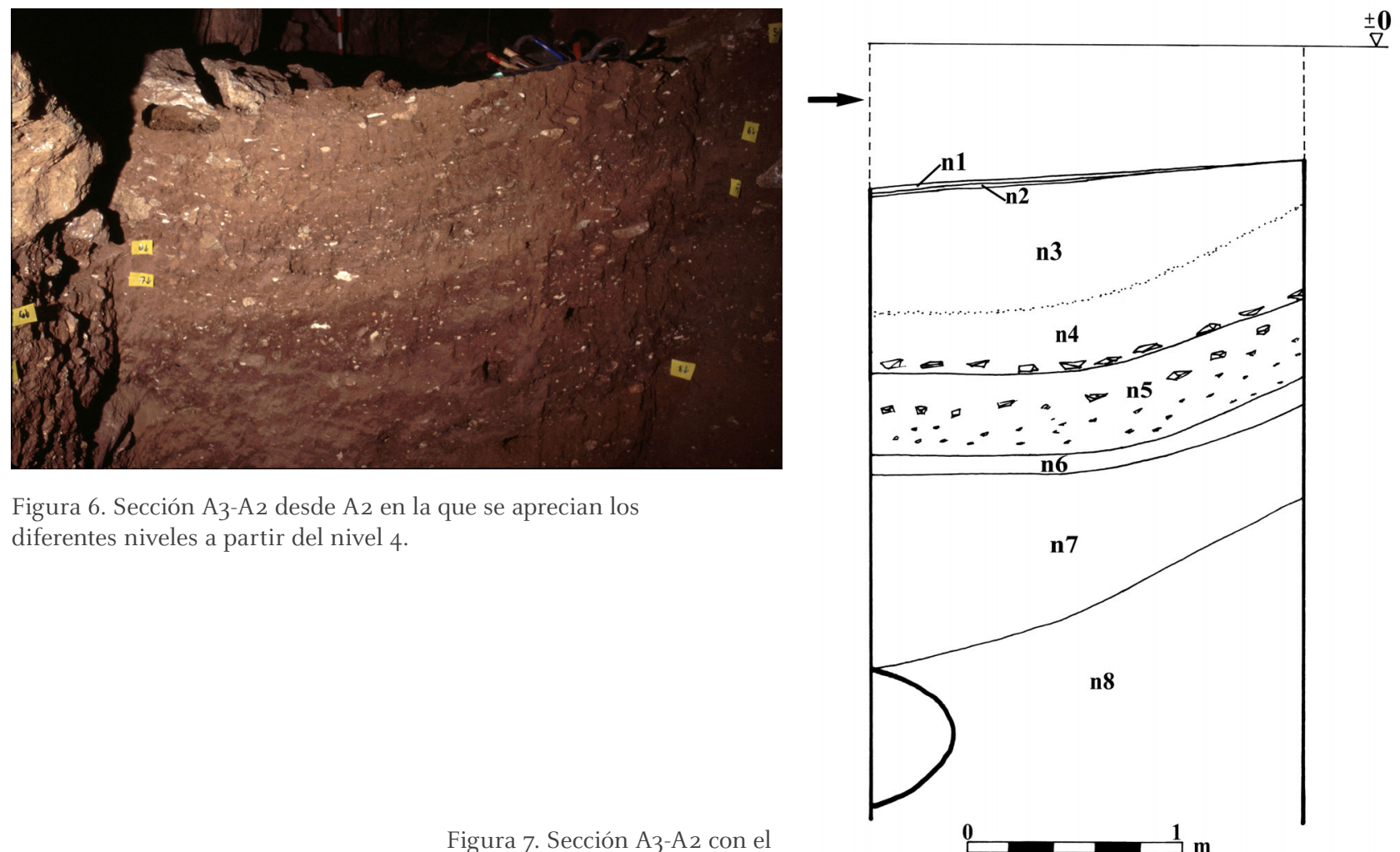

Figura 7. Sección A3-A2 con el

límite de los niveles reconocidos.

Figura 6. Sección A3-A2 desde A2 en la que se aprecian los diferentes niveles a partir del nivel 4 . 
Las cuadrículas A10, B4, B5, I1 e I2, adyacentes a la pared de la cueva, se excavaron siguiendo los mismos criterios utilizados en las cuadrículas contiguas (A1, A2 y A4). Las cuadrículas D4 y E11 (más la parte contigua de la E8) corresponden a bolsas de sedimento atribuibles al Holoceno. Durante el periodo de excavaciones se obtuvieron más de 120.000 huesos que representan probablemente menos de un $10 \%$ del total del material depositado en el yacimiento.

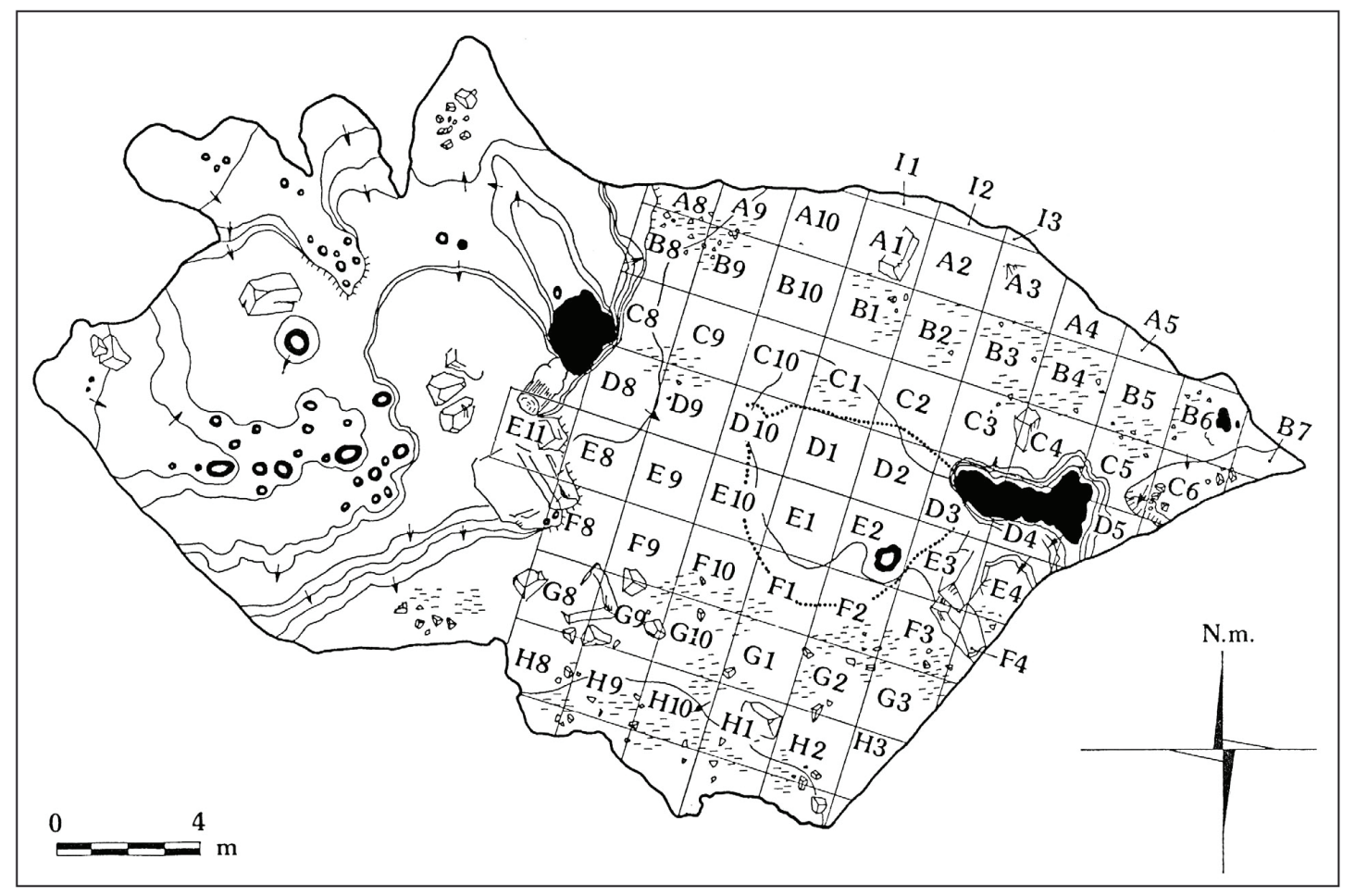

Figura 8. Planta del yacimiento con las cuadrículas de referencia.

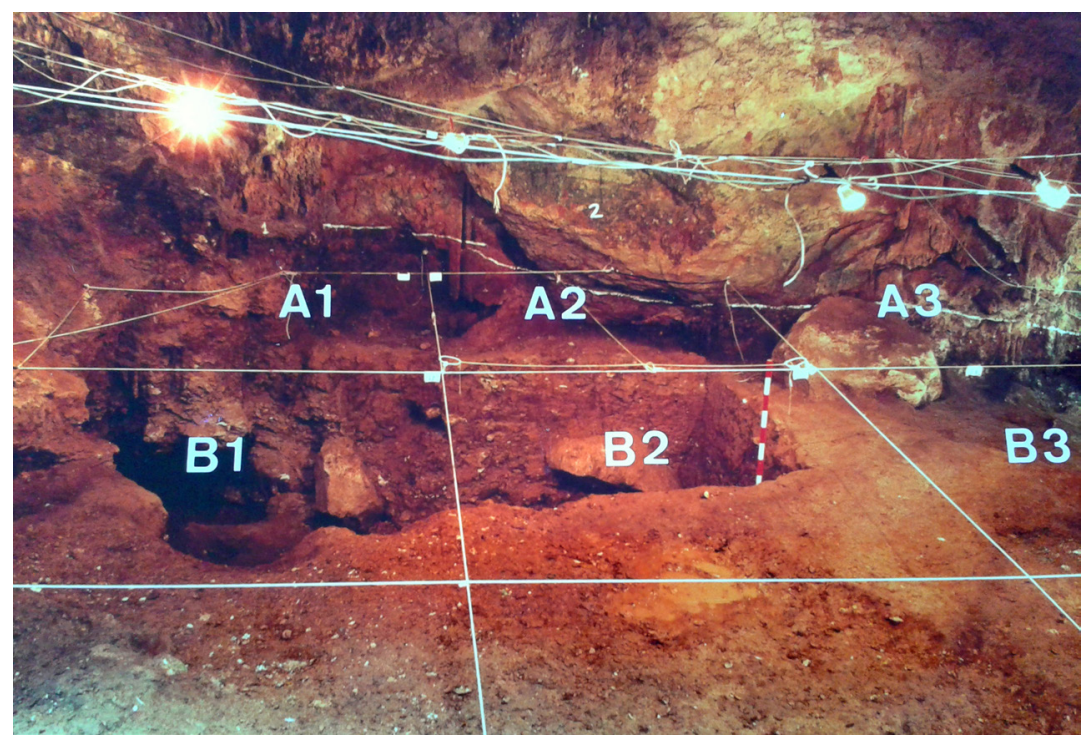

Figura 9. Detalle de algunas de las cuadrículas del yacimiento. 


\subsection{Dataciones}

Se han obtenido doce dataciones de $\mathrm{C}_{14}$, de las cuales nueve corresponden a niveles paleontológicos (pre-antrópicos) (Alcover 2003) y tres a niveles arqueológicos. Uno de estos últimos documenta la presencia humana más antigua en Ibiza (Alcover 2008) (tabla 1). El registro paleontológico contemplado en este estudio cubre un rango que abarca desde unos 35.000 años antes del presente en el nivel $8(-320 /-400 \mathrm{~cm})$ de la cuadrícula A3, hasta los 6000 años antes del presente en las cuadrículas A3 $(-60 /-80 \mathrm{~cm})$ y D4.

\begin{tabular}{|c|c|c|c|c|}
\hline Código lab. & Especies & Cuadrícula y nivel & Edad radiocarbónica $(\mathrm{BP})$ & $\begin{array}{c}2 \sigma \text { Intervalo calibración } \\
\text { (cal BC) }\end{array}$ \\
\hline Beta-162217 & Eliomys quercinus & Testigo pared & $3000 \pm 50$ & $1399-1057$ BC \\
\hline Beta- 162218 & Caprinae indet. & A3 superficie & $3^{210 \pm} \pm 0$ & $1611-1406$ BC \\
\hline KIA-29163 & Homo sapiens sapiens & $\mathrm{A}_{4} / \mathrm{B}_{4}(-70 \mathrm{~cm})$ & $3785^{ \pm 25}$ & $2290-2139$ BC \\
\hline UtC-6516 & Hueso de ave quemado & $D_{4}(-60 /-80 \mathrm{~cm})$ & $5650 \pm 60$ & $4652-4354 B C$ \\
\hline CSIC-870 & Anser sp. & $\mathrm{D}_{4}(-120 \mathrm{~cm})$ & $5770 \pm 100$ & $4844-4371$ BC \\
\hline UtC-6222 & Rallus eivissensis & А3 $(-60 /-80 \mathrm{~cm})$ & $6130 \pm 80$ & $5295-4848$ BC \\
\hline CSIC-1002 & $\begin{array}{l}\text { Carbón vegetal no } \\
\text { identificado }\end{array}$ & $\mathrm{H}_{14}(\mathrm{o} \mathrm{cm})$ & $7200 \pm 50$ & $6211-5991 \mathrm{BC}$ \\
\hline UtC-6673 & Grus grus & $\begin{array}{c}\text { A3 (nivel 6, parte } \\
\text { superior) }\end{array}$ & $16170 \pm 90$ & $17589-16969$ BC \\
\hline UtC-6674 & Corvus corax & A3 (nivel 7) & $23030 \pm 150$ & $26492-25036$ BC \\
\hline UtC-2928 & Hueso de ave & A3 (nivel 6) & $26200-300 /+400$ & $29322-28395$ BC \\
\hline CSIC-1019 & Haliaeetus albicilla & $\begin{array}{c}\text { A4 (nivel } 7,-280 \text { to }-300 \\
\mathrm{~cm} \text { ) }\end{array}$ & $26420 \pm 180$ & $29329-28790 \mathrm{BC}$ \\
\hline UtC-2929 & Hueso de ave & A3 (nivel 8) & $30700 \pm 600$ & $34694-32523$ BC \\
\hline
\end{tabular}

Tabla 1. Dataciones de C14 de diferentes niveles de es Pouàs. Las edades se expresan en años antes del presente (por convención, antes de 1950), con el error típico. La calibración se calculó con el software OxCal v4.1, usando la base de datos IntCalog. La edad calibrada se expresa en años antes de Cristo, a través del intervalo 2 sigma.

El material de este trabajo procede de diferentes niveles de las cuadrículas A1, A2, A3, A4, A5, A10, B2, B4, B5, D4, E8, E11, I1 e I2. La mayor parte del material del Pleistoceno superior aquí estudiado procede de niveles inferiores al nivel 3 de la cuadrícula A3. 


\subsection{Estudio y conservación}

Todo el material fósil se encuentra depositado en la colección de vertebrados del Instituto Mediterráneo de Estudios Avanzados (IMEDEA, UIB-CSIC) en el municipio de Esporles, Mallorca. Los registros de todos los huesos fósiles presentados en este trabajo, están disponibles para su consulta a través de la web de la Infraestructura Mundial de Información en Biodiversidad (GBIF) en el enlace: http://datos.gbif.es/collectory/public/show/co110
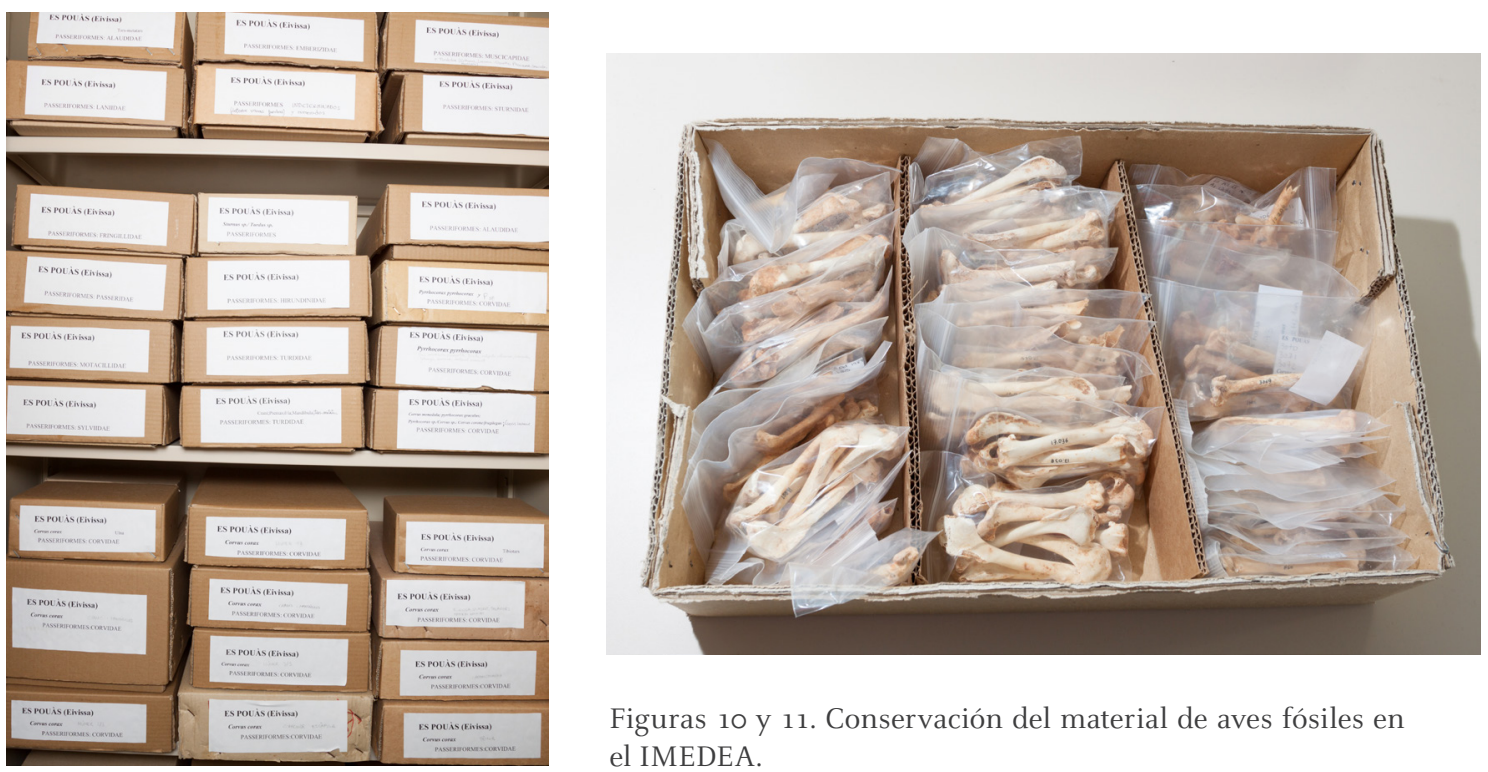

Figuras 10 y 11. Conservación del material de aves fósiles en el IMEDEA.

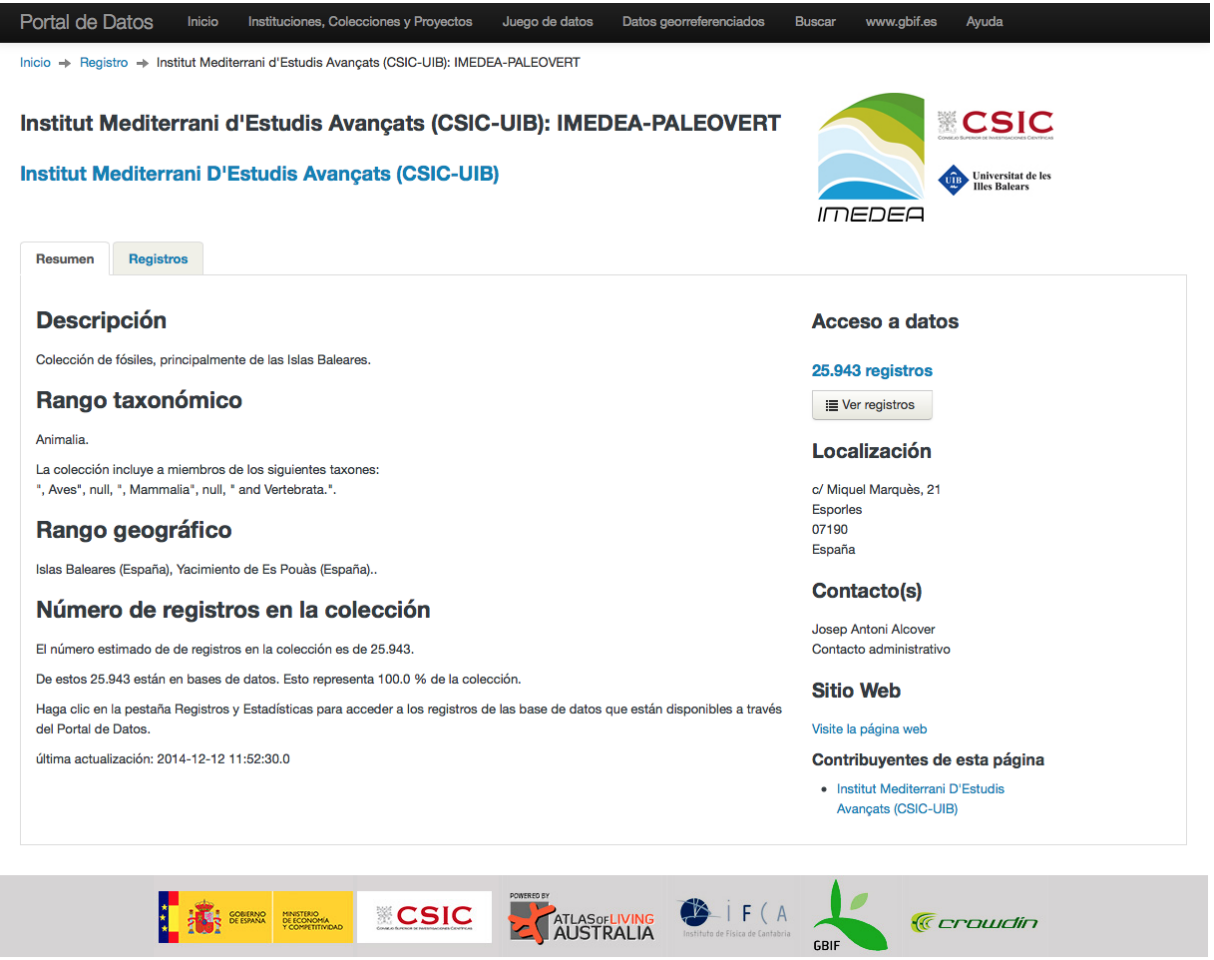

Figura 12. Página web de GBIF, colección digital de vertebrados fósiles del IMEDEA. 
La identificación de los fósiles se ha llevado a cabo mediante la comparación con esqueletos de individuos actuales procedentes de la colección de vertebrados del IMEDEA, del Natural History Museum at Tring (NHMT, Reino Unido) y del Natuurhistorisch Museum Rotterdam (NMR, Holanda). También se han utilizado diversas fuentes bibliográficas (e.g., Jánnosy 1983; Moreno, 1985, 1986 y 1987; Cuisin 1989; Tomek y Bocheński 200o; Wójcick 2002) así como la colección virtual de cráneos de la página web: www.skullsite.com

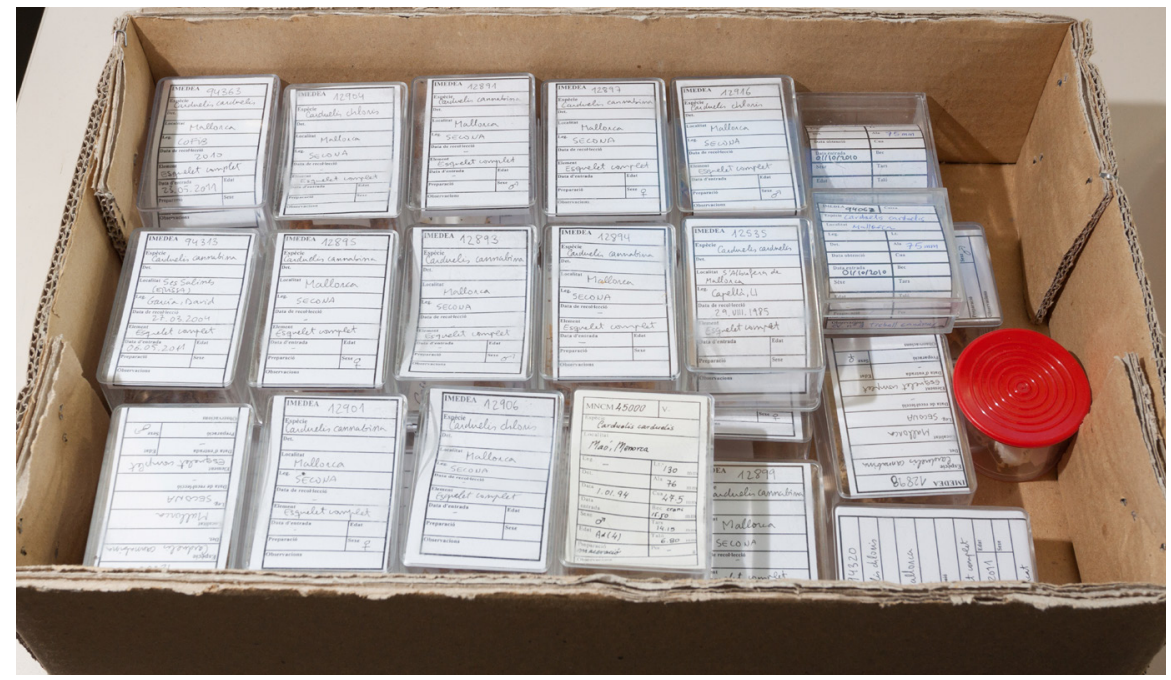

Figura 13. Colección de aves de comparación. Género Carduelis, IMEDEA.

Se ha priorizado la cautela en la identificación de las especies a todos los niveles taxonómicos, lo que ha originado una gran cantidad de material, la mayor parte perteneciente a especies de Passeriformes, con determinaciones imprecisas (sp., cf., o a nivel de familia). Estas determinaciones imprecisas no afectan sustancialmente a las interpretaciones tafonómicas, e implican que el número de especies de aves correspondientes al material estudiado es superior a la cifra expuesta.

\subsection{Osteometría y estadística}

Se han utilizado, como materiales de comparación, individuos de especies actuales procedentes de las colecciones de vertebrados del IMEDEA, del NHMT y del NMR, así como datos de diferentes publicaciones (e.g., Jánossy 1983; Moreno 1985, 1986 y 1987; Boev 2012).

Tanto los fósiles como los individuos usados para comparación se han medido con calibres digitales de precisión o,o1 mm. Las medidas se expresan siempre en mm y han sido tomadas en base a los criterios de Moreno (1985) para el cráneo y la mandíbula, excepto la anchura del maxilar (AM, ver más adelante). Para los huesos largos del esqueleto postcraneal se han seguido los criterios de Mourer-Chauviré (1975b). Así mismo, se han introducido otras cuatro medidas correspondientes al cráneo y a la mandíbula $(\mathrm{Cn}, \mathrm{C} 2$, LC2 y LS) (ver definición y figura 14 más adelante). Todas las medidas se han presentado en décimas de milímetro, ya que éste es el grado de precisión repetible si es necesario. 
Se presentan los parámetros estadísticos básicos de las medidas de los huesos fósiles obtenidos en es Pouàs y del material de comparación actual. Para ello, se han agrupado los huesos fósiles procedentes de todas las cuadrículas y niveles del yacimiento que se encontraban en buen estado de conservación. Para la obtención de estos parámetros se utilizó el programa Microsoft Office Excel 2007 y los resultados se muestran en las tablas anexas (2-35).

Solamente en dos de las especies obtenidas, Corvus corax y Pyrrhocorax pyrrhocorax, el número de huesos en buen estado constituye una muestra del tamaño adecuado para la realización de análisis estadísticos. Para el estudio biométrico de estas especies se realizaron análisis de la varianza y análisis no paramétricos, utilizando materiales procedentes de la cuadrícula $\mathrm{A}_{3}$, de la que se dispone una cronología más precisa de los niveles excavados. Solamente se tuvieron en cuenta ejemplares adultos y subadultos grandes y en buen estado de conservación, es decir, poco o nada fragmentados. La diferencia de talla entre los individuos fósiles y actuales de estas especies se testó mediante un ANOVA de un factor y en el caso de P. pyrrhocorax, se realizó además un test no paramétrico (SPSS versión 16.0 para Windows) para contrastar los resultados, debido al pequeño tamaño de muestra de los individuos actuales. Los resultados se presentan en las tablas anexas (39-52).

\subsection{Definición de las medidas utilizadas}

Las medidas osteológicas empleadas en este trabajo se detallan a continuación (ver figura 14):

- AM, anchura del maxilar: anchura del maxilar medida en el extremo craneal de las narinas.

- C, longitud del culmen: distancia desde el processus frontalis nasalis hasta el extremo craneal del premaxilar.

- Cn, longitud del culmen a partir de las narinas: distancia desde el extremo craneal de las narinas hasta el extremo craneal del premaxilar.

- C2, longitud del culmen 2: distancia desde el extremo caudal de las narinas hasta el extremo craneal del premaxilar.

- LC, longitud craneal: distancia desde el extremo caudal del os supraoccipitale hasta el extremo craneal del premaxilar.

- LCB, longitud cóndilo-basal: distancia desde el margen craneal del foramen magnum hasta el extremo craneal del premaxilar.

- LC2, longitud craneal 2: distancia desde el extremo caudal del os supraoccipitale hasta el processus frontalis nasalis.

- LM, longitud mandibular: distancia desde el extremo craneal de la sínfisis mandibular hasta el extremo caudal del cóndilo mandibular. 
- LS, longitud de la sínfisis mandibular: distancia desde el extremo craneal de la mandíbula hasta el extremo caudal de la sínfisis.

- DI, distancia interorbitaria: medida en el punto de menor amplitud.

- AEP, anchura de la epífisis proximal.

-Húmero: distancia desde el tuberculum dorsalis hasta el margen lateral externo de la cresta bicipital.

-Ulna: anchura máxima desde el margen lateral externo del cotyla dorsalis hasta el del cotyla ventralis.

• Radio: anchura máxima.

- Carpometacarpo: distancia desde el margen lateral externo del processus extensorius hasta el de la facies articularis ulnocarpalis.

-Fémur: distancia desde el margen lateral externo del caput femoris hasta el del trochanter femoris.

-Tibiotarso: distancia desde el margen lateral externo de la facies articularis medialis hasta el de la facies articularis lateralis.

-Tarsometatarso: distancia desde el margen lateral externo del cotyla lateralis hasta el del cotyla medialis.

- AED, anchura de la epífisis distal.

-Húmero: distancia desde el margen lateral externo del processus flexorius hasta el del epicondylus dorsalis.

-Ulna: distancia desde el margen lateral externo del condylus dorsalis ulnae hasta el del tuberculum carpale.

•Radio: anchura máxima.

- Carpometacarpo: distancia máxima tomada a la altura del extremo distal del digiti majoris.

-Fémur: distancia desde el margen lateral externo del condylus medialis hasta el del condylus lateralis.

-Tibiotarso: distancia desde el margen lateral externo del condylus medialis hasta el del condylus lateralis.

- Tarsometatarso: distancia desde el margen lateral externo de la trochlea metatarsi II hasta el de la trochlea metatarsi IV.

- AD, anchura de la diáfisis: medida en el punto medio del hueso.

- L, longitud total máxima. 
Las medidas utilizadas para el análisis de la varianza y los test no paramétricos corresponden a la longitud total (L), la anchura de la epífisis proximal (AEP), la anchura de la epífisis distal (AED), la anchura de la diáfisis (AD) y el índice de robustez (IR). El índice de robustez se calcula mediante la fórmula:

$$
\mathrm{IR}=\frac{\mathrm{AD}}{\mathrm{L}} \times 100
$$
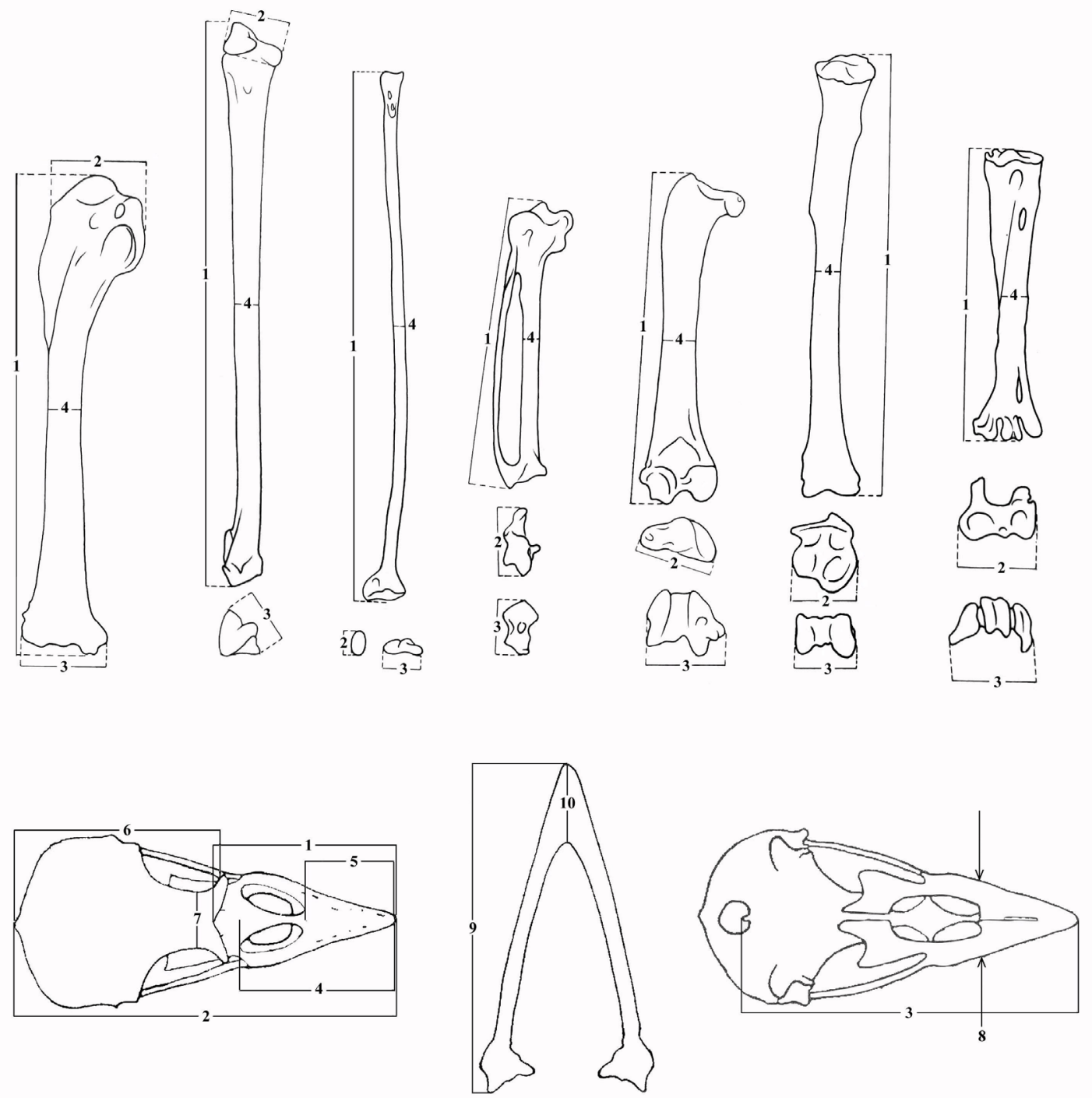

Figura 14. Esquema de medidas de los principales elementos óseos. Húmero, ulna, radio, carpometacarpo, fémur, tibiotarso y tarsometatarso, 1: L; 2: AEP; 3: AED; 4: AD. Cráneo y mandíbula, 1: C; 2: LC; 3: LCB; 4: Cn; 5: C2; 6: LC2; 7: DI; 8: AM; 9: LM; 10: LS. 


\subsection{Otras abreviaturas utilizadas}

AOB- Anuari Ornitològic de les Balears.

IMEDEA- Institut Mediterrani d'Estudis Avançats.

Ma- millones de años.

NHML- Natural History Museum at London.

NHMT- Natural History Museum at Tring.

NMR- Natuurhistorisch Museum Rotterdam.

NMI- Número mínimo de individuos.

SEO- Sociedad Española de Ornitología.

\subsection{Taxonomía y nomenclatura}

En este trabajo se ha seguido la clasificación taxonómica de la lista de las aves de España (Gutiérrez et al. 2012) de la Sociedad Española de Ornitología (SEO).

Para la terminología de anatomía osteológica se ha seguido principalmente la nomenclatura de Livezey y Zusi (2006) y, menos frecuentemente, la utilizada por Baumel (1979) y Tomek y Bocheński (2000).

Para la designación de los extremos proximal y distal de los huesos de los miembros, se han utilizado los términos "epífisis proximal" y "epífisis distal", respectivamente. El uso del término epífisis no es apropiado en el caso de las aves, ya que es una estructura exclusiva de los mamíferos, mientras que en las aves no existe un centro de osificación separado (Livezey y Zusi 2006). Sin embargo, en este trabajo y siguiendo el ejemplo de otros autores (e.g., Jánossy 1983, Bocheński y Bocheński 2008; Boev 2009; Louchart 2011), se han empleado dichos términos para facilitar las descripciones de los caracteres osteológicos.

\subsection{Presentación del texto}

La Tesis se estructura en torno al estudio de las aves fósiles procedentes del yacimiento de es Pouàs pertenecientes a tres órdenes, Passeriformes, Falconiformes y Strigiformes.

Tras la introducción de carácter general (capítulo 1) y la descripción de los materiales y métodos (capítulo 2), se presentan los capítulos correspondientes a los resultados de la investigación realizada.

En primer lugar (capítulo 3) se exponen los resultados obtenidos de la identificación y clasificación de las especies de aves Passeriformes del yacimiento de es Pouàs, seguidos de su discusión (capítulo 4). En la parte sistemática se presenta una lista del material estudiado y su posición estratigráfica, así como una estimación del número mínimo de individuos (NMI) de cada taxón y los criterios de identificación de dicho material. Si bien en la lista de material no se hace distinción entre los huesos completos y los fragmentos 
de hueso, tanto el estado de los mismos (información disponible en: http://datos.gbif.es/ collectory/public/show/co110) como su posición estratigráfica se han tenido en cuenta para la estimación del número mínimo de individuos. Así mismo, se presenta información sobre la presencia y abundancia de cada especie como fósil (siguiendo principalmente el catálogo de Tyrberg $[1998,2008])$ y en la actualidad en el Paleártico occidental.

El estudio de los depredadores y agentes bio-acumuladores potenciales de los Passeriformes de es Pouàs (es decir, las aves rapaces) es el objeto del capítulo 5. Dicho estudio se presenta en el trabajo "The Upper Pleistocene-Holocene raptorial bird guild from Eivissa Island (Pityusic Archipelago, Western Mediterranean Sea)" (Guerra et al. 2013), publicado en la revista Geobios. En este trabajo se presenta, en primer lugar, el material identificado y los criterios de identificación que permiten establecer los diagnósticos taxonómicos de las diferentes especies de aves rapaces del yacimiento de es Pouàs. A continuación se analizan las implicaciones paleo-ecológicas del gremio de las aves de presa en la comunidad de vertebrados del Pleistoceno superior y Holoceno de las Pitiusas.

Con el objeto de relacionar el estudio de faunas fósiles con el de las actuales e interpretar los efectos de las intervenciones humanas, se ha realizado un estudio sobre el comportamiento alimenticio actual de la lechuza (Tyto alba) en los islotes de las Pitiusas, que se presenta en el capítulo 6. Este artículo ha sido publicado en la revista Folia Zoologica con el título "Unusual foraging patterns of the barn owl, (Tyto alba) (Strigiformes: Tytonidae) on small islets from the Pityusic Archipelago (Western Mediterranean Sea)" (Guerra el al. 2014). En este trabajo se enfatiza la ausencia de la lechuza en el Pleistoceno superior de las Pitiusas, debida muy probablemente a la ausencia de mamíferos en las islas, así como su etología y ecología trófica en la actualidad. Este apartado representa una aplicación del estudio de los fósiles de es Pouàs al análisis de la presencia actual y de la etología y ecología trófica de una especie en las Pitiusas.

Finalmente se presenta una discusión general (capítulo 7) de los grupos objeto del presente estudio seguida de las conclusiones generales. 
2 - MATERIAL Y MÉTODOS 



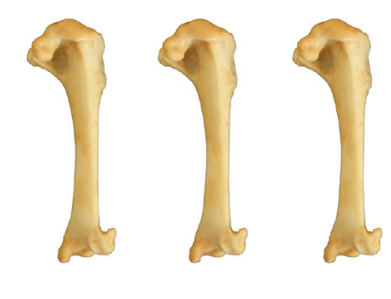

\section{ESTUDIO TAXONÓMICO DE LOS PASSERIFORMES DE ES POUÀS}




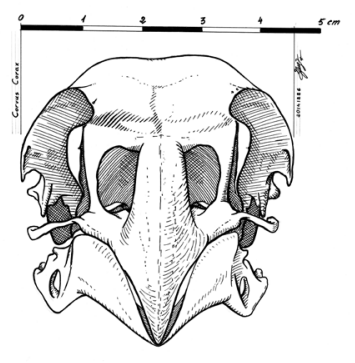

\title{
3. ESTUDIO TAXONÓMICO DE LOS PASSERIFORMES DE ES POUÀS
}

\author{
Alaudidae Vigors, 1825 \\ (Figura 3, anexo)
}

\section{Cráneo y mandíbula}

El cráneo de los aláudidos presenta un aspecto globular, con una distancia interorbitaria generalmente estrecha (con la excepción de Melanocorypha) (Verheyen 1958). El processus zygomaticus y el processus postorbitalis se unen dando lugar a una estructura continua en el borde latero-inferior de la órbita. Los foramina venae occipitalis externae se sitúan en el borde posterior del foramen magnum (Moreno 1985).

La forma de las narinas permite establecer dos grupos de aláudidos (Verheyen 1958; Moreno 1985). Calandrella y Melanocorypha presentan las narinas cortas y redondeadas mientras que en Lullula, Galerida, Alauda y Eremophila, son alargadas.

El premaxilar es alargado y robusto, con un corpus ossis premaxillaris alto y una impresión o canal en la parte central del mismo en vista ventral, que lo divide longitudinalmente.

No se ha dispuesto de material de comparación de Chersophilus duponti. El cráneo de esta especie presenta un premaxilar característico, largo y curvado, que no ha aparecido en es Pouàs. De Eremophila alpestris se ha dispuesto de fotografías del cráneo (www. skullsite.com) y del húmero (Boev 2012), así como de un esqueleto postcraneal de un ejemplar europeo y un esqueleto completo de E. alpestris praticola procedente de Canadá. El premaxilar es similar al de Calandrella, con un corpus ossis premaxillaris corto y ancho, pero con unas narinas más alargadas en Eremophila.

En cuanto a la mandíbula, la sínfisis mandibular es robusta, con una impresión en la parte central (en vista dorsal) que, al igual que en el premaxilar, la recorre longitudinalmente. El cuerpo óseo de la sínfisis es grueso y compacto hasta la crista tomialis de modo 
que la sínfisis es plana en vista dorsal, en vez de cóncava como ocurre en la mayor parte de especies de paseriformes. La inserción de las ramas mandibulares en la sínfisis conforma una estructura también robusta. Por último, la parte articular es muy característica, con un processus medialis mandibulae muy alargado y curvado ventralmente.

Ordenando las especies de aláudidos actuales (de Europa occidental) en base a la longitud de sus premaxilares y mandíbulas, tenemos (de menor a mayor longitud, y excluyendo a C. duponti): $1^{\underline{0}}$ Calandrella rufescens, $2^{\underline{0}}$ Calandrella brachydactyla, $3^{\underline{0}}$ Lullula arborea y Eremophila alpestris, $4^{\underline{0}}$ Alauda arvensis, $5^{\underline{0}}$ Galerida theklae y $6^{\underline{0}}$ Melanocorypha calandra y Galerida cristata.

\section{Húmero}

Los húmeros de Alaudidae se caracterizan por presentar una sola fossa pneumotricipitalis bien desarrollada. También presentan una ligera elevación del caput humeri, que provoca la aparición de una pequeña concavidad distal a él, la fosa dorsal (pars dorsalis), limitada posteriormente por el margo caudalis (Moreno 1985).

A diferencia de la fosa ventral (pars ventralis), la fosa dorsal está muy poco desarrollada. La cresta deltoidea es proporcionalmente larga en comparación con la anchura proximal del húmero, excepto la de Melanocorypha calandra que es proporcionalmente más corta que en Alauda, Galerida y Lullula (Louchart 2002). Así, la apariencia general de la parte proximal del húmero, excepto en Melanocorypha, es rectangular (Wójcik 2002).

Jánossy (1983) observa que los húmeros de los Alaudidae presentan una fosa ventral neumatizada y, en la epífisis distal, un processus supracondylaris dorsalis reducido.

El húmero de Eremophila alpestris presenta una longitud (23,2-25,1 mm, n=8; IMEDEA, NHMTT, Jánossy 1983, Boev 2012), superior a la del húmero de Calandrella y Lullula e inferior a la del húmero de Galerida cristata (ver figura 15). Además, a diferencia de Calandrella y Lullula, el húmero de E. alpestris es más robusto, especialmente su epífisis proximal. Boev (2012) observa que, a diferencia de Eremophila, el processus flexorius de Calandrella es más fino y el caput humeri de Lullula es menos robusto. La fosa dorsal en Eremophila es más tenue que en Galerida. Si bien la longitud del húmero de E. alpestris se solapa con la del húmero de A. arvensis, la cresta deltoidea de ésta última presenta un borde externo más recto.

El húmero de C. duponti, en comparación con el de L. arborea, presenta una longitud superior y una cresta deltoidea también más larga (Louchart 2002). A diferencia de $A$. arvensis, la fosa dorsal del húmero de $C$. duponti es más profunda. Por último, la parte distal de la cresta deltoidea está menos diferenciada de la diáfisis en C. duponti que en el resto de aláudidos (Louchart 2002). 
Los taxones con el húmero morfológicamente más similar a los aláudidos, con una única fosa bien desarrollada, pertenecen a las familias Oriolidae, Bombycillidae y Laniidae. Las diferencias con los húmeros de Laniidae se observan principalmente en la epífisis proximal. El tubérculo ventral se proyecta más distalmente y es más ancho y robusto en Laniidae, mientras que en Alaudidae es más fino y alargado y se proyecta más ventralmente. Además, en Laniidae la fosa ventral tiene forma redondeada, mientras que en Alaudidae es más alargada y aguda en su parte proximal. La cresta deltoidea es notablemente más larga en Alaudidae, y los húmeros de Laniidae no presentan fosa dorsal. En la epífisis distal, el conjunto del epicondylus dorsalis y el processus supracondylaris dorsalis se encuentra muy cercano a la diáfisis y paralelo a ella en Alaudidae. En cambio, su extremo proximal es prominente y redondeado en Laniidae y se encuentra más separado de la diáfisis.

Los húmeros de Oriolidae y Bombycillidae son morfológicamente más similares a los de los alcaudones y en el caso de Oriolus oriolus, la talla del húmero es muy superior a la de los ampelis y los aláudidos.

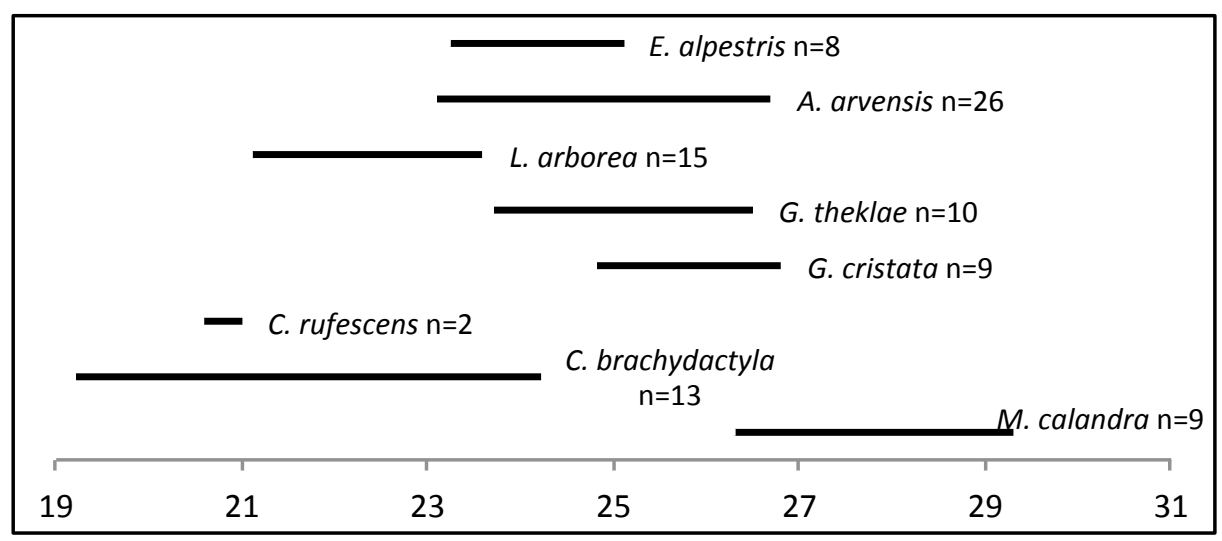

Figura 15. Longitud de los húmeros de las especies actuales de Alaudidae. Ejemplares procedentes de las colecciones del IMEDEA y el NHMT y de los trabajos de Jánossy (1983), Moreno (1985), Boev (2012) y Kessler (2013).

\section{Tarsometatarso}

El tarsometatarso de esta familia presenta un aspecto alargado, con unas trócleas muy cortas y con escasa separación entre sí. La trochlea metatarsi II se encuentra muy desarrollada, especialmente en su parte dorsal y lateral y no presenta un surco en su parte central. El retinaculum extensorium osseum se encuentra poco desarrollado y el foramen vasculare distale es muy sutil, apenas se aprecia.

La identificación de los géneros se ha realizado fundamentalmente en base a los datos biométricos, no habiéndose encontrado diferencias morfológicas inequívocamente diagnósticas entre los mismos. Como se puede observar en la figura 16, la longitud del tarsometatarso en Alaudidae se sitúa entre 19 y 26,7 mm.

Algunos taxones con tarsometatarsos de talla similar se incluyen en las familias Turdidae, Fringillidae, Motacillidae, Laniidae y Prunellidae. A diferencia de Alaudidae, la 
epífisis distal del tarsometatarso es más estrecha y la trochlea metatarsi III es notablemente más larga que las otras dos trócleas en Turdidae (excepto en Turdus y Monticola). En los tarsometatarsos de Fringillidae, la separación entre las trócleas es mayor que en Alaudidae. La epífisis distal en los tarsometatarsos de Alaudidae es proporcionalmente más ancha que en los de Motacillidae. A diferencia de Prunella, la trochlea metatarsi II está más desarrollada en Alaudidae. Por último, a diferencia de Alaudidae, los tarsometatarsos de Laniidae presentan una epífisis distal más estrecha y una mayor separación entre la trochlea metatarsi III y la $I V$.

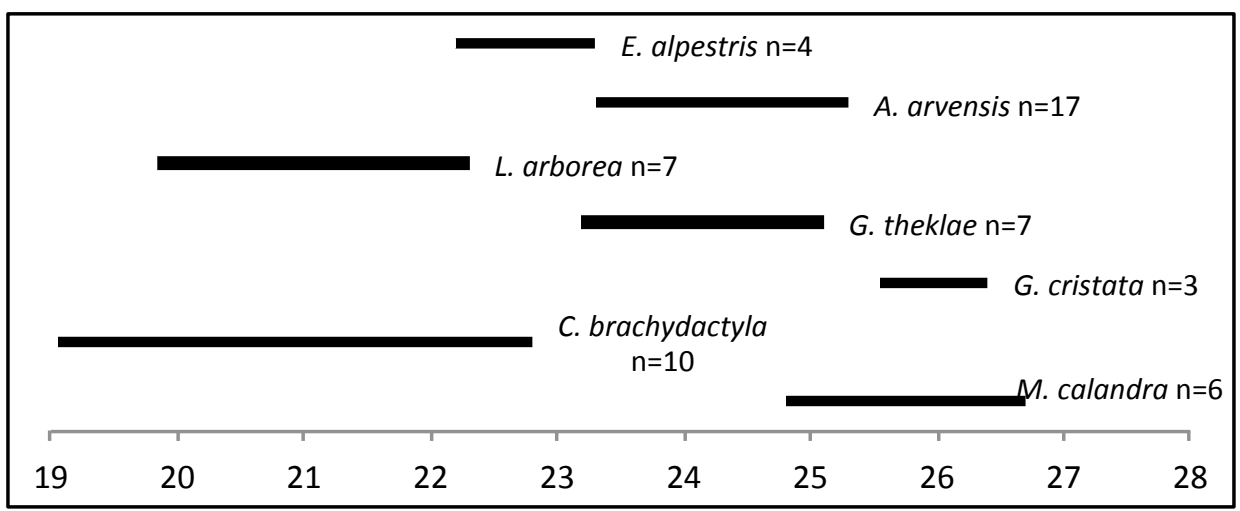

Figura 16. Longitud de los tarsometatarsos de las especies actuales de Alaudidae. Ejemplares procedentes de las colecciones del IMEDEA y el NHMT y del trabajo de Moreno (1985).

Melanocorypha Boie, 1828

Melanocorypha calandra (Linnaeus, 1766)

Calandria común

Material: 7 premaxilares, 1 mandíbula y 5 húmeros (3 derechos, 2 izquierdos). Total: 13. NMI: 7 (basado en los premaxilares).

Distribución estratigráfica en es Pouàs: presente en niveles del Pleistoceno superior y el Holoceno (niveles 3 y 7 de la cuadrícula A3 y cuadrícula D4).

Distribución actual en el Paleártico occidental: esta especie, esencialmente esteparia, se encuentra principalmente en latitudes medias y bajas del Mediterráneo occidental (Snow y Perrins 1998). Ausente en Baleares, únicamente se observa de forma accidental en Mallorca (López-Jurado 2011).

Registro fósil en el Paleártico occidental: $M$. calandra es muy poco frecuente en los yacimientos del Pleistoceno inferior, solamente aparece en España, Italia e Israel. También es una especie escasa en el Pleistoceno medio del este (Israel y Rusia) y del oeste (Francia y cf. M. calandra en España) de la región. Algo más abundante en el Pleistoceno superior, se ha citado en tres yacimientos de España, cuatro de Italia y tres de Francia. Aparece puntualmente en el Pleistoceno superior de Europa central y del este (Tyrberg 1998, 2008). En Baleares hay dos registros de esta especie procedentes de Mallorca, uno del Pleistoceno 
superior (Florit y Alcover 1987) y otro del Pleistoceno inferior (Melanocorypha cf. calandra, Alcover et al. 1981).

\section{Comentarios}

Cráneo y mandíbula: destaca el gran tamaño del cráneo de $M$. calandra, así como el de todas sus estructuras, consecuencia de un desarrollo extremo. En el pico, este desarrollo no es tan notable y se caracteriza sobre todo por sus narinas redondeadas y su talla superior a la de otros aláudidos, excepto G. cristata (Cuisin 1989).

La mandíbula es robusta, con una sínfisis y unas ramas mandibulares muy desarrolladas. La sínfisis mandibular es larga y presenta un estrechamiento progresivo hacia el ápice. Los elementos craneales de esta especie se diferencian fácilmente por ser los de mayor robustez de la familia.

Húmero: Jánossy (1983) describe el húmero de $M$. calandra como el más robusto de la familia, siendo el tubérculo ventral relativamente más grande en esta especie que en el resto de aláudidos. La cresta deltoidea es, en relación a la longitud del húmero, más corta que en otras especies y las neumatizaciones de la fossa pneumotricipitalis son profundas.

Solamente se ha dispuesto de fotografías de ejemplares de museo (skullsite y NHMT) y datos biométricos procedentes de dichos ejemplares y de la bibliografía. Los húmeros adscritos a esta especie presentan una talla muy superior a los de las otras especies de la familia. Sus epífisis son muy anchas y su longitud es superior a los $30 \mathrm{~mm}$ por lo que se descarta que pertenezcan a Galerida (longitud máxima 26,8 mm).

\section{cf. Melanocorypha calandra}

Material: 1 mandíbula y 9 húmeros (5 derechos, 4 izquierdos). Total: 10.

Comentarios: la sínfisis mandibular del fragmento de mandíbula es muy corta por lo que su atribución a esta especie es dudosa. La longitud de los húmeros, aunque superior, se solapa con la de Galerida por lo que, tanto para el material fragmentario de talla intermedia como para los húmeros de longitud inferior a $29 \mathrm{~mm}$, se ha optado por utilizar una nomenclatura abierta.

\section{Calandrella Kaup 1829}

Cráneo y mandíbula: tanto la mandíbula como el premaxilar en Calandrella son más cortos que en Galerida y Alauda. El corpus ossis premaxillaris de Calandrella es más plano en vista ventral, a diferencia del de Alauda que es más cóncavo y además más bajo y 
estrecho que en Calandrella. El processus frontalis premaxillare es corto y las narinas son redondeadas y también cortas. A diferencia de Calandrella, tanto la sínfisis mandibular como el corpus ossis premaxillaris son mucho más estrechos y más bajos en Lullula, y las ramas mandibulares son más altas en Calandrella que en Alauda y Lullula.

Húmero: la fosa dorsal del húmero de Calandrella está más desarrollada que la del húmero de Alauda. La cresta deltoidea es, en proporción a la longitud del hueso, notablemente más corta que en Lullula, Alauda y Galerida.

Se observa que el ángulo que forma la cresta bicipital con la diáfisis en Calandrella es más estrecho, mientras que en Alauda y en Galerida la cresta bicipital se une a la diáfisis de manera progresiva, formando un ángulo más abierto. Por otro lado, a diferencia de Lullula, la unión de la cresta deltoidea con la diáfisis forma un escalón en Calandrella (Bedetti y Pavia 2013). La atribución de los fósiles de es Pouàs a éste género es clara, si bien su diagnosis específica resulta más problemática, debido a la similitud entre las dos especies existentes en el Paleártico occidental. Por ello se ha optado por adoptar una nomenclatura abierta (Calandrella cf. brachydactyla, Calandrella sp.) para la asignación taxonómica de estos fósiles.

\section{Calandrella cf. brachydactyla \\ Terrera común}

Material: 4 húmeros (derechos). NMI: 4.

Distribución estratigráfica en es Pouàs: Pleistoceno superior (cuadrícula A3, nivel 4).

Distribución actual en el Paleártico occidental: especie básicamente esteparia, cría en latitudes medias y sobre todo bajas del Mediterráneo occidental. (Snow y Perrins 1998). En Baleares es una especie abundante como migrante y en época estival tanto en las Gimnesias como en Ibiza, criando en todas las islas mayores (López-Jurado 2011).

Registro fósil en el Paleártico occidental: es bastante escasa en el registro fósil del Paleártico occidental. Solamente se ha citado en yacimientos del Pleistoceno inferior de Italia, del Pleistoceno medio de Francia, Italia e Israel y del Pleistoceno superior de Francia y Grecia. En España se ha atribuido tentativamente a esta especie material de dos yacimientos del Pleistoceno inferior (Tyrberg 1998, 2008). C. brachydactyla aún no consta en el registro fósil de Baleares.

Comentarios: el húmero de C. brachydactyla presenta una fosa dorsal bastante notable (Weesie 1988). Jánossy (1983) destaca sus epífisis poco robustas. Los ejemplares proceden- 
tes de es Pouàs son biométricamente más similares a C. brachydactyla (si bien su talla es ligeramente superior a la de esta especie) que a C. rufescens.

\section{Calandrella sp.}

Material: 45 premaxilares, 1 mandíbula, 6 húmeros (5 derechos, 1 izquierdo) y 1 esqueleto postcraneal parcial. Total: 53 .

Comentarios: los rasgos morfométricos del material identificado coinciden con los de este género, si bien el estado del material junto con la escasez de individuos de comparación de C. rufescens impide realizar una diagnosis más precisa.

\section{cf. Calandrella}

Material: 11 premaxilares, 3 mandíbulas, 52 húmeros (30 derechos, 22 izquierdos) y 25 tarsometatarsos (14 derechos, 11 izquierdos). Total: 91.

Comentarios: el material que aquí se asigna a cf. Calandrella se encuentra, en su gran mayoría, en estado fragmentario.

Los húmeros y tarsometatarsos podrían atribuirse a Calandrella sp. o a Lullula arborea ya que la talla de dichos huesos se solapa en estos dos taxones. La escasez de material de comparación y el estado fragmentario de los fósiles, dificultan la identificación del material.

\section{Galerida Boie 1828}

Cráneo y mandíbula: el premaxilar presenta unas narinas amplias y alargadas. Tanto el corpus ossis premaxillaris como la sínfisis mandibular son más alargados que en el resto de géneros.

Húmero: el húmero de Galerida presenta una epífisis proximal más robusta que la del húmero de Alauda. Además, la fosa dorsal está más desarrollada en Galerida. Por último, la incisura capitis es más notable en Alauda, mientras que en Galerida es más tenue. No se han encontrado diferencias inequívocamente diagnósticas entre los húmeros de las dos especies de Galerida, que presentan una longitud similar, por lo que solamente han sido identificados a nivel genérico. 


\section{Galerida cristata (Linnaeus, 1758)}

Cogujada común

Material: 42 premaxilares, 59 fragmentos de mandíbula. Total: 101. NMI: 52 (basado en las mandíbulas).

Distribución estratigráfica en es Pouàs: Pleistoceno superior y Holoceno (niveles 1, 3 , 4, 5, 6, 7 y 8 de la cuadrícula A3 y un nivel de la cuadrícula D4).

Distribución actual en el Paleártico occidental: la cogujada común presenta una amplia distribución longitudinal y latitudinal en la región, excepto en las latitudes más altas (Snow y Perrins 1998). No se observa en la actualidad en Baleares (López-Jurado 2011).

Registro fósil en el Paleártico occidental: se ha registrado en yacimientos del Pleistoceno inferior del sur de Europa (España e Italia). En el Pleistoceno medio, es una especie relativamente frecuente en Francia y escasa en España e Italia. Es frecuente en yacimientos del Pleistoceno superior de toda la región, aunque no consta en el registro de las Islas Baleares (Tyrberg 1998, 2008), excepto por un registro del Pleistoceno superior de Ibiza con determinación imprecisa (Galerida theklae/cristata, Sondaar et al. 1995).

\section{Comentarios}

Cráneo y mandíbula: el corpus ossis premaxillaris es muy largo, de longitud notablemente superior al de G. theklae. G. theklae presenta un premaxilar más corto, más ancho en la base y de mayor altura que el de G. cristata. Para diferenciar a las dos especies del género, Moreno (1985) atiende también al perfil del pico. Según la autora, a diferencia de G. cristata, la crista tomialis presenta un perfil característico con un estrechamiento más o menos pronunciado en la parte anterior al punto más rostral de las narinas en Galerida theklae así como en el resto de especies de la familia. En general, los premaxilares y mandíbulas de G. cristata de es Pouàs superan en talla a los ejemplares actuales de comparación.

La sínfisis mandibular es más alargada y de mayor longitud que en las demás especies, si bien se solapa ligeramente con el rango de longitud de M. calandra. En general todas las estructuras mandibulares de G. cristata son de mayor tamaño que las de G. theklae.

Galerida theklae C.L. Brehm, 1858

Cogujada montesina

Material: 1 mandíbula. NMI: 1.

Distribución estratigráfica en es Pouàs: Pleistoceno superior (nivel 6 de la cuadrícula A3). 
Distribución actual en el Paleártico occidental: presente principalmente en el sudoeste de la región, es decir, noroeste de África, Portugal y España (Snow y Perrins 1998). Es una especie sedentaria en Baleares, abundante en las Pitiusas y de abundancia moderada en Mallorca y Menorca (López-Jurado 2011).

Registro fósil en el Paleártico occidental: se encuentra prácticamente ausente del registro de toda la región. Solamente ha aparecido en el Pleistoceno medio (cf. Galerida theklae) y en el Pleistoceno superior de España, aunque en otros países de la región se han registrado individuos de diversos yacimientos identificados como Galerida cristata/ theklae (Tyrberg 1998, 2008). En el registro del Pleistoceno superior de Ibiza ya constaba la presencia de material identificado como Galerida theklae/cristata (Sondaar et al. 1995).

Comentarios: la mandíbula de G. theklae es más larga que las de Lullula y Calandrella. A diferencia de la de G. theklae, la mandíbula de A. arvensis presenta unas ramas mandibulares más bajas y un processus medialis mandibulae más estrecho. Y a diferencia de $G$. cristata, tanto en el fósil como en G. theklae, la sínfisis es más corta.

\section{Galerida sp.}

Material: 8 premaxilares, 16 mandíbulas y 87 húmeros (34 derechos, 53 izquierdos). Total: 111 .

Comentarios: el estado fragmentario de los premaxilares y mandíbulas impiden una diagnosis más precisa, y las medidas de longitud de los húmeros de las dos especies se solapan totalmente. Por ello, se ha optado por utilizar una nomenclatura abierta.

\section{cf. Galerida}

Material: 2 premaxilares, 3 mandíbulas, 62 húmeros (42 derechos, 20 izquierdos) y 9 tarsometatarsos (3 derechos, 6 izquierdos). Total: 76.

Comentarios: los premaxilares, más estrechos que los de Calandrella y más cortos que los de G. cristata, son atribuibles a Galerida theklae aunque no se puede descartar que pertenezcan a Alauda arvensis. Los húmeros y tarsometatarsos son biométricamente atribuibles a Galerida sp., si bien no se puede descartar que pertenezcan a Melanocorypha calandra, ya que son más grandes que los del resto de aláudidos. 
Lullula Linnaeus, 1758

Lullula arborea Linnaeus, 1758

Alondra totovía

Material: 1 húmero (izquierdo). NMI: 1.

Distribución estratigráfica en es Pouàs: Pleistoceno superior.

Distribución actual en el Paleártico occidental: su área de distribución ocupa principalmente latitudes templadas y mediterráneas del oeste de la región. Cría en el oeste de Europa y Gran Bretaña. Principalmente residente, pasa el invierno en la mitad sur de su área de cría (Snow y Perrins 1998). Es una especie de presencia accidental en Mallorca e Ibiza y ausente en el resto del archipiélago balear (López-Jurado 2011).

Registro fósil en el Paleártico occidental: es una especie medianamente abundante en el Pleistoceno superior de Europa occidental y más escasa en el resto de la región. Ha aparecido en el Pleistoceno medio de Europa occidental (Francia, Italia, España) y en Rusia. Los únicos registros del Pleistoceno inferior corresponden a yacimientos de España (Tyrberg 1998, 2008). Uno de estos registros procede de material del Pleistoceno inferior de Mallorca (cf. Lullula arborea, Alcover et al. 1981) y constituye el único registro fósil de la especie en Baleares.

Comentarios: en el húmero, la parte proximal de la cresta bicipital se alarga ventralmente (Jánossy 1983). El húmero de Calandrella es menos robusto y la cresta deltoidea es notablemente más larga en Lullula.

\section{cf. Lullula arborea}

Material: 1 húmero (izquierdo) y 7 tarsometatarsos (3 derechos, 4 izquierdos). Total: 8.

Comentarios: el tarsometatarso, de longitud similar a Calandrella es, sin embargo, notablemente más robusto en Lullula y en los fósiles. El estado de los fósiles y la escasez de material de comparación impiden una identificación más precisa.

Alauda Linnaeus, 1758

Alauda arvensis Linnaeus, 1758

Alondra común

Material: 4 premaxilares, 19 mandíbulas y 98 húmeros (51 derechos, 47 izquierdos). Total: 121. NMI: 51 (basado en los húmeros). 
Distribución estratigráfica en es Pouàs: Pleistoceno superior y Holoceno $(-60 /-80 \mathrm{~cm}$ y niveles del 3 al 8 de la cuadrícula A3).

Distribución actual en el Paleártico occidental: $A$. arvensis se extiende por toda la región, criando en latitudes altas y medias-bajas de la misma. (Snow y Perrins 1998). La población de las islas del archipiélago balear es abundante pero solamente se encuentra en migración o invernada. En Ibiza es abundante como invernante y en migración (López-Jurado 2011).

Registro fósil en el Paleártico occidental: ampliamente distribuida y muy abundante, ha aparecido en más de 100 yacimientos del Pleistoceno superior del Paleártico occidental. Sin embargo es escasa en el Pleistoceno medio e inferior de la región (Tyrberg 1998, 2008). En las Gimnesias solamente se ha registrado en un yacimiento del Pleistoceno superior de Mallorca (Seguí el al. 1997). Su presencia en es Pouàs ya se había publicado anteriormente (Florit et al. 1989).

\section{Comentarios}

Cráneo y mandíbula: el premaxilar se estrecha hacia el ápice y presenta narinas alargadas y un processus frontalis premaxillare estrecho, a diferencia de Galerida. Tanto la sínfisis mandibular como el corpus ossis premaxillaris de Lullula son más estrechos y más bajos que los de Alauda. Otras diferencias con los demás géneros se han descrito en sus correspondientes apartados.

En la mandíbula de Alauda en vista dorsal, la rama mandibular continúa recta justo después de su inserción en la sínfisis mandibular, a diferencia de Calandrella, en la que ésta se ensancha y se bifurca ligeramente hacia el interior de la sínfisis. Así mismo, en vista lateral, el perfil de la parte craneal de la rama mandibular es recto, mientras que en Calandrella se estrecha repentinamente, formando un ángulo antes de la inserción con la sínfisis. Las ramas mandibulares son más altas en Alauda que en Lullula.

Húmero: la epífisis proximal es relativamente ancha y la cresta deltoidea en vista caudal muestra una línea curva (Jánossy 1983). Las diferencias con Calandrella y Galerida se describen en los apartados correspondientes a estas dos especies. Algunos de los húmeros identificados son más estilizados (finos y alargados) que los de los individuos actuales.

\section{cf. Alauda arvensis}

Material: 2 cráneos, 19 premaxilares, 33 mandíbulas, 552 húmeros (280 derechos, 272 izquierdos) y 24 tarsometatarsos (13 derechos, 11 izquierdos). Total: 630. 
Comentarios: todos estos huesos son atribuibles a Alauda arvensis, si bien en general, se trata de materiales tan fragmentarios que no se puede descartar su pertenencia a otras especies. Los fragmentos de premaxilar y mandíbula podrían corresponder a Alauda o a Calandrella, si bien tampoco se descarta su pertenencia a Lullula. Estos fragmentos presentan una sínfisis mandibular más corta que los de Galerida.

Los húmeros, la gran mayoría previamente determinados como Alauda/Galerida, presentan una talla intermedia entre los dos géneros y en su mayoría son fragmentos proximales por lo que no se puede estimar la longitud total del hueso. Se ha optado por utilizar una nomenclatura abierta también en el caso de los tarsometatarsos, ya que, si bien los fósiles y los de $A$. arvensis son algo más robustos que los de Galerida, su longitud se solapa con la de las especies de dicho género y su pertenencia a Alauda es dudosa.

\section{Alaudidae indeterminados}

Material: 1 cráneo, 34 premaxilares, 97 mandíbulas, 1539 húmeros (753 derechos, 786 izquierdos) y 11 tarsometatarsos (7 derechos, 4 izquierdos). Total: 1682.

Comentarios: el estado del material impide una identificación más precisa.

\section{Hirundinidae Vigors, 1825}

(Figura 4, anexo)

\section{Cráneo y mandíbula}

El aspecto más característico del cráneo de esta familia es la anchura de la base del premaxilar (e.g., Hamon 1964; Moreno 1986), que en ocasiones supera a la longitud. Los pterigoideos curvos son también característicos en esta familia. El processus zygomaticus y el processus postorbitalis están moderadamente desarrollados y tienen un tamaño similar. El foramen orbitonasale es doble y los foramina venae occipitalis externae se encuentran bastante separados entre sí y situados dorsalmente al foramen magnum (Moreno 1986).

Cuisin (1989) destaca el tamaño de cavidad orbital, que representa entre un 33\% y un 41\% de la longitud total del cráneo, según la especie.

El premaxilar es aplanado, ancho y corto, con todas las estructuras muy débiles y un corpus ossis premaxillaris aplanado y muy corto. Las narinas son muy amplias, ocupando casi toda la parte media y posterior del premaxilar.

La mandíbula, también muy amplia, presenta una sínfisis mandibular ancha, corta y casi plana. Las ramas mandibulares son muy finas con la fenestra mandibulae reducida 
y un ángulo mandibular muy marcado. Carece de processus coronoideus y de tubérculo pseudotemporal.

\section{Húmero}

El húmero es, dentro del esqueleto postcraneal de Hirundinidae, uno de los huesos que más se apartan del patrón general de los Passeriformes. La diáfisis es muy corta y, en contraste, destaca la anchura que alcanzan las epífisis, en particular la proximal. Presenta una fossa pneumotricipitalis bien desarrollada, si bien, al igual que en los Alaudidae, un elevamiento parcial del caput humeri hace que distalmente a él se produzca una pequeña depresión (Moreno 1986). Todos los procesos del hueso están muy desarrollados, especialmente el processus supracondylaris dorsalis.

Jánossy (1983) destaca el escaso desarrollo de la fosa dorsal y, en la epífisis distal, la robustez del processus supracondylaris dorsalis y el gran alargamiento distal del processus flexorius. Por su parte Hamon (1964) señala, entre otros caracteres, la epífisis proximal, de anchura superior a su longitud, con una cresta deltoidea notablemente expandida y una cresta bicipital redondeada.

Todo el material estudiado se adscribe a Hirundo/Cecropis y a Ptyonoprogne rupestris, las cuales se diferencian biométricamente del resto de taxones de la familia. Los huesos de Riparia riparia resultan fácilmente identificables ya que son de tamaño notablemente inferior a los de las demás especies de la familia. Tanto $R$. riparia como Delichon urbicum no han sido identificados en es Pouàs. Los húmeros de Delichon urbicum presentan una talla inferior a los de Cecropis daurica, Hirundo rustica y Ptyonoprogne rupestris. A diferencia de las dos últimas especies, los húmeros de D. urbicum sólo presentan un tubérculo (en vez de dos) en el ápice del processus supracondylaris dorsalis, que además se encuentra más separado de la diáfisis que en el resto de especies. Por último, el extremo proximal de la cresta deltoidea se encuentra más elevado, más extendido proximalmente, en $D$. urbicum que en las otras especies.

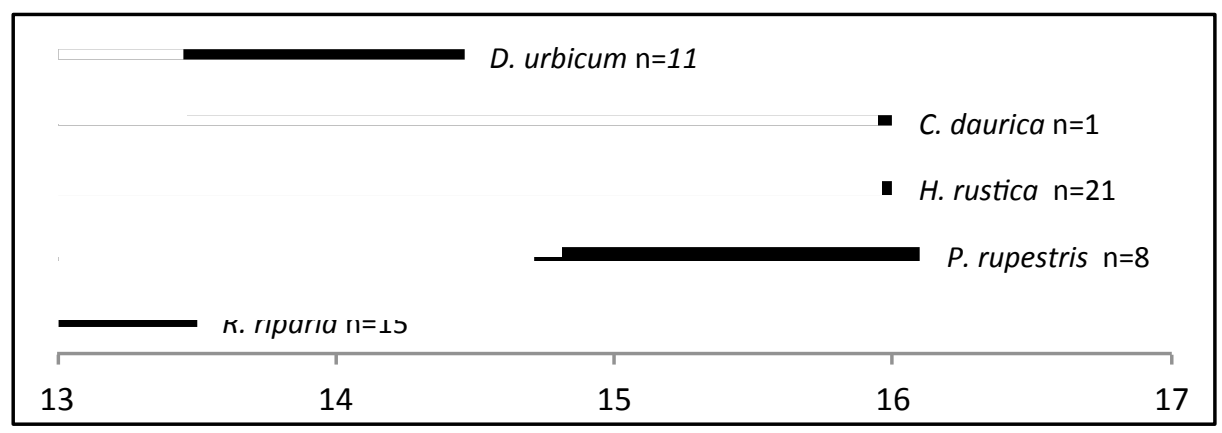

Figura 17. Longitud de los húmeros de las especies actuales de Hirundinidae. Ejemplares procedentes de la colección del IMEDEA y de los trabajos de Jánossy (1983) y Moreno (1986). 


\section{Tarsometatarso}

El tarsometatarso de los Hirundinidae es relativamente robusto y fácilmente identificable, ya que es el más corto de los de las familias de paseriformes estudiadas (figura 18). Hamon (1964) observa que los tarsometatarsos de esta familia presentan una eminentia intercondylaris grande y en la epífisis distal, la trochlea metatarsi II está moderadamente expandida mientras que la trochlea metatarsi III es recta y larga. La mayor parte de los tarsometatarsos de esta familia han sido identificados como Ptyonoprogne rupestris/ Hirundo rustica, ya que su morfometría se ajusta a la de estas dos especies y no ha aparecido ningún resto de las otras especies de la familia. El tarsometatarso de Cecropis es notablemente más largo que el del resto de especies, si bien solamente se dispone de las medidas de un ejemplar.

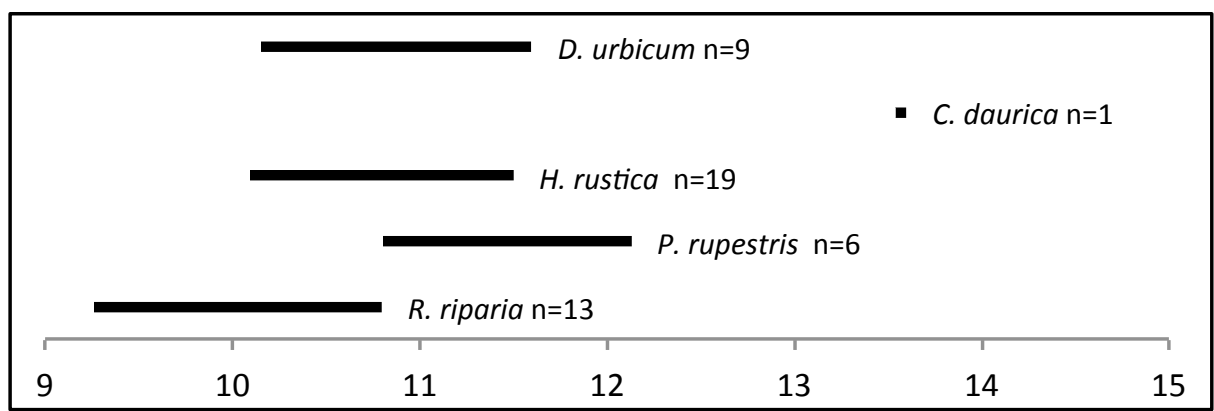

Figura 18. Longitud de los tarsometatarsos de las especies actuales de Hirundinidae. Ejemplares procedentes de la colección del IMEDEA y del trabajo de Moreno (1986).

\section{cf. Ptyonoprogne rupestris (Scopoli 1769) \\ Avión roquero}

Material: 2 húmeros (derechos) y 1 tarsometatarso (izquierdo). Total: 3. NMI: 2 (basado en los húmeros).

Distribución estratigráfica en es Pouàs: Pleistoceno superior y Holoceno (nivel 3 y nivel superficial de la cuadrícula A3).

Distribución actual en el Paleártico occidental: especie residente en la Península Ibérica, Italia, sur de Francia y norte de Argelia, cría en latitudes medias-bajas. Exceptuando a las poblaciones más norteñas, no realizan migración (Snow y Perrins 1998). Es abundante y cría en Mallorca, siendo más escasa en el resto de las islas. En Ibiza es una especie sedentaria escasa y abundante en invernada (López-Jurado 2011).

Registro fósil en el Paleártico occidental: P. rupestris es una especie escasa en los yacimientos del Pleistoceno medio, sólo aparece en Francia y España. Es abundante en el Pleistoceno superior de Europa occidental (España, Francia e Italia) y más escasa en el resto de la región (Tyrberg 1998, 2008). Ha sido identificada en un yacimiento del Pleisto- 
ceno superior de Mallorca (Florit y Alcover 1987; McMinn y Alcover 1992). En es Pouàs, Florit et al. (1989) mencionan Hirundo sp. indicando que podría tratarse de H. rupestris.

Comentarios: los criterios osteológicos para la identificación del húmero, se detallan en los comentarios correspondientes a Hirundo rustica/Cecropis daurica. En cuanto al tarsometatarso, el de $P$. rupestris es notablemente más robusto que el de $H$. rustica, especialmente la diáfisis.

\section{Ptyonoprogne rupestris/Hirundo rustica}

Material: 1 cráneo, 3 premaxilares, 1 mandíbula, 141 húmeros (73 derechos, 68 izquierdos), 25 tarsometatarsos (12 derechos, 13 izquierdos), 3 ulnas (1 derecha, 2 izquierdas) y 1 esqueleto postcraneal parcial. Total: 175 .

Comentarios: tanto los adultos dudosos como los individuos juveniles se han incluido en esta categoría, si bien no se puede descartar que algunos restos pertenezcan a $C$. daurica. No es el caso del cráneo, cuya distancia interorbitaria es mayor en $C$. daurica que en estas dos especies, ni de los tarsometatarsos cuya longitud es superior en C. daurica. Algunos tarsometatarsos son también biométricamente similares a los de D. urbicum, si bien no aparecido ningún resto inequívoco de esta especie. La longitud de los húmeros identificados es superior a la que presentan los de Delichon y Riparia. Las tres ulnas son más largas (hasta 25,9 mm) que las de las especies actuales de esta familia $(24,7 \mathrm{~mm}$ la de mayor longitud).

El esqueleto postcraneal parcial corresponde a un individuo subadulto. El húmero es de longitud similar a los de $H$. rustica y $P$. rupestris y más corto que el de $C$. daurica.

Hirundo rustica/Cecropis daurica

Golondrina común/Golondrina dáurica

Material: 72 húmeros (43 derechos, 29 izquierdos). Total: 72. NMI: 43.

Distribución estratigráfica en es Pouàs: presente en varios niveles del Pleistoceno superior y el Holoceno (niveles 1, 3, 4, 5, 6 y 8 de la cuadrícula A3 y un nivel de la cuadrícula D4).

Comentarios: estos húmeros fósiles son muy robustos y de longitud (15,2-17,5 mm) superior a los de las especies actuales (ver figura 17). Inicialmente habían sido atribuidos a H. rustica, pero debido a la ausencia de material de comparación de C. daurica y a la escasez de información en la bibliografía, no se puede descartar la posibilidad de que 
pertenezcan a esta especie. El húmero de $C$. daurica es ligeramente más robusto que el de H. rustica (Weesie 1988) y su longitud (15,95 mm, $\mathrm{n}=1$ [Moreno 1986]) se solapa con la de la golondrina común. Según Zelenkov et al. (2012), el extremo proximal de la cresta deltoidea se encuentra más elevado en Cecropis daurica que en $H$. rustica y $P$. rupestris.

Los húmeros de Hirundo rustica y Ptyonoprogne rupestris, se distinguen en función de las características de dos estructuras anatómicas. En primer lugar, los tubérculos del processus supracondylaris dorsalis en la mayoría de ejemplares de H. rustica son similares y próximos entre sí, formando un surco más o menos cerrado entre ambos. Además, el margen lateral externo del epicóndilo dorsal es ligeramente cóncavo (curvado ventralmente) en esta especie, mientras que en $P$. rupestris es más recto. En el húmero de $P$. rupestris el tubérculo externo es más prominente y de mayor tamaño que el interno y ambos están más separados entre sí que en $H$. rustica. En segundo lugar, en H. rustica la cresta deltoidea presenta el desarrollo del borde externo cóncavo con un extremo distal en forma de mamelón notablemente prominente. En P. rupestris el extremo distal de la cresta deltoidea forma un ángulo recto con la diáfisis. Además, el desarrollo de su borde externo es recto y toda la cresta en sí se extiende más dorsalmente, tiene una mayor superficie, que en H. rustica.

\section{cf. Hirundo rustica}

Material: 32 húmeros (16 derechos, 16 izquierdos) y 6 tarsometatarsos (4 derechos, 2 izquierdos). Total: 38 .

Comentarios: tanto los húmeros como los tarsometatarsos presentan rasgos osteológicos propios de H. rustica. Sin embargo el estado del material y/o su edad (muchos son subadultos) no permiten una identificación más precisa y no se puede descartar que pertenezcan a $P$. rupestris o, en el caso de los húmeros, a $C$. daurica. Por este motivo se ha optado por utilizar una nomenclatura abierta.

Hirundinidae indeterminados

Material: 1 premaxilar, 49 húmeros (24 derechos, 25 izquierdos) y 1 ulna (izquierda). Total: 51 .

Comentarios: se trata de individuos juveniles o material fragmentario que no permite una identificación más precisa.

Motacillidae Vigors, 1825

(Figura 4, anexo) 


\section{Cráneo y mandíbula}

El premaxilar presenta un cuerpo óseo largo y fino y unas narinas amplias y ovaladas. En la mandíbula se observan un par de pequeños processus coronoidei posteriores a la fenestra mandibulae. El tubérculo pseudotemporal está situado casi en el borde dorsal de la pared interna de la hemimandíbula (Moreno 1986). El processus retroarticularis, corto y ancho, junto con el processus medialis mandibulae forma un ángulo recto. Por último, la sínfisis mandibular es alargada y puntiaguda, a diferencia de la sínfisis de las mandíbulas de Sylviidae y Muscicapidae, que son más cortas y anchas.

\section{Húmero}

El húmero de Motacillidae presenta dos fosas confluentes, apenas separadas por la barra medial, y profundas (Jánossy 1983), especialmente la dorsal (Zelenkov 2012).

La epífisis proximal es, en general, menos robusta que en el húmero de las familias morfométricamente similares (Prunellidae, Emberizidae, Fringillidae y Passeridae), y la cresta deltoidea es más larga que en la gran mayoría de los taxones de dichas familias. La barra medial en Motacillidae está, en general, menos desarrollada que en las otras familias, a excepción de lo que ocurre en Anthus campestris, que presenta una barra medial bastante desarrollada. La epífisis distal presenta un aspecto globular característico. Es relativamente estrecha pero robusta, sobre todo en Motacilla y en A. campestris. Este carácter constituye otra de las principales diferencias con el húmero de las familias morfométricamente más similares.

Dentro de Motacillidae, para la identificación entre especies, también se ha considerado la biometría de los ejemplares actuales de colección (IMEDEA y NHMT) y de fuentes bibliográficas (Moreno 1996; Jánossy 1983; Kessler 2013).

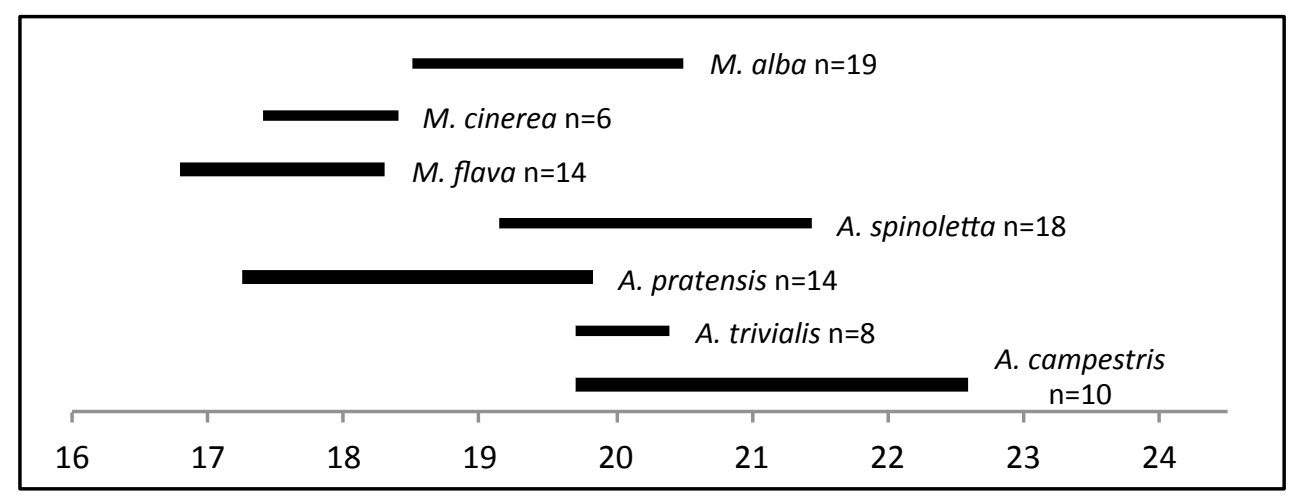

Figura 19. Longitud de los húmeros de las especies actuales de Motacillidae. Ejemplares procedentes de las colecciones del IMEDEA y el NHMT y de los trabajos de Jánossy (1983), Moreno (1986) y Kessler (2013).

\section{Tarsometatarso}

El tarsometatarso de Motacillidae es alargado y presenta una epífisis distal relativamente ancha, a diferencia de Sylviidae y Turdidae (excepto Oenanthe, Turdus y Monticola). Es más 
estilizado que los tarsometatarsos de Fringillidae, Passeridae y Prunellidae y, a diferencia del tarsometatarso de estas familias, la trochlea metatarsi II de los tarsometatarsos de Motacillidae presenta un margen lateral externo liso. El surco de dicha tróclea es bastante notable en Motacillidae. No se han encontrado diferencias entre los tarsometatarsos de los dos géneros de la familia, por lo que la identificación se basa, cuando es posible, en su biometría (figura 20).

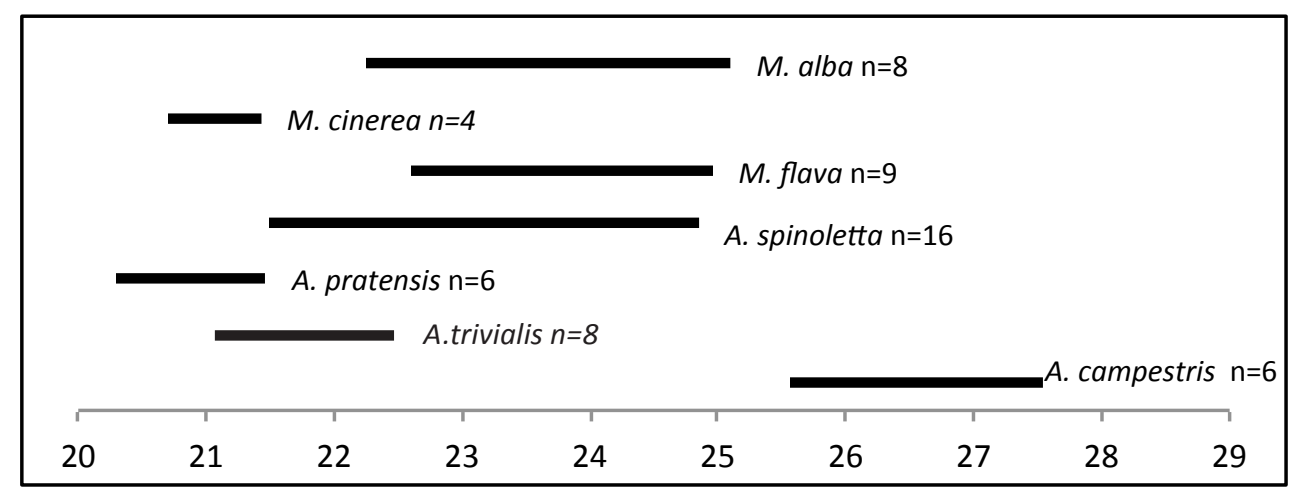

Figura 20. Longitud de los tarsometatarsos de las especies actuales de Motacillidae. Ejemplares procedentes de las colecciones del IMEDEA y el NHMT y del trabajo de Moreno (1986).

Anthus Bechstein, 1805

Cráneo y mandíbula: el premaxilar de Anthus es más alto y cuenta con un corpus ossis premaxillaris proporcionalmente más corto que el de Motacilla. El processus frontalis premaxillare en Anthus se eleva provocando un abultamiento en vista lateral, poco notable en $A$. campestris, a diferencia de lo observado en Motacilla, que mantiene un perfil recto (Cuisin 1989). No se ha podido estudiar ningún cráneo de Anthus pretrosus, si bien se dispone de su fotografía y medidas procedentes de la web "skullsite". En el caso de Anthus cervinus, se ha estudiado y medido un cráneo de del NHMT. Solamente se han identificado premaxilares y mandíbulas de $A$. campestris, los cuales superan en talla al resto de especies del género, incluidas $A$. petrosus y A. cervinus.

Húmero: en el húmero de Anthus (excepto en A. campestris) la barra medial se encuentra muy poco desarrollada, mucho menos que en el de Motacilla (Louchart 2002). Como consecuencia, en Anthus (con la excepción mencionada) no se aprecia el límite entre las dos fosas y aparenta tener una sola fosa muy amplia. Por otra parte, la cresta bicipital se proyecta más distalmente en Motacilla que en Anthus.

El húmero de Anthus cervinus (19,4 mm, n=1, NHMT) es de talla muy similar al de $A$. pratensis. Sin embargo, la barra medial y la cresta bicipital forman un ángulo agudo en A. pratensis, a diferencia de A. cervinus en el que ambas estructuras son casi paralelas 
(Jánossy 1983). En el registro fósil de la región paleártica occidental, solamente existe un registro de esta especie (Anthus cf. cervinus) procedente del Pleistoceno medio de Austria.

Anthus petrosus no ha sido identificado en ningún yacimiento del Pleistoceno de esta región. Según Tyrberg (1998), esta especie es probablemente indistinguible de Anthus spinoletta a nivel osteológico. Así mismo, Snow y Perrins (1998) señalan que la separación entre dichas especies actuales es, en ocasiones, confusa y no ha sido bien estudiada.

\section{Anthus campestris (Linnaeus, 1758)}

Bisbita campestre

Material: 2 premaxilares, 3 mandíbulas, 27 húmeros (12 derechos, 15 izquierdos) y 2 tarsometatarsos (izquierdos). Total: 34. NMI: 15 (basado en los húmeros).

Distribución estratigráfica en es Pouàs: Pleistoceno superior y Holoceno (nivel superior y niveles del 3 al 8 de la cuadrícula A3 y cuadrícula D4).

Distribución actual en el Paleártico occidental: se encuentra en latitudes medias-bajas y medias-continentales de la región, coincidiendo con su área de cría. Es una especie esencialmente migratoria. Sus poblaciones invernan principalmente en África (Snow y Perrins 1998). Se observa en época estival en Mallorca y Menorca, donde es una especie abundante, y en Ibiza y Formentera, más escasa. En migración y en época de cría, es moderadamente abundante en Baleares, excepto en Ibiza, donde es escasa (López-Jurado 2011).

Registro fósil en el Paleártico occidental: A. campestris es una especie rara en los yacimientos fósiles de la región. Se ha atribuido a esta especie material del Pleistoceno inferior de Francia e Israel (Anthus cf. campestris), y solamente hay un registro del Pleistoceno medio (Francia) y cuatro del Pleistoceno superior (Ucrania y España). No ha aparecido en ningún yacimiento de las Baleares (Tyrberg 1998, 2008).

Comentarios: es la especie de mayor talla entre los Motacillidae estudiados.

Cráneo y mandíbula: Moreno (1986) establece que el culmen (C) de A. campestris siempre es mayor de 16,05 mm, longitud superior a los del resto de especies del género. El premaxilar, alargado y robusto, presenta un processus orbitalis lacrimale muy desarrollado que protege perfectamente la cavidad orbital (Cuisin 1989). El abultamiento del processus frontalis premaxillare es mucho menos notable que en las otras especies de Anthus.

La mandíbula presenta una sínfisis muy alargada y unas fenestras mandibulares proporcionalmente pequeñas. 
Húmero: en el húmero de $A$. campestris la fosa ventral está muy bien definida y delimitada, incluso en su parte distal. Según las observaciones de Jánossy (1983), este húmero presenta una tendencia a la neumatización en ambas fosas, y el contorno interno de la cresta bicipital es afilado en su parte proximal.

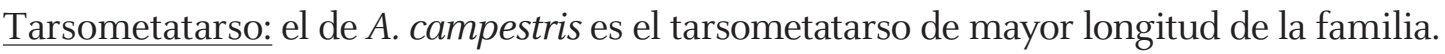

\section{cf. Anthus campestris}

Material: 2 premaxilares, 2 mandíbulas, 20 húmeros (10 derechos, 10 izquierdos). Total: 24 .

Comentarios: si bien estos restos son morfológica y biométricamente atribuibles a esta especie, el estado de los mismos impide la observación de caracteres inequívocamente diagnósticos.

\section{Anthus pratensis (Linnaeus, 1758) \\ Bisbita pratense}

Material: 52 húmeros (26 derechos, 26 izquierdos). MNI: 26.

Distribución estratigráfica en es Pouàs: Pleistoceno superior y Holoceno (nivel superficial y niveles del 1 al 8 de la cuadrícula A3 y cuadrícula D4).

Distribución actual en el Paleártico occidental: ampliamente distribuido por toda la región, $A$. pratensis cría en latitudes medias y altas e inverna en latitudes bajas (Snow y Perrins 1998). Hay una abundante presencia invernal de esta especie en todas las Baleares, y es abundante también en migración en Mallorca y Menorca, y más escasa en Ibiza (López-Jurado 2011).

Registro fósil en el Paleártico occidental: A. pratensis es una especie rara tanto en el Pleistoceno inferior (únicamente ha aparecido en España) como en el Pleistoceno medio (solamente en Francia) de la región. Es muy escasa en el Pleistoceno superior de Europa central (Alemania, Polonia y República Checa) y de Europa occidental (Francia y España), excepto en el Reino Unido, donde se ha registrado en cinco yacimientos. (Tyrberg 1998, 2008). Ha aparecido en niveles del Holoceno en un yacimiento de Mallorca (Seguí et al. 1997).

Comentarios: la epífisis proximal del húmero es más estrecha en A. pratensis que en las restantes especies de la familia, y la diáfisis es relativamente más estrecha que en $\mathrm{Mo}^{-}$ 
tacilla. La talla del húmero de A. pratensis es inferior a la del resto de especies del género estudiadas.

Anthus sp.

Material: 48 húmeros (29 derechos, 19 izquierdos) y 1 tarsometatarso (izquierdo). Total: 49 .

Comentarios: se ha adoptado una nomenclatura abierta debido al estado del material, a la escasez de material de comparación de las especies Anthus trivialis, A. spinoletta y A. cervinus, y a que no se ha dispuesto de húmeros y tarsometatarsos de A. petrosus.

\section{cf. Anthus}

Material: 1 premaxilar, 1 mandíbula, 18 húmeros (8 derechos, 10 izquierdos) y 2 tarsometatarsos (izquierdos). Total: 22.

Comentarios: si bien estos restos son morfométricamente más similares a Anthus, no ha sido posible determinar con seguridad el género debido al deterioro del material.

Motacilla Linnaeus, 1758

Motacilla alba Linnaeus, 1758

Lavandera blanca

Material: 13 húmeros (7 derechos, 6 izquierdos). NMI: 7.

Distribución estratigráfica en es Pouàs: Pleistoceno superior y Holoceno (niveles 3 y 4 de la cuadrícula A3 y cuadrícula A2 $(-70 /-90 \mathrm{~cm})$.

Distribución actual en el Paleártico occidental: es una especie de distribución muy extensa, desde las latitudes más altas de la región hasta las más bajas. Algunas poblaciones son migratorias, mientras que otras son sedentarias (Snow y Perrins 1998). Tanto las poblaciones migrantes como las invernantes son abundantes en todas las Baleares (López-Jurado 2011).

Registro fósil en el Paleártico occidental: esta especie está representada, aunque es muy escasa, en el Pleistoceno medio e inferior del este de la región. También es escasa en Europa en el Pleistoceno medio y no hay registros del Pleistoceno inferior. Sin embargo, se encuentra en el Pleistoceno superior de toda la región excepto en el área sudeste (Tyr- 
berg 1998, 2008). Ha aparecido en un yacimiento del Pleistoceno superior de Mallorca (Seguí 1997).

Comentarios: la longitud del húmero de $M$. alba es superior a la del resto de especies del género (Jánossy 1983), que tienen una talla muy similar entre sí (ver figura 19). Además de presentar un húmero de mayor longitud, la epífisis proximal es notablemente más robusta en $M$. alba.

\title{
Motacilla sp.
}

Material: 8 húmeros (6 derechos, 2 izquierdos).

Comentarios: se trata de siete húmeros atribuibles, con reservas, a M. alba, y uno a Motacilla flava/cinerea que, debido a su estado y a la similitud entre las especies del género, no permiten una identificación a nivel específico.

Motacillidae indeterminados

Material: 2 premaxilares, 4 mandíbulas, 41 húmeros (26 derechos, 15 izquierdos) y 2 tarsometatarsos (1 derecho, 1 izquierdo). Total: 49.

Comentarios: dentro de esta familia las diferencias entre los huesos estudiados de las distintas especies son en general sutiles, por lo que es difícil realizar determinaciones más precisas, especialmente cuando el material no se encuentra en buen estado de conservación.

\author{
Bombycillidae Swainson, 1831 \\ (Figura 4, anexo) \\ Bombycilla Vieillot, 1808 \\ Bombycilla garrulus (Linnaeus, 1758) \\ Ampelis europeo
}

Material: 1 húmero (derecho).

Distribución estratigráfica: Pleistoceno superior (nivel 8 de la cuadrícula A3). 
Distribución actual en el Paleártico occidental: cría en latitudes altas de la región, en zonas boreales y subárticas. Parcialmente migrante, inverna al sur del área de cría llegando ocasionalmente al sur de la región (España, Portugal, Grecia, etc.) (Snow y Perrins 1998). No se observa actualmente en las Baleares (López-Jurado 2011).

Registro fósil en el Paleártico occidental: es una especie muy escasa en el registro. Solamente se ha encontrado en el Pleistoceno inferior de Hungría y en el Pleistoceno superior de Bélgica (cf. Bombycilla garrulus), Alemania, Francia (Louchart 2002), Polonia y Bulgaria (Tyrberg 1998, 2008).

Comentarios: según las observaciones de Louchart (2002), el húmero de B. garrulus es muy característico ya que es muy robusto y presenta solamente una fosa en su epífisis proximal. La cresta deltoidea es corta y su margen externo recto. La diáfisis del hueso está algo retorcida, curvada hacia la cara craneal del húmero (Arvey 1951). El húmero de la especie morfológicamente más próxima, Lanius senator es, sin embargo, notablemente menos robusto. Además, el húmero de B. garrulus presenta un caput humeri mucho más robusto, un processus flexorius más largo y una cresta deltoidea que, a diferencia de la de L. senator, forma un escalón en su unión con la diáfisis.

Como se puede observar en la tabla 2, el fósil es biométricamente similar al húmero de B. garrulus y difiere notablemente del de L. senator.

\begin{tabular}{|c|c|c|c|c|c|c|c|c|c|c|c|}
\hline \multicolumn{4}{|c|}{ B. garrulus fósil } & \multicolumn{4}{c|}{ B. garrulus actual } & \multicolumn{4}{c|}{ L. senator actual } \\
\hline L & AEP & APD & AD & L & AEP & APD & AD & L & AEP & AED & AD \\
\hline 1 & 1 & 1 & 1 & 4 & 4 & 4 & 4 & 9 & 8 & 9 & 9 \\
24,2 & 7,5 & 6,1 & 2,45 & 23,6 & 7,9 & 5,7 & 2,6 & 22,5 & 6,45 & 5,0 & 2,0 \\
& & & & 0,466 & 0,208 & 0,167 & 0,050 & 0,806 & 0,221 & 0,120 & 0,089 \\
& & & & 23,1 & 7,7 & 5,6 & 2,5 & 21,4 & 6,1 & 4,75 & 1,8 \\
& & & & 24,2 & 8,2 & 6,0 & 2,6 & 23,5 & 6,8 & 5,15 & 2,2 \\
\hline
\end{tabular}

Tabla 2. Medidas de los húmeros actuales de L. senator y de los actuales y el fósil de B. garrulus.

Prunellidae Richmond, 1908

(Figura 5, anexo)

Prunella Vieillot, 1816

\section{Cráneo y mandíbula}

Las especies del género Prunella presentan un premaxilar robusto, con caracteres intermedios entre los de las especies granívoras y los de las insectívoras. De las primeras conserva el reforzamiento del processus maxillaris premaxillare y la solidez del processus frontalis premaxillare. De las segundas, un corpus ossis premaxillaris fino. Las narinas son amplias y, en vista lateral, en forma de "gota de agua" (Cuisin 1989). El processus frontalis 
premaxillare se eleva anormalmente interrumpiendo el perfil casi recto típico de otros paseriformes insectívoros (Moreno 1986). Este abultamiento es característico también en las especies del género Oenanthe. Sin embargo, el premaxilar de Prunella es más alto y robusto que el de Oenanthe y presenta unas narinas más cortas y amplias y un corpus ossis premaxillaris menos puntiagudo. El corpus ossis premaxillaris de Prunella es triangular y aplanado y, en vista ventral, presenta un canal en su parte central similar al del premaxilar de Emberizidae.

En la mandíbula, la fenestra mandibulae es pequeña, con dos processus coronoidei situados dorsalmente a la misma (Moreno 1986). La parte articular presenta un processus retroarticularis corto y un processus medialis mandibulae alargado, mientras que la sínfisis mandibular es medianamente ancha y muy cóncava en vista dorsal.

\section{Húmero}

La epífisis proximal presenta dos fosas confluentes y medianamente profundas, separadas por una barra medial muy corta. Jánossy (1983) destaca que la epífisis proximal es más estrecha y el borde de la cresta bicipital más reducido que en otros grupos de morfología similar. También observa que la cresta bicipital y la diáfisis forman un ángulo más abierto que en otros grupos. La cresta deltoidea no se extiende dorsalmente y es distalmente roma. Se une a la diáfisis de manera progresiva. En la epífisis distal destaca un processus supracondylaris dorsalis muy desarrollado.

\section{Tarsometatarso}

El tarsometatarso de los acentores presenta una longitud media-alta y una robustez media. La epífisis distal es ancha, con una trochlea metatarsi III muy desarrollada. La trochlea metatarsi II presenta un margen lateral anguloso y un surco no muy marcado en la parte central de la misma.

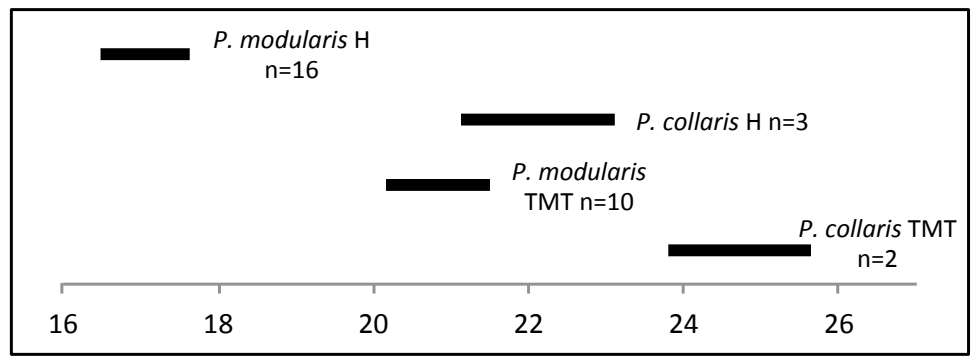

Figura 21. Longitud de los húmeros y tarsometatarsos de las especies actuales de Prunellidae. Ejemplares procedentes de la colección del IMEDEA y de las publicaciones de Jánossy (1983) y Moreno (1986).

Prunella modularis (Linnaeus, 1758)

Acentor común

Material: 1 mandíbula y 3 húmeros (derechos). Total: 4. NMI: 3 (basado en los húmeros). 
Distribución estratigráfica en es Pouàs: presente en niveles del Pleistoceno superior y del Holoceno (cuadrículas A4 y D4).

Distribución actual en el Paleártico occidental: se encuentra en latitudes medias y altas de la región donde hay poblaciones residentes, parcialmente migrantes y, en el norte y centro de Europa, totalmente migrantes. Las principales poblaciones continentales migran en invierno a latitudes bajas de la región, principalmente al Mediterráneo (Snow y Perrins 1998). En Baleares se observa al acentor común como migrante de moderado a escaso y como invernante moderado en todas las islas excepto en Formentera (López-Jurado 2011).

Registro fósil en el Paleártico occidental: se encuentra principalmente en el registro fósil de Europa occidental (Italia, Francia, Reino Unido y España), donde es una especie escasa en el Pleistoceno medio y algo más frecuente el Pleistoceno superior. Es poco común en el resto de la región. Sólo se ha registrado en Austria, Rumanía, Bulgaria y Ucrania. (Tyrberg 1998, 2008). También aparece en el Pleistoceno inferior de España, con un registro en Baleares (Prunella cf. modularis; Alcover et al. 1981), y en tres yacimientos del Pleistoceno superior de Baleares (McMinn y Alcover 1992; Seguí et al. 1997; Seguí 1999).

Comentarios: las dos especies se diferencian fácilmente a nivel biométrico, ya que $P$. collaris tiene una talla muy superior a la de P. modularis., como se observa en todos los huesos estudiados (ver figura 21). A diferencia de los húmeros de morfología y biometría similar correspondientes a otras familias (Fringillidae, Passeridae, Emberizidae y Motacillidae), los de P. modularis presentan ambas fosas notablemente menos profundas.

\section{cf. Prunella modularis}

Material: 1 tarsometatarso (izquierdo). Total: 1.

Comentarios: si bien la talla (21,4 mm de longitud) coincide con la de esta especie, algunos caracteres osteológicos no. La trochlea metatarsi III está menos desarrollada en el fósil que en $P$. modularis y la epífisis distal es ligeramente más ancha en el fósil.

\section{Prunella collaris (Linnaeus, 1769) \\ Acentor alpino}

Material: 1 premaxilar y 1 húmero (izquierdo). Total: 2. NMI: 1.

Distribución estratigráfica en es Pouàs: Pleistoceno superior (cuadrículas A3 [nivel 5] y A2). 
Distribución actual en el Paleártico occidental: P. collaris cría exclusivamente en alta montaña en latitudes medias. No migra, si bien realiza movimientos altitudinales u otros algo más distantes. Durante el invierno permanece en el sur de Europa (Snow y Perrins 1998). Se considera una especie escasa como invernante en Baleares (excepto en Formentera) y también escasa como migrante en Ibiza y Mallorca (López-Jurado 2011).

Registro fósil en el Paleártico occidental: se ha citado en el Pleistoceno medio de Francia, Grecia, España y República Checa. Es una especie bastante frecuente en el Pleistoceno superior de Europa occidental, habiéndose registrado en un total de 25 yacimientos de España, Francia e Italia. Aparece también, aunque es mucho más escasa, en Europa central y en Grecia (Tyrberg 1998, 2008). Hay dos registros de esta especie procedentes del Pleistoceno superior de Baleares (McMinn y Alcover 1992; Seguí 1999).

Comentarios: la talla del premaxilar de $P$. collaris y la del fósil son mayores que la del premaxilar de $P$. modularis, especialmente las narinas, que son mucho más amplias. El húmero también es notablemente más grande que el de $P$. modularis.

\section{cf. Prunella collaris}

Material: 1 húmero (derecho).

Comentarios: se trata de un fragmento proximal por lo que, si bien los caracteres de la epífisis proximal corresponden a los de esta especie, no podemos determinar su longitud ni algunos de los rasgos osteológicos.

\section{Turdidae Rafinesque, 1815}

(Figuras 5 y 6, anexo)

\section{Cráneo y mandíbula}

Se trata de una familia muy amplia, con una gran diversidad de tallas y caracteres osteológicos.

El aspecto general del cráneo es grácil, con los procesos muy reducidos y los forámenes y ventanas craneales grandes (Moreno 1987). El premaxilar es largo y fino, con narinas amplias. Moreno (1987) incluye dentro de Muscicapidae los taxones que en este trabajo se incluyen en las familias Turdidae y Sylviidae.

Cuisin (1989) sigue la misma clasificación taxonómica que se ha empleado en este trabajo y destaca, como carácter más evidente, el processus palatus maxillaris, que en esta 
familia se inserta en el cuarto superior de las narinas. Dicho proceso es visible a través de las narinas en vista dorsal, excepto en el género Turdus.

Para hacer referencia a los taxones de menor talla, se ha utilizado la denominación "Turdidae de talla pequeña" que incluye todos los géneros de la familia excepto Turdus y Monticola. El premaxilar de dichos Turdidae de talla pequeña es más ancho que el de otras especies de insectívoros de talla similar (en vistas dorsal y ventral). En la mandíbula los procesos están poco desarrollados, la sínfisis mandibular suele ser corta y la fenestra mandibulae es pequeña. La mandíbula de los Turdidae de talla pequeña presenta un processus retroarticularis más largo que el de la mandíbula de Motacillidae, Sylviidae y Prunellidae.

El cráneo y la mandíbula de Cercotrichas galactotes son de talla similar a los de Oenanthe y superior a los del resto de especies de Turdidae de talla pequeña. A diferencia de Oenanthe, el premaxilar de Cercotrichas es más estrecho en su parte caudal y presenta un perfil recto, sin abultamiento del processus frontalis premaxillare. En cuanto a la mandíbula, Cercotrichas presenta una fenestra mandibulae más amplia y un ángulo mandibular menos marcado que Oenanthe.

\section{Húmero}

El húmero de Turdidae presenta dos fosas desarrolladas, excepto en las especies pertenecientes a los géneros Erithacus y Luscinia, los cuales presentan la fosa dorsal en fase de desarrollo (Weesie 1988). La barra medial está bien desarrollada separando ambas fosas.

A diferencia de los húmeros de Sylviidae, los de Turdidae presentan una cresta deltoidea más larga y de borde recto (Jánossy 1983).

La talla del húmero de Cercotrichas galactotes es similar a la del húmero de Oenanthe y superior a la del resto de Turdidae de talla pequeña. A diferencia de Oenanthe, la fosa dorsal está menos desarrollada en el húmero de C. galactotes.

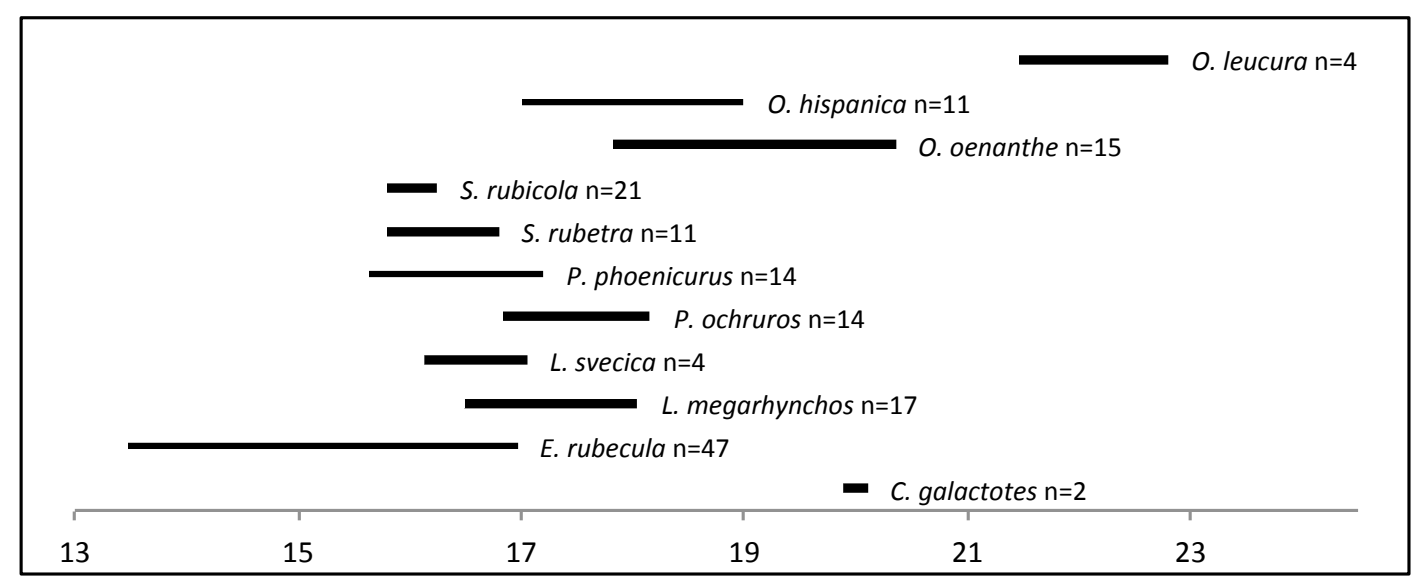

Figura 22. Longitud de los húmeros de las especies actuales de Turdidae (excepto Turdus y Monticola). Ejemplares procedentes de las colecciones del IMEDEA y el NHMT y de los trabajos de Jánossy (1983), Moreno (1987), Weesie (1988) y Kessler (2013). 


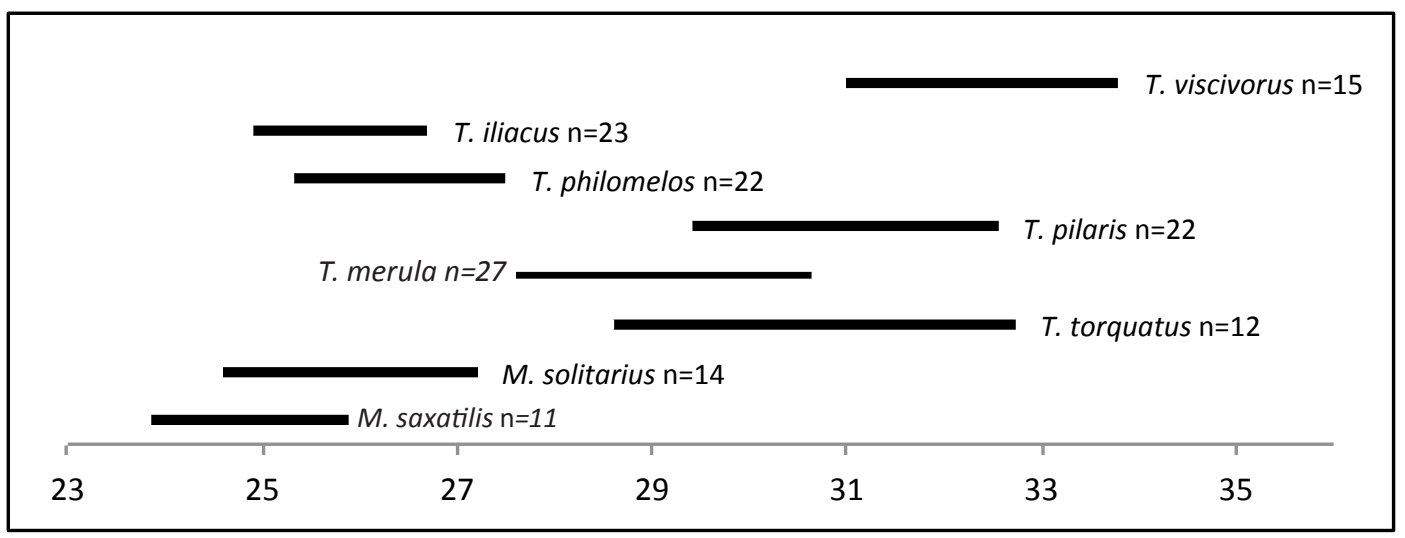

Figura 23. Longitud de los húmeros de las especies actuales de Turdus y Monticola. Ejemplares procedentes de las colecciones del IMEDEA y el NHMT y de los trabajos de Jánossy (1983), Moreno (1987), Weesie (1988) y Louchart (2004).

\section{Tarsometatarso}

De aspecto general muy largo y estilizado, es un tarsometatarso poco robusto, excepto en los taxones de talla grande. En los taxones de talla pequeña, la epífisis distal es relativamente estrecha, excepto en el género Oenanthe, cuyo tarsometatarso destaca precisamente por su robustez (en relación a la de los restantes Turdidae de talla pequeña) y por la anchura de sus epífisis.

Los tarsometatarsos de Sylviidae presentan una epífisis distal notablemente más estrecha, lo que marca la diferencia entre las dos familias. La longitud, muy inferior, de los tarsometatarsos de Muscicapidae, permite diferenciarlos fácilmente de los de Turdidae. Por último, a diferencia de los tarsometatarsos de Motacillidae, la trochlea metatarsi III está más desarrollada respecto a las otras dos en los tarsometatarsos de los Turdidae de talla pequeña.

Zelenkov (2012) destaca en los tarsometatarsos de Laniidae, Sturnidae y Turdidae (de talla grande) la notable longitud del hueso. Según el autor, a diferencia de Laniidae y Sturnidae, en Turdidae (de talla grande) la epífisis distal se ensancha abruptamente debido principalmente al ensanchamiento de la trochlea metatarsi II.

El tarsometatarso de C. galactotes presenta una talla similar al de Luscinia y Oenanthe (ver figura 24). A diferencia de Oenanthe, la eminentia intercondylaris es más patente en C. galactotes. Y a diferencia de Luscinia, el tarsometatarso de C. galactotes, es menos estilizado, especialmente su epífisis proximal. 


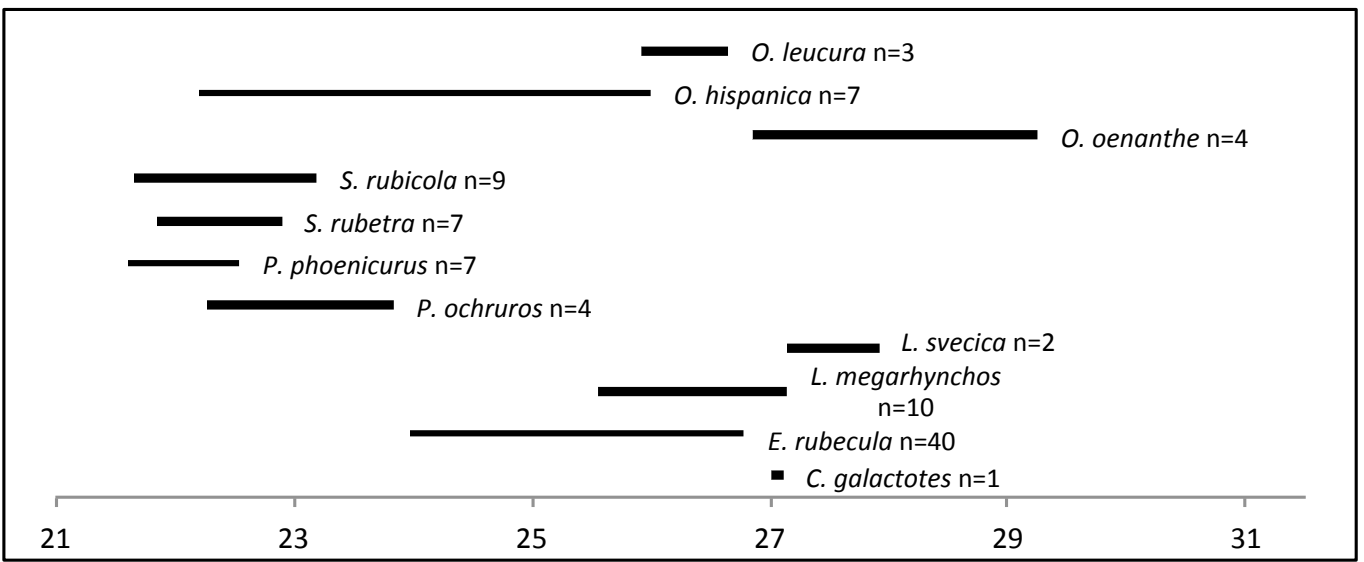

Figura 24. Longitud de los tarsometatarsos de las especies actuales de Turdidae (excepto Turdus y Monticola). Ejemplares procedentes de las colecciones del IMEDEA y el NHMT y del trabajo de Moreno (1987).

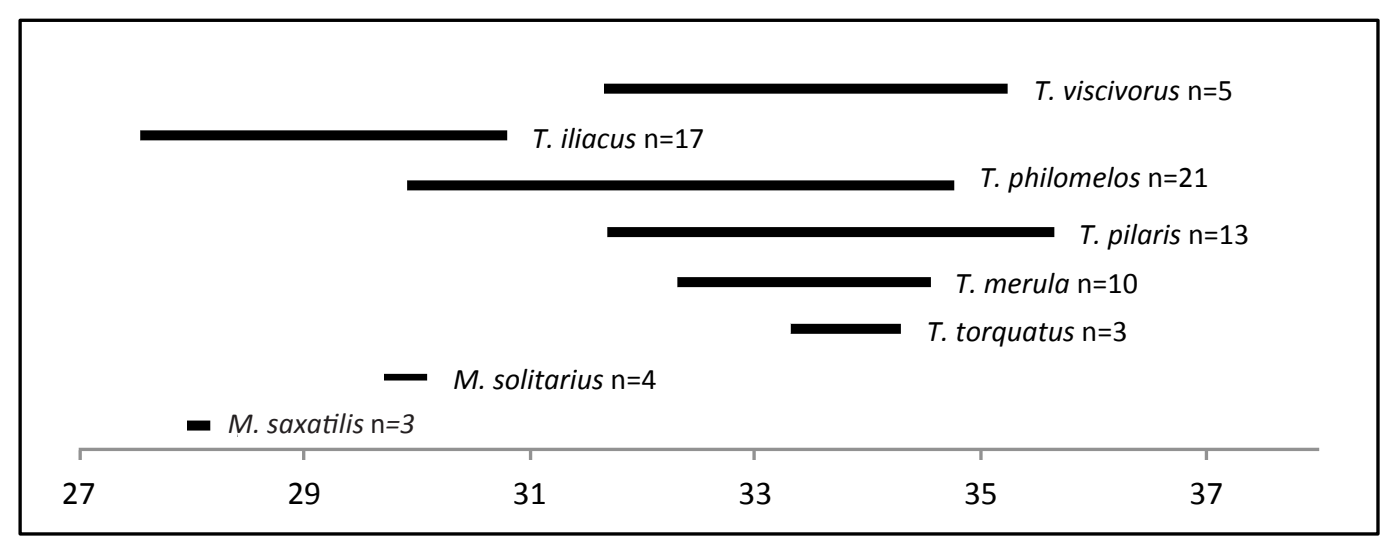

Figura 25. Longitud de los tarsometatarsos de las especies actuales de Turdus y Monticola. Ejemplares procedentes de las colecciones del IMEDEA y el NHMT y del trabajo de Moreno (1987).

\section{Erithacus Cuvier, 1800 \\ Erithacus rubecula (Linnaeus, 1758) \\ Petirrojo europeo}

Material: 1 cráneo, 3 premaxilares, 2 mandíbulas, 56 húmeros (31 derechos, 25 izquierdos) y 33 tarsometatarsos (18 derechos, 15 izquierdos). Total: 95. NMI: 31 (basado en los húmeros).

Distribución estratigráfica en es Pouàs: Pleistoceno superior y Holoceno (niveles del 1 al 4 de la cuadrícula A3, 6 niveles de la cuadrícula D4 y un nivel holocénico de la cuadrícula $\left.\mathrm{A}_{3}\right)$.

Distribución actual en el Paleártico occidental: especie ampliamente extendida por la región, con poblaciones sedentarias en el oeste y sudoeste de Europa aunque la mayoría de las poblaciones son parcialmente migrantes. Cría sobre todo en latitudes medias aun- 
que también en latitudes altas (Snow y Perrins 1998). Esta especie se encuentra en todas las Baleares, donde es abundante en migración y como invernante (López-Jurado 2011).

Registro fósil en el Paleártico occidental: el petirrojo está bien representado en el registro del Pleistoceno superior de toda la región. En cuanto al Pleistoceno medio, solamente ha aparecido en Europa occidental (Italia, Francia y Reino Unido) y en Israel (Tyrberg 1998, 2008). Es relativamente abundante en el registro de las Baleares. Se ha encontrado en tres yacimientos del Pleistoceno superior de Mallorca (Seguí 1997; Seguí et al. 1997; McMinn y Alcover 1992) y en uno del Pleistoceno inferior (Erithacus cf. rubecula, Alcover et al. 1981). Sondaar et al. (1995) citan su presencia en el Pleistoceno superior de Ibiza.

\section{Comentarios}

Cráneo y mandíbula: en el cráneo de esta especie, el processus postorbitalis es vestigial o inexistente (Cuisin 1989). En el processus frontalis premaxillare, en vista ventral y lateral, se observan, unidas a un pliegue del hueso, unas excrecencias óseas proyectadas hacia la parte ventral del premaxilar. Moreno (1987), establece que pertenecen a esta especie los individuos con una distancia interorbitaria menor de $2,7 \mathrm{~mm}$ y mayor de $2 \mathrm{~mm}$ y una relación longitud-anchura del culmen (C/AM) superior a 2. Es decir, el premaxilar es más largo que dos veces su anchura. Los foramina venae occipitalis externae se sitúan en el borde posterior del foramen magnum.

En cuanto a la mandíbula, la sínfisis mandibular es más ancha que la de Phoenicurus. A diferencia de la mandíbula de E. rubecula, la de Saxicola presenta un proceso retroarticular más largo y que forma un ángulo más agudo con el proceso medial mandibular. Dicho ángulo es más amplio en E. rubecula.

Húmero: presenta una epífisis proximal corta, comprimida, con una fosa dorsal en fase de desarrollo.

El género de Turdidae con el húmero morfométricamente más similar a Erithacus es Luscinia y, del resto de familias, Ficedula. Además de la longitud total del húmero y de la epífisis proximal, superior en Luscinia, se observan varios rasgos morfológicos que los diferencian. En primer lugar, la incisura capitis es más notable en el húmero de E. rubecula que en el de Luscinia y el de Ficedula. En el caput humeri del húmero de Luscinia el margen distal de esta estructura continúa en la cresta deltoidea, mientras que en Erithacus dicho borde desaparece al final de la parte proximal de la fosa dorsal, es decir, antes de la cresta deltoidea. A diferencia del húmero de E. rubecula, la cresta deltoidea del húmero de Luscinia megarhynchos es más extensa dorsalmente. Además, según Jánossy (1983), el húmero de Erithacus presenta una epífisis proximal y un tubérculo ventral más estrechos, mientras que en Luscinia el tubérculo ventral es corto y ancho cubriendo la mayor parte de la cresta bicipital. A diferencia de Erithacus, el húmero de Ficedula presenta la fosa dorsal más desarrollada. 
Tarsometatarso: presenta un aspecto general alargado y poco robusto. De longitud similar a los de Luscinia megarhynchos y Oenanthe hispanica, tanto la epífisis proximal como la distal son más estrechas y menos robustas en el tarsometatarso de E. rubecula. Por otra parte, los tarsometatarsos de Oenanthe presentan una eminentia intercondylaris más corta. El tarsometatarso de Saxicola rubicola, de menor longitud que el de E. rubecula, es además más robusto. Por último, a diferencia del tarsometatarso de Phoenicurus, la fossa metatarsi I se observa mucho más marcada en E. rubecula.

\title{
cf. Erithacus rubecula
}

Material: 1 premaxilar, 1 mandíbula, 73 húmeros (42 derechos, 31 izquierdos) y 10 tarsometatarsos (3 derechos, 7 izquierdos). Total: 85 .

Comentarios: algunos de estos huesos, se habían identificado previamente como Erithacus/Luscinia y Erithacus/Ficedula. Debido al estado del material, que impide observar caracteres osteológicos diagnósticos, se ha optado por utilizar una nomenclatura abierta.

\section{Luscinia Forster, 1817}

Cráneo y mandíbula: en el cráneo de éste género, en vista dorsal, el processus palatus maxillaris es visible a través de las narinas, a diferencia del de Sylviidae y el de Turdus (Moreno 1987). En el premaxilar destacan unas narinas alargadas y muy amplias, mayores que las de E. rubecula, Phoenicurus y Saxicola.

Húmero: la fosa dorsal se encuentra en fase de desarrollo, al igual que en Erithacus, y en ambas especies está menos desarrollada que en Ficedula. Los húmeros de Oenanthe son en general más robustos que los de Luscinia y presentan una fosa dorsal más desarrollada y una cresta deltoidea más larga. Las diferencias con los húmeros de Erithacus se detallan en la descripción de esta especie.

Tarsometatarso: entre los Turdidae de talla pequeña, Luscinia es el género con tarsometatarsos más largos, después de Oenanthe. A diferencia de Luscinia, los tarsometatarsos de Oenanthe presentan una eminentia intercondylaris más corta. Las epífisis son más anchas y robustas en Luscinia que en E. rubecula.

\author{
Luscinia megarhynchos C.L. Brehm, 1831 \\ Ruiseñor común
}

Material: 1 premaxilar y 2 húmeros (1 derecho, 1 izquierdo). Total: 3. NMI: 1. 
Distribución estratigráfica en es Pouàs: Pleistoceno superior (nivel 5 de la cuadrícula A3 y cuadrícula A4).

Distribución actual en el Paleártico occidental: esta especie, migratoria, cría en latitudes medias y medias-bajas de la región (Snow y Perrins 1998). En época estival se puede observar en Baleares en todas las islas, excepto en Formentera, siendo escasa en Ibiza. Es una especie abundante en migración en todo el archipiélago (López-Jurado 2011).

Registro fósil en el Paleártico occidental: L. megarhynchos, especie muy escasa en el registro fósil de la región, sólo aparece en dos yacimientos del Pleistoceno superior del oeste (España y Reino Unido) y otros dos del este de la misma (Tyrberg 1998, 2008). No se encuentra en el registro fósil de Baleares.

\section{Comentarios}

Cráneo y mandíbula: la longitud del premaxilar y el tamaño de las narinas de L. megarhynchos son superiores a los de Luscinia svecica. El premaxilar de L. svecica presenta un perfil irregular (Cuisin 1989) y es más corto y está más comprimido lateralmente que el de L. megarhynchos.

Húmero: si bien las medidas de longitud del húmero de las dos especies del género, $L$. megarhynchos y L. svecica, se solapan, se observa que la cresta deltoidea de la primera especie se extiende más dorsalmente que la de la segunda y por tanto, tiene más superficie.

\section{Luscinia sp.}

Material: 2 húmeros (derechos) y 5 tarsometatarsos (2 derechos, 3 izquierdos). Total: 7.

Comentarios: el estado de deterioro de los húmeros impide su determinación a nivel específico. No se han encontrado diferencias morfológicas que permitan separar los tarsometatarsos de las dos especies de éste género y, si bien los fósiles ( $\mathrm{L}=26-26,6 \mathrm{~mm}$ ) son biométricamente más similares a L. megarhynchos, se ha optado por utilizar una nomenclatura abierta.

\section{Phoenicurus Forster, 1817}

Cráneo y mandíbula: las especies del género Phoenicurus presentan un premaxilar muy característico debido a un abultamiento del culmen a nivel del processus frontalis premaxillare. Además, el premaxilar está comprimido lateralmente y por tanto es más estrecho, especialmente el corpus ossis premaxillaris, que en el resto de especies de la familia. 
Húmero: la epífisis proximal presenta dos fosas totalmente desarrolladas y separadas entre sí. El húmero de Saxicola, el género más próximo morfométricamente, presenta una fosa dorsal más pequeña que el de Phoenicurus. Por otra parte, la cresta deltoidea de los húmeros de Phoenicurus es más larga que la de los húmeros de Saxicola. El húmero de Oenanthe es de talla superior y presenta una cresta deltoidea más extendida dorsalmente.

\author{
Phoenicurus ochruros (S.G. Gmelin, 1774) \\ Colirrojo tizón
}

Material: 1 premaxilar y 4 húmeros (3 derechos, 1 izquierdo). Total: 5. NMI: 3 (basado en los húmeros).

Distribución estratigráfica en es Pouàs: Pleistoceno superior (cuadrícula A4) y Holoceno (cuadrículas A3 y D4).

Distribución actual en el Paleártico occidental: cría en latitudes medias y bajas del Paleártico occidental. Hay poblaciones sedentarias y parcial o totalmente migrantes. La principal zona de invernada de esta especie se encuentra en la cuenca mediterránea (Snow y Perrins 1998). En Baleares su población es abundante en invierno y también durante la migración en todas las islas (López-Jurado 2011).

Registro fósil en el Paleártico occidental: P. ochruros está escasamente representado en el registro fósil de la región. Sólo consta en el Pleistoceno superior del centro de Europa (Austria y Polonia) e Israel y en el Pleistoceno inferior y superior de España (Tyrberg 1998, 2008). En Baleares se ha citado en dos yacimiento del Pleistoceno superior, la Cova de Moleta (Seguí et al. 1997) y la Cova des Moro (cf. Phoenicurus ochruros, Seguí 1997). Sondaar et al. (1995) publicaron la presencia de Phoenicurus sp. en el Pleistoceno superior de Ibiza.

Comentarios: el premaxilar de Phoenicurus phoenicurus es más alto, más ancho y presenta unas narinas más amplias que el de P. ochruros.

En el húmero de $P$. ochruros, la cresta deltoidea es más larga y la epífisis proximal más grande (sobre todo más larga) que en P. phoenicurus. La longitud de los húmeros identificados es algo inferior a la que presentan los individuos actuales.

\title{
Phoenicurus phoenicurus (Linnaeus, 1758) \\ Colirrojo real
}

Material: 2 premaxilares y 10 húmeros (3 derechos, 7 izquierdos). Total: 12. NMI: 7 (basado en los húmeros). 
Distribución estratigráfica en es Pouàs: Pleistoceno superior (nivel 3 de la cuadrícula A3) y Holoceno (cuadrículas A3 y D4).

Distribución actual en el Paleártico occidental: especie migratoria que cría en latitudes altas y medias del Paleártico occidental, en el noroeste de Europa (Snow y Perrins 1998). En Baleares es abundante en migración en todas las islas (López-Jurado 2011).

Registro fósil en el Paleártico occidental: es una especie escasa en el registro fósil del Paleártico. Ha aparecido en el Pleistoceno medio de Francia y de Europa central (cf. Phoenicurus phoenicurus, Austria y Alemania) y en varios yacimientos del Pleistoceno superior del centro y oeste (Francia y Reino Unido) de Europa y del este de la región paleártica occidental. No consta en el registro de Baleares (Tyrberg 1998, 2008).

Comentarios: además de las diferencias ya mencionadas, el húmero de $P$. phoenicurus es, en general, más corto que el de P. ochruros.

\section{Phoenicurus sp.}

Material: 4 húmeros (2 derechos, 2 izquierdos).

Comentarios: el estado del material no permite su determinación a nivel específico.

\section{cf. Phoenicurus.}

Material: 29 húmeros (16 derechos, 13 izquierdos) y 5 tarsometatarsos (2 derechos, 3 izquierdos). Total: 34 .

Comentarios: debido a las características del material, no es posible comprobar todos los rasgos osteológicos que identifican a los colirrojos. Si bien la mayor parte de este material probablemente pertenece a Phoenicurus, no se puede descartar su atribución a Saxicola.

Saxicola Bechstein, 1803

Saxicola sp.

Material: 4 húmeros (derechos). NMI: 4.

Distribución estratigráfica en es Pouàs: Holoceno (cuadrícula D4). 
Distribución actual en el Paleártico occidental: Saxicola rubetra cría en latitudes altas y medias de la región y migra a la zona tropical africana en invierno. Saxicola rubicola cría en latitudes medias y medias-bajas del Paleártico occidental, en zonas templadas, esteparias y en el Mediterráneo. Varía de migratoria a residente en diferentes partes de su área de distribución (Snow y Perrins 1998). S. rubetra se puede observar en Baleares durante la migración, con una población abundante en Mallorca, Menorca e Ibiza y escasa en Formentera. Las poblaciones sedentarias de S. rubicola son abundantes en todo el archipiélago balear, excepto en Formentera. También está presente como invernante en todas las islas, excepto en Ibiza (López-Jurado 2011).

Registro fósil en el Paleártico occidental: Saxicola rubetra es una especie generalmente escasa en el registro. Ha aparecido en el Pleistoceno inferior de España y en el Pleistoceno medio de la mitad oeste de la región (España, Francia y República Checa). Es algo más abundante en los yacimientos del Pleistoceno superior, sobre todo del centro y oeste de Europa, aunque también se ha citado en el este de la región (Tyrberg 1998, 2008). Se ha identificado en un yacimiento del Pleistoceno superior de Mallorca (Seguí et al. 1997).

Saxicola rubicola, aún más escasa, aparece solamente en un yacimiento del Pleistoceno inferior (España) y en uno del Pleistoceno medio (cf. Saxicola rubicola, Alemania). Los únicos registros del Pleistoceno superior corresponden a Mallorca e Israel (Tyrberg 1998, 2008; Seguí et al. 1997).

Comentarios: el húmero de Saxicola presenta dos fosas totalmente desarrolladas y separadas entre sí, con una barra medial notablemente más desarrollada que en Phoenicurus. Otras diferencias osteológicas con este género se han detallado previamente en la descripción del mismo. Si bien el húmero de S. rubetra es ligeramente más largo y menos estilizado que el de S. rubicola, no se han encontrado diferencias osteológicas inequívocamente diagnósticas entre los húmeros de las dos especies de Saxicola.

\section{Oenanthe Vieillot, 1816}

Cráneo: la talla del premaxilar de Oenanthe es superior a la del resto de especies de Turdidae de talla pequeña. Es ancho en su parte caudal y presenta unas narinas alargadas. Al igual que las especies del género Phoenicurus, Oenanthe presenta un abultamiento del culmen a nivel del processus frontalis premaxillare. A diferencia del premaxilar de Phoenicurus, la longitud del culmen es muy superior en Oenanthe.

Húmero: en la epífisis proximal del húmero de Oenanthe se observan dos fosas bien desarrolladas y separadas entre sí y una cresta deltoidea relativamente larga. Al igual que el premaxilar, el húmero de este género es de talla diferente a la del resto de especies de Turdidae (ver figura 22). 
Oenanthe leucura (Gmelin, 1789)

Collalba negra

Material: 2 húmeros (derechos). NMI: 2.

Distribución estratigráfica en es Pouàs: Pleistoceno superior (nivel 4 de la cuadrícula A3).

Distribución actual en el Paleártico occidental: Oenanthe leucura tiene una distribución restringida al Mediterráneo occidental, principalmente en zonas de influencia costera. Generalmente sedentaria, su área de distribución coincide con su área de cría (Snow y Perrins 1998). En Baleares su presencia es accidental (López-Jurado 2011).

Registro fósil en el Paleártico occidental: sólo se ha citado en dos yacimientos del Pleistoceno superior de España y en uno de Francia (cf. Oenanthe leucura) (Tyrberg 1998, 2008). No se ha identificado en ningún yacimiento de Baleares.

Comentarios: tanto el húmero de los individuos actuales como los fósiles presentan una longitud superior a la del resto de especies de Oenanthe del sudoeste de la región paleártica. El caput humeri es más prominente en O. leucura y en los fósiles que en las otras especies del género.

\section{Oenanthe sp.}

Material: 1 premaxilar y 160 húmeros (83 derechos, 77 izquierdos). Total: 161. NMI: 83.

Distribución estratigráfica en es Pouàs: Pleistoceno superior (cuadrículas $A_{1}, A_{2}, A_{3}$ [niveles del 1 al 8], A4, A5, B5 e I2) y Holoceno (cuadrículas A2, A3, A4 y D4).

Comentarios: el estado del premaxilar impide identificarlo a nivel de especie. La identificación de los húmeros de éste género es complicada ya que, a excepción de O. leucura, no se han encontrado diferencias morfológicas entre los mismos y sus rangos de longitud se solapan. Por ello, se ha optado por utilizar una nomenclatura abierta, si bien todos los húmeros presentan una talla superior a la de las otras especies de "Turdidae de talla pequeña" identificadas.

Monticola Boie, 1822

Húmero: el húmero de Monticola presenta dos fosas bien desarrolladas y separadas entre sí. Es morfométricamente muy similar al de Turdus y Sturnus por lo que la dife- 
renciación entre estos géneros en base al húmero es complicada, si bien existen algunos rasgos diagnósticos.

La fosa ventral es más redondeada en el húmero de Turdus y Sturnus y la parte proximal de la cresta bicipital es más estrecha en Monticola. Además, ambas fosas están más separadas entre sí en Monticola (Wójcik 2002; Louchart 2004). La parte distal de la barra medial se inserta más superficialmente en la diáfisis en Monticola, a diferencia de Turdus y Sturnus en los que se inserta más profundamente, en la depresión en la que se sitúan las fosas. Así, la fosa ventral está más delimitada en Monticola y ambas fosas no confluyen. Además, no se encuentran a su vez situadas en una misma depresión, como sucede en Turdus y Sturnus.

Por último, la cresta deltoidea se extiende más dorsalmente, tiene mayor superficie, y presenta un margen externo más anguloso en el húmero de Monticola, a diferencia de los de Turdus y Sturnus, en los que no se extiende tanto y presenta un margen más uniforme (Wójcik 2002; Louchart 2004). El húmero de Sturnus es, en general, más robusto que el de Monticola y, según Wójcik (2002), de mayores dimensiones en tres estructuras óseas: el caput humeri, el condylus ventralis humeri y el processus flexorius.

\section{Monticola solitarius (Linnaeus, 1758) \\ Roquero solitario}

Material: 2 húmeros (1 derecho, 1 izquierdo). Total: 2. NMI: 1.

\section{Distribución estratigráfica en es Pouàs: Holoceno (sector 4).}

Distribución actual en el Paleártico occidental: $M$. solitarius cría en latitudes bajas y medias-bajas de la región. Cuenta con poblaciones sedentarias a lo largo de toda la costa norte y el oeste del Mediterráneo. Las principales zonas de invernada se encuentran en el norte de África y en Arabia (Snow y Perrins 1998). En Baleares la población sedentaria es abundante en Mallorca y Formentera y menos abundante en el resto de islas (López-Jurado 2011).

Registro fósil en el Paleártico occidental: es una especie poco común en el registro. Se ha encontrado en niveles del Pleistoceno medio y superior de Europa occidental (España, Italia y Francia) y en el Pleistoceno superior de Grecia e Israel (Tyrberg 1998, 2008). M. solitarius y $M$. saxatilis no constan en el registro fósil de Baleares.

Comentarios: los dos húmeros identificados probablemente pertenecen al mismo individuo, ya que se encontraron en el mismo nivel estratigráfico y son idénticos entre sí. La longitud de los huesos, $26,2 \mathrm{~mm}$, es similar a la de $M$. solitarius y superior a la de Monticola saxatilis (ver figura 23). El húmero de $M$. saxatilis presenta la parte proximal 
de la cresta bicipital más ancha que en $M$. solitarius y en los fósiles. Además, el margen distal del caput humeri continúa por la cresta deltoidea de forma mucho más patente en M. saxatilis. Por último, la cresta deltoidea es proporcionalmente más larga en el húmero de M. solitarius y en los fósiles que en M. saxatilis, Turdus y Sturnus.

\section{Turdus Linnaeus, 1758}

Cráneo y mandíbula: Turdus es, junto con Corvidae, Monticola, Sturnus, Lanius y Oriolus, el género que presenta el cráneo y la mandíbula de mayor tamaño entre los paseriformes del sudoeste del Paleártico occidental. Moreno (1987) y Cuisin (1989) observan que se trata del único género de la familia en el que el processus palatus maxillaris no es visible en norma dorsal a través de las narinas. Presenta un foramen orbitonasale doble y el processus zygomaticus, siempre mayor que el processus postorbitalis, aparece como una proyección dorso-rostral del ala timpánica. El rasgo más característico del cráneo de Turdus es que presenta la región escamosal abombada, al igual que las especies de Emberizidae (Moreno 1987).

Los géneros con el cráneo y la mandíbula morfométricamente más similares a Turdus son Monticola y Sturnus. El cráneo de Sturnus es notablemente más bajo y aplanado en vista dorsal que el de los otros dos géneros. A diferencia de Sturnus, el processus zygomaticus y el processus postorbitalis están más desarrollados en Turdus. Por último, el processus paraoccipitalis se encuentra también más desarrollado en Turdus que en los otros dos géneros citados.

El premaxilar está adaptado a una alimentación omnívora (Cuisin 1989). Es alargado, triangular y medianamente robusto. Con unas narinas amplias y un corpus ossis premaxillaris cóncavo en vista ventral, presenta un perfil uniforme y ligeramente curvo, más o menos dependiendo de la especie. La parte ventral presenta dos líneas paralelas a la crista tomialis y otras dos formando un ligero canal en el eje longitudinal y que, al igual que las primeras, no se extienden hasta el extremo craneal del premaxilar (Louchart 2004).

A diferencia de Turdus, el premaxilar de Sturnus es extremadamente plano, tanto en vista ventral como en vista dorsal. Sturnus presenta un processus frontalis premaxillare robusto que, al igual que el propio premaxilar, se estrecha hacia su parte caudal, a diferencia del de Turdus, de robustez uniforme. Monticola, a diferencia de Turdus, presenta un premaxilar más plano, con unas narinas más alargadas y un corpus ossis premaxillaris más estrecho y puntiagudo.

La mandíbula es robusta, con amplias fenestras mandibulares. Presenta un ángulo mandibular poco notable y una sínfisis triangular y cóncava en vista dorsal. Los procesos articulares están bastante desarrollados, pero no destacan por su longitud. 
A diferencia de Turdus, la mandíbula de Sturnus presenta un processus retroarticularis y un ángulo mandibular mucho más desarrollados. Por otra parte, la mandíbula de Monticola presenta una sínfisis mandibular más alargada y un processus medialis mandibulae más fino y alargado que en la mandíbula de Turdus. El ángulo que forman los procesos medial y retroarticular es más cerrado, más agudo, en Monticola que en Turdus.

Húmero: presenta una situación intermedia entre el tipo de dos fosas y el de una doble, ya que, si bien existe una comunicación parcial entre ambas, la barra medial está bien desarrollada (Moreno 1987). No se han encontrado diferencias morfológicas claras que permitan identificar las especies de Turdus en base al húmero, al igual que ha sucedido en trabajos precedentes (e.g., Jánossy 1983; Moreno 1987; Weesie 1988; Seguí 1997; Wójcik 2002). Clásicamente, los paleornitólogos que han identificado húmeros de Turdus se han basado en su biometría, y en este trabajo se aplica también este criterio. Las especies morfométricamente más similares a Turdus son las que pertenecen a los géneros Sturnus y Monticola.

Bock (1962) señala la disposición de las fosas como diferencia fundamental entre los húmeros de Turdus y Sturnus. Según este autor, en Turdus las dos fosas se disponen aparentemente encerradas en una única estructura donde la barra medial, todavía bien desarrollada, forma una pared que separa dos mitades distintas. Sin embargo, en Sturnus la fosa dorsal está completamente separada de la ventral, apareciendo, por tanto, como dos estructuras perfectamente diferenciadas. No obstante, algunos de los individuos actuales de Sturnus estudiados en este trabajo presentan fosas más o menos confluentes, la fosa dorsal no está totalmente aislada y por tanto no se ha establecido un criterio de diferenciación en base a las fosas en este caso.

Las diferencias entre los húmeros de Turdus y Sturnus observadas en este trabajo afectan a las crestas bicipital y deltoidea. El borde externo de la cresta bicipital es claramente más ancho en Turdus sobre todo en su parte proximal, mientras que en Sturnus es más fino en todo su recorrido. La cresta deltoidea es más alargada en los húmeros del género Turdus mientras que su superficie, su extensión dorsal, es mayor en Sturnus que en Turdus.

Las diferencias entre el húmero de Turdus y el de Monticola se han detallado en la descripción de este último género.

Tarsometatarso: presenta un aspecto alargado y esbelto, ensanchándose abruptamente en su parte distal (Zelenkov 2012). Es, junto con el tarsometatarso de Corvidae, Sturnus y Lanius meridionalis, el más robusto de los tarsometatarsos de los paseriformes estudiados, tanto en la diáfisis como en las epífisis. Según Seguí et al. (1997) y lo observado en este trabajo, los tarsometatarsos de Sturnus son más cortos y robustos que los de Turdus. A diferencia de Turdus, el tarsometatarso de Monticola presenta una trochlea metatarsi II 
con un margen lateral más irregular y, según Zelenkov (2012), una trochlea metatarsi III más grande y prominente.

La diferenciación entre los tarsometatarsos de las especies de Turdus es exclusivamente biométrica (figura 25), ya que no se han encontrado diferencias morfológicas. No obstante, no siempre ha sido posible identificar los tarsometatarsos a nivel específico, ya que las longitudes de los tarsometatarsos las especies de este género se solapan ampliamente.

\section{Turdus cf. torquatus \\ Mirlo capiblanco}

Material: 1 premaxilar. NMI: 1.

Distribución estratigráfica en es Pouàs: Pleistoceno superior (nivel 4 de la cuadrícula A3).

Distribución actual en el Paleártico occidental: cría en latitudes medias y altas. Se observan algunas poblaciones sedentarias en el sur de la región pero, en general, migran para invernar principalmente en el sur de España y el noroeste de África (Snow y Perrins 1998). En Baleares la población migrante es de escasa a abundante en todas las islas y también hay una pequeña población invernante en Ibiza y Mallorca (López-Jurado 2011).

Registro fósil en el Paleártico occidental: T. torquatus es, dentro del género, la especie menos abundante en el registro de la región. Ausente en el Pleistoceno inferior, se ha atribuido tentativamente a esta especie material del Pleistoceno medio de España, Francia y Alemania. Se ha citado en 21 localidades del Pleistoceno superior de Europa occidental, y en 10 de Europa central (Tyrberg 1998, 2008). No se ha identificado en ningún yacimiento de Baleares.

Comentarios: el premaxilar de esta especie presenta un processus frontalis premaxillare corto y estrecho, a diferencia del de Turdus viscivorus, que es más largo y ancho. Debido al estado fragmentario del premaxilar y a la escasez de material de comparación de esta especie, se ha optado por utilizar una nomenclatura abierta.

\section{Turdus cf. merula \\ Mirlo común}

Material: 21 húmeros (9 derechos, 12 izquierdos). NMI: 12.

Distribución estratigráfica en es Pouàs: Pleistoceno superior y Holoceno (niveles 2 y 4 de la cuadrícula A3 y varios niveles de la cuadrícula D4). 
Distribución actual en el Paleártico occidental: T. merula presenta un área de distribución amplia, desde las latitudes más altas a las más bajas de la región. Especie residente y migratoria, las poblaciones norteñas se desplazan a sus zonas de invernada en el oeste o el sur de Europa (Snow y Perrins 1998). Esta especie está presente en todas las Baleares de forma sedentaria, en migración y también en invernada. La población de la especie en Ibiza actualmente es más o menos abundante (López-Jurado 2011).

Registro fósil en el Paleártico occidental: al igual que en la actualidad, está ampliamente distribuido en el registro fósil de la región, siendo además una especie frecuente y abundante, especialmente en el Pleistoceno superior (más de 120 yacimientos). Sin embargo, es mucho menos abundante en el Pleistoceno medio. En el Pleistoceno inferior solamente se ha registrado en España, Francia y Rumanía (Tyrberg 1998, 2008). Se ha identificado en tres yacimientos del Pleistoceno superior de Mallorca (Seguí et al. 1997; Florit y Alcover 1987; McMinn y Alcover 1992; Mourer-Chauviré et al. 1977), en uno del Pleistoceno medio (cf. Turdus merula, Mourer-Chauviré et al. 1977) y en uno del Pleistoceno inferior (Turdus cf. merula, Alcover et al. 1981). Florit et al. (1989) mencionan la presencia de esta especie en es Pouàs entre los restos identificados como Turdus sp.

Comentarios: la atribución de este material a Turdus cf. merula se basa en su biometría. Como se puede observar en el gráfico, la longitud del húmero de esta especie se solapa parcialmente con la de Turdus pilaris y T. torquatus, si bien el húmero de estas especies presenta unas epífisis notablemente más robustas.

Turdus philomelos C.L Brehm, 1831

Zorzal común

Material: 2 premaxilares y 2 mandíbulas. Total: 4. NMI: 2.

Distribución estratigráfica en es Pouàs: Pleistoceno superior y Holoceno (nivel 3 de la cuadrícula A3 y cuadrícula D4).

Distribución actual en el Paleártico occidental: T. philomelos está ampliamente distribuido en toda la región. En el este y el sur de la misma se encuentran poblaciones principalmente residentes, mientras que en el norte suelen ser migrantes. La principal zona de invernada se encuentra en el noroeste de África y en el oeste y sur de Europa (Snow y Perrins 1998). En Baleares hay una abundante población tanto migrante como invernante en todas las islas (López-Jurado 2011).

Registro fósil en el Paleártico occidental: es una especie frecuente y ampliamente distribuida en los yacimientos del Pleistoceno superior de toda la región, siendo especialmente frecuente en Europa occidental. Sin embargo, es muy escasa en el Pleistoceno 
medio (citada en dos yacimientos centroeuropeos y dos de Europa occidental) y en el Pleistoceno inferior sólo se ha registrado en España y en un par de localidades (Turdus cf. philomelos) de la mitad este de la región (Tyrberg 1998, 2008). No ha aparecido en ningún yacimiento de Baleares.

Comentarios: el corpus ossis premaxillaris es más corto en el fósil y en T. philomelos, que en T. merula, y más largo que en Turdus iliacus.

La sínfisis mandibular es más corta que la de la mandíbula de T. merula y de mayor longitud que la de T. iliacus.

\section{Turdus cf. philomelos}

Material: 2 premaxilares y 9 tarsometatarsos (8 derechos, 1 izquierdo). Total: 11.

Comentarios: el estado fragmentario del premaxilar no permite una identificación más precisa, si bien las proporciones de las estructuras visibles se corresponden con las de esta especie.

Los tarsometatarsos son biométricamente atribuibles a esta especie. Si bien su longitud se solapa ampliamente con la de las especies de Turdus de talla superior (T. viscivorus, $T$. pilaris, T. merula y T. torquatus), los tarsometatarsos de T. philomelos y los fósiles presentan unas epífisis mucho menos robustas.

Turdus iliacus Linnaeus, 1766

Zorzal alirrojo

Material: 2 mandíbulas y 1 tarsometatarso (derecho). Total: 3. NMI: 2.

Distribución estratigráfica en es Pouàs: Pleistoceno superior y Holoceno (nivel 3 de la cuadrícula A3 y nivel superficial de la cuadrícula E11).

Distribución actual en el Paleártico occidental: T. iliacus cría en latitudes altas y medias-altas de la región, principalmente en las llanuras árticas y subárticas. Especie migratoria o parcialmente migratoria, pasa la temporada invernal en latitudes medias-bajas y bajas de la región (Snow y Perrins 1998). Es una especie escasa en Baleares, tanto en migración como en invernada, excepto en Formentera, donde sólo aparece en invernada (López-Jurado 2011).

Registro fósil en el Paleártico occidental: es abundante en el Pleistoceno superior, especialmente en Europa occidental, donde ha aparecido en más de 40 yacimientos. Todas 
las citas del Pleistoceno medio (14 yacimientos) corresponden a yacimientos del oeste de Europa. Se ha identificado en dos localidades del Pleistoceno inferior de España y, con determinación provisional, en Francia y el este de la región (Tyrberg 1998, 2008). Ha aparecido en un yacimiento del Pleistoceno inferior (Alcover et al. 1981), en uno del Pleistoceno medio (Mourer-Chauviré et al. 1977; Alcover et al. 1981; Seguí 1996) y en uno del Pleistoceno superior (Seguí et al. 1997) de Mallorca.

Comentarios: la longitud de una de las mandíbulas $(33 \mathrm{~mm}$, la otra mandíbula está fragmentada), la robustez de los procesos articulares y la amplitud de la fenestra mandibulae de T. iliacus y los fósiles, son inferiores a las de la mandíbula de T. philomelos.

Tanto la robustez como la longitud del tarsometatarso de T. iliacus y el fósil (29,5 mm), son inferiores a las del resto de las especies del género.

\section{Turdus cf. iliacus}

Material: 34 húmeros (15 derechos, 19 izquierdos) y 1 tarsometatarso (izquierdo). Total: 35.

Comentarios: si bien la longitud del húmero de T. iliacus $(24,9-26,1 \mathrm{~mm})$, se solapa con la longitud del de $T$. philomelos (25,3-27,5 mm), se observa que en general es inferior en el primero, al igual que su robustez. Los húmeros identificados son biométricamente más similares a T. iliacus, si bien no hay diferencias inequívocamente diagnósticas entre ambas especies, por lo que se ha optado por utilizar una nomenclatura abierta.

El tarsometatarso, morfológicamente atribuible a T. iliacus, presenta una longitud $(26,75$ $\mathrm{mm}$ ) inferior a la de los individuos actuales.

\section{Turdus viscivorus Linnaeus, 1758 \\ Zorzal charlo}

Material: 3 mandíbulas. NMI: 3 .

Distribución estratigráfica en es Pouàs: Holoceno (cuadrícula D4).

Distribución actual en el Paleártico occidental: ampliamente distribuida en la región, esta especie cría en zonas continentales de latitud media y alta, si bien en los dos últimos siglos ha extendido su área de cría hacia zonas oceánicas. En general, las poblaciones del sur y del oeste de la región son sedentarias, mientras que las del norte y el este migran a latitudes medias-bajas durante el invierno (Snow y Perrins 1998). En Baleares se observa 
como migrante e invernante, de moderado a escaso, tanto en las Gimnesias como en las Pitiusas (López-Jurado 2011).

Registro fósil en el Paleártico occidental: es muy abundante en el registro fósil de la región, especialmente en el Pleistoceno superior de Europa occidental, con más de 80 registros (entre ellos 20 en España, 38 en Francia y 15 en Italia). Se ha identificado en el Pleistoceno medio de España, Francia, Italia, Hungría y Rusia y en el Pleistoceno inferior del centro (Austria y Rumanía) y del oeste (Francia) de la región (Tyrberg 1998, 2008). Relativamente abundante en Baleares, se ha registrado en un yacimiento del Pleistoceno inferior (Turdus cf. viscivorus, Mourer-Chauviré et al. 1977), en uno del Pleistoceno medio (Mourer-Chauviré et al. 1977; Seguí 1996) y en cuatro del Pleistoceno superior de Mallorca (Cova Nova [McMinn y Alcover 1992], Cova de Son Mayol [Turdus cf. viscivorus, Mourer-Chauviré et al. 1977], Coves d'Artà y Bufador de Son Berenguer [Mourer-Chauviré, en Alcover et al. 1981]). Florit et al. (1989) mencionan la probable presencia de esta especie en es Pouàs.

\section{Comentarios}

Mandíbula: la longitud de la mandíbula de T. viscivorus $(38,8-40,3 \mathrm{~mm})$ se solapa parcialmente con la de T. torquatus $(36,3-39,1 \mathrm{~mm})$, y la sínfisis mandibular es relativamente corta en ambas especies. Sin embargo, el ángulo entre el processus medialis mandibulae y el processus retroarticularis es notablemente más abierto en T. torquatus, y la parte caudal de la rama mandibular es más alta en T. torquatus. Las mandíbulas identificadas superan en longitud a las de los individuos actuales y son más grandes que las de T. torquatus.

\section{Turdus cf. viscivorus}

Material: 20 premaxilares, 9 mandíbulas y 36 húmeros (27 derechos, 9 izquierdos) y un conjunto de material asociado (1 húmero, 1 ulna y 1 radio izquierdos). Total: 66.

Comentarios: los premaxilares y las mandíbulas fósiles son biométricamente similares a los de esta especie, incluso más grandes. Sin embargo, debido al estado fragmentario de los mismos se ha optado por utilizar una nomenclatura abierta.

Húmero: Wójcik (2002) afirma que los húmeros de T. viscivorus presentan el processus supracondylaris dorsalis dividido en dos ápices (dos tubérculos) mientras que en las otras especies está ligeramente o nada dividido. Sin embargo, los ejemplares de comparación de otras especies de Turdus utilizados en este trabajo también presentan dos ápices, por lo que no se ha considerado este carácter para la discriminación de T. viscivorus.

La longitud de los húmeros de T. viscivorus es la mayor del género aunque su rango se solapa parcialmente con el de T. pilaris y T. torquatus. 20 de los húmeros aquí identifica- 
dos presentan una longitud superior a la de dichas especies (mayor de $33 \mathrm{~mm}$, si bien la longitud máxima de $T$. torquatus es 32,7 mm ( $\mathrm{n}=12)$ y la de T. pilaris es 32,5 mm). Algunos de estos húmeros incluso superan en longitud (hasta 34,4 mm) y robustez a los húmeros de los individuos de T. viscivorus actuales.

Los 16 húmeros restantes son muy robustos y presentan una longitud dentro del rango de T. viscivorus (31-33,8 mm), pero en este caso, esa longitud se solapa con la de T. torquatus y/o con la de $T$. pilaris.

Dado que se ha constatado repetidamente la existencia de cambios en la talla corporal de las especies del género Turdus (e.g., Seguí 1997; Louchart 2002; Stewart 2007) se ha optado por adoptar una terminología abierta para su denominación. Tentativamente se asignan a Turdus cf. viscivorus, ya que presentan un aspecto general más similar al de la muestra de comparación de la que se dispone.

\section{Turdus sp.}

Se han identificado 2005 restos fósiles correspondientes a este género que solamente se han determinado a nivel genérico debido al estado de los mismos y a la similitud entre especies. Se ha realizado una clasificación por tamaños, de forma que los restos cuya biometría corresponde a la de T. iliacus o T. philomelos, se han denominado "Turdus sp. (de talla pequeña)", mientras que los de tamaño superior se asignan a "Turdus sp. (de talla grande)". Los restos fragmentados de talla dudosa se han identificado como Turdus sp.

Material: 8 cráneos, 17 premaxilares, 60 mandíbulas y 24 húmeros (17 derechos, 7 izquierdos) y 1 tarsometatarso (izquierdo). Total: 110.

Turdus sp. (de talla pequeña)

Material: 1 cráneo, 2 mandíbulas y 62 húmeros (31 derechos, 31 izquierdos). Total: 65.

Turdus sp. (de talla grande)

Material: 6 cráneos, 18 premaxilares, 46 mandíbulas y 1607 húmeros (770 derechos, 837 izquierdos) y 153 tarsometatarsos (78 derechos, 75 izquierdos) Total: 1830.

Sylviidae Vigors, 1825

(Figura 7, anexo) 


\section{Cráneo y mandíbula}

El cráneo de esta familia presenta un foramen orbitonasale simple y de forma más o menos alargada. El processus zygomaticus está bien desarrollado y el processus postorbitalis está casi tan desarrollado como el anterior, excepto en Sylvia y en Cettia cetti, en las que está más reducido. La posición de los foramina venae occipitalis externae no es la misma en todas las especies (Moreno 1987).

El premaxilar es frágil, fino y alargado, y presenta un processus palatus maxillaris cuya posición, no visible a través de las narinas en vista dorsal, permite diferenciarlo del premaxilar de Turdidae (Cuisin 1989). El corpus ossis premaxillaris es corto y estrecho (excepto en Sylvia hortensis).

En la mandíbula, muy poco robusta al igual que el premaxilar, destaca un processus retroarticularis muy corto. La sínfisis mandibular es muy estrecha, puntiaguda y cóncava en vista dorsal. Presenta unas ramas mandibulares bajas y también estrechas.

\section{Húmero}

En el húmero de esta familia la fosa ventral está bien desarrollada, mientras que la fosa dorsal no lo está, excepto en el húmero de Regulus (Bock 1962) y en el de Cisticola juncidis (Moreno 1987). Presenta una cresta deltoidea muy corta y que además, a diferencia de Luscinia y E. rubecula, no tiene el borde recto (Jánossy 1983). En la epífisis distal es muy característico el processus flexorius, que es muy alargado, como ocurre en Troglodytes troglodytes. Sin embargo, en T. troglodytes la fosa ventral está menos desarrollada que en Sylviidae.

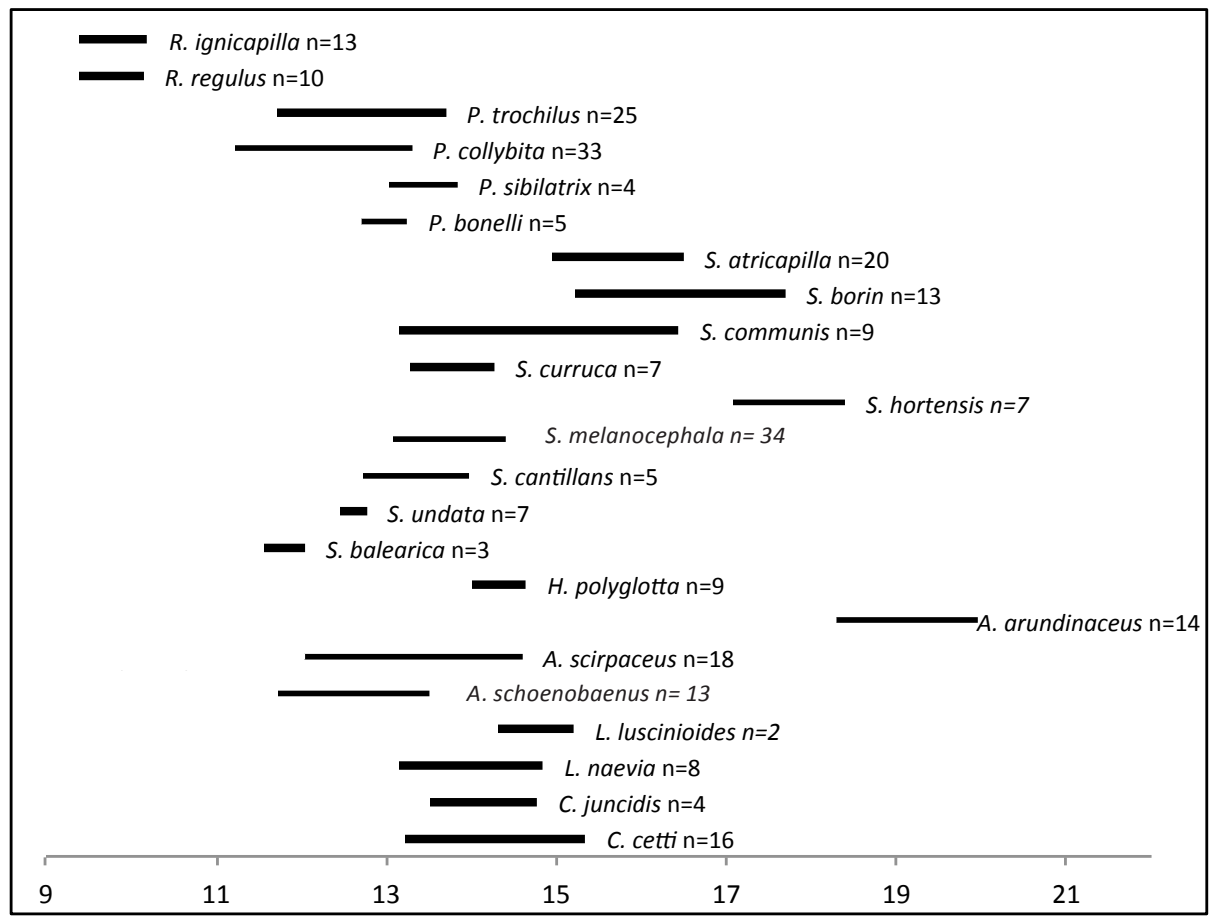

Figura 26. Longitud de los húmeros de las especies actuales de Sylviidae. Ejemplares procedentes de las colecciones del IMEDEA y el NHMT y de los trabajos de Jánossy (1983), Moreno (1987) y Kessler (2013). 


\section{Tarsometatarso}

El tarsometatarso de Sylviidae es poco robusto, con una diáfisis ancha, en general, en vista lateral, debido a un notable desarrollo de la crista medioplantaris. Presenta una epífisis distal muy estrecha. Junto con las de Muscicapidae, Paridae y Troglodytidae, es la más estrecha entre los paseriformes estudiados. Las trócleas presentan un escaso desarrollo, siendo cortas y poco robustas, especialmente la trochlea metatarsi II.

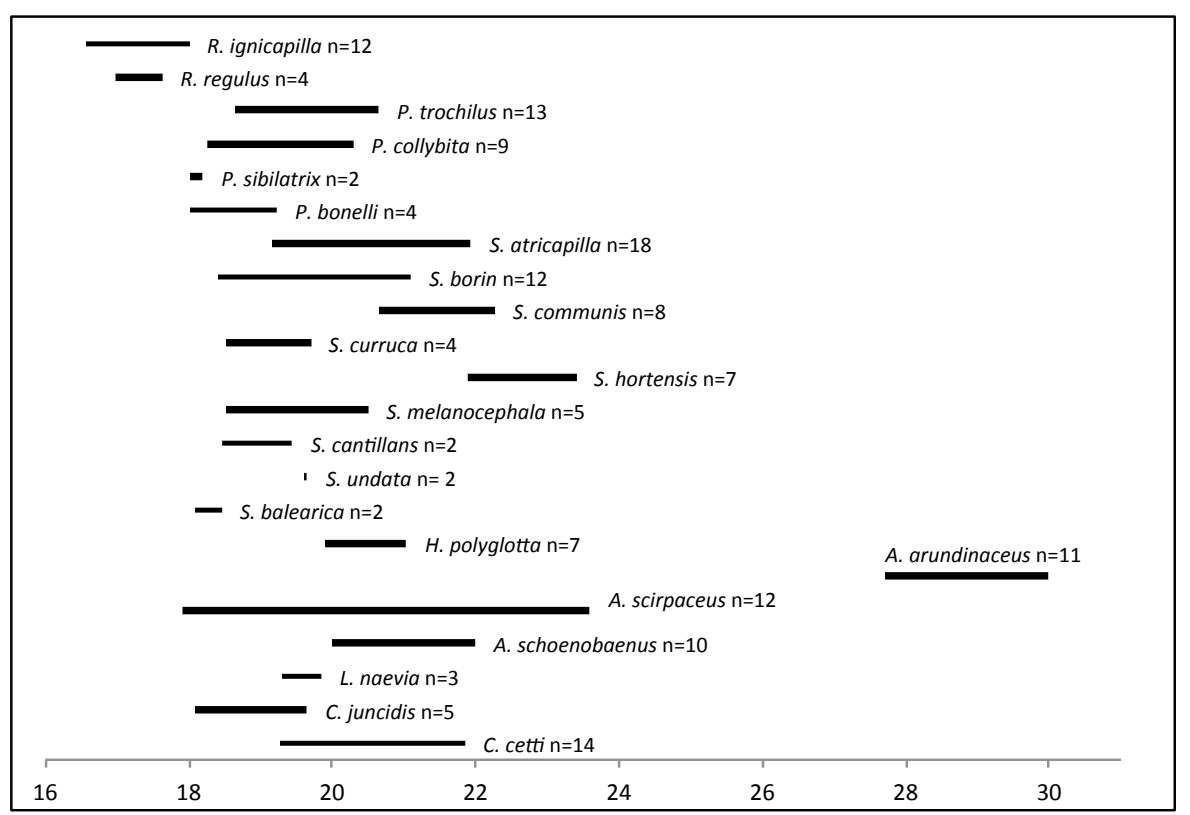

Figura 27. Longitud de los tarsometatarsos de las especies actuales de Sylviidae. Ejemplares procedentes de las colecciones del IMEDEA y el NHMT y del trabajo de Moreno (1987).

\section{Locustella Kaup, 1829 \\ Locustella sp.}

Material: 3 húmeros (1 derecho, 2 izquierdos). NMI: 2.

Distribución estratigráfica en es Pouàs: Pleistoceno superior (nivel 5 de la cuadrícula A3 y cuadrícula A2).

Distribución actual en el Paleártico occidental: Locustella naevia ocupa latitudes medias, principalmente zonas templadas continentales. Es una especie migratoria, de la que no se conoce con exactitud su zona de invernada, aunque se supone que está situada al sur del Sáhara. Locustella luscinioides se encuentra en latitudes medias y bajas de la región, invernando al sur del Sáhara (Snow y Perrins 1998). L. naevia es una especie migrante escasa en todas las islas del archipiélago balear y L. luscinioides es una especie de rara a accidental (López-Jurado 2011).

Registro fósil en el Paleártico occidental: L. naevia se encuentra prácticamente ausente del registro del Pleistoceno de la región. Solamente se ha identificado en un yacimiento 
del Pleistoceno superior de la República Checa (Tyrberg 1998, 2008). L. luscinioides no se ha encontrado en ningún yacimiento del Pleistoceno de la región.

Comentarios: solamente se ha dispuesto de material de comparación de L. naevia. El húmero de esta especie presenta una sola fosa bien desarrollada. Es muy característico el processus supracondylaris dorsalis, que se encuentra muy cercano a la diáfisis y está muy poco desarrollado, a diferencia del resto de húmeros de Sylviidae estudiados, en los que está más desarrollado y sobresale más dorsalmente. La cresta deltoidea es muy corta, proporcionalmente más corta que en Sylvia. Por último, a diferencia de Acrocephalus, el tubérculo ventral es más ancho en Locustella. No se ha encontrado información sobre la discriminación entre las dos especies del género en base al húmero, y la longitud de los mismos se solapa, si bien es algo superior en L. luscinioides y en los fósiles.

Sylvia Scopoli, 1769

Cráneo y mandíbula: en el cráneo de las especies del género Sylvia el processus postorbitalis es menor que el processus zygomaticus, llegando incluso a estar ausente en algunos ejemplares de Sylvia atricapilla. El hueso ectemoides presenta un borde externo más anguloso que en los otros géneros (Moreno 1987). En Phylloscopus, Hippolais y Acrocephalus, la lamella caudolateralis del os palatinum tiene un extremo caudal alargado y agudo, mientras que en Sylvia tiende a ser redondeado y más corto.

El premaxilar de Sylvia es ancho comparado con el del resto de géneros de la familia y presenta dimensiones muy variables. Sylvia borin, S. atricapilla y S. hortensis son las especies que presentan un premaxilar más masivo (Cuisin 1989).

El premaxilar de Phylloscopus es más estrecho que el de Sylvia, especialmente en su parte caudal, y presenta unas narinas proporcionalmente más largas. En la mandíbula de Phylloscopus, el processus lateralis mandibulae está más desarrollado y la fenestra mandibulae es más amplia que en la mandíbula de Sylvia.

Las especies de Acrocephalus (A. schoenobaenus, A. melanopogon y A. scirpaceus) presentan un premaxilar más estrecho y comprimido dorsoventralmente que las especies de Sylvia de talla similar. Además, en la mandíbula de estas especies la sínfisis es más estrecha y puntiaguda y el processus lateralis mandibulae está más desarrollado.

El premaxilar y la mandíbula de Locustella naevia y Cettia cetti son más estrechos y alargados que los de Sylvia. Sin embargo, los de Hippolais polyglotta son más robustos y aplanados y presentan la parte craneal (corpus ossis premaxillaris y sínfisis mandibular) más ancha y extensa que en Sylvia.

Cisticola presenta una sínfisis mandibular muy estrecha y puntiaguda, y un premaxilar de perfil curvo con unas narinas más cortas y redondeadas, a diferencia de Sylvia. 
Y por último, el premaxilar y la mandíbula de Regulus tienen una longitud inferior a los del resto de especies de la familia.

Húmero: los húmeros de Sylvia presentan solamente una fosa, si bien en algunas especies se intuye el comienzo del desarrollo de una segunda, menos desarrollada que en el resto de especies de la familia (excepto en Locustella). Jánossy (1983) observa en los húmeros de Sylvia un tuberculum ventrale bastante prominente. La cresta deltoidea por lo general se une progresivamente (sin formar un escalón) a la diáfisis en su parte distal a diferencia de lo que sucede en Phylloscopus y Acrocephalus (en los que sí forma un escalón). Además se extiende más dorsalmente, en dichos géneros que en Sylvia. El húmero de Hippolais y el de Cettia cetti presentan una fosa dorsal más notable y la cresta deltoidea de ésta última especie es más larga que la de Sylvia. La diferenciación interespecífica a partir del húmero es complicada en base a su morfología.

\section{Sylvia sarda/balearica Boddaert, 1783/(von Jordans, 1913) Curruca sarda/balear}

Material: 1 cráneo completo y 1 mandíbula pertenecientes al mismo individuo. NMI: 1.

Distribución estratigráfica en es Pouàs: Pleistoceno superior (nivel 6 de la cuadrícula A3).

Distribución actual en el Paleártico occidental: se trata de especies de distribución restringida, que solamente crían en algunas las islas del Mediterráneo. Las poblaciones de Córcega y Cerdeña son parcialmente migrantes mientras que las de las Baleares son sedentarias y abundantes en todas las islas excepto en Menorca (Snow y Perrins 1998; López-Jurado 2011). Si bien antiguamente se consideraba S. balearica como una subespecie de $S$. sarda, actualmente se tiende a considerar que $S$. balearica tiene un estatus específico propio (Sangster et al. 2012). Por tanto, las menciones antiguas de S. sarda en Baleares deberían referirse actualmente a $S$. balearica. Con todo, este estatus está en discusión y aquí se presentan los restos fósiles bajo la denominación Sylvia sarda/balearica.

Registro fósil en el Paleártico occidental: se han identificado en dos yacimientos del Pleistoceno superior, uno de Menorca y otro de Mallorca (Sylvia cf. sarda [Seguí 1999; Seguí et al. 1997]). Son los únicos registros de estas especies en el Pleistoceno de la región.

Comentarios: el cráneo y la mandíbula son morfológica y biométricamente similares a los de Sylvia undata. Sin embargo, los foramina venae occipitalis externae son más visibles en $S$. balearica y el fósil, ya que están más alejados del borde del foramen magnum. Además, el extremo caudal de la lamella caudolateralis es más ancho en dichas especies y en el fósil que en S. undata. No se han descrito caracteres osteológicos que permitan diferenciar a $S$. sarda de S. balearica. 


\section{Sylvia cf. sarda/balearica}

Material: 3 húmeros (2 derechos, 1 izquierdo).

Comentarios: los húmeros de S. balearica y los fósiles presentan una talla ligeramente menor a los de $S$. undata. Sin embargo, no se puede descartar la atribución de este material a esta última especie, por lo que se ha adoptado una nomenclatura abierta. Entre los sílvidos de talla similar, $S$. cantillans presenta un húmero de longitud similar pero de robustez notablemente superior al de S. balearica. El húmero de Phylloscopus collybita es más robusto, menos estilizado que el de $S$. balearica, con una cresta deltoidea de mayor superficie. En los húmeros de los Acrocephalus de talla similar a S. balearica y S. undata, el tubérculo ventral está más desarrollado que en dichas especies. Por último, las diferencias con L. naevia, se detallan en la descripción de esta especie.

\section{Sylvia cf. undata}

Curruca rabilarga

Material: 2 mandíbulas y 10 húmeros (6 derechos, 4 izquierdos). Total: 12. NMI: 6.

Distribución estratigráfica en es Pouàs: Pleistoceno superior y Holoceno (cuadrícula A3 niveles superficial, 3, 4 y 5 y cuadrícula D4).

Distribución actual en el Paleártico occidental: cría en el Mediterráneo y en latitudes medias-bajas de clima templado. Parcialmente migratoria, en invernada se encuentra en el noroeste de África y en las islas Mediterráneas. Las poblaciones de Iberia, sur de Francia, Córcega y Cerdeña son sedentarias (Snow y Perrins 1998). En Baleares la población sedentaria es escasa y sólo se da en Mallorca y Menorca. Se puede observar en migración en todas las islas y como invernante escaso en todas excepto Formentera (López-Jurado 2011).

Registro fósil en el Paleártico occidental: Sylvia undata no ha sido identificada en ningún yacimiento del Pleistoceno de la región.

Comentarios: la rama mandibular en las mandíbulas fósiles y en las de $S$. undata es más baja que en las de $S$. cantillans. Los húmeros $(\mathrm{L}=12,4-12,8 \mathrm{~mm})$ son de talla superior a los de $S$. balearica y similares a los de $S$. undata (figura 26). Además, los húmeros fósiles son notablemente menos robustos que los de $S$. cantillans. Debido a la similitud morfológica de estos huesos en $S$. balearica y $S$. undata, se ha optado por utilizar una nomenclatura abierta. 
Sylvia melanocephala Gmelin, 1789

Curruca cabecinegra

Material: 1 cráneo y 1 mandíbula. Total: 2. NMI: 1.

Distribución estratigráfica en es Pouàs: Holoceno (cuadrícula A3, niveles 1 y superficial).

Distribución actual en el Paleártico occidental: S. melanocephala cría en el sudoeste de Europa y sus poblaciones varían de parcialmente migrantes a sedentarias (Snow y Perrins 1998). Todas las islas del archipiélago balear cuentan con una abundante población de individuos sedentarios y en las Gimnesias se observan además individuos invernantes y en migración, aunque en ambos casos son escasos (López-Jurado 2011).

Registro fósil en el Paleártico occidental: solamente se ha registrado en un yacimiento del Pleistoceno medio de Francia y en uno del Pleistoceno superior de Israel (Tyrberg 1998, 2008). Se ha citado, con reservas, en dos yacimientos del Pleistoceno superior de Mallorca (S. melanocephala/curruca. Seguí 1977; Seguí et al. 1977).

Comentarios: tres especies del género presentan una longitud de cráneo similar a la de S. melanocephala: S. atricapilla, Sylvia communis y S. borin. En S. borin el premaxilar es más alto y curvo en vista lateral. La distancia interorbitaria (inferior a la de S. atricapilla y superior a la de $S$. communis), la forma de las narinas (más amplias y redondeadas en $S$. borin y S. atricapilla) y la posición de los foramina venae occipitalis externae (en el borde posterior del foramen magnum y más visibles que en S. communis) del fósil son características del cráneo de $S$. melanocephala.

En cuanto a la mandíbula de las especies biométricamente más similares, S. communis presenta cóndilos mandibulares más globulares y lisos en vista ventral. Por otro lado, $S$. atricapilla presenta un processus retroarticularis más corto y menos robusto que el de la mandíbula de S. melanocephala.

Sylvia sp.

Material: 1 cráneo y 10 húmeros (2 derechos, 8 izquierdos). Total: 11.

Comentarios: tanto el cráneo fósil como el de Sylvia y Cettia presentan un processus postorbitalis muy poco desarrollado, a diferencia del resto de especies de la familia. A diferencia de Cettia, el processus frontalis nasalis de Sylvia y del fósil es más corto y estrecho. El estado fragmentario del cráneo y la ausencia de premaxilar impiden una identificación más precisa. 
Debido a la morfometría tan similar del húmero en algunas especies de Sylvia, se ha adoptado una nomenclatura abierta para la asignación taxonómica de estos fósiles.

\section{Phylloscopus Boie, 1826 \\ Phylloscopus sp.}

Material: 25 húmeros (12 derechos, 13 izquierdos). NMI: 13.

Distribución estratigráfica en es Pouàs: Pleistoceno superior y Holoceno (cuadrícula D4 y cuadrícula A3, niveles superficial, 2, 3, 5, 6 y 7).

Comentarios: las especies del género Phylloscopus presentan un húmero de pequeñas dimensiones, con una epífisis proximal corta y robusta (a diferencia de Cettia e Hippolais). Junto con Cisticola y Regulus (de longitud inferior al resto) presentan una fosa dorsal más desarrollada que en los demás géneros de la familia. La cresta deltoidea, a diferencia de Sylvia, es más extensa y siempre forma un escalón en su unión con la diáfisis. A diferencia de Acrocephalus, Phylloscopus presenta una cresta deltoidea más larga y una fosa dorsal más profunda. La epífisis proximal de Phylloscopus es más ancha y robusta que la de Cisticola, cuyo húmero es más estilizado. No ha sido posible la identificación de estos húmeros a nivel de especie, debido a la ausencia de caracteres morfológicos y biométricos que los diferencien.

\section{Sylviidae indeterminados}

Material: 1 cráneo, 5 premaxilares, 1 mandíbula, 32 húmeros (13 derechos, 19 izquierdos) y 9 tarsometatarsos (3 derechos, 6 izquierdos). Total: 48.

Comentarios: las características de este material junto con la dificultad para identificar los huesos de las especies de esta familia impiden realizar una identificación más precisa.

Muscicapidae Fleming, 1822

(Figura 8, anexo)

\section{Cráneo y mandíbula}

El premaxilar de esta familia es ancho, largo y de sección triangular. Presenta una pars maxillaris palatini muy grande y un corpus ossis premaxillaris muy ancho debido a los hábitos alimenticios de los miembros de esta familia, que capturan insectos al vuelo (Cuisin 1989). 
A diferencia de las especies de Turdidae de talla similar, el premaxilar de los Muscicapidae presenta unas narinas más amplias. El premaxilar es más ancho que en Turdidae y presenta un aspecto más aplanado, especialmente a nivel del corpus ossis premaxillaris.

La mandíbula también es aplanada y ancha, especialmente la sínfisis mandibular. La rama mandibular, a nivel del ángulo mandibular, se encuentra reforzada con una proyección ósea. En la zona articular, el processus retroarticularis y el processus medialis mandibulae forman un ángulo más cerrado, a diferencia lo que se observa en las especies de Turdidae de talla similar.

\section{Húmero}

El húmero de los Muscicapidae presenta dos fosas bien desarrolladas, al igual que la barra medial que las separa. La epífisis proximal es más corta que en los Turdidae de talla pequeña, y la cresta deltoidea es, en general, más corta y de margen más recto que en los mismos (Jánossy 1983).

\section{Tarsometatarso}

Los individuos de esta familia presentan un tarsometatarso corto, con una epífisis distal relativamente estrecha. Los tarsometatarsos de los "Turdidae de talla pequeña" (21,6-29,2 $\mathrm{mm}$ ) son notablemente más largos que los de Muscicapidae (14,35-17,7 mm), por lo que se diferencian sin dificultad. De las familias con tarsometatarsos de longitud similar, $\mathrm{Pa}-$ ridae presenta una trochlea metatarsi II más larga y expandida lateralmente, y una fossa metatarsi I mucho más marcada, incluso en vista dorsal. Los tarsometatarsos de Fringillidae y Emberizidae, a diferencia de los de Muscicapidae, presentan una epífisis distal más robusta, y una trochlea metatarsi II notablemente más desarrollada.

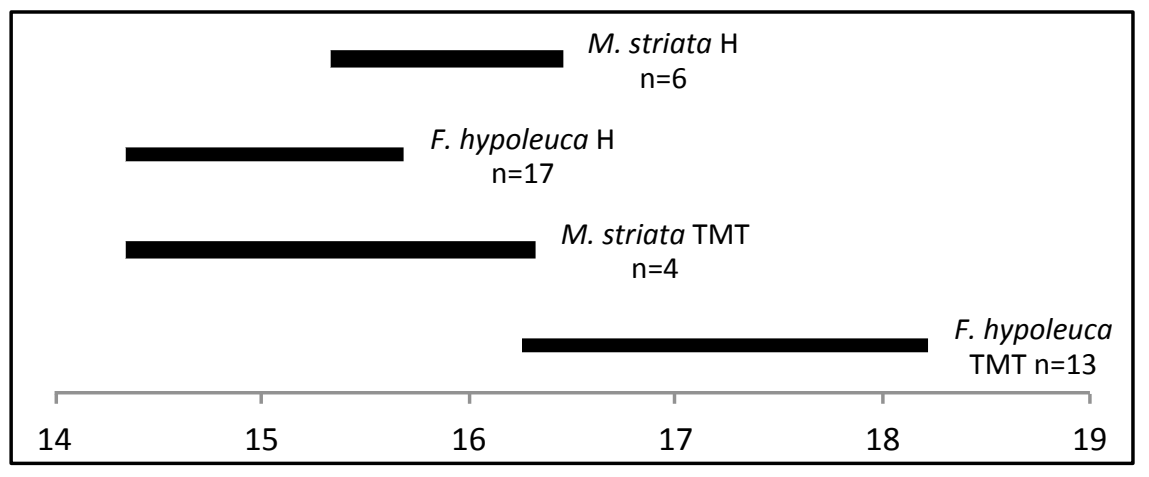

Figura 28. Longitud de los húmeros y tarsometatarsos de las especies actuales de Muscicapidae. Ejemplares procedentes de la colección del IMEDEA y de los trabajos de Jánossy (1983) y Moreno (1987). 
Muscicapa Brisson, 1760

Muscicapa striata Pallas, 1764

Papamoscas gris

Material: 4 húmeros (1 derecho, 3 izquierdos). NMI: 3.

Distribución estratigráfica en es Pouàs: Pleistoceno superior y Holoceno (nivel 4 de la cuadrícula A3 y -70/-100 cm de la cuadrícula A4).

Distribución actual en el Paleártico occidental: $M$. striata está ampliamente distribuido por la región. Cría en un extenso rango latitudinal, desde el Mediterráneo hasta el Ártico (Snow y Perrins 1998). Las poblaciones estivales y las migrantes son abundantes en todas las Baleares (López-Jurado 2011).

Registro fósil en el Paleártico occidental: se trata de una especie muy escasa en el registro. Se ha citado en dos localidades del Pleistoceno inferior de España, una de ellas en Mallorca (Muscicapa cf. striata, Alcover et al. 1981). Presente también en tres localidades del Pleistoceno medio (Francia, Austria e Israel) y en el Pleistoceno superior de España, Francia, Grecia, Polonia e Israel (Tyrberg 1998, 2008). No consta en el registro del Pleistoceno medio ni en del Pleistoceno superior de Baleares.

Comentarios: la fosa dorsal está más desarrollada (es más profunda) en el húmero de Muscicapa que en el de Ficedula. Por otra parte, el húmero de Muscicapa presenta una fosa dorsal menos profunda (Weesie 1988) y más redondeada y estrecha que el de las especies de Turdidae morfométricamente similares (Phoenicurus y Saxicola).

\section{cf. Muscicapa striata}

Material: 3 premaxilares, 1 mandíbula y 25 húmeros (14 derechos, 11 izquierdos). Total: 29 .

Comentarios: los premaxilares fósiles presentan un corpus ossis premaxillaris largo y por tanto, más similar al de Muscicapa. Debido al estado del material no se aprecian correctamente algunos caracteres diagnósticos, por lo que no se puede descartar su atribución a Ficedula. 
Ficedula Brisson, 1760

Ficedula hypoleuca Pallas, 1764

Papamoscas cerrojillo

Material: 1 premaxilar, 3 mandíbulas, 16 húmeros (8 derechos, 8 izquierdos) y 1 tarsometatarso (derecho). Total: 21. NMI: 8 (basado en los húmeros).

Distribución estratigráfica en es Pouàs: Pleistoceno superior y Holoceno (cuadrícula A3 [nivel 3 y $-80 /-110 \mathrm{~cm}$ ] y cuadrícula D4).

Distribución actual en el Paleártico occidental: cría en latitudes más norteñas que el resto de las especies del género, aunque también en zonas boreales y en el Mediterráneo. Es una especie migratoria de larga distancia, que migra en invierno a África occidental, al sur del Sáhara (Snow y Perrins 1998). La población migrante es abundante en Mallorca y menos abundante en Menorca e Ibiza (López-Jurado 2011).

Registro fósil en el Paleártico occidental: exceptuando un registro del Pleistoceno superior de Polonia, esta especie únicamente ha aparecido en yacimientos de Europa occidental de dicha época. Está representada a lo largo de todo el Pleistoceno en España y Francia (Tyrberg 1998, 2008). En Baleares se ha identificado en un yacimiento del Pleistoceno superior de Mallorca (Seguí et al. 1997) y en el Pleistoceno superior de Ibiza a nivel genérico (Ficedula sp., Sondaar et al. 1995).

\section{Comentarios}

Cráneo y mandíbula: el premaxilar de Ficedula es mucho más corto y de menor superficie que el de Muscicapa. La mandíbula de Ficedula es también más corta y presenta los procesos menos desarrollados que la de Muscicapa. La sínfisis mandibular es más redondeada en Ficedula, y el ángulo que forman el processus retroarticularis y el processus medialis mandibulae es más cerrado en Ficedula.

Húmero: la fosa dorsal del húmero de Ficedula es menos profunda que la del húmero de Muscicapa, si bien está más desarrollada y es más redondeada que en los húmeros de E. rubecula y Luscina sp. El tubérculo ventral es más corto (Jánossy 1983) y la incisura capitis está menos marcada en Ficedula que en Erithacus y Luscina. Por último, como se observa en la figura 28 , la longitud de este húmero es ligeramente inferior a la del húmero de Muscicapa. 
Tarsometatarso: el tarsometatarso de Ficedula y el fósil (17,4 mm) superan en longitud al de Muscicapa.

F. albicollis presenta una distribución más oriental que F. hypoleuca y solamente se observa en Baleares de forma accidental. En cuanto al registro fósil del Pleistoceno superior de la región, sólo ha aparecido en un yacimiento de Francia. No se han encontrado diferencias osteológicas entre las dos especies de Ficedula, si bien la presencia de F. albicollis en Pouàs es muy poco probable.

\section{cf. Ficedula hypoleuca}

Material: 2 premaxilares, 50 húmeros (22 derechos, 28 izquierdos) y 1 tarsometatarso (derecho). Total: 53 .

Comentarios: el estado fragmentario de los premaxilares impide una identificación precisa, si bien el corpus ossis premaxillaris de los fósiles es similar al de Ficedula hypoleuca. En el caso de estos húmeros, su atribución a Ficedula es dudosa, y el tarsometatarso presenta una biometría más similar al de esta especie, aunque no muy diferente a la del tarsometatarso de M. striata. Por estos motivos se ha optado por utilizar una nomenclatura abierta para la asignación taxonómica de estos fósiles.

\section{Paridae Vigors, 1825}

(Figura 8, anexo)

\section{Mandíbula}

La mandíbula de los páridos presenta una amplia fenestra mandibulae y un processus coronoideus de desarrollo variable según las especies (Moreno 1987). La sínfisis mandibular es muy característica, con una impresión en la parte central en vista dorsal. Esta situación se da también en la mandíbula de Alaudidae pero, a diferencia de la misma, la sínfisis de Paridae es más cóncava en vista dorsal.

\section{Húmero}

Los húmeros de Paridae presentan dos fosas, la ventral más amplia y la dorsal con una abertura reducida, pero muy desarrollada hacia el interior (Louchart 2002). Bock (1962) también destaca el completo desarrollo de la fosa dorsal en Paridae y Jánossy (1983) la neumatización de la misma. La fosa ventral, en su extremo distal, presenta una depresión redondeada también muy característica. En la epífisis distal, el processus flexorius es muy alargado, mientras que el epicóndilo dorsal (hasta el processus supracondylaris dorsalis) es relativamente corto. 
En comparación con los húmeros de Muscicapidae y Turdidae de talla similar, los húmeros de Paridae presentan un caput humeri menos robusto, una barra medial más fina y una cresta deltoidea más larga. La fosa dorsal está más desarrollada y la cresta deltoidea es más larga en Paridae que en Sylviidae.

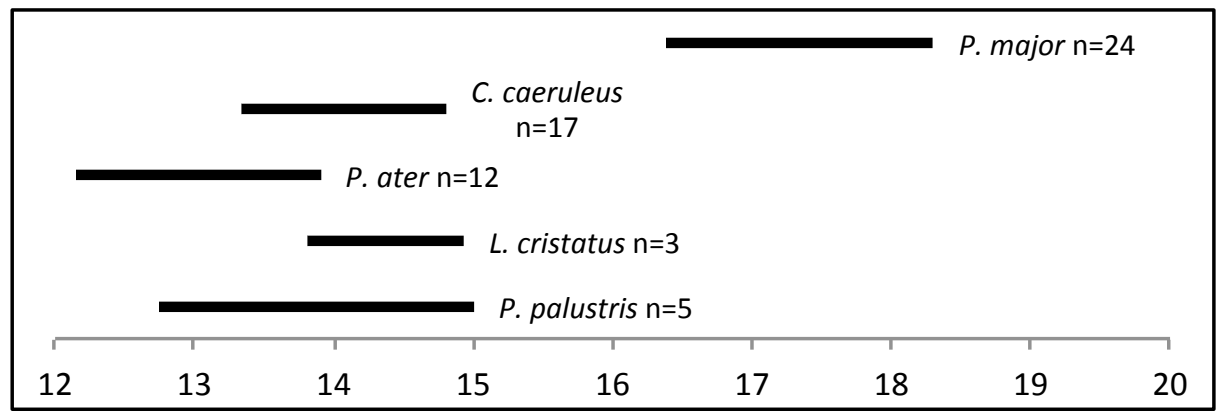

Figura 29. Longitud de los húmeros de las especies actuales de Paridae. Ejemplares procedentes de las colecciones del IMEDEA y el NHMT y de las publicaciones de Jánossy (1983), Moreno (1985) y Kessler (2013).

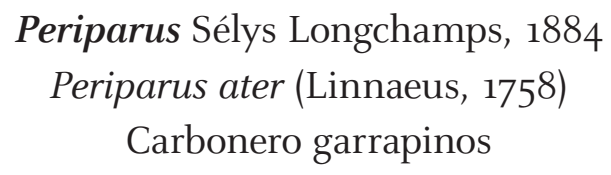

Material: 1 húmero (izquierdo). NMI: 1.

Distribución estratigráfica en es Pouàs: Pleistoceno superior (nivel 5 de la cuadrícula A3).

Distribución actual en el Paleártico occidental: cría en latitudes medias-altas y medias-bajas, desde clima boreal a mediterráneo. Es una especie sedentaria en el sur y el oeste de su área de distribución y en otras áreas es migrante de corta distancia, evitando cruzar amplias distancias por mar (Snow y Perrins 1998). Su presencia es accidental en Mallorca e Ibiza y no se observa en el resto de islas (López-Jurado 2011).

Registro fósil en el Paleártico occidental: se ha citado en un yacimiento del Pleistoceno inferior de Mallorca (Parus cf. ater, Alcover et al. 1981) y en el Pleistoceno medio de Hungría. Algo más frecuente en el Pleistoceno superior, se ha registrado en tres localidades del oeste de Europa: Mallorca (Seguí et al. 1997, único registro del Pleistoceno superior de 
Baleares), Francia y Reino Unido, así como en otras tres del centro de la región (Tyrberg 1998, 2008).

Comentarios: el de P. ater es el húmero de menor longitud de la familia, siendo también el más estilizado y el que presenta la cresta deltoidea más corta. A diferencia de Aegithalos y Remiz, P. ater y el fósil presentan una cresta deltoidea notablemente más larga. El húmero de Poecile palustris tiene una longitud (12,8-15 mm) ligeramente superior al fósil $(12,75 \mathrm{~mm})$ y al de $P$. ater (figura 29). No se ha dispuesto de material de comparación de esta especie, si bien según Jánossy, el húmero de $P$. palustris es menos grácil que el de $P$. ater y presenta un processus flexorius más ancho.

\section{Parus Linnaeus, 1758 \\ Parus cf. major \\ Carbonero común}

Material: 1 mandíbula y 1 húmero (izquierdo). Total: 2. NMI: 1.

Distribución estratigráfica en es Pouàs: Pleistoceno superior-Holoceno (cuadrícula A2, -110/-130 cm y cuadrícula A3, $-80 /-110 \mathrm{~cm})$.

Distribución actual en el Paleártico occidental: P. major está ampliamente distribuido, desde las latitudes más altas hasta cerca de las más bajas. Sus poblaciones son, en general, sedentarias aunque se dan movimientos altitudinales y migraciones de corta distancia en las poblaciones más norteñas (Snow y Perrins 1998). En Baleares se observan poblaciones sedentarias abundantes, excepto en Formentera (López-Jurado 2011).

Registro fósil en el Paleártico occidental: es la especie de la familia más frecuente en el registro, especialmente en el Pleistoceno superior. Aparece en el Pleistoceno inferior de España, Rumanía y Ucrania y en el registro del Pleistoceno medio solamente consta en Austria. Se ha citado en 14 yacimientos del Pleistoceno superior de Europa occidental y en 18 del resto de la región (Tyrberg 1998, 2008). En Baleares se ha identificado en un yacimiento del Pleistoceno inferior de Mallorca (Parus cf. major, Alcover et al. 1981).

Comentarios: la mandíbula identificada es un fragmento correspondiente a la sínfisis mandibular, que en P. major es la de mayor talla de esta familia. Tanto la mandíbula como el húmero son atribuibles a esta especie, si bien al tratarse de fragmentos, se ha optado por utilizar una nomenclatura abierta. 


\author{
Oriolidae Vigors, 1825 \\ (Figura 8, anexo) \\ Oriolus Linnaeus, 1766 \\ Oriolus oriolus (Linnaeus, 1758) \\ Oropéndola europea
}

Material: 1 húmero (izquierdo). NMI: 1.

Distribución estratigráfica en es Pouàs: Holoceno (cuadrícula D4).

Distribución actual en el Paleártico occidental: O. oriolus cría en latitudes medias y bajas de la región, tanto en zonas continentales como costeras. Se trata una especie migratoria, invernando en África subsahariana (Snow y Perrins 1998). En Baleares la población migrante es escasa excepto en Formentera donde es más abundante (López-Jurado 2011).

Registro fósil en el Paleártico occidental: esta especie solamente se ha identificado en yacimientos del Pleistoceno superior de la región. Al oeste de la misma se ha citado en seis yacimientos de Francia, Alemania, España e Italia (Tyrberg 1998, 2008). No hay ningún registro de la especie como fósil en Baleares.

Comentario: el húmero de O. oriolus es voluminoso, con una sola fosa, profunda y ligeramente neumatizada (Jánossy 1983). Presenta una longitud de 29,4 mm a 31,6 mm ( $\mathrm{n}=8$, IMEDEA y Moreno 1986). Las únicas especies de Passeriformes con húmeros de longitud similar son Melanocorypha calandra y Cyanopica cyanus, si bien su morfología es bastante diferente. A diferencia de M. calandra y C. cyanus, el húmero de Oriolus oriolus y el fósil son más curvos y robustos, presentan el tubérculo ventral más desarrollado, la cresta deltoidea más corta y la fosa ventral más profunda. El húmero de Lanius meridionalis presenta una longitud inferior y es proporcionalmente menos robusto que el de $O$. oriolus. Además, la cresta deltoidea en L. meridionalis es más estrecha, con un margen lateral externo de desarrollo recto, a diferencia de O. oriolus que presenta una cresta deltoidea extensa y de margen curvo.

\title{
Laniidae Swainson, 1824 \\ Lanius Linnaeus, 1758
}

(Figura 8, anexo)

\section{Cráneo y mandíbula}

El cráneo de los alcaudones es robusto, con el processus zygomaticus y el processus postorbitalis muy desarrollados, especialmente el primero. Presenta un foramen orbitonasale doble, y un par de fonticuli orbitales (Moreno 1986). 
El premaxilar es alto y muy robusto con un corpus ossis premaxillaris que en vista ventral es plano y presenta una impresión longitudinal en su parte central. La alimentación de los alcaudones, de hábitos depredadores, ha provocado un reforzamiento del premaxilar en todas las especies, pero especialmente en Lanius excubitor (Cuisin 1989).

La mandíbula, también muy robusta, presenta un processus coronoideus no muy desarrollado y situado en el borde dorsal mandibular. Por el contrario, el tuberculum pseudotemporale está más desarrollado, sobre todo en L. meridionalis en el que puede llegar a observarse un segundo tuberculum (Moreno 1986). La sínfisis mandibular es robusta y de aspecto triangular, con un ápice puntiagudo y un abultamiento en su parte dorsal.

No se ha identificado ningún resto de Lanius collurio en es Pouàs. El premaxilar de esta especie no presenta anfirrinia, está más comprimido lateralmente que el premaxilar de las otras especies y es el menos robusto de la familia. En la mandíbula de Lanius collurio, las ramas mandibulares son más bajas y los cóndilos articulares más pequeños que en los otros alcaudones. Por último, la sínfisis mandibular, al igual que el premaxilar, es más estrecha y menos robusta que la del resto de especies de la familia.

El premaxilar de Lanius minor $(\mathrm{C}=18,5-20 \mathrm{~mm}, \mathrm{n}=2$, Cuisin 1989) es más corto y ligeramente más robusto que el de L. meridionalis $(\mathrm{C}=20,05-22,3 \mathrm{~mm}, \mathrm{n}=7$, Moreno 1986), pero de talla superior al de L. collurio $(\mathrm{C}=15,7-17,2 \mathrm{~mm}, \mathrm{n}=10$, Moreno 1986) y Lanius senator $(\mathrm{C}=16,2-17,1 \mathrm{~mm}, \mathrm{n}=9$, Moreno 1986). Cuisin (1989) observa que L. minor presenta, en vista lateral, un tabique nasal óseo incompleto entre las narinas.

L. excubitor, taxón que tradicionalmente se contemplaba como una especie con 20 subespecies, (Vaurie 1959; Rand 1960), se separa actualmente en dos especies politípicas (Isenmann y Bouchet 1993; Lefranc y Worfolk 1997; Clements 2000; Harris 2000; Dickinson 2003; del Hoyo et al. 2008). Según esta clasificación, L. excubitor es la especie de distribución norteña, con varias subespecies, y L. meriodionalis es la especie a la que pertenecen las poblaciones al sur de Francia, también con varias subespecies. Incluso hay autores que contemplan algunas de estas subespecies como especies. Olsson et al. (2010) en base a análisis genéticos, discuten la incongruencia entre la taxonomía actual y sus resultados y proponen la existencia de 6 especies (en vez de dos) entre las que se encuentran L. excubitor y L. meridionalis.

Siguiendo las propuestas más aceptadas actualmente, los fósiles procedentes de Ibiza, previamente identificados como L. excubitor (Sondaar et al. 1995; Tyrberg 1998, 2008), se adscriben a L. meridionalis en este trabajo.

Todos los huesos de Laniidae identificados en este trabajo corresponden a L. senator y a L. meridionalis. Anteriormente, se había publicado la presencia de L. minor en Ibiza 
en base a material de es Pouàs (Alcover, com. pers.; Sondaar et al. 1995; Tyrberg 2008), si bien en este trabajo no se han encontrado evidencias de su presencia en el yacimiento. Algunos fragmentos e individuos juveniles dudosos han sido identificados a nivel genérico o con nomenclatura abierta.

\section{Húmero}

Al igual que el húmero de Oriolidae y Corvidae, el de Laniidae es el ejemplo típico de húmero con una sola fosa, que además en este caso se proyecta hacia el interior del caput humeri (Moreno 1986). El húmero de los alcaudones está más neumatizado que el de otros grupos de morfología similar y presenta un tubérculo ventral relativamente corto (Jánossy 1983). Wójcik (2002) destaca el aspecto redondeado de la epífisis proximal y la longitud de la cresta deltoidea, corta comparada con la anchura de la epífisis. Los taxones con el húmero morfométricamente más similar pertenecen a las familias Oriolidae, Bombycillidae y Alaudidae. El húmero de B. garrulus es más robusto que el de Laniidae y presenta un caput humeri mucho más desarrollado. Las diferencias con los húmeros de los aláudidos se detallan en la descripción de dicha familia y la talla, notablemente superior, de Oriolus oriolus (29,4-31,6 mm, n=8 [IMEDEA y Moreno 1986]) facilita su diferenciación.

El húmero de L. minor tiene una longitud de 24,6-26 mm (n=1, NHMT; n=8, Jánossy 1983), superior a la de L. senator y similar a L. meridionalis. Solamente se ha dispuesto de información bibliográfica y fotografías y medidas de ejemplares de museo como material de comparación de L. minor.

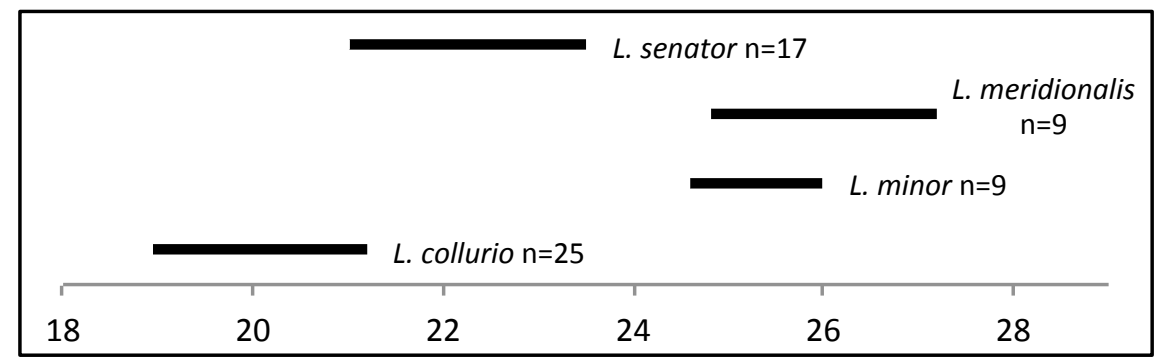

Figura 30. Longitud de los húmeros de las especies actuales de Laniidae. Ejemplares procedentes de las colecciones del IMEDEA y el NHMT y de los trabajos de Jánossy (1983) y Moreno (1986).

\section{Tarsometatarso}

Presenta un aspecto general largo y relativamente robusto, con una epífisis distal estrecha. Un rasgo muy característico de estos tarsometatarsos es la amplia separación entre la trochlea metatarsi III y la trochlea metatarsi $I V$, así como la gran longitud de esta última. El surco central de la trochlea metatarsi III, así como la propia trochlea, son más anchos que en otras familias.

Los taxones con tarsometatarsos biométricamente más similares corresponden a Alaudidae, Turdus, Oriolus, Sturnus, Montifringilla nivalis y Emberiza calandra. A diferencia de 
los tarsometatarsos de los cuatro primeros taxones, además de los rasgos descritos, los de Lanius presentan una epífisis distal proporcionalmente más estrecha. Los tarsometatarsos de Oriolus son menos estilizados que los de los alcaudones, especialmente su epífisis proximal que, al estar expandida lateralmente, es mucho más ancha. El tarsometatarso de Sturnus es más corto y robusto que el de Lanius. Al igual que el de E. calandra y $M$. nivalis, el tarsometatarso de Sturnus presenta una trochlea metatarsi II más desarrollada que el de Lanius.

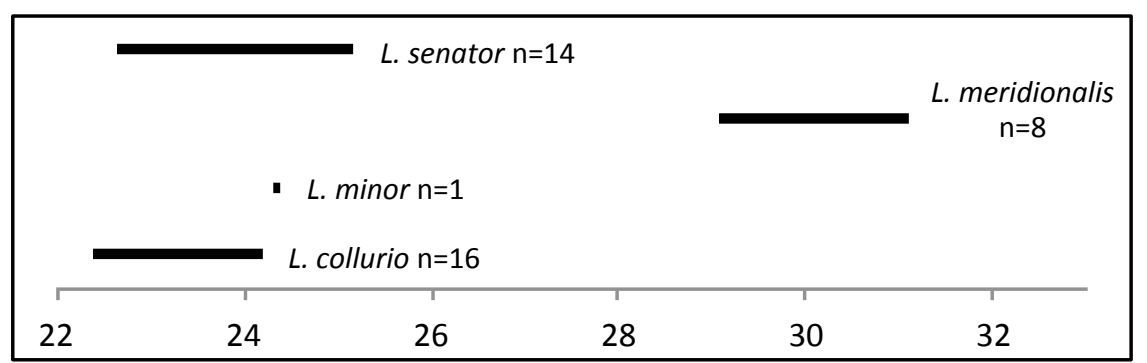

Figura 31. Longitud de los tarsometatarsos de las especies actuales de Laniidae. Ejemplares procedentes de las colecciones del IMEDEA y el NHMT y del trabajo de Moreno (1986).

Lanius meridionalis Temminck, 1820

Alcaudón real

Material: 2 cráneos, 2 mandíbulas, 8 húmeros (2 derechos, 6 izquierdos) y 1 tarsometatarso (izquierdo). Total: 13. NMI: 6 (basado en los húmeros).

Distribución estratigráfica en es Pouàs: Pleistoceno superior y Holoceno (niveles 1, 3 y 7 de la cuadrícula A3 y dos niveles de la cuadrícula D4).

Distribución actual en el Paleártico occidental: solamente se encuentra en el sudoeste de la región (sur de Francia, Península Ibérica y norte de África). Algunas poblaciones realizan migraciones parciales, pero principalmente son sedentarias (Snow y Perrins 1998). En Baleares es una especie muy escasa y sólo se observa como migrante e invernante en todas las islas, excepto en Menorca (López-Jurado 2011).

Registro fósil en el Paleártico occidental: si bien no hay ningún registro de L. meridionalis, L. excubitor se ha identificado en varios yacimientos del Pleistoceno superior de la región. Es común en Europa central (10 yacimientos) y en Europa occidental (siete yacimientos), mientras que en el este de la región solamente ha aparecido en Israel y Rusia. En el Pleistoceno medio e inferior solamente se ha citado en Israel (Tyrberg 1998, 2008). Si bien antiguamente se consideraba L. excubitor como la especie de Lanius de talla grande presente en la Península Ibérica y Baleares, en la actualidad se considera que estas poblaciones deben ser asignadas a L. meridionalis. 
L. meridionalis está presente en el registro del Pleistoceno superior de Mallorca (McMinn y Alcover 1992) y de Ibiza (Sondaar et al. 1995), citado como L. excubitor en ambos casos.

\section{Comentarios}

Cráneo: uno de los rasgos más característicos de esta especie es la anfirrinia, es decir, la presencia de dos pares de narinas (Olson 1989). L. meridionalis, L. excubitor y Pyrrhocorax pyrrhocorax, son las únicas especies de paseriformes europeos que presentan esta peculiaridad. El premaxilar es más largo y robusto que el de los otros lánidos y el processus frontalis premaxillare está más desarrollado que en los mismos. La talla y la robustez de las mandíbulas identificadas se ajustan inequívocamente a las de esta especie.

Húmero y tarsometatarso: como se observa en las figuras 30 y 31, la talla de estos huesos es superior en L. meridionalis que en las otras especies. Son más largos y robustos y por tanto fácilmente diferenciables. La talla de los húmeros se solapa parcialmente con la de los húmeros de L. minor, si bien no se han identificado otros restos que confirmen la presencia de esta especie.

Lanius senator Linnaeus, 1758

Alcaudón común

Material: 16 premaxilares, 50 mandíbulas, 372 húmeros (157 derechos, 215 izquierdos). Total: 438. NMI: 215 (basado en los húmeros).

Distribución estratigráfica en es Pouàs: Pleistoceno superior y Holoceno (del nivel 1 al 8 de la cuadrícula A3 y cuadrícula D4).

Distribución actual en el Paleártico occidental: cría al sur de la región, en el Mediterráneo, migrando en invernada al sur del Sáhara (Snow y Perrins 1998). Las poblaciones de Baleares, tanto estivales como migrantes, son más o menos abundantes en todas las islas (López-Jurado 2011).

Registro fósil en el Paleártico occidental: no se ha registrado en el Pleistoceno inferior de la región y es relativamente poco común en el Pleistoceno superior (Francia, España, Europa central e Israel). Se ha citado en yacimientos del Pleistoceno medio de Europa occidental (España, Francia e Italia) y en Israel (Tyrberg 1998, 2008). El único registro de Baleares corresponde a Ibiza (Sondaar et al. 1995).

\section{Comentarios}

Cráneo y mandíbula: el cráneo de esta especie es muy similar al de L. collurio, tanto que algunos autores (e.g., Moreno 1986) no encuentran caracteres diagnósticos claros para diferenciarlos. Sin embargo, como observa Cuisin (1989), el premaxilar está más desarro- 
llado en L. senator, es más robusto. Otras diferencias con el premaxilar de esta especie se han detallado en la descripción general del cráneo de Laniidae.

Húmero: el rango de longitud del húmero de la especie biométricamente más próxima, L. collurio, apenas se solapa con el de L. senator, de longitud superior (ver figura 30). En el húmero de L. senator, los tubérculos del processus supracondylaris dorsalis están situados más próximos a la diáfisis, a diferencia de L. collurio, en el que están ligeramente más separados. Además, el tubérculo interno en L. collurio es más estrecho que en L. senator. Por último, las epífisis del húmero de L. collurio son más pequeñas y menos robustas.

\section{Lanius cf. senator}

Material: 42 húmeros (22 derechos, 20 izquierdos) y 41 tarsometatarsos (21 derechos, 20 izquierdos). Total: 83 .

Comentarios: parte de los húmeros pertenecen a individuos juveniles o subadultos de talla similar a L. senator y otros se encuentran fragmentados. Para los tarsometatarsos se ha utilizado una nomenclatura abierta ya que los de L. senator, son biométricamente muy similares a L. collurio y L. minor (figura 31) y no se han encontrado rasgos morfológicos que permitan diferenciarlos.

\section{Lanius sp.}

Material: 1 premaxilar, 3 mandíbulas, 254 húmeros (128 derechos, 126 izquierdos) y 1 tarsometatarso (derecho). Total: 259.

Comentarios: el estado fragmentario de los huesos y/o su condición de juveniles, no permiten una identificación a nivel específico.

Corvidae Vigors, 1825

(Figuras 9, 10 y 11, anexo)

\section{Cráneo y mandíbula}

El aspecto robusto del cráneo es característico de esta familia, con un fuerte premaxilar y una disminución del número y tamaño de las fenestras y forámenes (sobre todo en las especies de mayor talla) propios de los paseriformes. En el cráneo de los córvidos, el foramen orbitonasale es simple (excepto en algún individuo de Pyrrhocorax pyrrhocorax) y el processus palatus maxillaris se encuentra ausente (Moreno 1986). El premaxilar, alargado y robusto, representa entre un 50\% y un 64\% de la longitud total del cráneo (Cuisin 1989). 
La mandíbula, igualmente robusta, presenta todos los procesos muy desarrollados y una sínfisis triangular. El tubérculo pseudotemporal no es de gran tamaño y el processus coronoideus aparece como un par de pequeñas prominencias de su borde dorsal (Moreno 1986).

Se han identificado cinco especies de esta familia a partir del material fósil del yacimiento de es Pouàs: Pyrrhocorax pyrrhocorax, Pyrrhocorax graculus, Corvus monedula, Corvus corone y Corvus corax. Todas presentan huesos de talla superior a los del resto de familias de Passeriformes estudiadas. Las diferencias morfológicas son escasas entre algunas de las especies citadas, si bien son suficientes como para permitir la identificación de la mayoría de los huesos (Tomek y Bocheński 2000). La talla de los huesos de C. corax, notablemente superior a la de las otras especies, permite identificarlos con facilidad.

\section{Húmero}

Los húmeros de los Corvidae se caracterizan por presentar una sola fossa pneumotricipitalis siempre bien desarrollada y que, en general, es más profunda en las especies de menor tamaño (Moreno 1986). En la epífisis proximal destaca una cresta deltoidea larga, un tubérculo ventral bien desarrollado y un caput humeri robusto. En la epífisis distal se observa un processus flexorius robusto, aunque no muy largo, y un processus supracondylaris dorsalis con dos tubérculos en su extremo proximal.

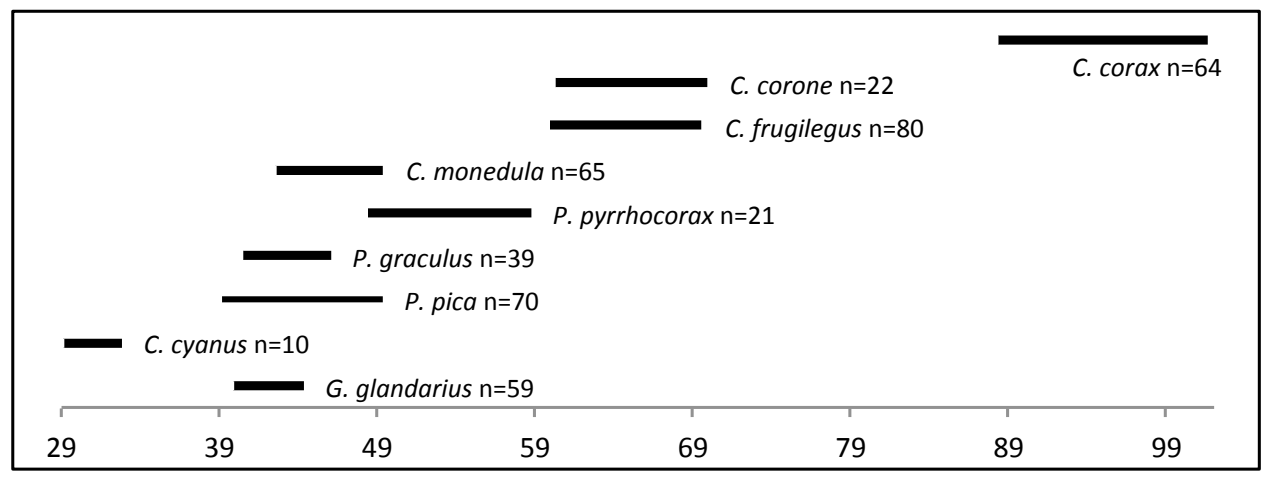

Figura 32. Longitud de los húmeros de las especies actuales de Corvidae. Ejemplares procedentes de la colección del IMEDEA y de los trabajos de Moreno (1986) y Tomek y Bocheński (2000).

\section{Tarsometatarso}

El tarsometatarso de los córvidos tiene un aspecto general recto y robusto. La epífisis distal es ancha y presenta la trochlea metatarsi III muy desarrollada. La trochlea metatarsi II se extiende lateralmente y la fossa metatarsi I está muy desarrollada. 


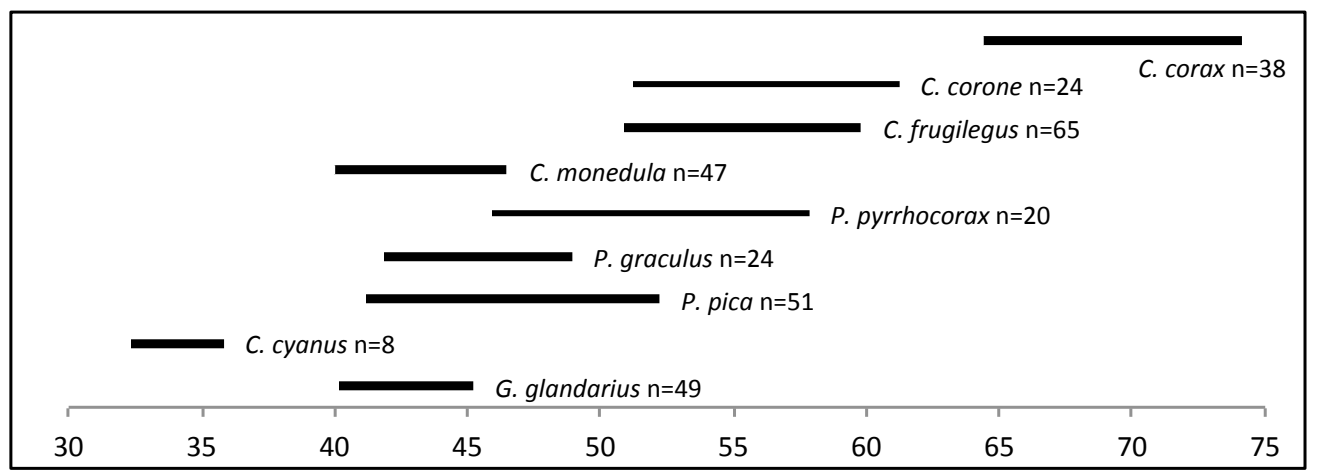

Figura 33. Longitud de los tarsometatarsos de las especies actuales de Corvidae. Ejemplares procedentes de la colección del IMEDEA y de los trabajos de Moreno (1986) y Tomek y Bocheński (2000).

\section{Pyrrhocorax Tunstall, 1760}

Cráneo y mandíbula: el cráneo de Pyrrhocorax presenta un processus zygomaticus bien desarrollado y un processus postorbitalis que es más grande en P. graculus. El premaxilar tiene un perfil superior curvo y un corpus ossis premaxillaris plano en vista ventral. En P. pyrrhocorax el premaxilar presenta dos pares de narinas (anfirrinia), mientras que en P. graculus y en el resto de paseriformes, excepto algunos Lanius, sólo presenta un par. El premaxilar de $C$. monedula es más alto y más ancho que el de las dos especies de Pyrrhocorax y presenta unas narinas más amplias que las de Pyrrhocorax. Además, en vista ventral, el corpus ossis premaxillaris es cóncavo en C. monedula, con una ancha depresión en forma de "U" (Tomek y Bocheński 2000).

La mandíbula de Pyrrhocorax es menos amplia que la de los otros córvidos (Tomek y Bocheński 2000) y presenta unas fenestras mandibulares más estrechas y alargadas que en las otras especies de la familia. El proceso coronoideo está muy poco desarrollado en P. graculus y ausente en P. pyrrhocorax.

Húmero: en el húmero de Pyrrhocorax destaca la gran amplitud de la fossa pneumotricipitalis y la robustez del epicóndilo dorsal. Las diferencias con el húmero de la especie morfométricamente más próxima, C. monedula, se detallan en la descripción de dicha especie.

Ulna: P. pyrrhocorax presenta una ulna notablemente más larga que las de C. monedula y $P$. graculus (Tomek y Bocheński 2000). Además, la ulna de P. pyrrhocorax es más robusta, sobre todo sus epífisis, que la de C. monedula y P. graculus.

Carpometacarpo: los carpometacarpos de $P$. pyrrhocorax son ligeramente más largos y más robustos, sobre todo su epífisis proximal, que los de C. monedula y P graculus (Tomek y Bocheński 2000). No se han observado diferencias morfológicas claras entre las tres especies. 
Fémur: a diferencia de C. monedula, la epífisis proximal del fémur de Pyrrhocorax en vista lateral presenta una cresta distal más larga. El fémur de P. pyrrhocorax es más largo y sus epífisis más anchas que los de P. graculus y C. monedula (Tomek y Bocheński 2000).

Tibiotarso: el tibiotarso de P. pyrrhocorax es notablemente más largo que el de $P$. graculus y C. monedula. A su vez, el de P. graculus es ligeramente más largo que el de $C$. monedula (Tomek y Bocheński 2000). Tanto el fémur como el tibiotarso de P. pyrrhocorax son más robustos, especialmente sus epífisis, que los de las otras dos especies.

Tarsometatarso: el aspecto más característico del tarsometatarso de Pyrrhocorax es la presencia de un segundo foramen vasculare distale, mientras que las otras especies de córvidos sólo presentan uno (Weesie 1988; Tomek y Bocheński 2000). Este segundo foramen se encuentra situado entre la trochlea metatarsi III y la trochlea metatarsi II, aproximadamente a la misma altura que el primero. A diferencia del tarsometatarso de C. monedula, la eminentia intercondylaris es unilobulada en Pyrrhocorax (Tomek y Bocheński 2000).

El tarsometatarso de P. pyrrhocorax presenta una longitud notablemente superior a la de los tarsometatarsos de C. monedula y $P$. graculus. A su vez, el de $P$. graculus es más largo que el de C. monedula (Tomek y Bocheński 2000).

\section{Pyrrhocorax graculus Linnaeus 1766 \\ Chova piquigualda}

Material: 2 mandíbulas, 13 húmeros (9 derechos, 4 izquierdos) y 1 tarsometatarso (izquierdo). Total: 16. NMI: 8 (basado en el húmero).

Distribución estratigráfica en es Pouàs: Pleistoceno superior y Holoceno (niveles del 4 al 8 de la cuadrícula A3 y cuadrícula A2).

Distribución actual en el Paleártico occidental: es una especie estrictamente montana que cría en latitudes medias de la región a altitudes elevadas, alcanzando hasta $3900 \mathrm{~m}$ de altitud en Marruecos. Excepto por los movimientos altitudinales, sus poblaciones son sedentarias (Snow y Perrins 1998). Su presencia en Baleares es accidental (López-Jurado 2011).

Registro fósil en el Paleártico occidental: esta especie es frecuente y está ampliamente representada en el registro fósil de la región. Sólo se ha identificado en dos localidades del Pleistoceno inferior, ambas en España. Más abundante en el Pleistoceno medio, se ha registrado en 16 localidades de Europa occidental, tres del centro y cuatro del este de la región. También se ha identificado en un yacimiento del Pleistoceno medio de Menorca (Seguí 1999). Es muy abundante en el Pleistoceno superior, habiéndose citado en más de 
200 yacimientos de Europa occidental (Tyrberg 1998, 2008), cinco de ellos en Mallorca (Mourer-Chauviré et al. 1975; Mourer-Chauviré et al. 1977; Florit y Alcover 1987; Seguí 1997; Seguí et al. 1997). Su presencia en Pleistoceno superior de Ibiza ya se había publicado anteriormente (Sondaar et al. 1995).

\section{Comentarios}

Mandíbula: la parte articular de la mandíbula de $P$. graculus es aplanada y poco angulosa en vista ventral. A diferencia de lo que ocurre en P. pyrrhocorax, en P. graculus el processus medialis mandibulae presenta una superficie más plana y con la sínfisis mandibular corta y más aplanada en vista dorsal. Además, el processus retroarticularis es plano y redondeado en la mandíbula de P. graculus, a diferencia del de la mandíbula de C. monedula (Tomek y Bocheński 2000).

Húmero: el húmero de esta especie es notablemente más corto que el de P. pyrrhocorax. En la epífisis distal, el processus flexorius tiene menor superficie que el de P. pyrrhocorax (en vista lateral). Tomek y Bocheński (2000) observan que, en el processus supracondylaris dorsalis de $P$. graculus, el tubérculo externo (el más alejado de la diáfisis) es más prominente que el interno, al contrario que en $P$. pyrrhocorax. Las diferencias con el húmero de $C$. monedula se detallan en la descripción de dicha especie. Pica pica y Garrulus glandarius presentan un húmero de longitud similar a P. graculus (figura 32). Sin embargo, la robustez del húmero, tanto de la diáfisis como de las epífisis, es muy superior en P. graculus.

Tarsometatarso: presenta los dos foramina vascularia distales y, en la epífisis proximal, la eminentia intercondylaris es unilobulada. Su longitud (45,3 $\mathrm{mm}$ ) y robustez corresponden a las de P. graculus y son inferiores a las que presenta el tarsometatarso de P. pyrrhocorax (figura 33).

\section{Pyrrhocorax pyrrhocorax (Linnaeus, 1758)}

Chova piquirroja

Material: 14 cráneos, 19 premaxilares, 180 mandíbulas (177 fragmentos, 3 completas), 147 húmeros (73 derechos, 74 izquierdos), 75 tarsometatarsos ( 38 derechos, 37 izquierdos), 80 ulnas (40 derechas, 40 izquierdas), 116 carpometacarpos ( 51 derechos, 65 izquierdos), 92 fémures ( 42 derechos, 50 izquierdos), 83 tibiotarsos (41 derechos, 42 izquierdos), 61 coracoides (31 derechos, 30 izquierdos), 18 radios (14 derechos, 4 izquierdos), 15 escápulas (9 derechas, 6 izquierdas), 32 falanges, 2 sinsacros y un esqueleto postcraneal. Total: 935 . NMI: 88 (basado en las mandíbulas).

Distribución estratigráfica en es Pouàs: Pleistoceno superior y Holoceno (niveles del 1 al 8 de la cuadrícula A3 y cuadrícula D4). 
Distribución actual en el Paleártico occidental: sus poblaciones no están confinadas a ambientes montanos, como es el caso de P. graculus, sino que crían a menor altitud y en latitudes medias-bajas de la región. Es una especie principalmente sedentaria (Snow y Perrins 1998). Su presencia es accidental en Menorca e Ibiza y es muy escasa en Mallorca como invernante (López-Jurado 2011).

Registro fósil en el Paleártico occidental: al igual que P. graculus, P. pyrrhocorax está ampliamente distribuida y es frecuente en los yacimientos del Pleistoceno superior en toda la región. Más escasa en el Pleistoceno medio, se ha encontrado en ocho yacimientos de Europa occidental. En el Pleistoceno inferior solamente se ha citado en cuatro localidades, dos españolas y dos de Bulgaria (Tyrberg 1998, 2008). Se ha identificado esta especie en siete yacimientos de Baleares. Cinco de ellos, uno del Pleistoceno inferior (Pyrrhocorax cf. pyrrhocorax, Alcover et al. 1981) y cuatro del Pleistoceno superior, corresponden a localidades de Mallorca (Mourer-Chauviré et al. 1977; Florit y Alcover 1987; Seguí 1997; Seguí et al. 1997). También se ha identificado en un yacimiento del Pleistoceno medio de Menorca (Reumer 1982) y en es Pouàs (Florit el al. 1989).

\section{Comentarios}

Cráneo y mandíbula: el premaxilar es muy característico y se diferencia fácilmente del de las otras especies de la familia ya que el corpus ossis premaxillaris es mucho más alargado, estrecho, y en vista ventral, es totalmente plano. El processus frontalis premaxillare es muy ancho. Presenta dos pares de pequeñas narinas (anfirrinia), a diferencia de las otras especies que sólo presentan un par, que además son más amplias. El premaxilar de P. graculus es mucho más corto, presenta un par de narinas de tamaño medio y un processus frontalis premaxillare más fino que el de $P$. pyrrhocorax.

Mandíbula: el processus medialis mandibulae es ondulado. Su superficie caudal y la del processus retroarticularis, son estrechas y se unen al final en ángulo recto (Tomek y Bocheński 2000). La sínfisis mandibular, especialmente hacia el ápice, es muy estrecha y alargada, a diferencia de las de $P$. graculus y $C$. monedula, en los que es mucho más corta. En vista dorsal, en $P$. pyrrhocorax la superficie de la sínfisis es plana hacia el ápice y ligeramente cóncava hacia el extremo caudal, aunque mucho menos cóncava que en las dos especies mencionadas.

Húmero: además de las diferencias con $P$. graculus mencionadas anteriormente, el margen externo de la cresta bicipital es más ancho, en P. pyrrhocorax. El margen interno de la cresta deltoidea del húmero de $P$. pyrrhocorax, en vista craneal, es más robusto y se encuentra más separado del margen externo, de forma que la anchura de la cresta es mayor en esta especie que en $P$. graculus. Por último, la incisura capitis es más notable en $P$. pyrrhocorax que en $P$. graculus.

Análisis estadísticos: se han estudiado las diferencias de tamaño de los fósiles de $P$. pyrrhocorax de es Pouàs en comparación con una muestra de ejemplares actuales. Para ello, 
se ha analizado la biometría de cinco huesos (húmero, carpometacarpo, fémur, tibiotarso y tarsometatarso), ya que no se dispone de una muestra del tamaño necesario para el resto de huesos. Para el análisis se han tomado seis medidas: longitud total (L), anchura de la epífisis proximal (AEP), anchura de la epífisis distal (AED), anchura de la diáfisis (AD) e índice de robustez (IR).

Tras el análisis estadístico (ANOVA de un factor) de las diferencias de talla entre los individuos actuales y los de es Pouàs, solamente se observan diferencias significativas en una medida del húmero (AEP) y en dos del carpometacarpo (L y AEP) (ver tablas 37-52, anexo). La muestra de individuos actuales de comparación es de tres ejemplares, el mínimo necesario para poder realizar este análisis. Dada la escasez de la muestra, se han contrastado dichos resultados con los obtenidos mediante un test no paramétrico, más robusto para muestras pequeñas. Según los resultados de este test, solamente hay diferencias significativas entre los individuos actuales y los fósiles en dos medidas del carpometacarpo (AEP y AD).

Los resultados del ANOVA, así como los del test no paramétrico, no permiten concluir que los individuos actuales sean diferentes a los fósiles, si bien sería necesario repetir el análisis disponiendo de un mayor número de individuos actuales de comparación.

\section{Pyrrhocorax sp.}

Material: 1 cráneo, 6 mandíbulas, 2 húmeros (derechos), 97 tarsometatarsos (45 derechos, 52 izquierdos), 7 ulnas ( 3 derechas, 4 izquierdas), 7 carpometacarpos (6 derechos, 1 izquierdo), 5 fémures (1 derecho, 4 izquierdos), 15 tibiotarsos (4 derechos, 11 izquierdos), 9 coracoides (4 derechos, 5 izquierdos) y 4 escápulas (1 derecha, 3 izquierdas). Total: 153.

Comentarios: debido a la condición de juveniles y/o al estado fragmentario de los fósiles, se adoptado una nomenclatura abierta para este material.

\section{cf. Pyrrhocorax}

Material: 3 cráneos, 1 premaxilar, 30 mandíbulas, 8 húmeros (4 derechos, 4 izquierdos), 3 tarsometatarsos ( 2 derechos, 1 izquierdos), 13 ulnas (5 derechas, 8 izquierdas), 51 carpometacarpos (23 derechos, 28 izquierdos), 24 fémures (9 derechos, 15 izquierdos), 46 tibiotarsos (27 derechos, 19 izquierdos), 21 coracoides (14 derechos, 7 izquierdos), 2 radios (izquierdos), 16 escápulas (10 derechas, 6 izquierdas), 8 esternones, 2 fúrculas, 4 sinsacros, 11 pelvis y 1 falange. Total: 244 . 
Comentarios: el estado del material junto con la similitud morfológica y biométrica entre las dos especies de Pyrrhocorax y, en este caso, también con C. monedula, impiden una determinación más precisa.

\section{Corvus Linnaeus, 1758}

Cráneo y mandíbula: las cuatro especies de este género presentan una morfología craneal muy similar, si bien son biométricamente diferenciables. Moreno (1986) propone que los individuos con $\mathrm{C}$ menor de $40 \mathrm{~mm}$ pertenecen a C. monedula, los individuos con $\mathrm{C}$ mayor de $60 \mathrm{~mm}$ pertenecen C. corax y medidas de $\mathrm{C}$ entre $60 \mathrm{~mm}$ y $40 \mathrm{~mm}$ pertenecen a C. corone o a Corvus frugilegus. El resto de los huesos identificados también se diferencian fácilmente en base a la biometría. Las diferencias con Pyrrhocorax se detallan en el apartado correspondiente a dicho género y en la descripción de C. monedula.

\section{Corvus monedula Linnaeus, 1758 \\ Grajilla occidental}

Material: 1 mandíbula, 2 húmeros (1 derecho, 1 izquierdo) y 3 tarsometatarsos (2 derechos, 1 izquierdo). Total: 6. NMI: 2 (basado en los tarsometatarsos).

Distribución estratigráfica en es Pouàs: Pleistoceno superior y Holoceno (niveles 1 y 3 de la cuadrícula A3 y cuadrícula A4 [-70/-100 cm]).

Distribución actual en el Paleártico occidental: se trata de una especie ampliamente distribuida que cría en latitudes altas y medias de la región, desde clima boreal hasta mediterráneo. De residente a migratoria, la zona de invernada se solapa casi por completo con la de cría (Snow y Perrins 1998). Su presencia en Baleares es accidental en Mallorca y no se observa en el resto de islas (López-Jurado 2011).

Registro fósil en el Paleártico occidental: es muy abundante en el registro de toda la región. Se ha citado en más de 150 yacimientos del Pleistoceno superior y en más de 20 del Pleistoceno medio de Europa. En el Pleistoceno inferior solamente se ha encontrado en localidades de España, República Checa e Israel (Tyrberg 1998, 2008). En Baleares se ha identificado en un yacimiento del Pleistoceno superior de Mallorca (Mourer-Chauviré et al. 1977) y ya se conocía su presencia en el Pleistoceno superior de Ibiza (Sondaar et al. 1995).

\section{Comentarios}

Mandíbula: en la mandíbula, más amplia y robusta que la de Pyrrhocorax, la superficie caudal de la parte articular es plana. El margen caudal entre el processus medialis mandibulae y el processus retroarticularis es angular o se curva gradualmente. La cresta que 
presenta el processus retroarticularis en vista ventral se dobla lateralmente (Tomek y Bocheński 2000). Por último, la sínfisis mandibular es triangular y cóncava en vista dorsal.

Húmero: en el húmero de C. monedula la fossa pneumotricipitalis es mucho más cerrada, menos amplia, que en Pyrrhocorax. Además, el condylus dorsalis humeri es notablemente menos robusto que en Pyrrhocorax. Por último, en el húmero de C. monedula el processus flexorius, en vista lateral, es más corto y tiene menor superficie que en el de Pyrrhocorax.

Tarsometatarso: el tarsometatarso de C. monedula, a diferencia del de Pyrrhocorax, presenta solamente un foramen vasculare distale. Además, la eminentia intercondylaris tiene un extremo doble o bilobulado en C. monedula, mientras que en $P$. pyrrhocorax y $P$. graculus es simple. El tarsometatarso de $P$. pyrrhocorax es notablemente más grande que el de $C$. monedula, que es biométricamente más similar a $P$. graculus. A diferencia del tarsometatarso de P. graculus, la trochlea metatarsi II y la trochlea metatarsi III están más desarrolladas en C. monedula (Louchart 2002).

\section{Corvus corone Linnaeus, 1758}

Corneja negra

Material: 1 carpometacarpo (derecho). NMI: 1.

Distribución estratigráfica en es Pouàs: Pleistoceno superior (nivel 5 de la cuadrícula A3).

Distribución actual en el Paleártico occidental: se trata de una especie ampliamente distribuida en toda la región. Cría desde zonas subárticas hasta el Mediterráneo en todo el rango latitudinal de la misma. Varía de migratoria en el norte de su área de distribución a sedentaria en el sur y el oeste de la misma (Snow y Perrins 1998). Su presencia en Baleares es accidental en Mallorca e Ibiza y no se observa en el resto de islas (López-Jurado 2011).

Registro fósil en el Paleártico occidental: no se ha encontrado en el Pleistoceno inferior y es una especie escasa en el Pleistoceno medio de la región (Alemania, España, Francia, Italia, Croacia y República Checa). Muy abundante en el Pleistoceno superior de toda la región (Tyrberg 1998, 2008), se ha identificado en un yacimiento del Pleistoceno superior de Mallorca (McMinn y Alcover 1992) y en Ibiza (Corvus cf. corone, Sondaar et al. 1995).

Comentarios: el carpometacarpo de C. corone es muy similar al de C. frugilegus, si bien Tomek y Bocheński (2000) describen algunas diferencias osteológicas que permiten diferenciarlos. En la parte distal del os metacarpale minus, en vista dorsal, hay una depresión que es mucho más profunda en el fósil y en C. corone. A diferencia de C. frugilegus, el sulcus tendinis, en su parte distal es más notable, estrecho y profundo en el fósil y en C. corone. 


\section{Corvus corax Linnaeus, 1758}

Cuervo

Material: 68 cráneos, 124 premaxilares, 338 mandíbulas (321 fragmentos, 17 completas), 770 húmeros (379 derechos, 391 izquierdos), 527 tarsometatarsos (268 derechos, 259 izquierdos), 542 ulnas ( 286 derechas, 256 izquierdas), 426 carpometacarpos (231 derechos, 195 izquierdos), 498 fémures (258 derechos, 240 izquierdos), 521 tibiotarsos (257 derechos, 264 izquierdos), 319 coracoides (167 derechos, 152 izquierdos), 186 radios (93 derechos, 93 izquierdos), 212 escápulas (115 derechas, 97 izquierdas), 147 falanges, 103 esternones, 77 fúrculas, 97 sinsacros 91 pelvis, 5 cuadrados y 6 esqueletos postcraneales. Total: 5057 . NMI: 280 (basado en los húmeros: 276 más 4 húmeros derechos procedentes del material asociado).

Distribución estratigráfica en es Pouàs: Pleistoceno superior y Holoceno (niveles del 1 al 8 de la cuadrícula A3 y varios niveles de la cuadrícula A4).

Distribución actual en el Paleártico occidental: tiene un área de distribución amplísima, criando prácticamente en toda la región. Es una especie básicamente sedentaria, si bien las poblaciones más norteñas pueden desplazarse al Sur en invierno (Snow y Perrins 1998). La población sedentaria de Baleares es escasa en todas las islas. Esta especie ha dejado de criar recientemente en Formentera y se encuentra al borde de la extinción en Ibiza donde, al igual que en Mallorca y Menorca, ha sufrido controles poblacionales recientes por parte de la administración (López-Jurado 2011, 2012).

Registro fósil en el Paleártico occidental: el cuervo es muy similar a C. monedula en cuanto a su distribución y abundancia en el Pleistoceno medio y superior. En el Pleistoceno inferior se ha registrado únicamente en Rumanía e Israel (Tyrberg 1998, 2008). Su presencia en es Pouàs ya se había publicado anteriormente, primero como Corvus antecorax (Florit el al. 1989) y más tarde como Corvus corax (Alcover com. pers.; Sondaar et al. 1995; McMinn et al. 2005). También se ha identificado en un yacimiento del Pleistoceno superior de Mallorca (Seguí 1996), si bien hay dudas al respecto (ver discusión).

\section{Comentarios}

Cráneo y mandíbula: en el cráneo, el processus zygomaticus y el processus postorbitalis están bien desarrollados, apareciendo además en el orbitosfenoides un par de crestas (crestas orbitosfenoidales) que tienden a ser más grandes que en las especies de Corvidae de menor talla. Sólo presenta un fonticulus orbitale, el ventral, y en lugar del fonticulus orbitale dorsal aparece un pequeño orificio. Por último, la distancia interorbitaria alcanza valores muy elevados en esta especie (Moreno 1986). 
El premaxilar, de gran tamaño, es el de mayor longitud de la familia y presenta unas narinas también muy amplias y elípticas. El corpus ossis premaxillaris es muy robusto y ligeramente cóncavo en vista ventral.

El aspecto de la mandíbula sigue el patrón general de los paseriformes. Es robusta con unas ramas mandibulares relativamente altas mientras que en la parte articular, el processus retroarticularis y el processus medialis mandibulae no son muy notables.

Húmero y otros huesos del esqueleto postcraneal: el húmero presenta un aspecto general robusto, con una fossa pneumotricipitalis bien desarrollada que normalmente presenta un canal neumático relativamente estrecho en comparación con el tamaño de la fosa.

Al igual que el húmero, el resto de huesos largos del esqueleto postcraneal de Corvus corax responden al patrón general de la familia y resultan muy fáciles de identificar, ya que presentan una talla notablemente superior a la del resto de especies de Corvidae.

Análisis estadísticos: todos los huesos identificados presentan una talla notablemente inferior respecto a los de los individuos actuales de comparación. Se han analizado las diferencias biométricas, entre los individuos de es Pouàs y los actuales, de seis huesos (húmero, ulna, carpometacarpo, fémur, tibiotarso y tarsometatarso) de Corvus corax. Del resto de huesos no se dispone de una muestra del tamaño necesario para su comparación.

Los resultados del análisis estadístico (ANOVA) muestran diferencias significativas en las medidas de todos los elementos comparados, excepto en el índice de robustez (IR) del húmero, el fémur y el tarsometatarso (ver tablas 37-52, anexo).

Estos resultados confirman que los individuos de Corvus corax de es Pouàs son significativamente más pequeños que los de las poblaciones actuales, si bien la robustez de algunos de sus huesos no varía significativamente entre los fósiles y los actuales.

\section{cf. Corvus}

Material: 2 cráneos, 1 premaxilar, 2 húmeros (izquierdos), 3 tarsometatarsos (1 derecho, 2 izquierdos) y 2 ulnas (1 derecha, 1 izquierda). Total: 10. 
Comentarios: algunos de estos restos son atribuibles a Corvus monedula o a especies de córvidos de talla similar aunque, debido a su estado, se ha optado por utilizar una nomenclatura abierta. Otros restos son muy similares a C. corax, si bien debido a su condición de juveniles no se puede realizar una identificación más precisa.

\title{
Corvidae indeterminados
}

Material: 14 mandíbulas, 17 húmeros (7 derechos, 10 izquierdos), 3 tarsometatarsos (1 derecho, 2 izquierdos), 2 carpometacarpos (izquierdos), 3 fémures (2 derechos, 1 izquierdo) у 1 tibiotarso (izquierdo). Total: 40.

Comentarios: debido al estado fragmentario de los huesos y/o a su condición de juveniles, no es posible realizar una identificación más precisa.

\author{
Sturnidae Vigors, 1825 \\ Sturnus Linnaeus, 1758
}

(Figura 12, anexo)

\section{Cráneo y mandíbula}

El premaxilar de Sturnus es extremadamente aplanado en comparación con el de la mayoría de especies de paseriformes. Este carácter es muy notable, tanto en vista dorsal como en vista ventral, ya que el corpus ossis premaxillaris en vista ventral presenta una superficie plana, en vez de cóncava como en la mayor parte de los paseriformes. El processus frontalis premaxillare es robusto, estrechándose hacia su parte caudal, a diferencia del de Turdus y Monticola, de anchura constante.

La mandíbula es muy característica, con un ángulo mandibular muy desarrollado y una sínfisis mandibular muy plana. El cóndilo articular presenta un processus retroarticularis muy desarrollado, el más grande de los tres que forman la pars caudalis. Todos estos caracteres permiten diferenciar la mandíbula de Sturnus de la de taxones de talla similar como Turdus y Monticola. Además, la sínfisis mandibular es más aguda en Monticola mientras que en Sturnus es notablemente más ancha. A diferencia de Sturnus, tanto en Monticola como en Turdus la sínfisis es cóncava en vista dorsal.

\section{Húmero}


Jánossy (1983) incluye al de Sturnus en el grupo de húmeros con dos fosas profundas y totalmente separadas entre sí. Proximalmente, es más estrecho que los húmeros de las especies de Turdus de talla similar, y el caput humeri es relativamente alto. En la epífisis distal, el processus supracondylaris dorsalis es también relativamente alto.

La dificultad para la identificación del húmero de Sturnus se debe a su gran similitud con el de Turdus. Aparte de la biometría, que solamente permite diferenciarlo de las especies más grandes de Turdus, existen algunas diferencias morfológicas. En primer lugar, el borde externo de la cresta deltoidea transcurre más paralelo a la diáfisis en el húmero de Sturnus. La extensión dorsal de dicha cresta es mayor, tiene mayor superficie, que en Turdus. En segundo lugar, el margen externo de la cresta bicipital, desde la fosa ventral hasta la diáfisis, es notablemente más estrecho en Sturnus. Y por último, como observan Seguí et al. (1997), la barra medial en Turdus se ve como una superficie plana, en vista caudoventral, mientras que en Sturnus hay cierto grado de inclinación dando una forma diferente a las fosas.

Otras diferencias con los húmeros de Turdus y Monticola se han incluido en la descripción de dichos géneros.

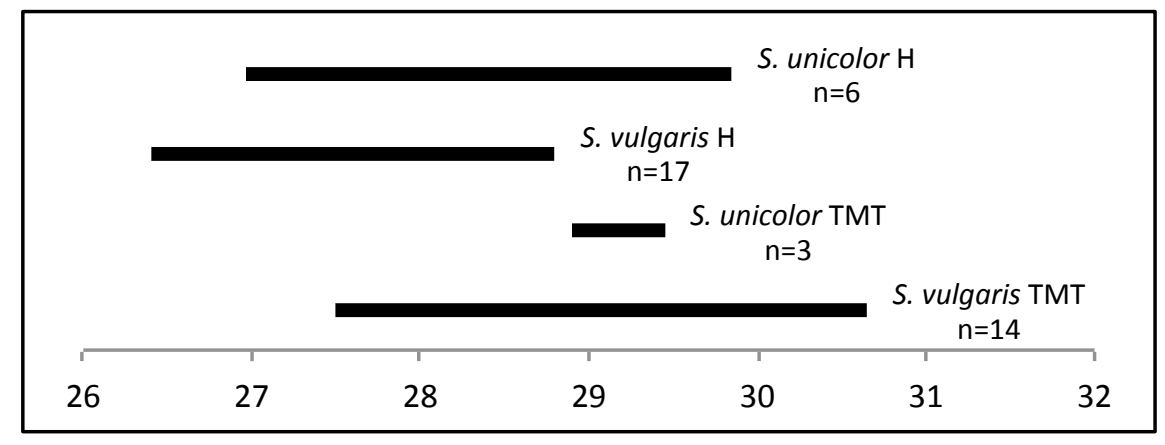

Figura 34. Longitud de los húmeros y tarsometatarsos de las especies actuales de Sturnidae. Ejemplares procedentes de la colección del IMEDEA y de los trabajos de Jánossy (1983) y Moreno (1986).

Sturnus sp.

Material: 1 premaxilar, 12 mandíbulas y 5 húmeros (2 derechos, 3 izquierdos). Total: 18. NMI: 6 (basado en las mandíbulas).

Distribución estratigráfica en es Pouàs: Pleistoceno superior (Niveles 4, 6 y 7 de la cuadrícula A3).

Distribución actual en el Paleártico occidental: Sturnus unicolor se encuentra únicamente en el Mediterráneo occidental y sus poblaciones son sedentarias o migrantes parciales de corta distancia. Sturnus vulgaris cría en latitudes altas y medias de la región, donde está ampliamente distribuido. Las poblaciones del norte y el este de la región son migrantes, las del sur y el oeste de la misma son sedentarias o parcialmente migrantes 
(Snow y Perrins 1998). En Baleares Sturnus unicolor es sedentario escaso en Menorca y accidental en Mallorca e Ibiza, mientras que Sturnus vulgaris cuenta con poblaciones invernantes y migrantes abundantes en todas las Baleares (López-Jurado 2011).

Registro fósil en el Paleártico occidental: Sturnus unicolor solamente se ha identificado en el Pleistoceno superior de Francia y, con reservas (Sturnus cf. unicolor), en un yacimiento en España y dos en el Reino Unido. Sin embargo, Sturnus vulgaris es muy abundante en el Pleistoceno superior, apareciendo en más de 30 yacimientos del oeste de la región (Tyrberg 1998, 2008). En Baleares solamente hay un registro del género correspondiente al Pleistoceno superior (Sturnus sp., Seguí et al. 1997).

Comentarios: el premaxilar, la mandíbula y el húmero son biométricamente similares en ambas especies y no se han encontrado diferencias morfológicas inequívocamente diagnósticas entre las mismas en este trabajo ni en la bibliografía (e.g., Moreno 1986; Weesie 1988; Cuisin 1989; Seguí et al. 1997; Louchart 2002). Por tanto, no ha sido posible la determinación a nivel específico. Algunos ejemplares fósiles presentan un tamaño superior al de la mayoría de los $S$. vulgaris actuales de comparación, asemejándose biométricamente a S. unicolor.

Passeridae Illiger, 1811

(Figura 12, anexo)

\section{Cráneo y mandíbula}

El cráneo de las especies de Passeridae presenta un par de crestas orbitosfenoidales, un solo fonticulus orbitale y un foramen orbitonasale simple (Moreno 1985). El processus zygomaticus y el processus postorbitalis están muy desarrollados, y el primero se encuentra curvado hacia la base, a diferencia de Fringillidae, en los que es recto (Cuisin 1989).

El premaxilar de Passeridae es similar al de Fringillidae. Ambas familias tienen picos de tipo granívoro. Sin embargo, el de Passeridae es robusto, con unas narinas cortas y redondeadas, a diferencia del de Fringillidae, con narinas en general más alargadas y elípticas (Bock 1964). El corpus ossis premaxillaris en vista ventral presenta dos crestas poco marcadas, longitudinales y paralelas entre sí que ocupan la parte central del mismo, a diferencia de Fringillidae cuyas crestas son más o menos convergentes en el ápice. Por último, el corpus ossis premaxillaris en vista ventral es más cóncavo en general en los fringílidos, mientras que en los paséridos es más plano.

La mandíbula, también robusta, presenta una sínfisis ancha y triangular y unas fenestras mandibulares pequeñas. En cada hemimandíbula aparecen un tuberculum pseudotemporale bien desarrollado y dos processus coronoidei. El proceso anterior es más ancho 
que el posterior, mientras que en los Fringillidae ambas estructuras son de tamaño similar (McMinn y Alcover 1992). En la zona articular destaca un processus medialis mandibulae muy desarrollado.

\section{Húmero}

En la epífisis proximal del húmero de los paséridos se observan dos fosas bien desarrolladas, con una barra medial reducida (Bock 1962; Jánossy 1983). La cresta bicipital está poco extendida ventralmente, a diferencia de lo que se observa en Emberizidae. En la epífisis proximal destaca la cresta deltoidea, muy corta (más que en Emberizidae, Motacillidae y Fringillidae) excepto en Montifringilla nivalis, en la que tiene una longitud notable, muy superior a la que presenta el resto de especies de la familia. Las diferencias con Fringillidae se detallan en la descripción de dicha familia.

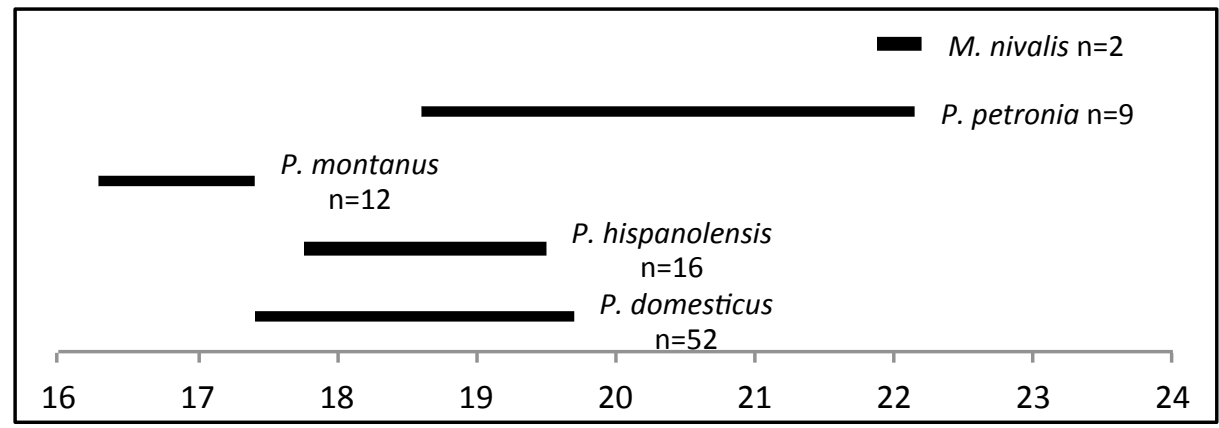

Figura 35. Longitud de los húmeros de las especies actuales de Passeridae. Ejemplares procedentes de las colecciones del IMEDEA y el NHMT y de las publicaciones de Jánossy (1983), Moreno (1985) y Wójcik (2002).

Passer Brisson, 1760

Passer domesticus (Linnaeus, 1758)

Gorrión común

Material: 1 premaxilar y 1 húmero (derecho). Total: 2. NMI: 1.

Distribución estratigráfica: Holoceno (cuadrícula A4, -110/-120 cm).

Distribución actual en el Paleártico occidental: $P$. domesticus se encuentra en toda la región, excepto en algunas islas atlánticas, zonas muy áridas de norte de África y la franja ártica. La mayoría de las poblaciones son sedentarias (Snow y Perrins 1998). Se observan poblaciones sedentarias abundantes en todas las Baleares (López-Jurado 2011).

Registro fósil en el Paleártico occidental: es una especie relativamente escasa en el registro, especialmente si se compara con su distribución actual. No hay ningún registro del Pleistoceno inferior y sólo se ha citado en el Pleistoceno medio de Francia. En el Pleistoceno superior, se ha citado en siete localidades del este de la región y ocho del oeste (Tyrberg 1998, 2008). Se ha identificado en un yacimiento del Pleistoceno superior de Mallorca, 
si bien se trata de una determinación imprecisa (cf. P. domesticus/hispanolensis, Seguí et al. 1997). Su presencia en Ibiza, se había publicado anteriormente (Sondaar et al. 1995).

\title{
Comentarios
}

Cráneo: al igual que en el resto de especies del género, el premaxilar carece de processus palatinus premaxillaris. La longitud del culmen (Moreno 1985) en esta especie (12,7-14 $\mathrm{mm}, \mathrm{n}=12)$ es mayor que la de Passer montanus (10,3-11,4 mm, $\mathrm{n}=10)$, y menor que la de Passer hispanolensis (13,9-15,1 mm, n=11). El premaxilar fósil mide 12,9 mm.

Tchernov (1962) describe una especie procedente del Pleistoceno superior de Israel, Passer predomesticus, que según el autor sería el predecesor del actual P. domesticus. El premaxilar de es Pouàs es de talla superior al de $P$. predomesticus y no presenta las características descritas por el autor para dicha especie.

Húmero: siguiendo las observaciones de Jánossy (1983), el húmero de P. domesticus es estrecho, en especial la epífisis distal, y presenta dos fosas profundas. A diferencia de la especie morfométricamente más similar, Passer hispanolensis, la fosa dorsal es más amplia y menos redondeada en $P$. domesticus.

\author{
Petronia Kaup, 1829 \\ Petronia petronia (Linnaeus, 1766) \\ Gorrión chillón
}

Material: 1 cráneo, 20 premaxilares y 11 mandíbulas. Total: 32. NMI: 20 (basado en los premaxilares).

Distribución estratigráfica: Pleistoceno superior y Holoceno (del nivel 1 al 8 de la cuadrícula A3).

Distribución actual en el Paleártico occidental: se trata de una especie sedentaria que cría en latitudes medias-bajas de la región (Snow y Perrins 1998). Las poblaciones sedentarias de Ibiza y Formentera son más o menos abundantes, mientras que la de Mallorca es escasa y en Menorca su presencia es accidental (López-Jurado 2011).

Registro fósil en el Paleártico occidental: es una especie escasa en el registro. Aparece en el Pleistoceno inferior de España y en el Pleistoceno medio de Europa occidental (España, Francia e Italia) e Israel. Se ha citado en yacimientos del Pleistoceno superior del oeste y del este de la región pero no en los del centro (Tyrberg 1998, 2008). Se ha identificado en un yacimiento del Pleistoceno superior de Mallorca (Seguí et al. 1997) y en niveles del Pleistoceno superior de Ibiza (Sondaar et al. 1995). 


\section{Comentarios}

Cráneo y mandíbula: las dimensiones del cráneo, incluida la distancia interorbitaria, superan a las del género Passer. Moreno (1985) observa que el processus zygomaticus y el processus postorbitalis están más desarrollados en $P$. petronia que en los otros paséridos y fringílidos de talla similar. Su estudio no incluye a M. nivalis, si bien, de acuerdo con el material de comparación disponible, se observa que dichos procesos están también menos desarrollados en esta especie que en $P$. petronia.

El premaxilar de Petronia es el más grande, ancho y robusto de la familia y, a diferencia de los otros paséridos, posee processus palatinus premaxillaris. En el premaxilar de $\mathrm{Pe}$ tronia la crista tomialis no es recta, sino que es prominente (angulosa) en su parte media en vista lateral, a diferencia del premaxilar del resto de paséridos y fringílidos. Además de las diferencias mencionadas entre las dos familias, las narinas son más amplias en Petronia que en Chloris chloris.

En la mandíbula de Petronia, todas las estructuras están mucho más desarrolladas que en la mandíbula del resto de los Passeridae. La altura de las ramas mandibulares es mayor en Petronia, sobre todo a nivel del processus coronoideus anterior (Moreno 1985). El ángulo mandibular apenas se aprecia en vista lateral en Petronia, a diferencia de Passer. La crista tomialis es más recta en vista lateral y las fenestras mandibulares son más pequeñas en Petronia que en C. chloris.

Los premaxilares y mandíbulas identificados a partir del material de es Pouàs, tienen un tamaño superior al que presentan en los individuos actuales.

\section{cf. Petronia petronia}

Material: 2 premaxilares, 1 mandíbula, 11 húmeros (8 derechos, 3 izquierdos). Total: 14.

Comentarios: el estado fragmentario de los premaxilares y la mandíbula impide una clasificación más precisa.

El húmero de Petronia presenta dos fosas confluentes y, a diferencia de $M$. nivalis, una cresta deltoidea corta. Los húmeros de los fringílidos de talla similar presentan una cresta deltoidea más larga y los de Emberiza calandra, Pinicola enucleator y Coccothraustes cocothraustes presentan epífisis más robustas. La atribución de estos fósiles a $P$. petronia es dudosa, por lo que se ha utilizado una nomenclatura abierta. Algunos húmeros presentan una robustez superior a la de los individuos actuales. 
Montifringilla C. L. Brehm, 1828

Montifringilla nivalis (Linnaeus, 1766)

Gorrión alpino

Material: 3 mandíbulas, y 1 húmero (derecho). Total: 4. NMI: 3.

Distribución estratigráfica: Pleistoceno superior y Holoceno (niveles 1, 2 y 5 de la cuadrícula A3 y un nivel holocénico de la cuadrícula A2).

Distribución actual en el Paleártico occidental: $M$. nivalis cría en latitudes medias de la región, en elevaciones alpinas y subalpinas de las zonas templadas. Es una especie principalmente sedentaria aunque algunos individuos realizan desplazamientos a corta distancia o altitudinales (Snow y Perrins 1998). Se observa como invernante, aunque muy escasa, en Mallorca y accidentalmente en el resto de las Baleares (López-Jurado 2011).

Registro fósil en el Paleártico occidental: es una especie bastante común en el Pleistoceno superior de la región, especialmente en el oeste, donde ha aparecido en 46 localidades. Sin embargo, no se ha encontrado en el Pleistoceno inferior y sólo hay un registro del Pleistoceno medio, procedente de Francia (Tyrberg 1998, 2008). Se ha identificado en dos yacimientos del Pleistoceno superior de Mallorca (McMinn y Alcover 1992; Seguí et al. 1997), uno de Menorca (Seguí 1999) y uno de Ibiza (Sondaar et al. 1995).

\section{Comentarios}

Mandíbula: la mandíbula de $M$. nivalis es robusta, aunque menos que la de Petronia petronia, y presenta una sínfisis larga y más estrecha que la de las mandíbulas del resto de especies de la familia. La cara interna de la rama mandibular presenta unos márgenes dorsal y ventral muy robustos, en contraste con el centro de la misma, que es muy fino.

Húmero: presenta una longitud superior a la de los húmeros del resto de especies de la familia (figura 35). La cresta bicipital es estrecha y la cresta deltoidea es más larga que en el resto de los Passeridae. Según McMinn y Alcover (1992), la fosa dorsal es más ancha en $M$. nivalis que en los otros paséridos.

\section{cf. Montifringilla nivalis}

Material: 1 mandíbula y 3 húmeros (1 derecho, 2 izquierdos). Total: 4.

Comentarios: la mandíbula es un pequeño fragmento. En cuanto a los húmeros, son más robustos que los de los individuos actuales y su morfología no se ajusta inequívocamente a la de esta especie. 
Fringillidae Leach, 1820

(Figuras 13 y 14, anexo)

\section{Cráneo y mandíbula}

El cráneo de los fringílidos presenta un conjunto de estructuras muy desarrolladas, con un premaxilar muy robusto, especialmente en el corpus ossis premaxillaris, en el os maxillare y en la pars maxillaris palatini (Cuisin 1989). El processus zygomaticus, el processus postorbitalis y el processus orbitalis quadrati también se encuentran muy desarrollados. Los foramina venae occipitalis externae se sitúan en el borde posterior del foramen magnum, excepto en C. coccothraustes (Moreno 1985). Ujhelyi (1992) destaca la presencia de una región interorbital ancha y un acortamiento del premaxilar y la mandíbula respecto a los paseriformes insectívoros.

El premaxilar de Fringillidae es ancho y robusto, con una gran diversidad morfológica y biométrica entre especies. Presenta dos crestas longitudinales poco marcadas en el corpus ossis premaxillaris (en vista ventral), más o menos paralelas a la crista tomialis (una a cada lado) y que convergen en el extremo craneal del premaxilar. Este carácter les distingue de los premaxilares de Passeridae en los que dichas crestas son paralelas entre sí y transcurren por la zona central del corpus ossis premaxillaris.

La mandíbula es también muy robusta, especialmente la sínfisis y la zona de inserción con las ramas mandibulares. La parte caudal de la sínfisis y la mandíbula en su conjunto, son muy amplias. En la zona articular, el processus retroarticularis es, en general, muy corto, a diferencia del processus medialis mandibulae que es muy alargado.

\section{Húmero}

Todas las especies presentan un húmero robusto con dos fosas completamente desarrolladas, profundas y confluentes. En la epífisis proximal destacan una barra medial muy reducida y una cresta deltoidea de tamaño reducido.

A diferencia de los húmeros de Passeridae, en los de Fringillidae la cresta deltoidea es más larga, las epífisis son más robustas y las dos fosas están más unidas entre sí, ya que la barra medial está menos desarrollada. Son también morfológicamente similares los húmeros de Emberizidae, si bien los de Fringillidae son más robustos, menos estilizados que los de Emberizidae de talla similar (Weesie 1988). Por último, los húmeros de Motacillidae presentan una epífisis distal característicamente redondeada, robusta y estrecha, a diferencia de la epífisis distal más ancha y estilizada de Fringillidae. 


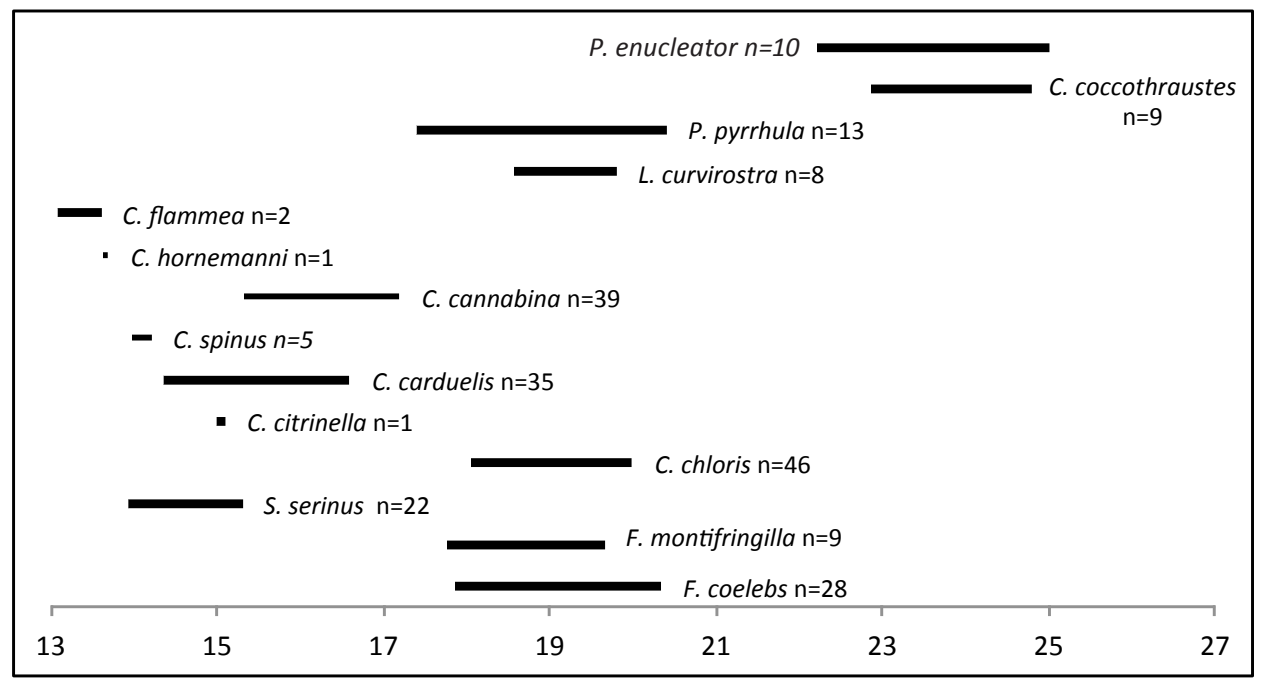

Figura 36. Longitud de los húmeros de las especies actuales de Fringillidae. Ejemplares procedentes de la colección del IMEDEA y de los trabajos de Jánossy (1983), Moreno (1985) y Weesie (1988).

\section{Tarsometatarso}

Los tarsometatarsos de las especies de esta familia son, en general, cortos y robustos, aunque hay una gran diversidad morfométrica. La epífisis distal es notablemente ancha, lo que permite diferenciarlos de otros grupos con tarsometatarsos de longitud similar. A diferencia de los tarsometatarsos de Alaudidae, la trochlea metatarsi III es más larga respecto a las otras dos trócleas en los fringílidos. Además, la separación entre trócleas está más marcada en Fringillidae que en Alaudidae. Los tarsometatarsos de Passeridae son más robustos que los de Fringillidae de longitud similar, excepto el de P. montanus y también el de Montifringilla nivalis, que es más esbelto que los de los fringílidos de longitud similar (Coccothraustes y Pinicola). Sylviidae, Prunellidae y Paridae (excepto P. major) presentan tarsometatarsos menos robustos, más estilizados. Por último, las diferencias con los tarsometatarsos de Emberizidae, Motacillidae y Muscicapidae se detallan en la descripción de dichas familias. 


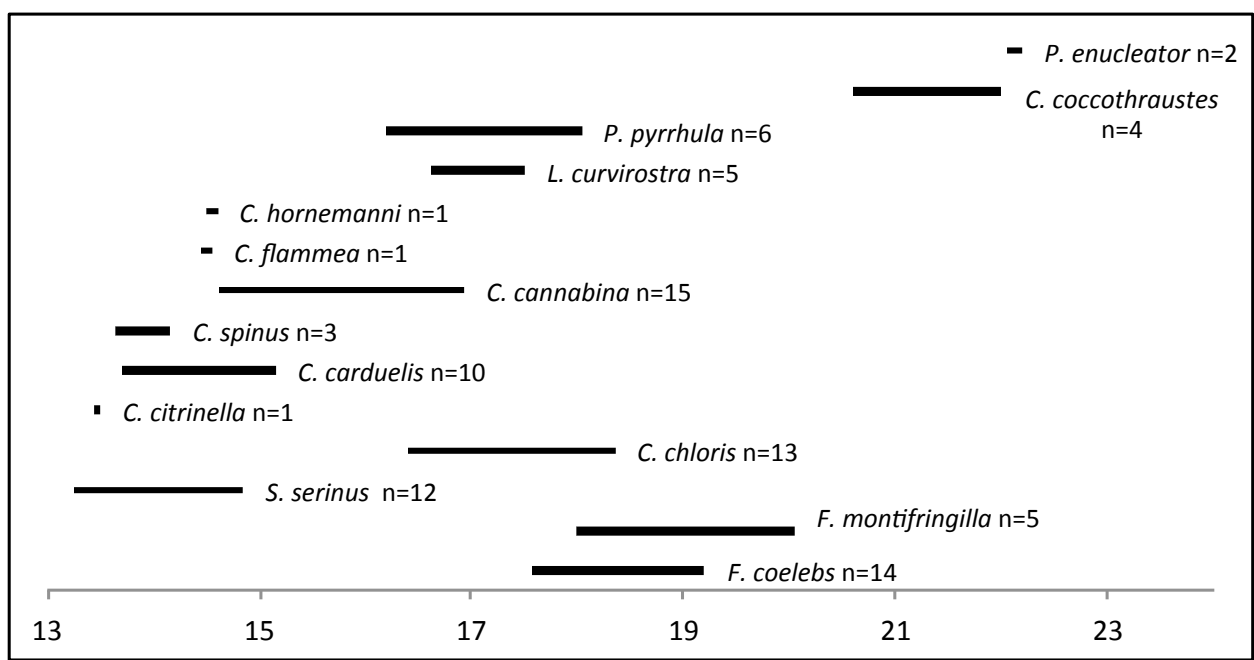

Figura 37. Longitud de los tarsometatarsos de las especies actuales de Fringillidae. Ejemplares procedentes de la colección del IMEDEA y del trabajo de Moreno (1985).

\section{Fringilla Linnaeus, $175^{8}$}

Cráneo y mandíbula: a diferencia de los otros géneros de Fringillidae, el premaxilar en Fringilla es proporcionalmente más largo y estrecho, con unas narinas más amplias y que ocupan una posición más lateral.

En la mandíbula, el ángulo mandibular es poco notable y las ramas mandibulares son relativamente más bajas (respecto a la longitud mandibular) que en el resto de especies de la familia. Presenta una sínfisis mandibular alargada, más puntiaguda que en otras especies.

Húmero: según las observaciones de Jánossy (1983), la parte proximal de la cresta bicipital (crus ventrale fossae) es ancha con una pequeña depresión. El tubérculo ventral es poco robusto y la barra medial muy fina. Destaca la unión entre las dos fosas, que es prácticamente completa, consecuencia de la gran reducción de la barra medial. La cresta deltoidea es relativamente larga en comparación con el resto de taxones de la familia. Los húmeros de Fringilla son también diferenciables a nivel biométrico de la mayoría de taxones de la familia (ver figura 36). 
Fringilla sp.

Material: 4 mandíbulas y 8 húmeros (3 derechos, 5 izquierdos). Total: 12. NMI: 5 (basado en los húmeros).

Distribución estratigráfica en es Pouàs: Pleistoceno superior y Holoceno (cuadrícula A3 niveles 3, 5 y 8 y cuadrícula D4).

Distribución actual en el Paleártico occidental: Fringilla coelebs está ampliamente distribuida, cría en áreas forestales templadas de la región, desde zonas mediterráneas hasta boreales. De sedentaria a migratoria, inverna principalmente dentro del área de cría en Europa y en Asia. En cambio, Fringilla montifringilla cría en las zonas boreales y subárticas de la región. Todas las poblaciones son migrantes, invernando al sur de su área de cría, en latitudes medias y medias-bajas de la región (Snow y Perrins 1998). Se observan poblaciones de F. coelebs sedentarias en Mallorca y Menorca, invernantes en Mallorca e Ibiza y migrantes en todas las Baleares. F. montifringilla es una especie escasa como migrante e invernante en Mallorca y Menorca. En Ibiza la población es aún más escasa y solamente invernante (López-Jurado 2011).

Registro fósil en el Paleártico occidental: Fringilla coelebs es una especie escasa en el Pleistoceno inferior, solamente se encuentra en España, Italia e Israel. Relativamente abundante en el Pleistoceno medio de Europa occidental, se ha citado en ocho yacimientos (España, Italia y Francia). Es más común y está más ampliamente distribuida en el Pleistoceno superior (Tyrberg 1998, 2008). En Baleares se ha identificado en un yacimiento del Pleistoceno inferior (Fringilla cf. coelebs, Alcover et al. 1981) y en uno del Pleistoceno superior de Mallorca (Mourer-Chauviré et al. 1977).

Fringilla montifringilla solamente se ha identificado en el Pleistoceno superior de la región, con 15 registros en la mitad oeste y cuatro en la mitad este (Tyrberg 1998, 2008). Esta especie no consta en el registro fósil de Baleares, si bien hay dos registros del género, Fringilla sp., procedentes del Pleistoceno superior, uno de Mallorca (McMinn y Alcover 1992) y otro de Ibiza (Sondaar et al. 1995).

Comentarios: no ha sido posible la identificación a nivel específico ya que no se observan diferencias morfológicas ni biométricas claras entre ambas especies.

\section{cf. Fringilla}

Material: 4 premaxilares, 3 mandíbulas y 3 húmeros (2 derechos, 1 izquierdo). Total: 10. 
Comentarios: el material es morfométricamente atribuible a este género, si bien debido a su estado, se ha utilizado una nomenclatura abierta para su asignación taxonómica.

\author{
Serinus Koch, 1816 \\ Serinus serinus (Linnaeus 1766) \\ Serín verdecillo
}

Material: 1 premaxilar y 1 húmero (izquierdo). Total: 2. NMI: 2.

Distribución estratigráfica en es Pouàs: Pleistoceno superior y Holoceno (cuadrícula A3, niveles 5 y $-55 \mathrm{~cm} /-70 \mathrm{~cm})$.

Distribución actual en el Paleártico occidental: confinado a la región paleártica, originalmente $S$. serinus sólo se encontraba en la zona mediterránea, expandiéndose al norte de la región en el siglo XIX. Es una especie de sedentaria a migratoria, invernando al sur de su área de cría (Snow y Perrins 1998). Se observa una abundante población sedentaria en Baleares, excepto en Menorca. La población migrante e invernante es escasa en Mallorca, Menorca e Ibiza (López-Jurado 2011).

Registro fósil en el Paleártico occidental: S. serinus es muy escaso en el registro. Solamente consta en tres localidades del Pleistoceno inferior (Austria y España), dos del Pleistoceno medio (Francia y Reino Unido) y en tres del Pleistoceno superior (España e Israel) (Tyrberg 1998, 2008). No se ha encontrado en ningún yacimiento de Baleares.

\title{
Comentarios
}

Premaxilar: esta especie presenta un culmen de longitud menor a 9,95 mm (Moreno 1985). El corpus ossis premaxillaris es ancho y redondeado a diferencia de las otras especies de talla pequeña, tales como Carduelis flammea, Carduelis hornemanni y Carduelis spinus, por lo que es inconfundible. A diferencia de S. serinus, el premaxilar de Carduelis citrinella (anteriormente Serinus citrinella), presenta una forma más puntiaguda, más triangular, y unas narinas más cortas (Cuisin 1989).

Húmero: de aspecto general poco robusto, alargado y de pequeñas dimensiones, el húmero de $S$. serinus presenta una barra medial reducida y una cresta deltoidea corta (Jánossy 1983). La parte proximal de la cresta bicipital (crus ventrale fossae) y el tuberculum ventrale son estrechos. Es el húmero de menor longitud de todas las especies de fringílidos identificados en es Pouàs. A diferencia de la especie biométricamente más próxima, $C$. spinus, la cresta bicipital y la diáfisis forman un ángulo más cerrado en $S$. serinus y el fósil. El húmero de C. flammea es más corto, al igual que el de C. citrinella y C. hornemanni $(\mathrm{L}=13,7, \mathrm{n}=1, \mathrm{IMEDEA})$. 


\section{Serinus/Carduelis}

Material: 3 mandíbulas.

Comentarios: se trata de fragmentos de la parte craneal de la mandíbula. Se asimilan a $S$. serinus por la longitud y forma más o menos redondeada de la sínfisis, si bien no se puede descartar que pertenezcan a C. citrinella, C. flammea o C. hornemanni.

Chloris Cuvier, 1800

Chloris chloris (Linnaeus 1758)

Verderón común

Material: 1 cráneo, 24 premaxilares, 15 mandíbulas y 4 húmeros (1 derecho, 3 izquierdos). Total: 44. NMI: 25 (basado en los 24 premaxilares y el cráneo completo).

Distribución estratigráfica en es Pouàs: Pleistoceno superior y Holoceno (niveles del 3 al 8 de la cuadrícula A3 y cuadrícula D4).

Distribución actual en el Paleártico occidental: especie ampliamente distribuida. Cría en prácticamente toda la región paleártica, excepto en el Ártico. Parcialmente migratoria en la mayor parte de su área de distribución, inverna en la zona de cría con concentración de poblaciones en el Mediterráneo (Snow y Perrins 1998). Las poblaciones sedentarias son abundantes en todas las Baleares y las de individuos invernantes y migrantes son más escasas (López-Jurado 2011).

Registro fósil en el Paleártico occidental: es una especie bastante común en el registro fósil de la región. Aparece en seis localidades del Pleistoceno inferior de Italia y España (Seguí 1996; Tyrberg 1998, 2008) y también en Israel y Francia (cf. Chloris chloris). Se ha registrado en seis yacimientos del Pleistoceno medio del oeste de Europa y también en Grecia e Israel. Ampliamente distribuida en el Pleistoceno superior de la región (Tyrberg 1998, 2008), se ha identificado en un yacimiento de Mallorca (Seguí et al. 1997) y en otro de Ibiza (Sondaar et al. 1995).

\section{Comentarios}

Cráneo y mandíbula: el cráneo, de mayor tamaño que el de las especies de Carduelis, presenta un processus zygomaticus muy desarrollado y una distancia interorbitaria también superior a la de dichas especies. El premaxilar es más ancho y robusto que los de las especies del género Carduelis. Según el criterio de Moreno (1985), los individuos que pertenecen a esta especie presentan una relación longitud-anchura del culmen (C/AM) menor de 2,1 y una longitud de culmen mayor de 12,5 $\mathrm{mm}$. 
Los premaxilares fósiles obtenidos presentan, en general, unas narinas más grandes y son más cortos que los de los individuos actuales.

La mandíbula es más amplia y presenta todas las estructuras más desarrolladas que en Fringilla y Carduelis. La sínfisis mandibular es notablemente ancha y robusta. Su punto de unión con las ramas mandibulares es una estructura ósea muy robusta, sólo superada por la de la mandíbula de Coccothraustes. Petronia, con una mandíbula de talla similar, presenta una sínfisis más estrecha y menos robusta, una crista tomialis más recta y unas fenestras mandibulares más cerradas. La sínfisis mandibular de Pinicola es más redondeada que la de C. chloris mientras que la de Loxia es más corta y puntiaguda.

Húmero: el húmero de $C$. chloris presenta unas epífisis robustas y una cresta deltoidea corta (Jánossy 1983; Wessie 1988). Considerando las especies biométricamente más similares, el húmero de $C$. chloris presenta unas epífisis más robustas que las de las dos especies de Fringilla, aunque menos robustas que las del húmero de Loxia curvirostra. Además, a diferencia de Fringilla, la barra medial está más desarrollada en el húmero de $C$. chloris.

\section{Carduelis Brisson, 1760}

Cráneo y mandíbula: el cráneo de Carduelis presenta un sólo fonticulus orbitale, el dorsal, y un foramen orbitonasale simple y alargado. Tanto el premaxilar como la mandíbula varían enormemente dependiendo de la especie. Cuisin (1989) no encuentra ningún carácter exclusivo y distintivo del género.

Húmero: la epífisis proximal del húmero de Carduelis es ancha y robusta y presenta una cresta deltoidea corta y una barra medial muy fina.

\section{Carduelis cannabina (Linnaeus, 1758)}

Pardillo común

Material: 13 premaxilares, 8 mandíbulas y 4 tarsometatarsos (2 derechos, 2 izquierdos). Total: 25. NMI: 13 (basado en los premaxilares).

Distribución estratigráfica en es Pouàs: Pleistoceno superior y Holoceno (niveles 3, 4, 7 y 8 de la cuadrícula A3 y cuadrícula D4).

Distribución actual en el Paleártico occidental: cría en latitudes medias y bajas de la región, desde zonas boreales hasta mediterráneas, incluyendo la costa norte de África. Es una especie parcialmente migratoria, invernando dentro de su área de cría con concentraciones en el Mediterráneo (Snow y Perrins 1998). La población sedentaria es abundante 
en todas las Baleares, y más escasa como invernante y migrante en Mallorca y Menorca (López-Jurado 2011).

Registro fósil en el Paleártico occidental: esta especie se encuentra ampliamente distribuida en el registro del Pleistoceno superior de la región, aunque es poco abundante. Aparece en dos yacimientos del Pleistoceno medio (Francia y Ucrania) y no se ha citado en niveles del Pleistoceno inferior. Se ha citado en cuatro yacimientos del Pleistoceno superior de España (Tyrberg 1998, 2008) y, en Baleares, en un yacimiento del Pleistoceno medio (Ballman y Adrover 1970) y en el Pleistoceno superior de Ibiza (Sondaar et al. 1995).

\section{Comentarios}

Cráneo y mandíbula: el premaxilar, de anchura y longitud medias, no presenta un corpus ossis premaxillaris alargado y afilado como en C. carduelis o C. spinus, sino que es más corto y ancho. A diferencia de C. cannabina, el premaxilar de dichas especies está comprimido lateralmente. En C. cannabina las narinas son de tamaño medio y más redondeadas que en dichas especies. Según el criterio de Moreno (1985), la relación longitud-anchura del culmen (C/AM) en esta especie es menor de 2,1 y la longitud del culmen se sitúa entre 11,15 mm y 10,1 mm.

La mandíbula presenta una sínfisis de tamaño medio, más corta que la de Fringilla y de mayor tamaño que las de C. hornemanni y C. flammea. Es relativamente ancha y redondeada, a diferencia de las de $C$. carduelis y $C$. spinus, en los que es más puntiaguda. El punto de unión de las ramas mandibulares con la sínfisis mandibular es muy robusto, como ocurre en C. chloris, aunque en menor medida que en éste. Cuisin (1989) destaca que las fenestras mandibulares son característicamente pequeñas en la mandíbula de $C$. cannabina.

Tarsometatarso: los tarsometatarsos de C. cannabina y los fósiles son más largos (figura 37) y estilizados que los de C. carduelis, y más cortos y de epífisis menos robustas que los de C. chloris. Los valores de longitud de los fósiles (15,3-15,7 mm) se corresponden con los de C. cannabina y no se solapan con los de ninguna otra especie de la familia.

\section{Carduelis cannabina/Carduelis carduelis}

Material: 31 húmeros (18 derechos, 13 izquierdos).

Comentarios: se trata de dos especies con húmeros muy similares morfológicamente y biométricamente. Las medidas de longitud de los húmeros de ambas especies se solapan, si bien la del húmero de C. cannabina es ligeramente superior. Carduelis spinus y Serinus serinus presentan húmeros de longitud inferior, y con epífisis proximales menos robustas. 
cf. Carduelis (talla pequeña)

Material: 7 húmeros (1 derecho, 6 izquierdos).

Comentarios: en esta categoría se incluyen los húmeros de Carduelis con determinación imprecisa y que corresponderían a las especies con los húmeros de menor talla del género tales como, C. hornemanni, C. flammea y C. spinus. La nomenclatura es abierta ya para alguno de los húmeros no se puede descartar su atribución a Serinus.

\section{cf. Carduelis/Chloris}

Material: 4 premaxilares, 1 mandíbula, 4 húmeros (1 derecho, 3 izquierdos) y 1 tarsometatarso (izquierdo). Total: 10.

Comentarios: bajo esta denominación se incluyen restos atribuibles a Carduelis o a Chloris, con determinación imprecisa y talla media y grande, es decir, C. chloris, C. cannabina y C. carduelis. La nomenclatura es abierta, ya que en el caso de algún elemento no se puede descartar su atribución a Fringilla.

Loxia Linnaeus, 1758

Loxia curvirostra Linnaeus, 1758

Piquituerto común

Material: 2 premaxilares y 2 mandíbulas. Total: 4. NMI: 2.

Distribución estratigráfica en es Pouàs: Pleistoceno superior y Holoceno (cuadrículas A2 y D4).

Distribución actual en el Paleártico occidental: esta especie, mayoritariamente sedentaria, se encuentra principalmente en zonas boscosas boreales y subárticas y también en zonas insulares y montanas de clima templado y mediterráneo (Snow y Perrins 1998). Hay una población sedentaria abundante en Mallorca y más escasa en Ibiza. En el resto de las Baleares su presencia es sólo accidental (López-Jurado 2011).

Registro fósil en el Paleártico occidental: no hay ningún registro del Pleistoceno inferior de esta especie y solamente hay un registro del Pleistoceno medio procedente de la República Checa (cf. Loxia curvirostra). Es más común en el Pleistoceno superior, con 15 registros en Europa occidental (España, Francia, Italia y Reino Unido) y 22 en el resto de la región (Tyrberg 1998, 2008). Ha aparecido en tres yacimientos del Pleistoceno superior de Mallorca (Florit y Alcover 1987; McMinn y Alcover 1992; Seguí 1997; Seguí et al. 1997). 


\section{Comentarios}

Cráneo y mandíbula: a diferencia de los otros géneros de la familia, existe una notable asimetría entre el premaxilar y la mandíbula (Ujhelyi 1992), de forma que los ápices del premaxilar y la mandíbula se cruzan cuando el pico permanece cerrado. El premaxilar de Loxia es muy alto, de perfil curvo, robusto, afilado y comprimido lateralmente, excepto en la parte caudal, en la zona de las narinas. El corpus ossis premaxillaris (en vista ventral) está dividido por una fisura longitudinal en la parte central del mismo cuyos bordes tienen forma aserrada. El tamaño del premaxilar así como el de la mandíbula los diferencia inequívocamente de los de Loxia pytyopsittacus, que presentan una talla muy superior.

La mandíbula es muy amplia con un processus retroarticularis en forma de amplia superficie semicircular y unas fenestras mandibulares también muy amplias. La sínfisis es corta y triangular, de extremo caudal ancho y ápice puntiagudo y presenta una característica curvatura en vista ventral.

\section{Loxia sp.}

Material: 8 húmeros (5 derechos, 3 izquierdos).

Comentarios: el húmero de éste género se diferencia bien de los del resto de la familia, ya que es relativamente corto y muy robusto. Jánossy (1983) y Seguí (1997) destacan la robustez de las epífisis como carácter diagnóstico de L. curvirostra. La longitud de los húmeros actuales de L. curvirostra (18,6-19,8 mm, n=8) es inferior a la de los fósiles (entre $20,2 \mathrm{~mm}$ y $21,5 \mathrm{~mm}$ ), que presentan una talla similar a la de los húmeros de Loxia pytyopsittacus $(20,7 \mathrm{~mm}, \mathrm{n}=1)$. Debido a estas diferencias biométricas y dado que solamente se ha dispuesto de un individuo de comparación de L. pytyopsittacus, se ha optado por utilizar una nomenclatura abierta para su asignación taxonómica.

\section{cf. Pinicola enucleator (Linnaeus, 1758) \\ Camachuelo picogrueso}

Material: 3 húmeros (1 derecho, 2 izquierdos). NMI: 2.

Distribución estratigráfica en es Pouàs: Pleistoceno superior (nivel 3 de la cuadrícula A3 y cuadrícula A4).

Distribución actual en el Paleártico occidental: se encuentra, tanto en época de cría como en invernada, en latitudes altas de la región, en bosques boreales al norte de la línea de árboles (Snow y Perrins 1998). Mayoritariamente sedentario, se desplaza a corta distancia, al sur de la zona de cría. No se observa en Baleares (López-Jurado 2011). 
Registro fósil en el Paleártico occidental: P. enucleator se ha identificado en el Pleistoceno inferior de Austria (cf. Pinicola enucleator) y en el Pleistoceno medio únicamente consta en España y Francia. Es poco común en el Pleistoceno superior, especialmente en la mitad oriental de la región, y no se ha citado en ningún yacimiento de Baleares (Tyrberg 1998, 2008).

Comentarios: el húmero de P. enucleator presenta una longitud similar al de C. coccothraustes. No obstante, la cresta deltoidea es notablemente más larga en el húmero de Pinicola y los fósiles que en el de Coccothraustes. Además, la parte proximal de la cresta bicipital es más robusta en $C$. coccothraustes. Por último, a diferencia de Pinicola, en la epífisis distal del húmero de C. coccothraustes se observa una excrecencia ósea uniendo la diáfisis y el processus supracondylaris dorsalis. Solamente se ha dispuesto de un ejemplar completo de comparación y otro fragmentado de Pinicola, por lo que se ha optado por utilizar una nomenclatura abierta.

\section{cf. Pyrrhula pyrrhula (Linnaeus, 1758) \\ Camachuelo común}

Material: 3 húmeros (1 derecho, 2 izquierdos). NMI: 2.

Distribución estratigráfica en es Pouàs: Pleistoceno superior (nivel 3 de la cuadrícula A3).

Distribución actual en el Paleártico occidental: especie ampliamente distribuida. Cría en latitudes medias y altas, tanto en clima continental como oceánico. De sedentarias a migrantes, la mayoría de las poblaciones invernan dentro de su área de cría o al sur de la misma, hasta el norte del Mediterráneo (Snow y Perrins 1998). Su presencia es accidental en Mallorca y está ausente en el resto de las Baleares (López-Jurado 2011).

Registro fósil en el Paleártico occidental: bastante común en el Pleistoceno superior. Se ha registrado en más de 25 localidades de Europa occidental, en más de 20 de Europa central y en siete del resto de la región. Solamente hay un registro del Pleistoceno inferior (Bulgaria) y seis del Pleistoceno medio (Croacia, Hungría, Francia e Italia) (Tyrberg 1998, 2008). Se ha citado en un yacimiento del Pleistoceno superior de Mallorca (Florit y Alcover 1987; McMinn y Alcover 1992).

Comentarios: el húmero de Pyrrhula presenta unas epífisis robustas, una cresta deltoidea corta, aunque de mayor longitud que la de Carduelis y Chloris, y una barra medial reducida. El rango de longitud del húmero de esta especie se solapa con los de Fringilla, C. chloris y Loxia. Sin embargo, las epífisis en el húmero de Pyrrhula son menos robustas que en los de C. chloris y Loxia. Según las observaciones de Jánossy (1983) y Weesie 
(1988), a diferencia de Fringilla, la parte proximal de la cresta bicipital es más fina y menos extendida ventralmente en Pyrrhula. Debido a la falta de otros huesos con caracteres diagnósticos y a la similitud del húmero con las especies citadas, se ha optado por una nomenclatura abierta.

\author{
Coccothraustes Brisson, 1760 \\ Coccothraustes coccothraustes (Linnaeus, 1758) \\ Picogordo común
}

Material: 1 premaxilar, 1 mandíbula y 6 húmeros (3 derechos, 3 izquierdos). Total: 8. NMI: 3 .

Distribución estratigráfica en es Pouàs: Pleistoceno superior y Holoceno (niveles 3 y 8 de la cuadrícula A3 y cuadrícula D4).

Distribución actual en el Paleártico occidental: cría en latitudes medias y bajas de la región, en clima templado pero también en zonas boreales, mediterráneas y esteparias. De sedentarias a migrantes, las poblaciones norteñas son más migrantes, invernando principalmente dentro de su área de cría (Snow y Perrins 1998). Es una especie poco abundante en migración en Baleares. La población invernante es más o menos abundante en Mallorca y escasa en Menorca e Ibiza (López-Jurado 2011).

Registro fósil en el Paleártico occidental: solamente se ha citado en el Pleistoceno inferior de Israel y Bulgaria. Es poco común en el Pleistoceno medio del este de la región y más frecuente en el oeste, con registros en yacimientos de la República Checa, Alemania, Hungría, Francia, Italia y España. Sin embargo, es frecuente en el Pleistoceno superior de la región, apareciendo en más de 50 yacimientos de Europa occidental (Tyrberg 1998, 2008). Relativamente frecuente en Baleares, se ha registrado en un yacimiento del Pleistoceno inferior (Alcover et al. 1981), en el Pleistoceno medio (Ballman y Adrover 1970) y en el Pleistoceno superior (Seguí et al. 1997) de Mallorca. Sondaar et al. (1995) mencionaron su presencia en el Pleistoceno superior de Ibiza.

\title{
Comentarios
}

Cráneo y mandíbula: en general, todas las estructuras craneales están muy desarrolladas en esta especie. Es, con diferencia, la especie con el cráneo y mandíbula más robustos de la familia, por lo que es inconfundible. El premaxilar es muy grande con unas narinas relativamente pequeñas y redondeadas que no son visibles en vista ventral.

La mandíbula de C. coccothraustes es muy ancha, con una sínfisis mandibular extremadamente grande que presenta un par de expansiones en su parte caudal, que se unen directamente a la parte dorsal de las ramas mandibulares. 
Húmero: el húmero de esta especie es, junto con el de Pinicola, el de mayor longitud de los representantes europeos de esta familia. En la epífisis proximal, la cresta deltoidea es corta y la fosa dorsal es más amplia que la ventral. En la epífisis distal se observa una expansión de la diáfisis hacia los tubérculos del processus supracondylaris dorsalis que une ambas estructuras.

\section{cf. Coccothraustes coccothraustes}

Material: 10 húmeros (5 derechos, 5 izquierdos).

Comentarios: debido al estado del material y a la similitud del húmero de esta especie con el de Pinicola, se ha optado por una nomenclatura abierta en estos casos, en los que no se pueden observar inequívocamente los caracteres osteológicos distintivos del húmero del Coccothraustes coccothraustes.

Fringillidae indeterminados

Material: 1 premaxilar, 3 mandíbulas, 4 húmeros (derechos) y 1 tarsometatarso (derecho). Total: 9 .

Comentarios: el estado del material no permite una identificación más precisa.

\section{Emberizidae Vigors, 1831}

(Figura 14, anexo)

\section{Cráneo y mandíbula}

Uno de los caracteres más típicos del esqueleto craneal de las especies de Emberizidae, en comparación con otros paseriformes de pico granívoro, es la forma angular del premaxilar y la mandíbula, muy llamativa en vista lateral. Cuisin (1989) destaca la forma puntiaguda que presentan la parte apical de la mandíbula y del premaxilar de las especies de esta familia. Esta forma del premaxilar y de la mandíbula, comprimidos lateralmente, junto con su tamaño, más esbelto y menos masivo, diferencian a las especies de esta familia de las de Fringillidae y Passeridae.

En el premaxilar, el processus maxillaris nasale es muy delgado, rodeando postero-lateralmente las narinas. Éstas presentan forma elipsoide a diferencia de las casi circulares de Fringillidae y Passeridae (Moreno 1985). El corpus ossis premaxillaris, en vista ventral, presenta un canal longitudinal en su parte central, que es más o menos ancho y profundo dependiendo de la especie. 
Prunella modularis presenta un corpus ossis premaxillaris que se asemeja ligeramente al de Plectrophenax nivalis en vista ventral, si bien el premaxilar en P. modularis es mucho menos robusto, las narinas son más amplias y el processus maxillaris nasale es mucho más corto que en $P$. nivalis.

La mandíbula presenta unas fenestrae mandibulae amplias, y un ángulo mandibular muy marcado, que se proyecta lateralmente dando lugar a una silueta característica. Solamente presenta un processus coronoideus y el tuberculum pseudotemporale está situado en una posición más dorsal que en Fringillidae y Passeridae. Además, está menos desarrollado que en dichas familias y, sin embargo, alcanza un tamaño mayor que el processus coronoideus (Moreno 1985).

\section{Húmero}

El húmero de Emberizidae presenta una fosa doble y una barra medial muy reducida. La epífisis proximal es pequeña (excepto en E. calandra), con una cresta deltoidea poco desarrollada y una cresta bicipital notablemente ancha. Según las observaciones de Jánossy (1983), las fosas son confluentes y la parte proximal de la cresta bicipital y el tuberculum ventrale son más anchos que en otras especies de morfología similar. Las especies más grandes de esta familia presentan una estructura robusta y unas epífisis anchas.

Las familias con húmeros morfológicamente más similares, que presentan el mismo tipo de fossa pneumotricipitalis, son Passeridae, Motacillidae y Fringillidae. A diferencia de dichas familias, en los húmeros de Emberizidae la cresta bicipital es ancha y se expande ventralmente. Los húmeros de Motacillidae presentan una epífisis distal ancha, más globular. Además, en Emberizidae la fosa dorsal es más profunda y, debido a un mayor desarrollo de la barra medial, se encuentra, en general, más separada de la fosa ventral que en Motacillidae. Por lo general, los húmeros de Fringillidae tienen una epífisis proximal más robusta que los de Emberizidae.

La diferenciación de las distintas especies de Emberizidae en base al húmero sólo ha sido posible en algunos casos y se basa en diferencias biométricas.

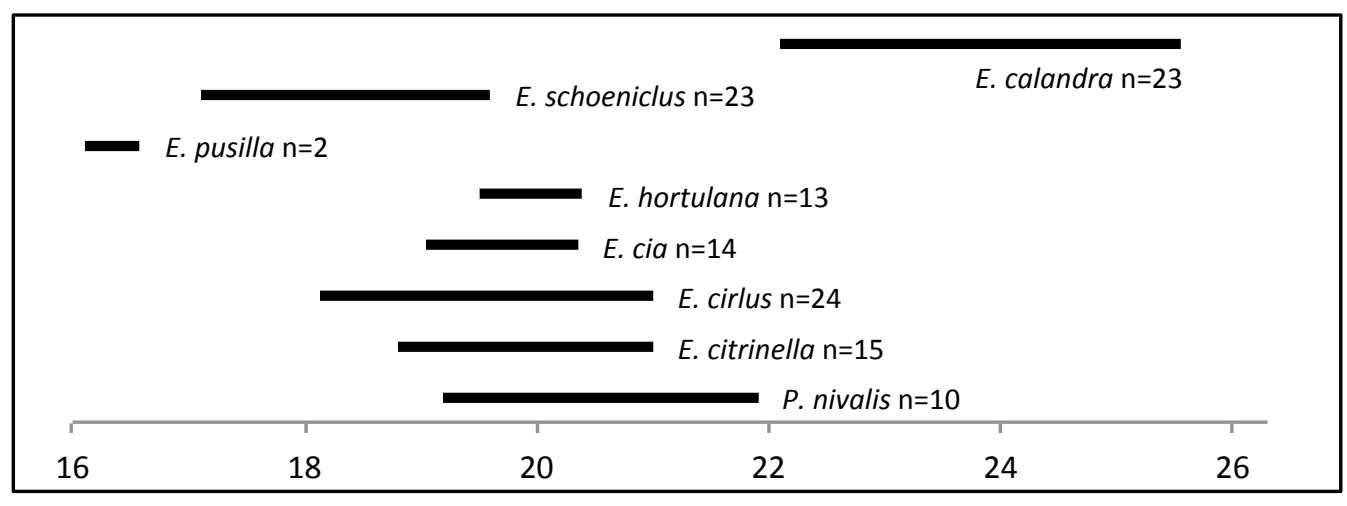

Figura 38. Longitud de los húmeros de las especies actuales de Emberizidae. Ejemplares procedentes de las colecciones del IMEDEA y el NHMT y de los trabajos de Jánossy (1983) y Moreno (1985). 


\section{Tarsometatarso}

El aspecto del tarsometatarso de Emberizidae es similar al de Alaudidae, de tamaño y robustez medios. Ambos presentan una epífisis distal ancha, con una trochlea metatarsi II desplazada lateralmente. Sin embargo, la trochlea metatarsi IV está más desarrollada en Emberizidae. Prunella, biométricamente similar, presenta trócleas más cortas. A diferencia de Emberizidae, los tarsometatarsos de Fringillidae cuentan con una prominencia en la superficie medial de la trochlea metatarsi II (Zelenkov 2012).

Los únicos tarsometatarsos identificados corresponden a E. calandra cuya talla es muy superior a la del resto de especies de la familia. Las diferencias entre esta especie y otras de talla similar se detallan más adelante en el texto.

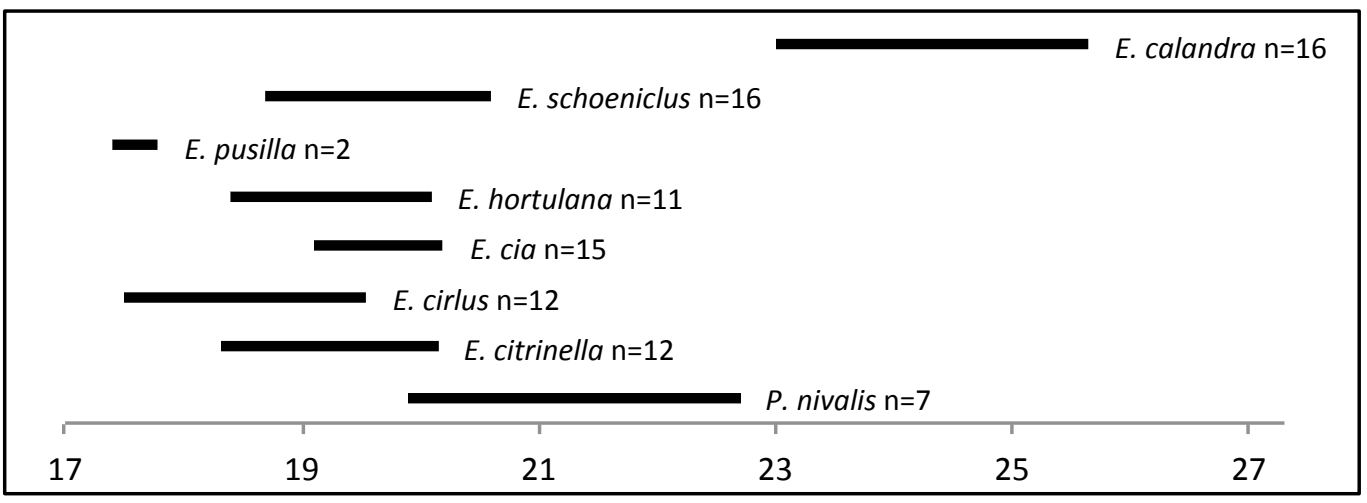

Figura 39. Longitud de los tarsometatarsos de las especies actuales de Emberizidae. Ejemplares procedentes de las colecciones del IMEDEA y el NHMT y del trabajo de Moreno (1985).

\section{Plectrophenax Stejneger, 1882 \\ cf. Plectrophenax nivalis \\ Escribano nival}

Material: 3 premaxilares. NMI: 3 .

Distribución estratigráfica en es Pouàs: Pleistoceno superior (nivel 4 de la cuadrícula A5, nivel 5 de la cuadrícula A4 y parte superior de la A2).

Distribución actual en el Paleártico occidental: P. nivalis se encuentra en latitudes altas, boreales, criando en áreas circumpolares. Sus poblaciones, de parcialmente migrantes a migrantes, invernan en zonas costeras o en llanuras continentales en latitudes medias de la región (Snow y Perrins 1998). En Baleares solamente se ha observado en Mallorca y Menorca, si bien su presencia es accidental (López-Jurado 2011).

Registro fósil en el Paleártico occidental: se trata de una especie escasa en los yacimientos del Pleistoceno inferior (con sólo un registro correspondiente a España) y del Pleistoceno medio (con dos registros correspondientes a Francia) del oeste de la región. 
Algo más abundante en el Pleistoceno superior de Europa occidental, se ha identificado en un yacimiento de España, en siete de Francia y en 12 de Alemania, Reino Unido e Italia (Tyrberg 1998, 2008). No se ha citado en el registro fósil de las Baleares.

Comentarios: el premaxilar de $P$. nivalis presenta un aspecto más aplanado que el de Emberiza, y unas narinas alargadas. El corpus ossis premaxillaris en vista ventral es amplio y plano con un canal en su parte central, en proporción estrecho y poco profundo, en comparación con el del resto de los Emberizidae. Para la identificación de estos premaxilares se ha dispuesto de material de los museos de Rotterdam y Tring así como de información bibliográfica.

Según Zelenkov (2012), el premaxilar de Plectrophenax se ensancha en su extremo caudal de forma más abrupta que en Emberiza. La longitud del culmen de los individuos actuales de comparación es de 9-11,6 mm (n=6, NHMT) y la longitud de los premaxilares de es Pouàs es de 10,6 mm, 10,9 mm y 11,5 mm.

\section{Emberiza Linnaeus, 1758}

Emberiza pusilla Pallas 1776

Escribano pigmeo

Material: 1 premaxilar y 1 húmero (derecho). Total: 2. NMI: 2.

Distribución estratigráfica en es Pouàs: Pleistoceno superior y Holoceno (niveles -70/$90 \mathrm{~cm}$ y 7 de la cuadrícula A3).

Distribución actual en el Paleártico occidental: cría exclusivamente en zonas de clima continental boreales y árticas. Todas las poblaciones son migrantes, invernando en el sur de Asia. También se observa anualmente en el oeste de la región: Gran Bretaña, Sicilia y Francia (Snow y Perrins 1998). Su presencia en Baleares es accidental (López-Jurado 2011).

Registro fósil en el Paleártico occidental: no hay ningún registro de esta especie procedente de yacimientos del Pleistoceno de la región.

\section{Comentarios}

Premaxilar: E. pusilla, a diferencia del resto de especies, cuenta con un processus frontalis premaxillare y unas narinas muy cortos y estrechos. Es la especie de Emberizidae de menor talla de todas las estudiadas. El perfil del corpus ossis premaxillaris es recto (a diferencia de Emberiza schoeniclus) y el canal que presenta en vista ventral es estrecho (a diferencia de Emberiza citrinella). 
Húmero: el fósil presenta los rasgos osteológicos generales de la familia. Su talla, muy inferior a la del resto de Emberizidae (16 mm de longitud), corresponde a la de E. pusilla $(16,1-16,6 \mathrm{~mm}, \mathrm{n}=2)$.

Sería conveniente comparar estos fósiles con Emberiza rustica, especie también de talla pequeña, de la que no se ha dispuesto de material actual. Esta especie ocupa latitudes altas de la región paleártica. No se ha observado nunca en las Baleares y, hasta hace muy poco, nunca se había observado en la Península Ibérica. No consta en el registro fósil de la región paleártica y su presencia en es Pouàs es altamente improbable.

\section{Emberiza schoeniclus Linnaeus, 1758 \\ Escribano palustre}

Material: 1 mandíbula. NMI: 1.

Distribución estratigráfica en es Pouàs: Pleistoceno superior (nivel 8 de la cuadrícula A3).

Distribución actual en el Paleártico occidental: presenta un área de distribución muy extensa, criando desde las regiones climáticas ártica y boreal hasta el Mediterráneo, incluso en zonas de estepa y desierto. La mayor parte de poblaciones son sedentarias, aunque algunas migran al sur de su área de distribución, a latitudes bajas en el Mediterráneo (Snow y Perrins 1998). En Baleares se encuentra principalmente como migrante e invernante, con poblaciones de abundantes a escasas. La población actual de Ibiza es escasa en invernada y rara en migración (López-Jurado 2011).

Registro fósil en el Paleártico occidental: es una especie muy poco común en el registro. Solamente se ha citado en el Pleistoceno superior del centro y del oeste de la región (República Checa, Austria, Hungría, Reino Unido e Italia) (Tyrberg 1998, 2008). No se ha citado en ningún yacimiento de Baleares.

Comentarios: E. schoeniclus es, junto con Emberiza cia y Emberiza hortulana, la especie en la que menos se proyecta lateralmente el ángulo mandibular (Moreno 1985). La mandíbula de E. cia es más corta y menos robusta que la de E. schoeniclus y la del fósil. El perfil de la crista tomialis de E. hortulana es recto, a diferencia del perfil de E. schoeniclus y el fósil, que son curvos. 


\section{Emberiza cf. schoeniclus}

Material: 1 premaxilar.

Comentarios: el perfil del premaxilar de esta especie es continuamente curvo sin que se observe ningún punto de inflexión claramente definido, lo que diferencia a esta de las demás especies de Emberizidae (Moreno 1985). El corpus ossis premaxillaris en vista dorsal, presenta un canal poco profundo. Debido al estado fragmentario del fósil, se ha optado por una nomenclatura abierta.

\section{Emberiza calandra Linnaeus, 1758 \\ Escribano triguero}

Material: 8 premaxilares, 2 mandíbulas, 25 húmeros (14 derechos, 11 izquierdos) y 2 tarsometatarsos (derechos). Total: 37. NMI: 14 (basado en los húmeros).

Distribución estratigráfica en es Pouàs: Pleistoceno superior y Holoceno (niveles del 3 a 6 de la cuadrícula A3 y varios niveles de la cuadrícula D4).

Distribución actual en el Paleártico occidental: cría en latitudes medias del sudoeste del Paleártico. Sus poblaciones son sedentarias o parcialmente migrantes, invernando dentro de su área de cría y algunas en el norte de África (Snow y Perrins 1998). Especie sedentaria en Baleares. Sus poblaciones son abundantes en Mallorca y Menorca y más escasas en las Pitiusas (López-Jurado 2011).

Registro fósil en el Paleártico occidental: es una especie muy escasa en el registro fósil de la región. Ausente en el Pleistoceno medio, aparece en el Pleistoceno inferior de España (cf. Miliaria calandra) y en el Pleistoceno superior del este, el centro (Grecia, Polonia) y el oeste (Alemania, Francia, Italia y en nueve localidades de España) de la región (Tyrberg 1998, 2008). Se ha identificado en el Pleistoceno superior de Mallorca (cf. Miliaria calandra, Seguí 1997) y de Ibiza (Sondaar et al. 1995).

\section{Comentarios}

Cráneo y mandíbula: es la especie de mayor talla, por lo que se distingue fácilmente del resto de especies de la familia. El corpus ossis premaxillaris en vista ventral presenta un canal profundo, más pronunciado que en el resto de especies. Las narinas son amplias y alargadas y el perfil superior del premaxilar es curvo, mientras que el inferior presenta una ondulación en su parte caudal.

La mandíbula presenta un aspecto robusto, con todos los procesos y estructuras más desarrollados que en el resto de especies y un ángulo mandibular muy marcado. 
Según los datos biométricos de Moreno (1985), valores de LM superiores a 21,4 mm corresponden a esta especie.

Húmero: su talla es notablemente superior a la del resto de especies de la familia (figura 38). La epífisis proximal es corta y robusta, con una fosa dorsal muy amplia, una cresta deltoidea corta y una cresta bicipital muy desarrollada.

Tarsometatarso: al igual que el húmero y el cráneo, el tarsometatarso de E. calandra presenta una talla y robustez superior a los del resto de especies de la familia (figura 39). Otros taxones con tarsometatarsos de longitud similar se incluyen en Lanius, Montifringilla, Muscicapidae y Motacillidae. El tarsometatarso de E. calandra es notablemente más robusto que el de las especies de Muscicapidae y Motacillidae de longitud similar. La diáfisis y la epífisis proximal del tarsometatarso de E. calandra son más robustas que las de M. nivalis y, a diferencia de lo que se observa en Lanius, la trochlea metatarsi II está más desarrollada y expandida lateralmente en E. calandra.

\section{Emberizidae indeterminados}

Material: 8 premaxilares, 3 mandíbulas y 28 húmeros (15 derechos, 13 izquierdos). Total: 39 .

Comentarios: el estado de las mandíbulas y los premaxilares impide una identificación más precisa. En cuanto a los húmeros, algunos se encuentran fragmentados y otros pertenecen a especies no diferenciables biométrica ni morfológicamente. 



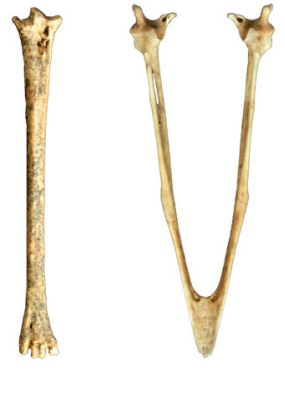

DISCUSIÓN 


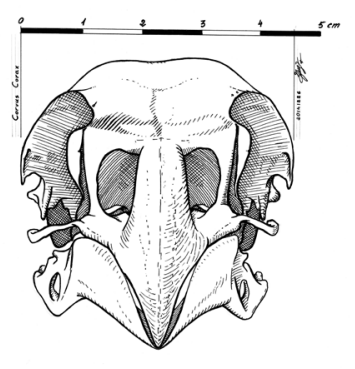

\section{4 - DISCUSIÓN}

El yacimiento de es Pouàs ha proporcionado hasta la fecha un mínimo de 103 especies de aves, de las cuales 13 corresponden a los órdenes Falconiformes y Strigiformes, un mínimo de 60 especies pertenecen a Passeriformes y las 30 restantes se incluyen en otros órdenes. Algunos de los restos obtenidos en este yacimiento han sido identificados a nivel de género. Estas denominaciones genéricas podrían representar a más de una especie. Ocho de las 13 especies de aves rapaces habían sido identificadas y publicadas por otros autores, y de las no menos de 60 especies de paseriformes, 20 constaban ya en el registro de este yacimiento (Florit et al. 1989; Alcover y McMinn 1992; McMinn et al. 2005; Tyrberg 1998, 2008). Por tanto, en este trabajo se presentan 45 especies de aves nuevas para el registro fósil del depósito de es Pouàs, cinco de las cuales son especies de aves rapaces y un mínimo de 40 son especies de paseriformes.

\subsection{Comparativa con la ornitofauna fósil de áreas próximas}

\subsubsection{Gimnesias}

En las últimas décadas se han producido numerosos avances en el conocimiento de las avifaunas fósiles de las Baleares (e.g., Alcover et al. 1981; Florit y Alcover 1987; McMinn y Alcover 1992; Seguí 1997; Seguí et al. 1997; Alcover 2001; Alcover et al. 2004; Bover et al. 2014). No obstante ningún yacimiento ha aportado una riqueza ornítica similar a la de es Pouàs (Florit et al. 1989; Alcover y McMinn 1992; McMinn et al. 2005).

De los paseriformes fósiles identificados en es Pouàs, 20 especies (ver tabla 1, anexo) se han incorporado, por primera vez al registro fósil del conjunto de las Baleares. $L$. arborea, Muscicapa striata y Parus cf. major solamente se habían identificado con determinación taxonómica abierta y en niveles correspondientes al Pleistoceno inferior de las Gimnesias (como Muscicapa cf. striata, cf. Lullula arborea y Parus cf. major, Alcover et al. 1981) y C. cannabina en niveles del Pleistoceno medio (Ballman y Adrover 1970, Alcover et al. 1981), mientras que unos restos de posibles $P$. domesticus, identificados como cf. P. domesticus/hispanolensis (Seguí et al. 1997), constituyen el único registro 
disponible de esta especie en las Gimnesias. Así, el yacimiento de es Pouàs ha aportado un total de 24 especies de paseriformes nuevas para el registro del Pleistoceno superior-Holoceno de las Baleares.

Cuatro de las especies de paseriformes fósiles incluidas en el registro del Pleistoceno superior-Holoceno de las Gimnesias (F. coelebs [Mourer-Chauviré et al. 1997], O. oenanthe [Seguí et al. 1997], L. minor [Florit y Alcover 1987] y cf. Pica pica [Alcover et al. 1981; Seguí 1996]), no se han mencionado específicamente en el registro de las Pitiusas. O. oenanthe y F. coelebs muy probablemente se encuentran entre los restos identificados en el presente trabajo como Oenanthe sp. y Fringilla sp. El registro de $L$. minor procedente de Mallorca, corresponde a un tarsometatarso. Tras su revisión, se descarta su atribución a Laniidae. La presencia de Pica pica en el registro de Mallorca, se basa en un coracoides cuya adscripción a esta especie es dudosa y que no se encuentra disponible para su revisión, por lo que no se ha tenido en cuenta en este trabajo. Por tanto, lo más probable es que ninguna de las especies de paseriformes del registro de las Gimnesias esté ausente en es Pouàs.

Algunos de los taxones identificados destacan especialmente por su abundancia en es Pouàs (ver figura 1, anexo), tanto respecto a las otras especies del yacimiento como respecto a las especies del Pleistoceno superior de las Gimnesias. Es el caso de la familia Alaudidae, de la que se han obtenido más de 2900 restos fósiles en es Pouàs frente a 12 en las Gimnesias. Son especialmente comunes A. arvensis y G. cristata, cuya abundancia en términos absolutos en es Pouàs ( 51 y 52 individuos respectivamente) es muy superior a la de las mismas en las Gimnesias (un individuo [Seguí et al. 1997] y ninguno respectivamente).

Los restos fósiles de Motacillidae (en especial A. pratensis, con 26 individuos en es Pouàs) e Hirundinidae son también escasos en el registro de Mallorca y Menorca. Se han obtenido seis huesos de cada familia en las Gimnesias mientas que en es Pouàs se han obtenido 251 y 339 huesos respectivamente.

El alcaudón común, L. senator, es especialmente abundante en es Pouàs, con 215 individuos identificados y, sin embargo, se encuentra ausente hasta ahora en el registro de las Gimnesias. Por último cabe destacar la diferencia entre los dos archipiélagos en riqueza de individuos de tres especies: P. petronia (20 individuos vs. uno), C. chloris (25 individuos vs. dos) y E. calandra (14 individuos vs. uno [cf.]).

Estas cifras, si bien cuantifican la riqueza del yacimiento, son difíciles de interpretar ya que el registro es muy desigual en ambos archipiélagos. Por otra parte, los datos disponibles de las Gimnesias no son directamente comparables (salvo en el caso de los córvidos) al tratarse de conjuntos que incluyen diferentes huesos. En el caso de Alaudidae, Motacillidae, Laniidae e Hirundinidae, en términos relativos, la abundancia de restos en es Pouàs es muy superior a la del registro total obtenido en las Gimnesias. No obstante, la abundancia relativa (es decir, el número de ejemplares obtenidos respecto al total de huesos existentes en los yacimientos correspondientes) de $P$. petronia, $C$. chloris y E. calandra en las Pitiusas, no difiere tanto de la obtenida en las Gimnesias. 
En la familia Corvidae la diversidad de especies y la abundancia global de las mismas es superior en es Pouàs respecto a otros yacimientos del Pleistoceno superior de las Gimnesias. Es Pouàs, con cinco especies identificadas, es el yacimiento con más diversidad de especies de córvidos de Baleares. Corvus corax no consta (aparentemente, ver más adelante en el texto) en el registro de las Gimnesias, mientras que el resto de especies de córvidos identificadas en es Pouàs han sido obtenidas también en los yacimientos del Pleistoceno superior de las Gimnesias.

Dos de las especies de córvidos, P. pyrrhocorax y C. corax, destacan por la riqueza de restos obtenidos en es Pouàs. Se han identificado 935 huesos de un mínimo de 88 individuos de P. pyrrhocorax, frente a 149 huesos pertenecientes a un mínimo de 26 individuos obtenidos en los yacimientos del Pleistoceno superior de las Gimnesias (Mourer-Chauviré et al. 1977; Florit y Alcover 1987; Seguí 1997; Seguí et al. 1997). De la especie C. corax se han identificado más de 5057 huesos de un mínimo de 280 individuos, mientras que en las Gimnesias solamente se ha citado esta especie a partir de huesos procedentes de un yacimiento no especificado y de edad desconocida (Lambrecht 1933), conservados en el NHML. El hecho de que más de cien años de exploraciones paleontológicas en Mallorca no hayan permitido la obtención de nuevos restos de esta especie, sugiere que dichos restos probablemente pertenecían a individuos actuales.

De C. monedula se han obtenido dos individuos en es Pouàs frente a uno en las Gimnesias. P. graculus es más escasa en es Pouàs con 16 huesos de un mínimo de ocho individuos frente a más de 246 huesos de al menos 27 individuos en las Gimnesias.

Como síntesis del presente apartado, las diferencias más notables entre la comunidad ornítica fósil de las Pitiusas y las Gimnesias se encuentran en el grado de abundancia, muy superior en las Pitiusas, de los siguientes taxones: Alaudidae, Hirundinidae, Motacillidae, Laniidae, P. pyrrhocorax y C. corax.

En el caso de Alaudidae y Motacillidae, su abundancia en Ibiza estaría favorecida por la existencia de un hábitat favorable de llanuras abiertas y secas. Por otra parte, la abundancia de lagartijas (Podarcis pityusensis) en las Pitiusas puede ser la causa de la abundancia de Laniidae. En el caso de Hirundinidae, las paredes del yacimiento habrían dado cobijo a los individuos de esta familia favoreciendo su presencia en el depósito. Por último, el éxito de C. corax podría estar relacionado tanto con la disponibilidad de alimento procedente de carroña de aves gran tamaño (e.g., grullas, avutardas, gansos) como con la ausencia de aves carroñeras de gran tamaño en las Pitiusas (e.g., buitres). C. corax muestra una gran adaptabilidad a las variaciones tanto locales como estacionales en la disponibilidad de alimento (Marquiss y Booth 1986; Cugnasse y Riols 1987). Por otra parte se ha documentado la importancia de las anátidas en su dieta en algunos ambientes (e.g., Amat y Obeso [1989]).

La escasez de individuos de P. graculus debe estar relacionada con un clima menos favorable (más cálido) en las Pitiusas. Las Gimnesias, con una latitud más septentrional y las sierras de Tramuntana y de Llevant, contendrían hábitats más adecuados para esta especie. 


\subsubsection{Mediterráneo continental adyacente}

En el yacimiento de es Pouàs se han identificado 28 nuevas especies de paseriformes que no se encuentran en el registro fósil del área continental cercana a Ibiza (Calandrella cf. brachydactyla, G. cristata, A. campestris, A. pratensis, B. garrulus, P. modularis, E. rubecula, L. megarhynchos, P. phoenicurus, P. ochruros, Turdus cf. torquatus, Locustella sp., S. sarda/balearica, S. undata, S. melanocephala, Phylloscopus sp., M. striata, P. ater, L. senator, L. meridionalis, M. nivalis, S. serinus, L. curvirostra, cf. Pinicola enucleator, $C$. cocothraustes, cf. Plectrophenax nivalis, E. pusilla y E. schoeniclus).

Sin embargo, otras especies presentes en el área continental próxima a Ibiza en el Pleistoceno superior y que, por tanto, se podrían esperar en las islas, están ausentes en el registro de las Pitiusas. Entre ellas se encuentran de cinco a once especies de paseriformes (Garrulus glandarius, P. pica, O. oenanthe, T. pilaris, R. riparia, M. saxatilis, Fringilla coelebs, C. carduelis, E. citrinella, Acrocephalus arundinaceus, A. spinoletta). En el caso de O. oenanthe, T. pilaris, F. coelebs, C. carduelis, E. citrinella y A. spinoletta no se puede descartar su presencia en es Pouàs, ya que se han obtenido numerosos restos de sus correspondientes géneros, cuya identificación a nivel específico no ha sido posible. Estos restos presentan rangos de medidas entre los que se encuentran los de las citadas especies.

Los datos sobre especies de aves fósiles del Pleistoceno superior-Holoceno del Mediterráneo continental adyacente (Castellón, Valencia, Alicante, Murcia y Almería) se han obtenido a partir de los siguientes trabajos: Villalta 1964; Eastham 1973, 1988, 1989, 1998, 2001, 2005; Sánchez Marco 1988, 2004, 2007b; Davidson 1989; Badal et al. 1991; Hernández 1993; Cacho et al. 1995; Walker y Gibert 1998; Walker 2001, 2003 y Tyrberg 1998, 2008.

La identificación de los restos fósiles de es Pouàs aporta una valiosa información sobre la avifauna del Pleistoceno superior-Holoceno del sudoeste del litoral mediterráneo. Es Pouàs ha proporcionado 28 nuevas especies al conjunto de Passeriformes del sudoeste del Mediterráneo, lo que representa un incremento de más de un 50\% para dicho conjunto, que ha pasado de 53 a 81 especies.

\subsection{Comparación con la ornitofauna actual de Baleares}

\subsubsection{Especies nidificantes}

La obtención e identificación de huesos de individuos juveniles, de osificación incompleta, confirma que al menos 11 de las especies de paseriformes y rapaces de es Pouàs criaban en las Pitiusas en el pasado. Entre ellas se encuentran tres especies de rapaces diurnas (H. albicilla, Falco naumanni y Falco tinnunculus) una rapaz nocturna, (Otus scops) y siete especies de paseriformes (L. senator, A. arvensis, P. pyrrhocorax, $P$. graculus, C. corax, Turdus sp. y al menos una especie de la familia Hirundinidae). Aun- 
que todos los restos de Bubo sp. identificados corresponden a individuos adultos, esta especie también criaba en el pasado en Ibiza, ya que representa una especie endémica de las Pitiusas.

La mitad de dichas especies no crían en la actualidad en Baleares (H. albicilla, F. naumanni, Bubo sp., A. arvensis, P. pyrrhocorax y P. graculus) y C. corax, muy abundante en es Pouàs (más de 5000 restos fósiles), es una especie escasa en la actualidad en todas las islas, especialmente en las Pitiusas (López-Jurado 2012). El estatus de las dos especies de Pyrrhocorax ha cambiado aún más drásticamente siendo especies de presencia accidental en la actualidad en Baleares.

Por otra parte, en base a su estatus actual como especies nidificantes en Ibiza, se puede inferir que, además de las especies citadas, dos especies de rapaces (Falco peregrinus y Falco eleonorae) y al menos 18 especies de paseriformes presentes en el registro muy probablemente criaban en Ibiza durante Pleistoceno superior-Holoceno. Estas son: Calandrella cf. brachydactyla, G. theklae, cf. Ptyonoprogne rupestris, A. campestris, L. megarhynchos, M. solitarius, Turdus cf. merula, S. sarda/balearica, S. melanocephala, M. striata, Parus cf. major, P. domesticus, P. petronia, S. serinus, C. chloris, C. cannabina, L. curvirostra y E. calandra. Los dos grupos, aves nidificantes y probablemente nidificantes, sumarían un total de 32 especies de aves, de las que solamente 27 que crían en la actualidad en las Pitiusas.

En cambio, 15 de las especies de paseriformes y rapaces que crían actualmente en las Pitiusas no se han obtenido en es Pouàs: T. alba, A. otus, D. urbicum, T. troglodytes, $C$. cetti, C. juncidis, A. scirpaceus, R. ignicapilla, P. montanus, S. rubicola, C. carduelis, E. cirlus $M$. flava, O. oenanthe, S. atricapilla. De las seis últimas especies, se han identificado sus géneros en es Pouàs, sin haberse podido llegar a una determinación específica concreta. No se puede descartar su presencia en es Pouàs. Si esta se confirmase serían nueve las especies nidificantes actualmente en las Pitiusas y ausentes en es Pouàs.

\subsubsection{Especies ausentes en la actualidad en Baleares.}

En primer lugar, como se ha indicado, es notable la abundancia en es Pouàs de especies de córvidos que actualmente o bien presentan poblaciones muy escasas o bien se encuentran extintas en las Baleares. De las cinco especies de esta familia identificadas en el Pleistoceno superior de Ibiza solamente C. corax cría en las Baleares, y las restantes especies no se encuentran en la actualidad, salvo algunas de ellas accidentalmente $(P$. pyrrhocorax, P. graculus y C. corone). Las desapariciones de córvidos, al igual que en las Pitiusas, se han producido en el pasado en varias islas mediterráneas, como Mallorca $(P$. pyrrhocorax y P. graculus), Menorca (P. pyrrhocorax), Córcega (P. pica y P. pyrrhocorax) y Cerdeña (P. graculus) (Louchart 2002). Louchart (2002) apunta a un cambio en el entorno como causa de la desaparición de las dos especies de Pyrrhocorax, y atribuye la desaparición de la urraca, dependiente de cadáveres de grandes mamíferos como recurso alimenticio, a la desaparición de Megaloceros. 
Al menos otras diez especies de paseriformes identificadas en es Pouàs no se encuentran en la actualidad en las Islas Baleares (ver tabla 1, anexo), a excepción de alguna presencia accidental. Por otra parte, $M$. nivalis no se encuentra en la actualidad en las Pitiusas, pero sí aparece ocasionalmente en invierno en las Gimnesias, donde además también consta en el registro fósil. Se trata de una especie de alta montaña y de clima frío, por lo que su ausencia actual en Ibiza podría estar relacionada con la ausencia de hábitats adecuados, ya que la altitud máxima de la isla es inferior a $500 \mathrm{~m}$ y el clima es más cálido en la actualidad.

\subsubsection{Especies fuera de su área de distribución actual}

Se han identificado tres especies de paseriformes cuya área de distribución actual ocupa latitudes mucho más altas que el Mediterráneo. En primer lugar, B. garrulus cría en el norte de la región Paleártico-occidental, alcanzando ocasionalmente latitudes medias del oeste de Europa. De las otras dos especies, identificadas provisionalmente, P. enucleator solamente se encuentra en latitudes altas del Paleártico y P. nivalis alcanza latitudes medias y medias-bajas del centro y del este de la región. La presencia de estas especies en es Pouàs, está muy probablemente relacionada con periodos de clima frío como se explica más adelante en el texto.

\subsubsection{Especies ausentes en el registro de es Pouàs}

La reducida área de Ibiza junto con la enorme cantidad de restos de aves obtenidos en es Pouàs y la presencia en este yacimiento de diversos agentes bio-acumuladores, permiten suponer que la probabilidad de que algunas especies de aves hayan podido escapar a la deposición sea muy pequeña. Sin embargo, puede haberse dado un cierto sesgo en la deposición debido a la selección de presas por parte de los principales agentes bio-acumuladores del yacimiento y a la propia selección de hábitat por parte de las aves. Este sesgo permitiría entender la ausencia de diferentes especies de Charadriiformes limícolas en es Pouàs. A pesar de todo, la gran riqueza de este yacimiento tiende a minimizar la posibilidad de que la diversidad real de aves Passeriformes que criaban en el Pleistoceno superior-Holoceno de las Pitiusas, varíe notablemente respecto a la mostrada en este trabajo.

Algunas de las especies relativamente abundantes en la actualidad en las Pitiusas (migrantes, invernantes o sedentarias de abundancia moderada), se encuentran ausentes en el registro de es Pouàs. Entre ellas se encuentran cuatro especies de aves rapaces (dos que crían actualmente, Asio otus y T. alba, y dos presentes regularmente como migrantes, Pernis apivorus y Circus aeruginosus) y 15 especies de paseriformes. De estas especies, 10 crían en la actualidad en las Pitiusas (ver atrás en el texto) y las otras cinco se encuentran como migrantes y/o invernantes: R. riparia, A. trivialis, Hippolais icterina, H. polyglotta y Regulus regulus. 


\subsection{Indicaciones paleo-ecológicas generales del Pleistoceno superior-Ho- loceno de las Pitiusas}

El estudio de las faunas fósiles de es Pouàs evidencia la ausencia de mamíferos terrestres previa a la llegada del hombre. Esta peculiaridad del ecosistema del pasado de las Pitiusas no se conoce en ninguna otra isla de superficie similar de la cuenca mediterránea (Florit et al. 1989; Alcover et al. 1994; Palmer et al. 1999; Bover et al. 2008; Alcover y Bover 2008).

Poco se conoce de la avifauna correspondiente al episodio faunístico anterior al Pleistoceno superior-Holoceno de las Pitiusas. Seguí y Alcover (1999) postulan que la extinción masiva de las especies de vertebrados de dicha época, habría conducido a un cambio en la composición de la comunidad ornítica de las islas. Dicha comunidad se vería favorecida por la enorme cantidad de recursos disponibles debida a la ausencia de mamíferos, que permitiría a estas islas albergar una diversidad y abundancia de aves, muy elevadas en relación a su área.

La comunidad ornítica del Pleistoceno superior-Holoceno de las Pitiusas presenta algunos paralelismos con la del archipiélago de Hawái (ver Seguí y Alcover 1999). Ambos archipiélagos (Hawái y las Pitiusas) albergan islas cuyas comunidades de vertebrados presentan una estructura trófica peculiar. En dichas comunidades, las águilas marinas ocupan el nicho de superdepredadores y los anseriformes ocupan el nicho de los herbívoros de talla media-grande. Así mismo, se supone que en ambos archipiélagos se han dado conductas peculiares en ciertos grupos de aves: las rapaces nocturnas presentarían hábitos más diurnos o crepusculares, existen aves endémicas (rálidos) de hábitos más terrestres que sus parientes continentales y las rapaces diurnas serían o bien generalistas o especialistas en aves. Por último, ni en Hawái ni en las Pitiusas habitaba ninguna especie de la familia Tytonidae pero sí una gran diversidad de paseriformes omnívoros de talla media (córvidos) y de pequeños paseriformes (Seguí y Alcover 1999).

\section{4·3.1 Origen del depósito}

Algunos de los restos de aves del depósito de es Pouàs deben pertenecer a individuos que vivían y criaban en las paredes del yacimiento y que habrían sido incorporados al mismo tras su muerte natural. Este sería el caso de varias especies de rapaces, como H. albicilla, F. tinnunculus y O. scops, que habrían usado las paredes de la cavidad para nidificar y/o como posaderos. Entre los paseriformes, los taxones que podrían haber habitado las paredes del yacimiento y, por tanto, haber sido incorporados al mismo de forma natural tras su muerte son los siguientes: P. ochruros, M. solitarius, C. corax, C. monedula, P. pyrrhocorax, P. graculus e Hirundinidae.

Entre las especies de aves rapaces identificadas se encuentran los principales responsables de la incorporación de aves y otros vertebrados e invertebrados al yacimiento, mediante bio-acumulación de restos procedentes de su alimentación (ver Guerra et al. 2013). 
El pigargo europeo es probablemente el agente bio-acumulador de restos de especies de aves de talla media y grande como gansos, grullas, avutardas, así como seguramente también una parte de los cuervos y chovas obtenidos en el depósito (Alcover y McMinn 1992). Entre las otras especies de rapaces diurnas, el halcón peregrino, el azor y el gavilán podrían haber incorporado restos de aves de talla mediana y pequeña al yacimiento. Por último, entre las especies de rapaces nocturnas, los únicos potenciales bio-acumuladores de aves son la lechuza campestre y el búho (Bubo sp.).

\section{4·3.2 Paleo-ambiente}

El hábitat que ocupan actualmente las especies de aves identificadas en es Pouàs, permite establecer hipótesis sobre los rasgos del paisaje del pasado de las Pitiusas. La comunidad ornítica obtenida refleja un ambiente con llanuras abiertas, espacios rocosos y áreas de bosque y matorral, en cuyas cercanías debía existir alguna zona palustre (permanente o periódica) (ver tabla 1, anexo). El Pla de Corona y el Pla de son Gilabert, localizados en los alrededores del yacimiento, son cuencas endorreicas inundables que probablemente constituían dichas zonas palustres. La comunidad ornítica refleja así mismo la riqueza de recursos del área marina circundante, que sustentaba abundantes poblaciones de varias especies de Procellariiformes.

Varias especies de aves identificadas en es Pouàs son típicas de ambientes rocosos (e.g., Apus apus, cf. Ptyonoprogne rupestris, P. pyrrhocorax, P. ochruros, M. solitarius, Hirundo sp., Columba livia, cf. Plectrophenax nivalis, F. tinnunculus y F. eleonorae). Así mismo, en el Pleistoceno superior-Holoceno de las Pitiusas constan varios taxones relacionados con ambientes marinos (Hydrobates pelagicus, Calonectris diomedea, $\mathrm{Pu}$ ffinus puffinus, Phalacrocorax aristotelis), llanuras abiertas (e.g., Grus grus, Burhinus oedicnemus, Coturnix coturnix, Porzana porzana, Otis tarda, O. scops, A. flammeus, Alaudidae, Motacillidae), entornos forestales (e.g., Scolopax rusticola, B. garrulus, P. modularis, E. rubecula, P. phoenicurus, Turdus, Paridae, O. oriolus), áreas de matorral (e.g., A. pratensis, L. megarhynchos, Sylvia sarda/balearica, C. cannabina) y terrenos palustres (e.g., R. eivissensis, Anser sp., Numenius arquata, Porzana porzana, Pluvialis squatarola, Gallinago gallinago, Anas crecca, E. schoeniclus) (Florit et al. 1989; McMinn et al. 2005; Guerra et al. 2013).

\section{4·3·3 Indicaciones paleo-climáticas}

Huntley y Webb (1989) constatan que durante los periodos glaciales, las principales cordilleras del Paleártico occidental perdían la vegetación arbórea y, en consecuencia, la biota forestal se concentraba en el sur y el sudeste de Europa. En los periodos interglaciales, dicha biota, se re-expandía hacia el Norte. Al igual que sucede con las comunidades vegetales, muchas especies de aves de latitudes altas se han encontrado en yacimientos fósiles que datan del último periodo glacial, situados muy al sur del área de distribución actual de dichas especies (Mourer-Chauviré 1993). 
La región mediterránea ha actuado como un refugio para algunas especies de aves al menos desde finales del Pleistoceno inferior y especialmente durante la última glaciación. En consecuencia, los límites de la distribución de esas aves han variado notablemente durante el cuaternario (Sánchez Marco 2004). Según este autor, para analizar la relación entre las ornitocenosis y el clima, conviene centrarse en el análisis y comparación de las comunidades orníticas fósiles y actuales, una de las bases del modelo de los refugios mediterráneos estables (ASMR).

Seis de las especies presentes en el Pleistoceno superior de Ibiza tienen una significación climática especial, ya que son claros indicadores de climas fríos. Cinco de estos taxones (B. garrulus, P. collaris, P. graculus, cf. Pinicola enucleator y cf. Plectrophenax nivalis) se encontraban en Ibiza durante el Pleistoceno superior mientras que el otro taxón, $M$. nivalis, también se ha identificado en un nivel correspondiente al Holoceno. Solamente una de estas especies se encuentra en Ibiza en la actualidad, P. collaris, donde es escasa y solamente se encuentra como inmigrante invernal. El resto de especies han desaparecido de las Pitiusas y, en general, de las Baleares excepto $M$. nivalis, de presencia rara como invernante en Mallorca. La presencia de estas especies en el pasado apunta a que el clima de Ibiza durante la deposición de sus restos era más frío que en la actualidad, favoreciendo su presencia en latitudes bajas. Este período frío del Pleistoceno superior correspondería al final de la última glaciación, que tuvo su máximo entre los años 30.000-18.000 antes del presente (Ivi-Ochs et al. 2008).

Los hallazgos de es Pouàs constituyen una nueva evidencia del desplazamiento de algunas especies de aves hacia latitudes más bajas durante la última glaciación. La abundancia de taxones con significación climática junto con su ausencia o escasez extrema en la actualidad en Baleares, son acordes al modelo ASMR.

\section{4·3.4 Efectos de la llegada del hombre sobre la ornitofauna}

La llegada del hombre a Ibiza fue devastadora para la fauna autóctona con unos rangos de extinción elevados. A diferencia de lo ocurrido en muchas islas oceánicas, donde tras la llegada de los humanos desaparecieron numerosas especies endémicas, las Pitiusas solamente parecen haber perdido dos especies endémicas (Rallus eivissensis y Bubo sp.). No obstante, tras la llegada de los humanos a Ibiza, desaparecieron diferentes especies de aves de talla grande y disminuyó considerablemente la abundancia de aves marinas (Alcover et al. 1994). La desaparición de especies de talla grande afectó a todas las aves de más de 1,5 kg ligadas al medio terrestre (G. grus, O. tarda, Anser sp. y H. albicilla).

La desaparición de algunas de las especies de aves identificadas en este trabajo, puede estar relacionada con los cambios ecológicos acontecidos tras la llegada de los humanos. Entre las especies de paseriformes presentes en el Pleistoceno superior-Holoceno de es Pouàs, nueve han desaparecido de las Pitiusas por causas aparentemente ajenas a las condiciones climáticas actuales (L. arborea, O. leucura, P. ater, P. pyrrhocorax, C. corone, C. monedula, cf. Pyrrhula pyrrhula, E. pusilla y E. schoeniclus). 
La pérdida de tres de las cinco especies de córvidos, P. pyrrhocorax, C. monedula y C. corone, y la pérdida de la población autóctona de C. corax, podrían ser consecuencia del cambio en el entorno, como se ha dicho anteriormente en el texto. Además del impacto en la vegetación, la desaparición de aves de talla grande pudo causar un impacto en las poblaciones de carroñeros que se alimentaban de sus cadáveres. Las tres especies de Corvus son carroñeras ocasionales y $P$. pyrrhocorax se alimenta de los cadáveres directamente (Rolando et al. 2008) o, más comúnmente, de los insectos (adultos y larvas) que encuentran en los mismos. La explotación de carcasas de aves por estas especies se ha descrito en la actualidad (e.g., Hiraldo et al. 2009; Mason y Mcdonald 2009) y, ante la ausencia de mamíferos y la posible escasez de otros recursos tróficos, debe haber tenido más importancia en la dieta de los córvidos del pasado de las Pitiusas.

Las razones de la desaparición de las restantes especies (L. arborea, O. leucura, P. ater, cf. Pyrrhula pyrrhula, E. pusilla y E. schoeniclus) son más difíciles de conocer y probablemente están relacionadas con la pérdida de hábitat.

Otras especies, ausentes en el registro fósil de es Pouàs, muy probablemente se han asentado con éxito en las Pitiusas tras la llegada del hombre, favorecidas por los cambios que nuestra especie ha realizado en estos ecosistemas tales como el desarrollo de la agricultura y la introducción de nuevas especies. Es el caso de dos especies de rapaces, T. alba y A. otus, consideradas colonizadores recientes cuyo asentamiento exitoso en Ibiza se produjo probablemente gracias a la introducción de especies de micromamíferos (Guerra et al. 2013).

De la misma forma, se puede considerar que algunas de las especies escasas en el registro de las Pitiusas habrían aumentado su abundancia en la actualidad, debido a las transformaciones antrópicas del ecosistema. En esta categoría se encuentra el gorrión (P. domesticus), identificado en un nivel holocénico y en otro estrato no datado. La expansión holocénica del gorrión en Europa, que presumiblemente se produjo de manera simultánea a la de la agricultura (Ericson et al. 1997), coincide con su aparición en el registro fósil de Ibiza. Del mismo modo, otras especies granívoras probablemente se han vuelto más frecuentes y sus poblaciones más numerosas gracias al desarrollo de la agricultura.

\subsection{Evolución insular}

La situación de las Islas Baleares, separadas durante millones de años del continente, las convierte en las más aisladas (geográfica y cronológicamente) del Mediterráneo. Este aislamiento ha favorecido la evolución insular de algunas especies, que han adquirido características propias que las diferencian de las poblaciones coetáneas continentales.

En el caso de las Pitiusas, gracias al estudio de la fauna de es Pouàs, se han identificado dos especies endémicas, una descrita (R. eivissensis) y otra identificada a nivel genérico y de la cual no se dispone de material adecuado para su descripción (Bubo sp.). 
Por otra parte se han constatado cambios en las medidas y proporciones corporales en poblaciones de aves fósiles de Ibiza. En algunos casos estos cambios de talla se relacionan con la insularidad mientras que otros se pueden relacionar con cambios climáticos o ecológicos que afectan tanto a poblaciones insulares como a continentales.

Estos factores actuarían en la evolución de las especies del pasado de las Pitiusas, dando lugar a cambios en la morfología de algunas especies y a la aparición de nuevas especies y subespecies.

\subsubsection{Especies endémicas}

Rallus eivissensis es la única especie de ave endémica descrita a partir de material fósil de es Pouàs. Se trata de una especie cercana al rascón europeo, Rallus aquaticus, de aspecto más pequeño y robusto que éste. La talla de las alas de R. eivissensis, más cortas que las de su pariente actual, sugiere una reducción de la capacidad de vuelo. La extinción de esta especie en Ibiza coincide con la colonización humana de las Pitiusas y está probablemente relacionada con este evento (McMinn et al. 2005).

Los restos fósiles identificados como Bubo sp. proceden de niveles del Pleistoceno superior y muestran una talla notablemente diferente a los de la especie actual. Tanto el premaxilar como las falanges son más pequeños que los de Bubo bubo actuales, excepto una falange terminal, de talla similar a las de especie actual (Guerra et al. 2013). Del mismo modo que Bubo insularis en Córcega y Cerdeña (Mourer-Chauviré y Weesie 1986; Louchart 2002), el búho real de Ibiza podría haber evolucionado hacia una reducción de la talla corporal dando lugar a una nueva especie endémica. Sin embargo, la escasez de material fósil suficientemente diagnóstico impide realizar un estudio más completo de esta nueva especie.

\subsubsection{Cambios en la talla corporal}

Al menos dos de las especies identificadas presentan características biométricas peculiares que se pueden relacionar con el aislamiento insular: Haliaeetus albicilla y Corvus corax.

Todos los individuos de H. albicilla obtenidos en es Pouàs son más grandes que sus coetáneos continentales y que los individuos actuales (tabla 36, anexo). Algunos de estos individuos habrían llegado incluso a alcanzar un peso de unos $9 \mathrm{~kg}$ y una talla similar al águila más grande del género, Haliaeetus pelagicus (Alcover y McMinn 1992). En cambio, los restos fósiles procedentes de otras islas mediterráneas presentan una talla similar a la de los individuos fósiles y actuales del continente (e.g., Mourer-Chauviré 1975; Weesie 1988; Louchart 2002), y son muy escasos. Los recursos disponibles en estas islas probablemente eran insuficientes para sustentar una población como la de Ibiza. Los individuos de es Pouàs representan, por tanto, un caso de evolución insular hacia una talla corporal mayor, probablemente favorecida por la abundancia y el tamaño de las presas y la ausencia de competidores y depredadores. 
La gran cantidad de restos fósiles de C. corax, ha permitido conocer al detalle las características osteológicas de esta especie en el pasado en Ibiza. El cuervo del Pleistoceno superior-Holoceno de las Pitiusas, fue identificado inicialmente como Corvus antecorax (Florit et al. 1989) debido a su talla, significativamente más pequeña que la de las poblaciones actuales. Estudios recientes sugieren que $C$. antecorax debería ser incluido en Corvus corax (Stewart 2007), ya que la variación de su talla respecto a las poblaciones actuales, no es superior a la variación que existe entre las distintas subespecies actuales, si bien Louchart (2008) aboga por mantenerlo como una crono-subespecie. C. antecorax (Mourer-Chauviré 1975) fue descrito a partir de materiales del Pleistoceno medio y las dimensiones de sus huesos son superiores a las de los individuos de es Pouàs.

Los individuos de C. corax procedentes de yacimientos del Pleistoceno superior de la Península Ibérica son biométricamente similares a los de las poblaciones actuales. Se han descrito varias subespecies actuales de C. corax de talla pequeña, como C. corax tingitanus en el norte de África, C. corax hispanus en la Península Ibérica y Baleares y C. corax canariensis en las Islas Canarias (Hernández et al. 1993). El cuervo de es Pouàs presenta un tamaño corporal sumamente reducido, inferior incluso al de estas tres subespecies. En el Pleistoceno superior-Holoceno europeo no se conoce ninguna población de Corvus corax de tamaño reducido, por lo que debe considerarse que el tamaño corporal de los fósiles ibicencos es el resultado de un proceso de evolución insular. Esta población autóctona de cuervos ha desaparecido de las Pitiusas tras la llegada de los humanos. Los cuervos presentes en la actualidad en estas islas se atribuyen a C. corax hispanus y proceden de una colonización reciente.

Los ejemplares de otras especies obtenidas en es Pouàs son biométricamente diferentes a los individuos actuales de comparación. Entre ellas se encuentran Asio flammeus y otros Passeriformes.

Así mismo, los restos de A. flammeus procedentes de es Pouàs, presentan una talla superior a la de los ejemplares de las poblaciones actuales. Por el contrario, los individuos procedentes de 14 yacimientos del Pleistoceno superior y seis del Pleistoceno medio de Francia presentan la misma talla que las poblaciones actuales de esta especie (Mourer-Chauviré 1975). Los individuos obtenidos en el Pleistoceno superior de Creta (Weesie 1988), Córcega (Louchart 2002) y en Gibraltar (Cooper 1999) son también similares a los de las poblaciones actuales. Por tanto, las diferencias osteológicas de los individuos de es Pouàs respecto a dichas poblaciones, podrían ser el resultado de un proceso de evolución insular hacia una talla superior en los individuos de Ibiza.

Además de las citadas, otras especies de paseriformes presentan cráneos o húmeros de talla superior a los de los individuos actuales de comparación. Turdus cf. viscivorus y Calandrella cf. brachydactyla presentan húmeros más largos y robustos que sus respectivos actuales. Varias especies, presentan modificaciones en las medidas del cráneo, especialmente en el premaxilar y la mandíbula, respecto a las poblaciones actuales. Es el caso de P. petronia, G. cristata, C. chloris (algunos individuos presentan narinas 
más grandes y pico más corto), C. cannabina (premaxilar y mandíbula ligeramente más cortos). Sin embargo, estas diferencias pueden no ser atribuibles a evolución en condiciones de insularidad.

Clegg y Owens (2002) sugieren, para ambientes insulares, la existencia de una "regla insular" según la cual en las islas se produciría una reducción de la talla corporal de las especies de aves de talla grande, mientras que las especies de talla pequeña sufrirían un aumento en su talla corporal. Sin embargo, Meiri et al. (2010), tras analizar miles de especies de aves, no encontraron ninguna evidencia de esta hipótesis sino todo lo contrario. En la mitad de los géneros de aves objeto de su estudio, la especie de mayor talla corporal correspondía a una especie endémica insular. Louchart (2005), en un estudio específico sobre Strigiformes, postula que en las islas las aves Strigiformes tienden a incrementar su talla corporal.

Las medidas de los ejemplares de $H$. albicilla procedentes de es Pouàs documentan que esta especie adquirió una talla corporal superior en las Pitiusas. Esta evidencia es contraria a la "regla insular" postulada por Clegg y Owens (2002). En cambio, Bubo sp. habría sufrido una reducción de talla corporal. Si bien esta reducción de talla corporal es acorde con la teoría de Clegg y Owens (2002), no se ajusta a la tendencia evolutiva de aumento de la talla corporal que se da en las rapaces nocturnas en las islas (ver Louchart 2005). En definitiva, los fósiles de es Pouàs cuestionan las dos teorías mencionadas. H. albicilla contradice a Clegg y Owens (2002), mientras que Bubo sp., ( al igual que Otus frutuosoi de las Azores y Bubo insularis de Córcega y Cerdeña) cuestiona la teoría de Louchart (2005). 
4 - DISCUSIÓN 



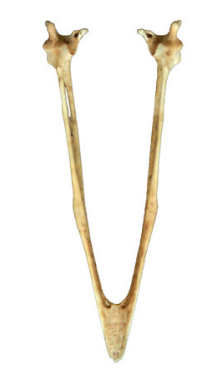

EL GREMIO

DE LAS AVES RAPACES

DEL PLEISTOCENO

SUPERIOR-HOLOCENO DE IBIZA 


\section{5 - EL GREMIO DE LAS AVES RAPACES DEL PLEISTOCENO SUPERIOR-HOLOCENO DE IBIZA}

\subsection{Introducción}

Las aves rapaces son una pieza esencial de los ecosistemas tanto presentes como pasados. Su estudio, dentro de las redes tróficas, es fundamental para entender el funcionamiento de las mismas. En las islas carentes de mamíferos, ejercen el monopolio de la depredación de vertebrados (Alcover y McMinn 1994). Las aves depredadoras de vertebrados terrestres se incluyen básicamente dentro de los órdenes Falconiformes y Strigiformes. El único género eventualmente depredador de vertebrados terrestres identificado en es Pouàs y que no pertenece a dichos órdenes es Lanius (ver capítulo 3).

En el pasado, diferentes aves depredadoras han contribuido a la bio-acumulación de material fósil tras la ingesta de presas y la posterior deposición de sus restos en forma de egagrópilas. En el caso de es Pouàs, las aves rapaces son las responsables de la incorporación de la mayor parte del material de vertebrados fósiles del depósito y por tanto, han determinado la riqueza del yacimiento.

En la publicación del apartado 5.2 se presenta la comunidad de aves de presa identificadas a partir del material obtenido en es Pouàs. La muestra de material fósil estudiada es probablemente la mayor, en número de huesos de aves de presa, procedente del Pleistoceno superior-Holoceno de una isla del Mediterráneo. Esta abundancia de material sugiere que muy pocas o ninguna de las especies de rapaces del pasado de las Pitiusas habrían escapado a la deposición en es Pouàs. Por tanto, este conjunto fosilífero ofrece una oportunidad única para establecer la estructura del antiguo gremio de depredadores, así como para valorar hipótesis biogeográficas.

Este estudio ha permitido evaluar los patrones de evolución de la talla corporal en las rapaces insulares propuestos por diferentes autores (e.g., Blondel y Frochot 1967; Blondel et al. 1988; Clegg y Owens 2002), en un ambiente libre de la influencia humana. 
La comparación de la avifauna de rapaces fósiles de las Pitiusas con la de otras islas del Mediterráneo, ha permitido documentar la singularidad de dicha avifauna. A su vez, se ha establecido una comparación con el gremio de depredadores que habita las Pitiusas actualmente, con el fin de realizar una aproximación al grado de perturbación de la actividad humana en la comunidad actual de rapaces de estas islas.

Por último, se ha analizado la importancia de cada especie como bio-acumulador de restos de vertebrados e invertebrados procedentes de su alimentación.

\subsection{Publicación}

\section{The Upper Pleistocene - Holocene raptorial guild from the Pityusic Islands (Western Mediterranean Sea)}

\begin{abstract}
Predators are essential to understand the ecology of trophic networks in past and present ecosystems and their role as bone bioaccumulators may determine the richness of fossil sites. Prior to human arrival terrestrial mammals were absent from the Pityusic Islands (Eivissa and Formentera, Western Mediterranean Sea), a feature that represents an ecological singularity on the Meditterranean. The predatory guild from the Upper Pleistocene and Holocene of the Pityusic Islands is approached here through the study of Accipitridae, Falconidae and Strigidae. All the fossils come from Es Pouàs, an extraordinarily rich fossil site in Eivissa that provided more than two thousand bones of birds belonging to these three families. The importance of each species as bioaccumulator and a comparison with current fauna are outlined.
\end{abstract}

\section{Introduction}

The fossil record usually consists of bone remains that document selected parts of ancient biotas (Winn Jones, 2006). The limited representativeness of the available fossil assemblage, combined with the presence of extinct species without unambiguous living ecological relatives, frequently impedes a detailed approach to the structure and function of ancient communities. Nevetheless, the study of palaeo-food webs has been identified as a fruitful avenue for future ecological research on trophic networks (Ings et al., 2008; table 2). Presented here is an ancient guild of predators reasonably approached through the fossil record of the Accipitridae, Falconidae and Strigidae from the Upper Pleistocene and Holocene of the Pityusic Island of Eivissa (Western Mediterranean Sea). The relatively recent origin of this fauna precludes the presence of highly derived endemic species with uncertain ecological roles. The richness of the studied sample (probably the richest sample, in number of obtained fossil bones, of a predatory bird guild ever found in the Upper Pleistocene - Holocene on a Mediterranean island) allows us to assume that probably very few, if any predator species of this ancient guild escaped fossilization. 
Indeed, the huge sample of raptorial fossil bones obtained offers a unique opportunity to test some biogeographic hypotheses. As ecological by-products derived from the theory of the island biogeography (MacArthur and Wilson, 1967), different authors have explored questions such as the patterns and evolution of size in insular raptorial birds (e.g., Blondel and Frochot, 1967; Blondel et al., 1988; Clegg and Owens, 2002). This study allows testing some proposals of these authors on the basis of the analysis of a raptorial community free of the human influence and disturbance.

Eivissa is the largest of the Pityusic Islands, an archipelago situated $90 \mathrm{~km}$ off the Iberian mainland comprising two main islands (Eivissa, 541 sq km, and Formentera, $82 \mathrm{sq} \mathrm{km}$ ) and about 90 surrounding islets. These islands have acted as an isolated archipelago since the end of the Messinian (5.35 Ma), merging recurrently during glacial periods, and splitting during the interglacials. The faunal succession on these islands has been described elsewhere (Bover et al., 2008). For the purposes of our research the most relevant point is the presence of a peculiar and highly disharmonious fauna that survives into (at least) the Upper Pleistocene and the Holocene (prior to human arrival). This fauna has been considered as the strongest faunal anomaly in the Mediterranean, being the Pityusic Islands the only non-desert territory larger than $500 \mathrm{sq} \mathrm{km}$ in this region that was totally devoid of terrestrial mammals (Florit et al., 1989). Among vertebrates, only birds, a lizard (Podarcis pityusensis), and several bats (Alcover, 2003) were present in the Pityusic Islands when humans first settled, probably around 4150-4350 years ago (Alcover, 2008).
Although the evidence of absence of terrestrial mammals in the Pleistocene and Holocene of the Pityusic Islands was presented ca. 25 years ago (Florit et al., 1989; Alcover et al., 1994), the bird fauna still remains poorly known. Fossil sites are scarce in the Pityusic Islands, less than a dozen places have been described so far (Alcover, 2001). Nevertheless, one of the sites (Es Pouàs, Sta. Agnés de Corona, Ets Amunts, north of Eivissa; Florit et al., 1989) is extraordinarily rich, and has furnished numerous remains of extinct fauna. In this paper, a part of this fauna (consisting of the representatives of two orders that include the main members of the predatory guild) is analysed and discused. At least 279 different individual birds of prey have been recovered, represented by 2394 bones of Accipitridae, Falconidae and Strigidae.

Es Pouàs is a 19 m-deep and ca. 7 m diameter sinkhole (Trias, 1983) that acted as a sedimentary trap at least during the last 30,000 years. More than 120,000 bones where recovered during 6 months of fieldwork (1989-1994). This huge amount probably represents less than $10 \%$ of the material deposited at the site, according to the limited volume excavated. Among these remains, the record of predatory birds allows to establish some comparison with the extant Pityusic fauna (to evaluate its degree of disturbance) and also to compare it with the Upper Pleistocene and Holocene of other Mediterranean islands. Additionally, some data on the structure of predatory guilds on islands will be discussed.

\section{Material and methods}

Material curated at the Institut Mediterrani d'Estudis Avançats (IMEDEA) has been 
studied. The sample consists of selected bones recovered at Es Pouàs (UTM 37222.92 m, 4321971.66 m). Skulls, jaws, long bones and bones of shoulder and pelvic girdle were determined using comparative material curated at IMEDEA, the Natural History Museum (London), the Natuurhistorisch Museum (Rotterdam), as well as with literature (Milne Edwards, 1867-71; Langer, 1980; Otto, 1981; Schmidt-Burger, 1982; Solti, 1980, 1981a, 1981b, 1996). Ribs, vertebrae and phalanges were identified only in a few cases (e.g., those from Haliaeetus albicilla).

A summarized list of materials and an estimate of the minimal number of individuals are presented for each taxon (Table 53, annex, and text). Note that no differentiation between complete or fragmented bones has been made in these lists, although the preservation state of the bones, as well as their stratigraphic position, have been considered for MNI estimates. Relevant data on the known fossil record is summarized for each taxon, mainly following Tyrberg's catalogue and its addenda (Tyrberg, 1998, 2008) and additional literature.

All the material presented here was recovered at Es Pouàs, at levels dated from the last glaciation to the first arrival of humans. Information on the chronology of findings, mainly obtained in squares $\mathrm{A}_{3}$ and $\mathrm{D}_{4}$, is presented. Currently, twelve ${ }^{14} \mathrm{C}$ AMS-dates are available from Es Pouàs, nine of them concerning the palaeontological (pre-anthropic) deposit (Alcover, 2003), and three related to archaeological layers, documenting the earliest known human presence on the Pityusic Islands (Alcover, 2008). The palaeontological dates cover ca. 35,000 ka (square $\mathrm{A}_{3}$, level 8, at $-320 /-400 \mathrm{~cm}$ from reference level measured at the wall of the cave; Alcover, 2003) until ca. 6 ka (square
A3, at $-60 /-80 \mathrm{~cm}$, and square D4). From the Upper Pleistocene, the major part of the material comes from levels placed under level 3 of A3. The material from square $\mathrm{D}_{4}$ includes a higher representation of Holocene bones.

The sedimentary filling of Es Pouàs during the deposition time span is very homogeneous, which can be related to the absence of terrestrial mammals on the island. When present, terrestrial mammals compact the sediment, through trampling (e.g., Gé et al., 1993; Vallverdú, 2002), allowing an easier differentiation of stratigraphic units.

\section{Systematic paleontology}

Family ACCIPITRIDAE

Genus Haliaeetus Savigny, 1809

Haliaeetus albicilla (Linnaeus, 1758)

Fig. 15, annex

Material: 2 crania, 1 lacrimal, 1 praemaxilla, 6 mandibles, 3 quadrates ( 2 left, 1 right), 5 humeri (2 left, 2 right, 1 medial), 11 ulnae (6 left, 4 right, 1 medial), 7 radii (2 left, 4 right, 1 medial), 4 ossa carpi ulnare (3 left, 1 right), 3 ossa carpi radiale (1 left, 2 right), 4 carpometacarpi ( 2 left, 2 right), 12 coracoidea (4 left, 8 right), 6 scapulae (4 complete, 2 fragments), 4 fibulae (2 left, 2 right), 6 sterna, 2 synsacra, 15 ribs, 50 vertebrae , 4 pelves, 8 femora (4 left, 4 right), 4 tibiotarsi (1 left, 3 right), 9 tarsometatarsi (7 left, 2 right), 3 metatarsi I, and 49 phalanges. Total: 219 bones. Minimum number of individuals (from here on, MNI): 8 (based on the coracoidea).

Stratigraphic range: present in two levels of square $\mathrm{A}_{3}$ (4 and 8), and in one level of square D4. It is spread over the complete stratigraphic range (Upper Pleistocene to Holocene). 
Current Western Palaearctic Distribution: the White-tailed Eagle is widespread as breeder in the northern part of the Palaearctic region, Iceland and coastal Greenland and a few pairs may still breed in Turkey, Greece and Croatia. It winters as south as India and Southeast Asia. Its populations are in decline (Snow and Perrins, 1998). Absent currently from Eivissa and vagrant (accidental) in Mallorca (AOB, 2011).

Fossil occurrence: common in the Palaearctic Late and Middle Pleistocene sites of Northern, Central and Eastern Europe (United Kingdom, Austria, Belgium, Germany, France, Croatia, Georgia, Greece, Hungary, Poland, Romania, Russia), less common in Iberian localities (some findings in $\mathrm{Gi}^{-}$ braltar, Castelló and Girona; Tyrberg, 1998, 2008). Also present in the Canary Islands fossil record (Rando, 1995).

Comments: the White-tailed Eagle was identified by Alcover and McMinn (1992) as the top predator of the Upper Pleistocene in Eivissa. The bones of the White-tailed Eagle from Es Pouàs display diagnostic features such us the peculiar shape of the bill, the relatively narrow caput humeri, the humerus fossa pneumotricipitalis wider and more rounded that in Aquila, the shape of the processus lateralis of the coracoid, the very long crista tibiae of tibiotarsus, the short and robust tarsometatarsus with a slightly developed crista lateralis and a poorly developed tuberositas musculus fibularis. Phalanges 1 and 2 of the second pedal digit are fused, in contrast with Aquila (Olson, 1982; Boessneck, 1985). Ratios between bone measurements agree with those known for the species.

The size of the bones of the White-tailed Eagle from Es Pouàs is considerably larger than those of the largest specimens meas- ured by Boessneck (1985), Jánossy (1985) and Olson and James (1991), or overlap with them (Alcover and McMinn, 1992). At least some specimens were unusually large (in comparison to the current standards). One bone (a coracoid) represents a juvenile specimen, supporting that the species was breeding on Eivissa during the Upper Pleistocene. It is also present (11 bones, very probably of the same specimen) in the Holocene sediments from Cova des Riuets, Formentera (Pityusic Islands; Alcover et al., 2004).

\section{cf. Aquila/Haliaeetus}

Fig. 16, annex (L-M)

Material: 3 pedal phalanges. MNI: 1 .

Stratigraphic range: Holocene.

Comments: three pedal phalanges similar in size and shape to those of the Golden Eagle (Aquila chrysaetos) have been recovered. The shape of the Phalanx 2 of digit IV in Haliaeetus albicilla is elongated, while in Aquila chrysaetos and in the fossil (two bones, one left and one right) it is shorter and more robust. The tuberculum extensorium is more prominent in Haliaeetus albicilla than in the last two, while the fovea ligamenti collateralis, in ventral view, stands out more in Aquila chrysaetos and in the fossil. In ventral view the Phalanx 2 of digit II have the diaphysis slimmer and with a flat surface in Haliaeetus albicilla, while in the Golden Eagle and the fossil it is more robust and has a concave surface. The tuberculum flexorium in Haliaeetus albicilla is sharper than in the Golden Eagle and the fossil. Although theses traits suggest the identity of the fossils with Aquila, the scarcity of comparison material and the poor taxonomic significance of the pedal 
phalanges compel us to present them tentatively as cf. Aquila/Haliaeetus.

Genus Circus Lacépède, 1799

Circus cyaneus (Linnaeus, 1766)

Fig. 16, annex (E-K)

Material: 5 mandibles (fragments), 1 humerus, 2 ulnae (1 left, 1 right), 2 carpometacarpi (left), 1 scapulae, 1 sternum, 1 femur, 2 tibiotarsi (1 left, 1 right), 2 tarsometatarsi (1 left, 1 right) and 2 phalanges. Total: 19. MNI: 5 (based on the mandibles).

Stratigraphic range: the species is present both in the Upper Pleistocene and the Holocene.

Current Western Palaearctic Distribution: widespread in northern and middle latitudes of the Palaearctic region. Migrant breeding occurs in northeast areas, and winter distribution includes the west and southeast of the Palaearctic region (Snow and Perrins, 1998). It is rare in winter in Eivissa (AOB, 2011).

Fossil occurrence: scarce in the Late Pleistocene fossil sites of Europe (Austria, Germany, Croatia, France, Hungary, Russia, and Ukraine). Present in the Sardinian Pleistocene (Malatesta and Suriano, 1970) and rare at European sites more ancient than Late Pleistocene (Tyrberg, 1998, 2008).

Comments: the identification of Circus cyaneus bones is based on the diagnostic characters of the genus and on the size of bones. Circus is a mid sized Accipitridae displaying very long wings and legs in relation to its weight. Legs bones are easily identifiable because they include a high number of diagnostic features, such as elongated femora, tibiotarsi and tarsometatarsi, that are thinner than other mid sized Accipitridae, fem- ora with slightly differentiated epiphyses, trochlea fibularis small and with a reduced lateral expansion, crista cnemialis cranialis narrow and more expanded distally than in other Accipitridae. The humeri, ulnae and carpometacarpi are very long and thin, compared to other Accipitridae of similar weight. Within Circus, the length of bones fits well with Circus cyaneus, and differs to the remaining species currently present in the Western Palaearctic. The remains obtained at Es Pouàs represent the first fossil record of the species in the Balearic Islands.

Genus Accipiter Brisson, 1760 Accipiter gentilis (Linnaeus, 1758)

Fig. 16, annex (A)

Material: 1 humerus (left). Total: 1. MNI: 1. Stratigraphic range: Upper Pleistocene (square A1).

Current Western Palaearctic Distribution: widespread in northern and middle latitudes where it is sedentary. It spreads mainly within temperate and boreal climate zones (Snow and Perrins, 1998). The Goshawk is currently vagrant in Mallorca, and it is absent from Eivissa (AOB, 2011).

Fossil occurrence: the species is rare in the Middle Pleistocene fossil sites of Central Europe (Croatia, France and Italy). It is common in the Late Pleistocene sites of Central-Western Europe (Spain, Italy, France, and United Kingdom), appearing also in Greece, Iceland, Poland, Russia and Macedonia (Tyrberg, 1998, 2008). It is present in the Pleistocene of Crete (Weesie, 1988), Corsica and Sardinia too (Alcover et al., 1992).

Comments: the humerus of this species is a highly diagnostic bone (Otto, 1981; Olson and James, 1991), displaying a characteris- 
tic torsion of the diaphysis and a markedly expanded crista pectoralis. The size of the specimen fits well with a male. This bone represents the first fossil record of the species in the Balearic Islands.

\section{cf. Accipiter gentilis}

Material: 1 mandible. MNI: 1.

Stratigraphic range: Holocene (square D4).

Comments: a small symphysis fragment agrees with $A$. gentilis in shape, although it is less robust than the available comparison material. It could represent a male.

Accipiter nisus (Linnaeus, 1758)

Fig. 16, annex (B-D)

Material: 2 mandibles, 2 ulnae (1 left, 1 right), 2 coracoidea (right), 2 scapulae, 1 furcula, 1 femur (right) and 1 tarsometatarsus (right). Total: 11 bones. MNI: 2 (based on mandibles, coracoidea and scapulae).

Stratigraphic range: A3 levels 4 and 5, I1 (Upper Pleistocene); D4 (Holocene levels).

Current Western Palaearctic Distribution: well represented in all Europe, including the Mediterranean region (Snow and Perrins, 1998), the Sparrowhawk is scarce during migration and in winter in Eivissa (AOB, 2011).

Fossil occurrence: very scarce in the Middle Pleistocene sites of Europe. In the Late Pleistocene sites it is moderately abundant in Central and Western Europe (France, Czech Republic, Spain, Germany, Austria and Italy) and appears in Eastern Europe and Asia too (Georgia, Syria, Greece, Ukraine, Russia, Romania, Israel) (Tyrberg, 1998, 2008). Present in Crete (Weesie, 1988) and in Mallorca: Cova de Son Maiol (Mourer-Chauviré et al., 1977) and Cova Nova (McMinn and
Alcover, 1992).

Comments: all bones from square $\mathrm{D} 4$ probably belong to the same individual, according to size and proportions. The material from the Upper Pleistocene stratigraphic units probably also belongs to another single individual.

Bones attributed here to Accipiter nisus display diagnostic characters of genus Accipiter, such as absence of foramina at basis of processus procoracoideus (Otto, 1981; Olson and James, 1991), reduced processus procoracoideus, characteristic sabre-shaped scapula with wider caudal part than rest of Accipitridae, robust, short and markedly curved ulnae, relatively long tarsometatarsus with foramina vascular proximal medial characteristically placed between crista lateralis hypotarsi and crista medialis.

\section{Family FALCONIDAE Vigors, 1824}

Genus Falco Linnaeus, $175^{8}$

The species included in genus Falco have highly distinctive bone morphology. Diagnostic characters are present over the entire skeleton and include traits such as, among others, a characteristic dentation of the praemaxilla, a powerfully built humerus with a characteristic general shape, displaying a marked crista deltoidea, a deep fossa olecrani and a powerful processus flexorius, absence of procoracoid foramen in the coracoid, very elongated inner calcaneal ridge of the hypotarsus, tapering gradually and extending over the length of the shaft of tarsometatarsus. The different species included in this genus differ in size and proportions. 
Falco naumanni Fleischer, 1818

Fig. 17, annex (F-I)

Material: 1 cranium, 3 mandibles, 1 praemaxilla, 6 humeri (4 left, 2 right), 5 ulnae (4 left, 1 right), 1 radius (left), 9 carpometacarpi (7 left, 2 right), 1 scapula (left), 1 femur (right), 13 tibiotarsi (6 left, 7 right) and 40 tarsometatarsi (24 left, 16 right). Total: 81 bones. MNI: 22 (based on tarsometatarsi).

Stratigraphic range: Present over the complete stratigraphic record.

Current Western Palaearctic Distribution: well represented in middle latitudes of Western and Eastern Europe (Snow and Perrins, 1998). It is a rare migrant in Mallorca and Menorca and accidental in the Pityusic Islands (AOB, 2011).

Fossil occurrence: rare in the Middle Pleistocene sites appearing only in France and Spain. In the Late Pleistocene it appears at least in 9 sites of Eastern Europe and 32 of Western Europe (France, Spain and Italy; Tyrberg, 1998, 2008).

Comments: the Lesser Kestrel is the smallest falconid present at Es Pouàs. Their bones are smaller than those of the Common Kestrel. Its shortened tarsometatarsus appears as the most easily identifiable diagnostic element. Some of the obtained bones represent juvenile specimens.

\section{Falco tinnunculus Linnaeus, 1758}

Fig. 17, annex (A-E)

Material: 21 mandibles, 11 praemaxillae, 77 humeri (40 left, 37 right), 42 ulnae (22 left, 20 right), 6 radii (4 left, 2 right), 41 carpometacarpi (20 left, 21 right), 33 coracoidea (15 left, 18 right), 18 scapulae (10 left, 8 right), 3 synsacra, 1 pelves, 33 femora (16 left, 17 right), 59 tibiotarsi (28 left, 31 right), 74 tarsometatarsi (37 left, 37 right) and 2 phalanges. Total: 421 bones. MNI: 35 (based on tarsometatarsi).

Stratigraphic range: present over the complete stratigraphic record.

Current Western Palaearctic Distribution: widespread in Europe from the lowest to the highest latitudes (Snow and Perrins, 1998). It is a very common breeder in Eivissa (AOB, 2011).

Fossil occurrence: the Common Kestrel appears in three Early Pleistocene fossil sites of Western Europe. In the Middle Pleistocene sites it is scarce, but in the Late Pleistocene it turns abundant and widespread along Europe, having been recorded in more than one hundred sites (Tyrberg, 1998, 2008).

Comments: the Common Kestrel appears as the most abundant species of falconid at Es Pouàs.

\section{Falco tinnunculus/naumanni}

Material: 5 mandible, 1 praemaxilla, 1 humerus (right), 1 ulna (right), 2 carpometacarpi (left), 5 coracoidea (1left, 4 right), 8 scapulae (4 left, 4 right), 4 tibiotarsi (1 left, 4 right) and 3 tarsometatarsi (1 left, 2 right). Total: 30.

Comments: these remains belong to juvenile individuals too young as to be specifically identified, or are too fragmented, or both.

\section{Falco subbuteo Linnaeus, 1758}

Fig. 17, annex (K-L)

Material: 2 humeri (1 left, 1 right). Total: 2. 
MNI: 2.

Stratigraphic range: Upper Pleistocene and Holocene.

Current Western Palaearctic Distribution: widespread in Europe except at highest latitudes and nearly absent from Northern Africa (Snow and, Perrins 1998). It is accidental in Eivissa and scarce migrant in Mallorca and Menorca (AOB, 2011).

Fossil occurrence: this species appears only in one Early Pleistocene site in Europe. In the Middle Pleistocene sites it is scarce. It is relatively abundant in the Late Pleistocene of middle-Eastern and Western Europe (Tyrberg, 1998, 2008).

\section{Falco cf. subbuteo}

Material: 1 praemaxilla and 1 mandible.

Comments: their size and shape agrees with Falco subbuteo, but their damaged condition does not allow a more accurate diagnosis.

\section{Falco tinnunculus/subbuteo}

Material: 1 cranium fragment, 5 humeri (1 left, 4 right), 1 carpometacarpus (right), 2 coracoidea, 1 scapula, 9 femora (3 left, 6 right), 1 tibiotarsus (left), 5 tarsometatarsi (4 left, 1 right). Total: 25 bones.

Comments: the fragmented or youth condition of these bones do not allow their precise determination.

Falco eleonorae Géné, 1839

Fig. 17, annex (J)

Material: 3 tibiotarsi (left). MNI: 3 .

Stratigraphic range: Upper Pleistocene/Holocene.
Current Western Palaearctic Distribution: breeding occurs in the Western Palaearctic, only on Mediterranean islands (Snow and Perrins, 1998) and wintering takes place mainly in Madagascar. It is common in summer in Mallorca and Eivissa, and scarce migrant in Menorca and Formentera (AOB, 2011).

Fossil occurrence: rare in the Middle Pleistocene sites from Mediterranean France and Italy, and scarce in sites of the Mediterranean Late Pleistocene (Tyrberg, 1998, 2008).

Comments: the species is present at Es Pouàs, although it is less abundant than initially assumed (Florit et al., 1989).

\section{Falco tinnunculus/eleonorae}

Material: 1 femur (right) and 1 tarsometatarsus (right). Total: 2 fragmented bones.

Comments: these three bones are too small and fragmented as to allow their specific diagnosis.

Falco peregrinus Tunstall, 1771

Fig. 17, annex (M-N)

Material: 1 fragmented mandible (condyle), 1 ulna (right), 1 radius (left), 1 carpometacarpus (right) and 2 coracoidea (left) Total: 6. MNI: 3 .

Stratigraphic range: Upper Pleistocene and Holocene levels.

Current Western Palaearctic Distribution: in the Western Palaearctic, from tropics to high Arctic (Snow and Perrins, 1998). Is a scarce breeder in the Pityusic Islands (AOB, 2011).

Fossil occurrence: rare at the Middle Pleistocene sites (France, Czech Republic and Azerbaijan) and frequent in the Late Pleistocene 
along Central, Eastern and Western Europe (Tyrberg, 1998, 2008).

Comments: the mandibular condyle belongs to a large specimen, very probably a female.

\section{Falco sp.}

Material: 1 praemaxilla, 14 mandible fragments, 12 humeri (2 left, 10 right), 7 ulnae (1 left, 6 right), 5 carpometacarpi (3 left, 2 right), 7 coracoidea (4 left, 3 right), 2 scapulae (right) 2 femora (1 left, 1 right), 1 tibiotarsus (right) and 15 tarsometatarsi (9 left, 6 right). Total: 66 bones.

Comments: very damaged bones, which allow only to identify them at generic level.

Family STRIGIDAE Leach, 1819

Subf. Buboninae

Genus Otus Pennant, 1769

Otus scops (Linnaeus, 1758)

Fig. 18, annex (I-M)

Material: 1 cranium, 15 praemaxillae, 23 mandibles, 263 humeri (139 left, 121 right), 70 ulnae (45 left, 25 right), 23 radii (16 left, 7 right), 130 carpometacarpi (81 left, 49 right), 187 coracoidea (98 left, 89 right), 50 scapulae (21 left, 29 right), 1 furcula (right fragment), 33 femora, (15 left, 18 right), 133 tibiotarsi (59 left, 74 right) and 461 tarsometatarsi (230 left, 231 right). Total: 1390 bones. MNI: 186 (based on tarsometatarsi; the figures presented up include fragments of bones).

Stratigraphic range: the species is present at all levels, from the Upper Pleistocene to the Holocene.

Current Western Palaearctic Distribution: breeds in middle and lower middle latitudes where is common and widespread, mainly in continental temperate and Mediterranean regions (Snow and Perrins, 1998). The European Scops Owl is very common in Mallorca and Eivissa and less frequent in Menorca (AOB, 2011).

Fossil occurrence: very rare in the Early Pleistocene sites (Spain) and in the Middle Pleistocene (Italy). Moderately abundant in the Late Pleistocene sites of Central and Western Europe: France, Spain, Italy, Greece, Czech Republic (Tyrberg, 1998, 2008). Mallorca: Cova de Son Bauçà (Ballman and Adrover, 1969) and Pedrera de s'Ònix (Alcover et al., 1981). Crete (Weesie, 1988); Malta (Fischer and Stephan, 1974); Tylos, Sardinia and Corsica (Alcover et al., 1992).

Comments: the most abundant species of an small strigiform at Es Pouàs corresponds clearly to Otus scops. Bones have been compared with those of the other small-size species of Strigiformes from the Western Palearctic (Glaucidium passerinum, Athene noctua and Aegolius funereus). Diagnostic characters are present on all the skeletal elements. Although some specimens are very small (and they were initially considered to be an undescribed new species of Otus by Florit et al., 1989), they represent the extremes (even outliers) of the range covered by Otus scops. Some specimens represent immature non-flying individuals, documenting the breeding of the species at Eivissa during the Upper Pleistocene and the Holocene.

Genus Athene Boie, 1822 Athene noctua (Scopoli, 1769) Fig. 18, annex (E-G)

Material: 2 praemaxillae, 2 mandibles, 8 
humeri (5 left, 3 right), 1 ulna (right), 3 carpometacarpi (right), 4 coracoidea (3 left, 1 right), 3 tibiotarsi (2 left, 1 right) and 7 tarsometatarsi ( 2 left, 5 right). Total: 30 bones. MNI: 4 (based on humeri).

Stratigraphic range: Upper Pleistocene and Holocene

Current Western Palaearctic Distribution: widespread and resident in the entire Western Palaearctic except at highest latitudes. Also it is well represented in Northern Africa (Snow and Perrins, 1998). The Little Owl is scarce as migrant in Eivissa and uncommon in Mallorca, Menorca and Eivissa during the winter. It is accidental in Formentera (AOB, 2011).

Fossil occurrence: rare in the Early Pleistocene sites. In the Middle Pleistocene sites is scarce, appearing in 11 deposits of Central Europe. It is more common in the Late Pleistocene sites, mainly in Central Europe (Tyrberg, 1998, 2008). Present in the Late Pleistocene of Mallorca, Karpathos, Tylos and Sardinia (Alcover et al., 1992).

Comments: a second small-sized strigiform is present at Es Pouàs. Features of the skeleton of Athene have been described by Olson and Hilgartner (1982) and Weesie (1982). The shape of the praemaxilla of Athene noctua is characteristic, and among other characters it displays a characteristic bony ridge at the ventral external margin of the nasal opening (regio vestibularis), not present in other Strigiformes. The processus procoracoideus of the coracoid is wide and with a highly characteristic triangular shape. The humerus, larger than in Otus, have a wide and characteristic proximal epiphysis, and the crista bicipitalis is much more developed than in Otus. The diaphysis of tarsometatarsus is elongated and with a fossa dorsalis that spreads over two-thirds of the bone (it is much more reduced in Otus).

\section{Athene/Otus}

Material: 1 praemaxilla, 8 humeri (3 left, 5 right), 1 radius, 1 ulna (right), 3 carpometacarpi (left), 6 coracoidea (5left, 1 right). Total: 20.

Comments: these materials are too small and fragmented as to allow a more accurate generic diagnostic.

\section{Genus Bubo Duméril, 1805 Bubo sp.}

Fig. 18, annex $(\mathrm{H})$

Material: 1 praemaxilla (distal fragment) and 14 pedal phalanges. Total: 15. MNI: 4 (as based on three basal phalanges of right digit I and a distal phalanx belonging to a larger specimen).

Stratigraphic range: Upper Pleistocene.

Comments: a praemaxilla and 13 phalanges reveal the presence of a species closely related to the Eagle Owl, but considerably smaller. A single distal pedal phalanx presents a similar size to Bubo bubo.

The attribution of the praemaxilla to genus Bubo derives from its identical shape, with a characteristic profile of the upper surface, and from the diagnostic, markedly steped, crista tomialis. These characters exclude the attribution to other Strigiformes. Additionally, the bone differs from Bubo scandiacus in its compression (in Bubo bubo only the posterior upper part of the praemaxilla is compressed). The pedal phalanges are identical shaped to those of Bubo but smaller 
and less robust, except the distal phalanx above mentioned.

In Corsica and Sardinia, Bubo insularis, a Pleistocene endemic Eagle Owl has been described (Mourer-Chauviré and Weesie, 1986). It is characterized by its small size and distinctive bone proportions (Louchart, 2002). The praemaxilla of this species has not been described or illustrated. The presence of a small-sized Eagle Owl in Corsica and Sardinia suggests than an independent evolution towards reduction in size could have occurred also on Eivissa, originating an endemic species. These bones from Es Pouàs may well represent an endemic species from this island. Nevertheless, the available material is insufficient to formally describe and name it.

\section{Subf. Striginae}

Genus Asio Brisson, 1760 Asio flammeus Pontoppidan, 1763

Fig. 18, annex (A-D)

Material: 1 mandible, 3 praemaxillae, 1 humerus (left), 4 ulnae (3 left, 1 right), 2 coracoidea (right), 1 sternum, 1 femur (left), 7 tibiotarsi (4 left, 3 right), 1 tarsometatarsus (left) and 24 pedal phalanges. Total: 45 bones. MNI: 3 (based on tibiotarsi).

Stratigraphic range: Upper Pleistocene to Holocene.

Current Western Palaearctic Distribution: widespread in Eastern Europe, mainly in middle and high latitudes where migrant individuals breed. It is less common in the rest of the continent (Snow and Perrins, 1998). It is a scarce migrant in Eivissa and Formentera (AOB, 2011).

Fossil occurrence: frequent in the Middle Pleistocene sites in Central Europe and present in Western Europe. It is frequent and widespread in the Late Pleistocene of Europe (Tyrberg, 1998, 2008).

Comments: the Short-eared Owl Asio flammeus is a middle-size owl very similar osteologically to the Long-eared Owl Asio otus, but differing in its longer wings, heavier sternum and more elongated cranium. The processus frontalis of the os nasale of Asio has a characteristic proximal margin, different to Strix. The crista nasalis is notably heavier in Asio flammeus than in Asio otus. The body of the coracoid (between the facies articularis sternalis and the facies articularis humeralis) is heavily built in Asio flammeus, while it is thinner in Strix, Surnia and Asio otus. The humerus of Asio flammeus is characteristic for its richness in diagnostic features, with a large and rounded condylus ventralis, while the ulna is straighter than in Asio otus and with a deeper and more distally expanded depressio musculi brachialis. The tibiotarsi are attributed with some uncertainty to Asio flammeus, because the tibiotarsi of both species of Asio are virtually identical.

Asio sp.

Material: 2 fragments of mandible. Total: 2 . Comments: they probably represent Asio flammeus, but the lack of diagnostic characters does not allow for a specific diagnosis.

\section{Discussion}

\subsection{Birds of prey as bioaccumulator agents}

At least nine diurnal and four nocturnal birds of prey were present in the Upper Pleistocene and Holocene of Eivissa. Some 
of them could have been active bio-accumulator agents at Es Pouàs, being responsible for the incorporation of bones at this site. On the basis of the pool of vertebrate species recorded at Es Pouàs it is possible to explore the predatory role of the different birds of prey of the guild. It is also necessary to consider the insects, no recorded in the fossil site, but unquestionably present in the island during the Pleistocene and Holocene.

The White-tailed Eagle arises as a candidate for the accumulation of large to middle-sized birds, such as geese, cranes, bustards, ravens and choughs (Alcover and McMinn, 1992). The Common Kestrel and the Lesser Kestrel should be considered as efficient bioaccumulators of lizard remains, extremely abundant at this site. Other, much less frequent diurnal birds of prey probably played a lesser role in the bone accumulation of Es Pouàs. Potentially, the Peregrine Falcon, the Goshawk and the Sparrowhawk could have acted as occasional bioaccumulator agents, although their sole presence at the site does not prove it. The Scops Owl and the Little Owl probably have not played a relevant role in the origin of the vertebrate fossil deposit. Their diet mainly consists on invertebrates, small mammals (absent then in the Pityusic Islands), and only rarely on birds. Little Owls are very opportunistic (see references in Mikkola, 1983) and feed on the most abundant available preys. In the absence of small land mammals, Little Owls can feed on birds, reptiles, insects, earthworms and even on bats, although no extant population is known with a full absence of small mammals in their diet. In the Mediterranean, the recorded proportion of birds in its diet is $<4 \%$ (Angelici et al., 1997; Gotta and Pigozzi, 1997).
The only two nocturnal birds of prey that could have effectively acted with some regularity as bio-accumulators in the site are Asio flammeus and Bubo sp., although they appear in low numbers in the fossil record. In Northern Europe, Short-eared Owls almost exclusively hunt Microtus voles (Mikkola, 1983). In areas without voles, this species can hunt other small mammals and birds as alternative food resources (Mikkola, 1983). Eagle Owls do not tolerate other raptors in its territory (Mikkola, 1983) and probably Bubo sp. from Es Pouàs displayed a similar behaviour. Bubo bubo has been documented as a predator of a wide variety of nocturnal (including Otus scops, Athene noctua and Asio flammeus; Herrera and Hiraldo, 1976; Mikkola, 1986, Serrano, 2000) and diurnal birds of prey (including Falco tinnunculus, Falco peregrinus, Accipiter gentilis, Accipiter nisus, Circus sp., Mikkola, 1983; Juillard, 1991; Serrano, 2000). The Bubo sp. present at Es Pouàs probably evolved from Bubo bubo and in an environment without terrestrial mammals should have developed predatory habits on birds.

\subsection{Birds of prey living and/or breeding in Es Pouàs}

Some of the raptor bones may have been incorporated to the deposit through the accumulation of corpses of individuals that bred and lived on the walls of the sinkhole or within its catchment basin. This could be the case for the White-tailed Eagle (at least one practically complete skeleton has been obtained, see Fig. 15, annex). Kestrels and Scops Owls may also have used the walls of Es Pouàs as roosting or breeding places, and some of the obtained fossils of these species were also incorporated to the deposit as results of mortality inside the cave. 
Nevertheless a part of the bones of Kestrels and Scops Owls were probably incorporated as prey items.

Evidence of breeding on Eivissa, based on juvenile bones (with incomplete ossification), has been obtained for Haliaeetus albicilla, Falco naumanni, Falco tinnunculus, and Otus scops. Bubo sp. should have also bred on Eivissa, since it possibly represents a still undescribed/unnamed endemic form, neither recorded in the neighbouring mainland, nor in the Gymnesic islands (Mallorca and Menorca). At least two other falconids should be considered as breeders on Eivissa during the Upper Pleistocene and Holocene, Falco peregrinus and Falco eleonorae. The Eleonora's Falcon is a migrant species that is only present in the Mediterranean Islands when breeding. The Peregrin Falcon breeds regularly in the Balearics, where it is sedentary and there is no reason to consider that during the Pleistocene and Holocene it had a different breeding status.

\subsection{Species absent from the Es Pouàs fossil record}

The small area of Eivissa, together with the vast amount of fossils recovered and the wide hunting territories of some of the bio-accumulator agents present at Es Pouàs, allow us to look at this raptorial fossil record as a firs-order estimate of the past raptorial biodiversity on the island. Indeed, the species of birds of prey absent in the Es Pouàs record were very likely to be absent or very scarce in the pre-anthropic Upper Pleistocene and Holocene of the Pityusic Islands. This could be the case with vultures, absent from the record and very probably absent from the fauna; also it is not expected that Aegypius, Gyps, Gypaetus and even Neophron were present, at least in a regular way.

Several other species of diurnal birds of prey are also absent:: Hieraaetus sps., Circaetus gallicus, Buteo buteo and Milvus sps. The lack of their remains probably represents a true absence of these species: they normally hunt mammals and reptiles (snakes), which were absent from the Pityusic Islands. The Osprey was formerly reported as member of the Pleistocene fauna of Eivissa (Sondaar et al., 1995) on the basis of a pedal phalanx recovered at Es Pouàs. Unfortunately, the bone was lost and in this work we remove this species from the fossil record of Es Pouàs awaiting the identification of new material. If the species was present, it was probably scarce.

Another remarkable absence in the Eivissan fossil record concerns the Barn Owl. This species is not elusive in fossil sites (e.g., Andrews, 1990). Today it is frequent to obtain its remains on breeding places, where young or adult specimens sporadically die (e.g., in the Pityusic Islands today, Guerra et al., submitted). The absence of bones of Tyto alba at Es Pouàs very probably reflects its actual absence during the Upper Pleistocene and Holocene at the Pityusic Islands. Barn Owl is usually considered as a specialised predator of small mammals (Andrews, 1990; Bond et al., 2004), and it is suggested that it cannot breed in territories where its potential prey are limited to birds (Oteni, 1971). In our view, Barn Owls were absent from the Upper Pleistocene and Holocene of the Pityusic Islands or, if present, they should have been extremely scarce.

\subsection{Comparison with the current birds of prey guild}

Four of the six species of birds of prey that currently breed on Eivissa appear in 
the fossil record. The other two, Tyto alba and Asio otus, prey on small mammals, and should have been absent or extremely scarce in Eivissa during the Upper Pleistocene and Holocene. They should be most probably considered as recent colonizers that spread and progressed over the Pityusic Islands after the ecological changes derived from human arrival, that included the introduction of rodents.

At least three of the seven species of birds of prey (i.e., $>40 \%$ ) breeding on Eivissa during the Upper Pleistocene and Holocene disappeared after human arrival, i.e., Haliaeetus albicilla, Bubo sp. and Falco naumanni. The structure of the predatory bird guild has changed substantially after human arrival. Then, the predatory guild lost its larger diurnal and nocturnal representatives. The Barn Owl and the Long-Eared Owl, two predators that forage mainly on small mammals, have been incorporated, representing now key species for the Pityusic ecosystems.

Blondel and Frochot (1967) suggest that the Corsican bird fauna is currently structured in a peculiar way, excluding the largest species of different orders that are nevertheless present in the neighbouring mainland. According to Blondel et al. (1988), large species would tend to be under-represented in island faunas, where the average size of individuals is lower than in mainland areas. According to these authors, "Small size, high population densities, and sedentary existence in this kind of stable environment are probable factors allowing more species to coexist". Clegg and Owens (2002) suggest that there is an "island rule" for birds, consisting on the decrease of body size in large species and the increase in small birds. On the contrary, Meiri et al.
(2010), after analyzing 8069 bird species, found no evidence for an "island rule" at the genus and family level. Furthermore, they observed that in almost half of the bird genus analyzed, the largest member was an insular endemic. Louchart (2005) also points against the existence of an "island rule" in Strigiformes.

Evidence obtained from the Pleistocene predatory bird paleoguild of Eivissa disagrees also with the results and suggestions of Blondel et al. (1988) and Clegg and Owens (2002). If the large predatory niche on the Pityusic Islands is currently not occupied by a large species, it can be a consequence of human activities. During the Pleistocene, the largest predatory bird on Eivissa was a huge Haliaeetus albicilla, which displayed larger size than its contemporaneous mainland relatives (Alcover and McMinn, 1992). In this case, not only was the Eivissan top predator selected from the largest predators present on the mainland, but also it evolved to a larger size on the island. This selection points against the Blondel et al. (1988) hypothesis, and the recorded change of size no supports the Clegg and Owens (2002) hypothesis.

The fossil record from other Mediterranean islands points to the same coclusion: the top Pleistocene diurnal predators were also large species. A. chrysaetos simurgh was described from the Upper Pleistocene of Crete (Weesie, 1982; but see Louchart et al., 2005, for a discussion of its taxonomic attribution). Aquila appears also in the Pleistocene of Sicily (Cassoli, 1980) and Malta (Northcote, 1992). The large eagle Aquila nipaloides has been described from the Pleistocene localities of Corsica and Sardinia (Louchart et al., 2005), whereas Aquila chrysaetos is present in the fossil record 
of Mallorca (Mourer-Chauviré et al., 1977; Florit and Alcover, 1987) and Menorca. A fragment of coracoid recovered in Menorca was attributed to a very large Aquila chrysaetos (Alcover et al., 2004), although its size exceeds the range of this species. The current absence of large diurnal predators on Mediterranean islands should not be considered as a characteristic of the undisturbed (i.e., prehuman) ecosystems, but as a consequence of their recent lost probably due to human impact.

The presence of a small-sized Eagle Owl in the Upper Pleistocene and Holocene of Eivissa agrees with the size-reduction also recorded in another insular species of the genus (B. insularis, from Corsica and Sardinia). Even if it fits well with the expectances of Clegg and Owens (2002), it should be considered as an exception to the general trend for size evolution of owls in islands (Louchart, 2005).

Fossils of diurnal and nocturnal birds of prey from Es Pouàs can be used to understand a unique guild of raptors, different from that currently present on the Pityusic Islands. This palaeo-guild includes a huge top diurnal predator, the White- tailed Eagle. The presence of this coastal raptor can be explained by the food resources abundance, such as seabirds and wildfowl associated with coastal wetlands. Other species belonging to the diurnal raptor guild of Es Pouàs preyed on small to mid-sized birds, and on insects. Among the open country raptors we find the Hen Harrier, which preys on thrush-sized birds, the Common Kestrel, which feeds on reptiles, small birds and insects and the Lesser Kestrel, which is mostly insectivorous. The Peregrine Falcon is a specialised bird hunter on open terrain or coastal areas. Among raptors character- istic for woodlands, the Goshawk is a specialised forest hunter of medium and small sized birds, the Sparrowhawk, also a forest hunter of small birds, prefers marginal edges of wooded areas. The European Hobby Falcon hunts small birds and insects in open areas near wooded terrain. The Eleonora's Falcon is a highly specialised hunter of small birds, mainly migratory birds, in coastal areas. Thus, the reported diurnal fossil raptor assemblage shows a peculiar and highly distinctive composition including a large predator and scavenger, some medium- to small size-bird hunters, smallbird and insect hunters, and one exclusive insect feeder specialist. Each of these types of hunters was adapted to different habitats (open country, wooded areas or the coast) with very little dietary overlap among the species characteristic of each type of habitat.

The nocturnal raptor guild of Es Pouàs also exhibited similar characteristics to the diurnal guild, with open terrain hunters and species that prefer partially wooded areas. The Short-eared Owl is an open country hunter that probably was adapted on Eivissa to catch exclusively small birds and bats. The Little Owl is also an open country hunter of insects and small birds. The Eagle Owl hunts medium or small birds in open terrain or partially wooded areas, while the small Scops Owl feeds mostly on insects in open wooded terrain. As in the case of the diurnal raptor guild, in this palaeo-guild there was very little dietary overlap between the different species at each habitat.

\subsection{Comparison with other Mediterrane- an Islands}

The predatory birds present in the Pityusic fossil record comprise at least 13 docu- 
mented species. This figure is higher than those obtained for the Gymnesic Islands (Mallorca and Menorca, 6 documented species) and Malta (10 documented species), and markedly smaller that those obtained for the cirno-sardinian massif (Corsica and Sardinia, 26 species), and Crete (19 species) (Alcover et al., 1992; Louchart, 2002; Tyrberg, 2008).

The low number of predatory birds recorded until now in the Pleistocene and Holocene of the Gymnesic islands could reflect some sampling bias. The figures for the remaining islands (i.e., Malta, Corsica and Sardinia, and Crete) document probably better the actual predatory guilds of the past. Some authors consider that a large number of predatory birds (larger than the current one), including endemic species, characterised some past insular Mediterranean faunas (e.g., Weesie, 1988). The Pityusic predatory bird guild fits well in this hypothesis, with the Pleistocene guild comprising a larger number of breeding species than the current fauna. If the number of fossil raptors is smaller on Eivissa than on other Mediterranean islands, it is probably a consequence of the smaller area of this island.

\section{Conclusion}

The study of the composition of the pre-anthropic Upper Pleistocene-Holocene predatory bird guild from the Pityusic Islands offers as suitable approach for the understanding of a vertebrate community structure under natural conditions, previous to human interferences, in an insular context. Indeed, it has been possible to clarify the ecological role and potential bio-accumulation importance of each raptor spe- cies in the Pityusic natural ecosystems. The Pityusic paleo-guild of raptorial birds has enabled to evaluate biogeographic hypotheses on patterns of body size evolution in islands. The current under-representation of large raptors in some Mediterranean Islands (Blondel et al., 1988) definitively should be considered as an artificial feature: a likely consequence of human interferences on the natural insular ecosystems.

A first approach to the ecological changes that took place on Eivissa after the human arrival can be put forward, but the actual tempo and mode of the transformation of the Eivissan raptorial guild after human arrival still needs more research. The precise chronology and actual drivers for the disappearance of different raptors (H. albicilla, F. naumanni, and Bubo sp.) remains unknown. Although the fossil record documents that the species assemblage has been strongly affected by human presence in Eivissa, there is no evidence of hunting by prehistoric humans, and disappearance of a colonial breeder such as F. naumanni, frequently found in or close to human settlements, is even more puzzling. At this time, it remains unknown if changes in the structure of the predatory bird guild were the direct consequence of human impacts (e.g., hunting, voluntary introductions) or if they were the indirect result of the environmental changes they caused (e.g., fire,accidental introduc-tion of invasive species, new successful invasions). 
5 - EL GREMIO DE LAS AVES RAPACES DEL PLEISTOCENO SUPERIOR-HOLOCENO DE IBIZA 



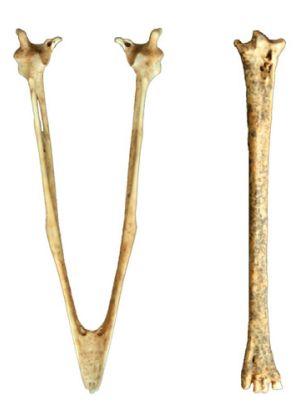

ESTUDIO DEL COMPORTAMIENTO ALIMENTICIO DE

\author{
LA LECHUZA (Tyto alba) \\ EN ISLOTES DE LAS PITIUSAS
}




\section{6 - ESTUDIO DEL COMPORTAMIENTO ALIMENTICIO DE LA LECHUZA (Ty to alba) EN ISLOTES DE LAS PITIUSAS}

\subsection{Introducción}

Solamente una de las tres especies de Strigiformes que crían en la actualidad en las Pitiusas, Otus scops, habitaba las islas durante el Pleistoceno superior-Holoceno (Guerra et al. 2013). Las otras dos, Tyto alba y Asio otus, están ausentes en el registro fósil de Ibiza y Formentera. El estudio de la alimentación de una de estas dos especies (Tyto alba) en islotes de las Pitiusas ofrece una oportunidad para valorar los cambios ecológicos acontecidos tras la llegada de los humanos.

El comportamiento alimenticio de la lechuza incluye la selección del territorio de caza, dentro del cual muestra una conducta oportunista (Herrera 1974; Bond et al. 2004; Figueroa et al. 2009).

El análisis de los restos de alimentación de T. alba procedentes de algunas islas menores de las Pitiusas, ha permitido valorar algunos cambios ecológicos acontecidos tras la llegada de los humanos y descubrir rasgos del comportamiento alimenticio de esta especie hasta ahora desconocidos, como el cruce recurrente de canales marinos relativamente amplios para cazar. Individualmente, los pequeños islotes con escasa influencia humana no proporcionan alimento suficiente para la lechuza. En consecuencia, esta especie expande su área de campeo para incluir varias islas o islotes. Así mismo, destaca la importancia, para los individuos de los islotes, de presas normalmente consideradas marginales en la alimentación de la especie como conejos y paíños (Hydrobates pelagicus).

Tras la identificación de miles de restos fósiles de aves, la ausencia de la lechuza en el registro fósil de las Pitiusas indica muy probablemente su ausencia real en el pasado, o alternativamente, su escasez extrema. En cualquier caso, su ausencia o escasez, debe estar relacionada con la propia ausencia de su principal fuente de alimento: los micromamíferos. Tras la colonización humana de las islas Pitiusas hace 4150-4350 años (Alcover 2008), la introducción de micromamíferos por parte del hombre, habría permitido el asentamiento de una población de lechuzas en estas islas. 
La expansión de la lechuza en islas en las que previamente no existía o era muy escasa se ha dado también en algunas islas oceánicas: Hawái, Nueva Caledonia y Eua entre otras (Berger 1981; Balouet y Olson 1989; Steadman 2006; Van der Werf et al. 2007). A pesar de que, a diferencia de las Pitiusas, en dichas islas la lechuza fue introducida deliberadamente para el control de roedores, tanto en ellas como en las Pitiusas, la población de lechuzas se estableció con éxito tras sendas intervenciones por parte del hombre. Los resultados de este estudio evidencian que las lechuzas que habitan actualmente en las Pitiusas, se alimentan principalmente (hasta un 90\% de su dieta) de presas que expandieron su área de distribución a las islas tras los cambios introducidos en el ambiente por las actividades humanas en las mismas.

\subsection{Publicación}

\section{Unusual foraging patterns of the barn owl, Tyto alba (Strigiformes: Tytonidae), on small islets from the Pityusic archipelago (Western Mediterranean Sea)}

\begin{abstract}
Research on the diet of barn owls on some of the lesser Pityusic Islands (Formentera, s'Espalmador and s'Espartar) reveals a previously undescribed opportunistic trophic behaviour based on regular foraging in patches of territory separated by relatively broad sea channels. Individually, small islets with reduced human influence do not usually provide enough food for the barn owl. Consequently, the species expands its home range to include multiple islands or islets. This study is the first to document the regular crossing of broad sea channels (one of which exceeds $4.5 \mathrm{~km}$ ) by barn owls in order to hunt. The islets provide the barn owls with prey otherwise considered as marginal (such as Oryctolagus cuniculus and Hydrobates pelagicus).
\end{abstract}

\section{Introduction}

Three owl species currently breed on the Pityusic Islands (Eivissa, Formentera and surrounding islets, western Mediterranean Sea): the barn owl, the long-eared owl, Asio otus, and the European scops owl, Otus scops. Of these, the only one to have been found in the Pityusic Upper Pleistocene and Holocene fossil record is the scops owl (Guerra et al. 2013).

Before the arrival of humans, no terrestrial mammals were present on the Pityusics (Bover et al. 2008, Bover \& Alcover 2008), making these islands the largest territory in the entire Mediterranean region without terrestrial mammals. The absence of the barn owl's principal prey (i.e. terrestrial small mammals) must have had consequences on the past presence of the barn owl in the Pityusics (Guerra et al. 2013). The complete absence of fossil barn owl bones from the vast paleornithological record of the Pityusic Islands suggests that the barn owl successfully colonized or 
substantially increased its population on these islands only after the arrival of humans and the coeval introduction of small mammals, beginning roughly 4150-4350 years ago (i.e. 2150-2350 BC, Alcover 2008).

There is a general consensus that barn owls select their territories, and that they displays an opportunistic hunting behaviour within them (Herrera 1974, Bond et al. 2004, Figueroa et al. 2009). The home range of the barn owl has been estimated to be 3 to $28 \mathrm{~km}^{2}$ (Taylor 1989, Bond et al. 2004, Martínez \& Zuberogoitia 2004), being an irregular area extending a maximum of $3 \mathrm{~km}$ from the nest or roost (Andrews 1990). The analysis of owl pellets from some of the small Pityusic Islands presented here sheds light on two poorly known topics: 1) the foraging behaviour of the barn owl on small islets, and 2) the importance for barn owls on the islets of prey species otherwise considered as marginal.

\section{Material and Methods}

We have studied barn owl pellets from 5 localities in the Pityusic Islands (Figure 40). Localities 1 to 3 correspond to two small Pityusic islets (s'Espalmador - with two sites only about $50 \mathrm{~m}$ apart, here named "old nest" or locality 1 and "recent nest" or locality 2, and s'Espartar, locality 3). Localities 4 and 5 provide new data from two localities in Formentera (Estany Pudent and La Mola). This island $\left(82 \mathrm{~km}^{2}\right)$ is the smallest of the inhabited Pityusic Islands. s'Espalmador (c. $2 \mathrm{~km}^{2}$ ), close to Formentera, is a flat island with some cliffs on its western coast. Its northern point is $4.5 \mathrm{~km}$ from Eivissa. s'Espartar $\left(1900 \mathrm{~m}^{2}\right)$ is situated $1.3 \mathrm{~km}$ from Eivissa $\left(570 \mathrm{~km}^{2}\right)$. The samples are presented in Table 54 (annex), and include complete owl pellets (localities 2, 3 and 5), recently disaggregated pellets (localities 2, 3, 4), and bone concentrations derived from old disaggregated pellets (locality 1). The "old nest" (locality 1) has not been used by barn owls in a long time, and it is documented by a concentration of bones (including bones of prey and bones of barn owl chicks) in a sedimentary layer. Sampling dates for the different sites are presented in Table 54 (annex).

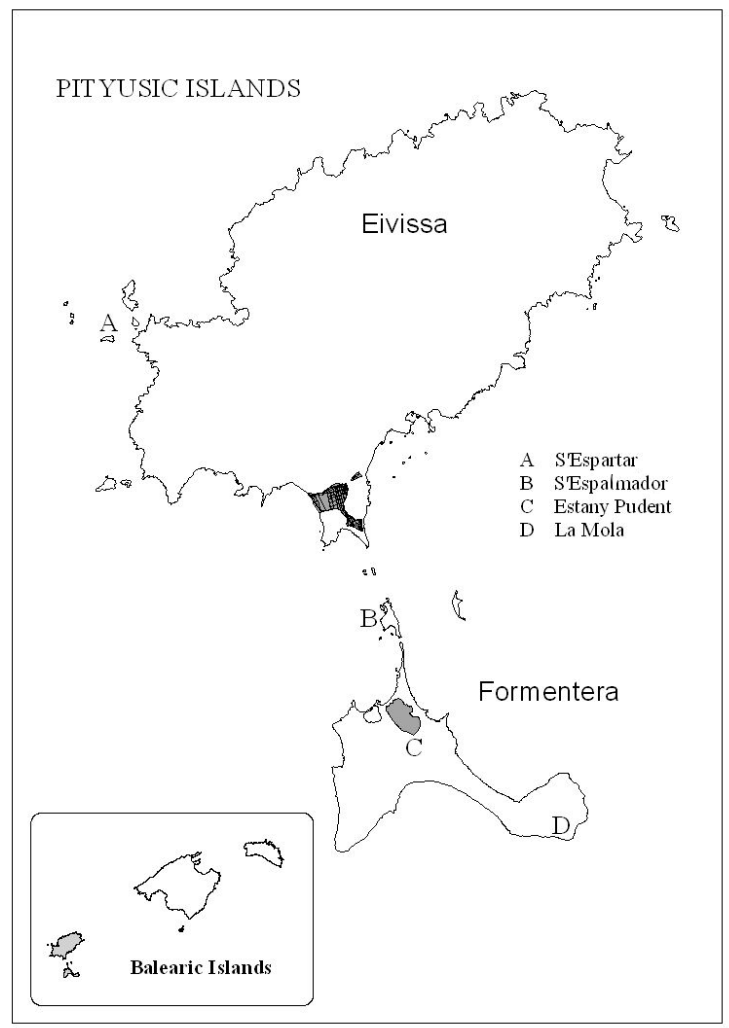

Figure 40. Map of localities. (A) s'Espartar islet. The site is located at the NE corner of the islet. (B) s'Espalmador islet. The two sites are $50 \mathrm{~m}$ apart, on the east of the islet. (C) Quarry close to s'Estany Pudent, Formentera. (D) Torrent des Serverer, La Mola, Formentera.

The minimum number of individuals of each prey species was estimated on the basis of the best-represented bone in each site. The prey species were identified through direct comparison with bones curated at the IMEDEA (Mediterranean 
Institute for Advanced Studies) vertebrate reference collection, and using identification keys (Moreno 1985, 1986, 1987). To approach the biomass of consumed prey we used the average weights of rodents and shrews obtained on the Pityusic Islands (from Alcover $1983 \mathrm{PhD}$ thesis and unpublished data). Common rabbit kittens, Oryctolagus cuniculus weights were estimated through regression curves (Donázar \& Ceballos 1989). The sole mouse-eared bat, Myotis myotis found was a young specimen, without fused epiphysis, so it was tentatively assigned a weight of $20 \mathrm{~g}$. For birds, the data of Snow \& Perrins (1998) were used. The average weights for reptiles were obtained from lizards from s'Espalmador (V. Pérez-Mellado, pers. comm.).

\section{Results and Discussion}

In this study 1245 prey individuals were identified. Globally, small mammals represented the most abundant prey (c. $80 \%$ ), followed by birds (18.3\%), reptiles (1.2\%) and amphibians (0.08\%, one specimen). The size of the prey varied from more than $100 \mathrm{~g}$ (some adult black rats, Rattus rattus, adult Formenteran garden dormice Eliomys quercinus ophiusae, and juvenile common rabbits, Oryctolagus cuniculus; the largest specimen of rabbit must have weighed c. $220 \mathrm{~g}$ ) to less than $10 \mathrm{~g}$ (Moorish geckos, Tarentola mauritanica, Eivissan lizards, Podarcis pityusensis, North African whitetoothed shrews, Crocidura pachyura, and some small birds; the smallest prey was close to $7 \mathrm{~g}$ ).

Small mammals usually represented c. $90 \%$ of prey in Eivissa, the largest of the Pityusic Islands (Rey \& Rey 1974, based on 2988 prey individuals; Alcover 1977, on the basis of 5242 prey individuals; Sommer et al. 2005, on the basis of 2755 prey individuals) and in s'Espalmador, but they fell to $48 \%$ in s'Estany Pudent (Formentera), and to $25 \%$ in s'Espartar. At these sites, birds were present in greater numbers than mammals $(51.1 \%$ in the Formenteran locality at s'Estany Pudent, and $65.6 \%$ in s'Espartar). Shrews were absent from all the samples from Formentera, while they were present in small percentages $(1.7 \%$ to $3.6 \%)$ in s'Espalmador.

Usually rabbits are rarely preyed on by barn owls (e.g. Herrera \& Jaksic 1980). Only one among 5242 specimens was obtained by Alcover (1977) in Eivissa, and none by Rey \& Rey (1974) and by Sommer et al. (2005). In the old nest on s'Espalmador (locality 1) there were 45 rabbit kittens (5.7 \% in number, representing 24 $\%$ of the preyed biomass). All rabbits were very young, showing non-fused epiphyses on long bones, with femur length (without the epiphyses) between 30.5 and $48.1 \mathrm{~mm}$, and jaw length mainly between 24 and $25.8 \mathrm{~mm}$ (although there was an outsider with a jaw length of $33.6 \mathrm{~mm}$ ). They had an estimated weight between 140 and 220 $\mathrm{g}$, close to that displayed by rabbit kittens when they leave their burrows for the first time. At that age, kittens are naive regarding predators (Mykytowycz et al. 1959). Thus, the s'Espalmador barn owls probably consumed rabbits only during a short period of the year (in spring, the breeding season of rabbits). The absence of rabbit remains in the recent nest of s'Espalmador (locality 2) correlates with the current absence of rabbits on the islet.

Black rats constituted $9.2 \%$ of the diet of the s'Espalmador barn owls. On the Mediterranean mainland, rats contribute 
a minor percentage (usually less than 2.5 $\%$ ) of the barn owl's diet (e.g. Bontzorlos et al. 2005). The garden dormouse did not form part of the diet on Eivissa but it appeared as an important prey item in the Formenteran localities (from $15.9 \%$ in Estany Pudent to $26.8 \%$ in La Mola). On the contrary, at s'Espalmador its presence was very low (c. $1 \%$ ).

The presence of bats in the diet of owls is usually very scarce (Speakman 1991, Vernier 1993, García et al. 2005). They rarely appear in barn owl pellets from the Balearic Islands (Rey \& Rey 1974, Alcover 1977, de Pablo 2000, Sommer et al. 2005). Here we report a young Myotis myotis from the old nest on s'Espalmador (locality 1). This species has never been observed alive in the Pityusics, although it is autochthonous of these islands, as documented by its abundant remains in the Upper Pleistocene-Holocene deposit of es Pouàs, Eivissa (Alcover 2003). In addition, a jaw of one specimen of this species appeared in Cova Xives, Eivissa (Alcover 1984). This finding at s'Espalmador confirms its presence in the recent past.

Birds represented about $18.3 \%$ of the total of consumed prey reported in this paper. One third of the consumed birds corresponded to the house sparrow, Passer domesticus. Sparrows are among the birds most frequently preyed upon by the barn owl in the Pityusic Islands, although their significance decreases at the two localities in Formentera and does so to the point of disappearing on lesser islets, where the importance of migratory birds or seabirds increases. Globally, the results of this study supports the hypothesis of Johnston \& Hill (1987) that the barn owl diet includes, as an average, a greater number of birds on small islands than on mainland sites. In mainland Spain the proportion of birds in the diet of barn owl is very low (Herrera 1974, Delibes et al. 1984), while in Eivissa it is about 6-7 \% or even less (Rey \& Rey 1974, Alcover 1977, Sommer et al. 2005).

\section{Foraging behaviour on small islets}

The prey assemblages studied here revealed some peculiar characteristics of the foraging behaviour of the barn owl in the lesser Pityusic Islands. In relation to the use of islets as hunting areas, two behavioural strategies can be identified. Sites at s'Espalmador correspond to nesting deposits containing a high number of prey (as well as some bones of barn owl chicks). On the other hand, the s'Espartar site, a roosting place, only delivered a few pellets that could have been deposited by a sole occasional, although recurrent, visitor.

\section{s'Espalmador}

The North African white-toothed shrew, Crocidura pachyura is useful as a marker for hunting sites used by the barn owls at s'Espalmador. In the Pityusics, shrews are only present on Eivissa (Alcover 1979). Finding the North African white-toothed shrew in different pellets indicates a recurrent hunting behaviour of the s'Espalmador barn owl, involving razzias from s'Espalmador to Eivissa, flying at least 11 $\mathrm{km}$ on each occasion: i.e. crossing a gap of $5.5 \mathrm{~km}$ (including $>4.5 \mathrm{~km}$ over the sea) and, once on the main island, flying inland to reach suitable habitats for shrew and other prey, and later coming back to s'Espalmador. It is generally accepted that barn owls hunt in an area around their nests or roosts of a maximum diameter of c. 2-3 km (Andrews 1990). The recurrent 
capture of the shrews on Eivissa by the s'Espalmador barn owls documents that, under special circumstances, this species can regularly fly over longer distances.

Some other prey also seemed to have been caught on Eivissa. Two sibling species of mice occur on Eivissa, the Western Mediterranean mouse, Mus spretus and the domestic mouse, Mus musculus, although only the latter lives on Formentera and s'Espalmador. Following the criteria established by Darviche \& Orsini (1982), at least one specimen from s'Espalmador belongs to the Western Mediterranean mouse (thus, it was captured on Eivissa). Other remains from s'Espalmador indicate that "mainland" Eivissa is not the sole hunting area for the barn owl from s'Espalmador. The presence of remains of the European storm petrel, Hydrobates pelagicus, absent from s'Espalmador, Formentera and Eivissa, suggest the use of some other islet as a nearby hunting place. Several islets scattered in the sea channel separating Eivissa and Formentera, as well as the s'Espardell islet (c. $3 \mathrm{~km}$ from s'Espalmador), contain breeding colonies of the European storm petrel (García \& Arbona 2007).

In comparison to more suitable and continuous territories, such as would normally be selected by the barn owl in mainland areas, the hunting habitat fragmentation discussed here (i.e. islets separated by sea channels) implies an increased metabolic cost. The data suggest that barn owls survive at s'Espalmador under conditions of prey shortage that force them to diversify their hunting areas, extending their home range to Eivissa and to other islets. The sea represents an unsuitable hunting area for barn owl, which must fly to reach adequate areas (islands or islets) to catch prey.
The evidence collected in this study indicates that the s'Espalmador barn owls hunt a relatively high number of small birds. The house sparrow, the most abundant bird prey found in Eivissa (Sommer et al. 2005), is scarce in the diet at s'Espalmador. House sparrows mainly forage on cultivated crops and in villages, and neither crops nor villages are present at s'Espalmador (an uninhabited islet), or at Punta des Trucadors in Formentera (the closest site to s'Espalmador). Thus, owls at these sites are lacking a resource that is important in other Pityusic localities (see Sommer et al. 2005 and Formenteran sites in Table 54, annex). Instead of house sparrows, a plethora of migrant species appears in the diet of the s'Espalmador barn owls. The winter pellet assemblages (January 2006 and 2008) contain a high percentage of migrant birds. Among them, the most abundant are the European robin, Erithacus rubecula and the black redstart, Phoenichurus ochrurus. The diet recorded for s'Espalmador barn owls indicates that they hunt over longer distances than is usual in mainland owls. The crucial point here is that hunting patches are separated by sea channels and this type of hunting behaviour is unusual in this species. These barn owls bred on a small islet (s'Espalmador), while they foraged not only there but also on larger islands (Eivissa and Formentera), and on some of the smaller surrounding islets. A foraging strategy including sporadic overseas displacements between Alegranza and Lanzarote (Canary Islands) has been suggested for the Canarian barn owl, Tyto alba gracilirostris although it remains unproven (Siverio \& Palacios 2004). 


\section{s'Espartar}

Diet analysis at s'Espartar reveals a different behavioural strategy. Barn owls do not breed at s'Espartar. The pellet assemblage recovered there is small, comprising only 14 complete pellets, suggesting a short depositional period, close to the time of their collection. The pellet contents at s'Espartar included remains of European storm petrel as well as of shrews and of a specimen of field mouse, Apodemus sylvaticus. The last two species are not present at s'Espartar and they must therefore have been captured on the Eivissan mainland (about $1.3 \mathrm{~km}$ from s'Espartar). As shrews were found in different pellets, the pellet assemblage documents a recurrent crossing of the sea channel. The owl pellets were found at the entrance of a cave at s'Espartar where there is a colony of European storm petrels. In this case, in contrast to s'Espalmador, the evidence points to a barn owl living and breeding on Eivissa and visiting s'Espartar occasionally to hunt.

\section{Storm petrels as a prey of the barn owl}

Until now, only Araujo et al. (1977) in Cabrera, Delgado (1993) and Delgado et al. (1992) in Montaña Clara and Alegranza (Canary Islands) had reported H. pelagicus as an occasional prey of the barn owl. Such scarce data suggest that hunting of European storm petrels by barn owls has not been sufficiently studied or is uncommon. The data presented here add some behavioural information. The breeding success of the European storm petrel is affected by the presence of rats, so it usually breeds on islands free of rats (de León et al. 2006). s'Espartar is an islet free of rats with a breeding colony of these birds (García-Gans et al. 2005). s'Espalmador, on the contrary, is a rat-infested islet and does not harbour a breeding colony of petrels (Ruffino et al. 2009), although several small islets nearby, such as s'Espardell (3 km apart) and some other islets at es Freus, do (García \& Arbona 2007). s'Espartar is used sporadically as a hunting area by a barn owl that breeds on Eivissa, while s'Espalmador is the base of a couple that forages on small islets with breeding colonies of European storm petrels. In the latter case, the barn owl visits one or more colonies, but without detected roosting on the islets where the petrels breed (i.e. returning back home, to s'Espalmador, and regurgitating the pellets there). Although European storm petrels could presumably have been captured flying over the sea, this behaviour has never been reported anywhere, and can be dismissed as being highly improbable. The evidence from s'Espartar suggests that the barn owl catches petrels on land, while they are on the ground near the entrance of their breeding colony. On June $21^{\text {st }}, 2006$, > 30 specimens of European storm petrels were found dead inside a cave (see Figure 41) at s'Espartar (locality 3). Barn owls appeared to be the most probable cause of death of these specimens, all partially consumed, since no other potential predator able to visit caves (such as cats or rats) were detected on the islet. This attribution agrees with the documented presence of storm petrels in the owl pellets obtained at the entrance of the cave. The location of the remains of storm petrels inside the cave implies that the barn owl had entered on foot through a short, low, and narrow corridor to kill the storm petrels close to their nests in a dim light zone.

Additionally, a barn owl pellet contain- 
ing remains of European storm petrels has been found at Illa Murada, another Pityusic small islet without rats, $1.75 \mathrm{~km}^{2}$, c. 200 $\mathrm{m}$ from Eivissa, and containing a breeding colony of petrels (J. Mayol, pers. comm.). Thus, the predation on European storm petrels, although sporadic, seems to be more frequent than previously considered. The actual impact of barn owl predation on the breeding colonies of the European storm petrel on the Pityusics remains to be evaluated.
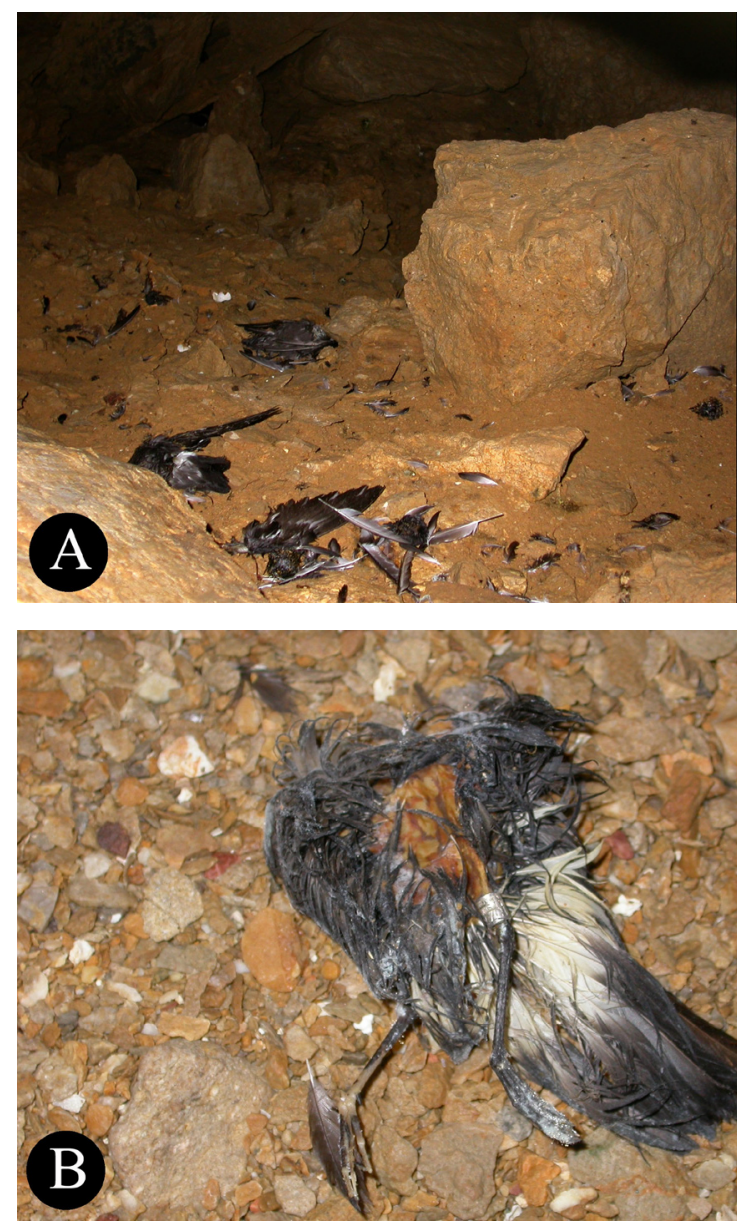

Figure 41. Remains of Hydrobates pelagicus presumably preyed upon by Tyto alba at s'Espartar. (A) General view, and (B) detail of a partially consumed ringed specimen. Photographs by David García. 



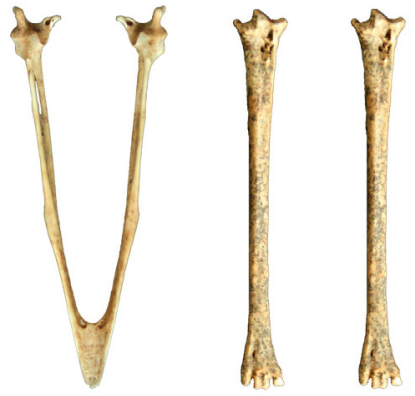

DISCUSIÓN GENERAL 


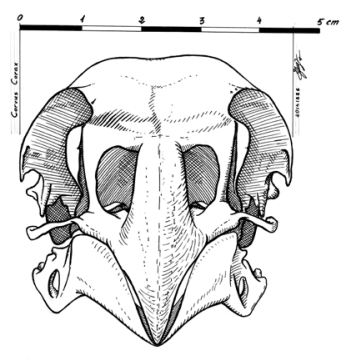

\section{7 - DISCUSIÓN GENERAL}

El estudio de las aves rapaces de es Pouàs ha proporcionado seis especies nuevas para el registro fósil de las Baleares (Circus cyaneus, Accipiter gentilis, Falco subbuteo, F. peregrinus, Asio flammeus y Bubo sp.). En cambio, dos de las especies de rapaces del registro del Pleistoceno superior-Holoceno de las Baleares, Aquila sp. (cf. Aquila chrysaetos: Mourer-Chauviré et al. 1977; Florit y Alcover 1987a, 1987b; Alcover et al. 2004) y T. alba (Mourer-Chauviré et al. 1977; McMinn y Alcover 1992; Seguí et al. 1997), están ausentes en es Pouàs. Se han identificado varias falanges correspondientes a un águila de gran tamaño (cf. Aquila/Haliaeetus, Guerra et al. 2013), por lo que la ausencia real del género Aquila en el pasado de las Pitiusas es incierta.

Tres de las especies de aves rapaces obtenidas en es Pouàs están ausentes en el registro del Pleistoceno superior-Holoceno del área continental próxima a las Pitiusas (F. subbuteo, C. cyaneus y A. flammeus). Sin embargo, la biodiversidad de rapaces es superior en el Pleistoceno superior del continente, en cuyo registro constan nueve especies ausentes en el registro de las Pitiusas: cf. Aegypius monachus, T. alba, Aegolius funereus, Strix aluco, Glaucidium passerinum, Aquila chrysaetos, Falco rusticolus, Falco columbarius y Buteo buteo).

Dichas diferencias son el resultado de la comparación con las especies de aves rapaces fósiles publicadas en los siguientes trabajos: Villalta 1964; Eastham 1973, 1988, 1989, 2001, 2005; Sánchez Marco 1988, 1995b, 2004; Davidson 1989; Badal et al. 1991; Hernández 1993; Cacho et al. 1995; Villaverde 1997, 1999; Walker y Gibert 1998; Tyrberg 1998, 2008; Walker 2001, 2003 y Tortosa et al. 2002. Estos trabajos recogen el registro de aves fósiles de varios yacimientos del Pleistoceno superior-Holoceno de Castellón, Valencia, Alicante, Murcia y Almería. 
Las diferencias de biodiversidad entre Ibiza y el continente cercano podrían estar relacionadas con diferencias ecológicas entre ambas áreas. En el caso de las grandes rapaces (Aquila y Aegypius), la ausencia de grandes mamíferos en las Pitiusas, y en el caso de las rapaces de talla mediana (T. alba, G. passerinum, A. funereus, S. aluco y B. buteo), la ausencia de micromamíferos, habrían impedido establecerse a estas especies para las que dichas presas constituyen un recurso trófico esencial.

Entre las especies de aves presentes en el Pleistoceno superior-Holoceno de es Pouàs, cinco especies de rapaces (H. albicilla, A. gentilis, F. naumanni, F. subbuteo y Bubo sp.) han desaparecido de las Pitiusas en la actualidad. Tres de dichas especies criaban en el pasado en las Pitiusas (H. albicilla, A. gentilis y F. naumanni).

La ausencia actual de $H$. albicilla no se debe a una redistribución geográfica de la especie debido al clima, ya que su área de cría alcanza latitudes bajas del Paleártico occidental (e.g., Turquía, Grecia, Albania). Incluso hasta hace unas décadas, el pigargo europeo también criaba en Córcega y Cerdeña. Se han documentado extinciones recientes de esta especie por causas antrópicas, directas (caza) e indirectas (agotamiento de recursos) (Cramp y Simmons 1980), si bien la recesión de su área de distribución en Europa comenzó ya en el Pleistoceno superior. A partir de algunos restos identificados, aunque escasos, se ha confirmado la presencia de la especie en el Pleistoceno superior de otras islas del Mediterráneo (Córcega, Cerdeña y Creta [Seguí y Alcover 1999]). Su presencia en yacimientos arqueológicos es poco frecuente. El hallazgo de un coracoides en un nivel arqueológico de es Pouàs (Alcover y McMinn 1992) constituye, junto con los restos de un individuo identificado en la Cova des Riuets (Formentera, Alcover et al. 2004), uno de los registro fósiles más recientes de la especie en el Mediterráneo occidental. Todas las evidencias sugieren que la extinción de esta especie en las Pitiusas es posterior a la llegada del hombre y está relacionada con las actividades antrópicas directas o indirectas (Alcover y McMinn 1992).

La ausencia de mamíferos depredadores es característica de muchas de las comunidades de vertebrados insulares (Sondaar 1977) y permite que el nicho de los superdepredadores sea ocupado por aves (Alcover y McMinn 1994). La comunidad del Pleistoceno superior-Holoceno de las Baleares estaba estructurada de forma que en cada uno de los dos archipiélagos dominaba un ave como superdepredador, H. albicilla en las Pitiusas y Aquila sp. (cf. Aquila chrysaetos) en las Gimnesias (Alcover et al. 2004). La diferencia en composición de superdepredadores entre islas está probablemente relacionada con la diferencia de recursos tróficos entre las mismas. A juzgar por la cantidad de fósiles encontrados, la población de $H$. albicilla debía ser relativamente abundante en las Pitiusas.

Como investigación colateral a este trabajo, se ha analizado la alimentación actual de una de las aves rapaces ausentes en el pasado en las Pitiusas, la lechuza, teniendo en cuenta el carácter autóctono/alóctono de sus presas. Los resultados de Guerra et al. (2014) evidencian en primer lugar que la dieta de estas lechuzas (hasta un 90\% de las presas) consiste principalmente en especies introducidas por los humanos y especies que se asentaron en las Pitiusas tras la llegada de los mismos a las islas. Así mismo se ha observado que las lechuzas que viven en la actualidad en las islas menores de las Pitiusas, desarrollan com- 
portamientos alimenticios atípicos, entre los que se incluye el cruce recurrente de canales de mar para cazar aves y pequeños mamíferos. Este comportamiento incluye además el consumo de presas que habitualmente no forman parte de la dieta de esta especie como conejos y paíños (H. pelagicus).

La investigación realizada sugiere que durante el Pleistoceno superior-Holoceno las Pitiusas no contenían una población (al menos significativa) estable de Tyto alba, especie especializada en la depredación de pequeños mamíferos (Andrews, 1990; Bond et al., 2004). La aparente ausencia de T. alba en el Pleistoceno superior-Holoceno de Ibiza se ajusta a las conclusiones de Oteni (1971), según quién T. alba no dispondría de los recursos alimenticios necesarios para criar en territorios donde sus presas potenciales fuesen solamente aves. La presencia actual de Tyto alba en las Pitiusas se debe relacionar con los cambios ecológicos acontecidos tras la llegada de los humanos a Ibiza y Formentera. 
7 - DISCUSIÓN GENERAL 



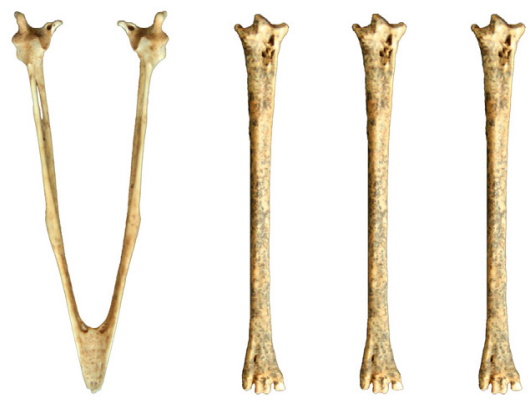

CONCLUSIONES 


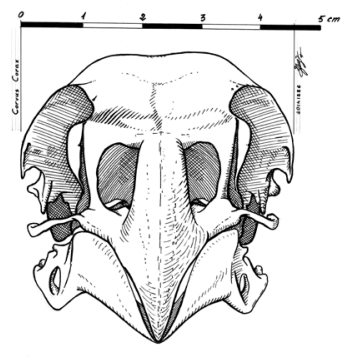

\section{8 - CONCLUSIONES}

El yacimiento paleontológico de es Pouàs, ha permitido estudiar la avifauna fósil del Pleistoceno superior-Holoceno de las Pitiusas, en un ambiente insular singular y en condiciones naturales pre-antrópicas.

1. El estudio de la avifauna de es Pouàs ha permitido incorporar numerosas especies de aves fósiles al registro del Pleistoceno superior-Holoceno de las Baleares y de la zona continental adyacente. Se han incorporado 24 especies de Passeriformes, cuatro especies de Falconiformes y dos de Strigiformes al registro del Pleistoceno superior-Holoceno de las Baleares, y 28 especies de Passeriformes, una de Falconiformes y dos de Strigiformes al registro del Pleistoceno superior-Holoceno del área continental adyacente a las Pitiusas.

2. Se ha ampliado el área de distribución paleártico-occidental de taxones de Passeriformes hasta ahora considerados ausentes o muy poco representados en el registro fósil del Pleistoceno superior-Holoceno en dicha área. Es el caso de Galerida theklae, Oenanthe leucura, Locustella sp., Sylvia sarda/balearica, Sylvia undata, Sylvia melanocephala, Serinus serinus y Emberiza pusilla. 
3. Para la identificación de los diferentes géneros y especies de Passeriformes, se han incorporado numerosos criterios diagnósticos inéditos. Este trabajo constituye, en sí mismo, una herramienta para futuros estudios de identificación osteológica de aves paseriformes.

4. Se han analizado las diferencias en la composición de la fauna fósil de aves rapaces y paseriformes entre las Gimnesias y las Pitiusas. Además de la ya conocida presencia de Haliaeetus como suprerdepredador de la fauna de las Pitiusas, se destaca la importancia de los córvidos en la fauna fósil de estas islas, donde presentan una mayor diversidad que en las Gimnesias.

5. Destacan las diferencias entre las Gimnesias y las Pitiusas en abundancia de siete taxones: Alaudidae, Hirundinidae, Motacillidae, Laniidae, C. corax, P. pyrrhocorax y P. graculus. Los restos fósiles de los seis primeros taxones son mucho más abundantes en es Pouàs que en el total del conjunto de yacimientos de las Gimnesias, mientras que los de la última especie son notablemente más escasos.

6. La abundancia de restos de dos de las especies identificadas, ha permitido analizar las diferencias biométricas entre la muestra fósil de es Pouàs y las poblaciones actuales de C. corax y P. pyrrhocorax. No se han encontrado apenas diferencias significativas entre los individuos de P. pyrrhocorax de es Pouàs y los de las poblaciones actuales. En cambio, los individuos fósiles de C. corax son significativamente más pequeños que los de todas poblaciones actuales de esta especie.

7. Se ha identificado una nueva especie endémica en el registro fósil ibicenco, Bubo sp., de la que no se ha obtenido material adecuado para su descripción.

8. Se han documentado cambios biométricos, relacionables con procesos de evolución insular, en H. albicilla, A. flammeus y C. corax y Bubo sp. Dos de esas especies, H. albicilla y A. flammeus, sufrieron un incremento de la talla corporal, mientras que las otras dos especies, sufrieron una reducción en su talla.

El conjunto ornítico analizado ha permitido realizar aproximaciones paleo-ecológicas relacionadas con el hábitat y la climatología del pasado de las Pitiusas, así como establecer el impacto de la llegada del hombre sobre la comunidad ornítica.

9. Seis de las especies de paseriformes identificadas, tienen una significación climática indicativa de ambientes fríos. Su presencia en Ibiza constituye una nueva evidencia del desplazamiento de especies de aves hacia latitudes más bajas durante la última glaciación. Cuatro de estas especies (B. garrulus, P. graculus, cf. Pinicola enucleator y cf. Plectrophenax nivalis) se encuentran ausentes en la actualidad en Baleares, y las especies restantes, $P$. collaris y $M$. nivalis, son muy escasas. 
10. El hábitat que ocupan actualmente las especies identificadas, ha permitido inferir rasgos del paisaje del entrorno de es Pouàs en el Pleistoceno superior-Holoceno. Ese paisaje contenía espacios de llanuras abiertas, zonas rocosas, áreas de bosque y matorral y algunas zonas palustres. El área de origen de esta ornitofauna fósil debe haber incluido, no sólo el entorno más inmediato, sino las dolinas adyacentes al yacimiento (Pla de Corona y Pla de son Gilabert).

11. La acumulación de restos de aves en es Pouàs tiene un doble origen. En primer lugar, se han incorporado restos de aves que criaban o usaban las paredes de la sima como posadero, y en segundo lugar, los restos de aves y otros vertebrados incorporados al depósito por la acción de bio-acumuladores. Entre las aves de presa se han identificado los diferentes agentes bio-acumuladores que explican la incorporación de restos de vertebrados en es Pouàs.

12. El gremio de aves de presa de las Pitiusas presentaba una estructura peculiar, diferente a la de otras islas mediterráneas en las que habitaban mamíferos y también diferente a la del continente. En términos globales, el gremio de aves de presa contenía más especies en el pasado en estas islas. Cinco de las especies identificadas en es Pouàs se encuentran extintas en la actualidad en las Pitiusas.

13. La desaparición de al menos dos especies de depredadores (H. albicilla, y Bubo sp.), y la incorporación exitosa de otros dos (T. alba, A. otus) se relaciona con la colonización humana de las Pitiusas, iniciada hace alrededor de 4150-4350 años. La desaparición de diez especies de Passeriformes, ausentes en la actualidad en las Pitiusas, por causas aparentemente ajenas al clima, podría estar también relacionada con la llegada del hombre a las islas. Dichas especies son: L. arborea, O. leucura, P. ater, P. pyrrhocorax, C. corone, C. monedula, Corvus corax, cf. Pyrrhula pyrrhula, E. pusilla y E. schoeniclus. Estos fenómenos son, muy probablemente, consecuencia de las modificaciones en el paleo-ambiente de estas islas, debidas a las actividades humanas.

14. El estudio de la dieta de T. alba en la actualidad en las islas menores de las Pitiusas, evidencia la importancia de los micromamíferos en la dieta de la lechuza para establecerse en un territorio. Los resultados obtenidos permiten considerar a esta especie un colonizador exitoso reciente en las Pitiusas. 
8 - CONCLUSIONES 

BIBLIOGRAFÍA 


\section{BIBLIOGRAFÍA}

Agustí, J., Moỳ̀-SolÀ, S., 1990. Neogene-Quaternary mammalian faunas of the Balearics, in: Azzaroli, A., Ed., Biogeographical Aspects of Insularity. Atti dei Convegni Lincei, Accademia Nazionale dei Lincei, Roma, 238, 459-469.

Alcover, J.A., 1977. The Longtailed Field Mouse or Wood Mouse Apodemus sylvaticus (Linné, 1758) from the island of Ibiza, Pityusics. Säugetierkundliche Mitteilungen 25, 204-213.

Alcover, J.A., 1979. Els mamífers de les Balears. Manuals d'Introducció a la Naturalesa 2. Editorial Moll, Palma de Mallorca.

Alcover, J.A., 1983. Contribució al coneixement dels mamífers de les Balears i Pitiüses. Ph. D. Thesis, Universidad de Barcelona, Barcelona.

Alcover, J.A., 1984. Subrecent small mammal fauna of Eivissa, in: Kuhbier, H., Alcover, J.A., Guerau d'Arellano, C., Eds., Biogeography and Ecology of the Pityusic Islands. Dr Junk Publishers, The Hague, pp. 377-392.

Alcover, J.A., 2000. Vertebrate Evolution and Extinction on Western and Central Mediterranean Islands. Tropics $10(1), 103-123$.

Alcover, J.A., 2001. Nous avenços en el coneixement dels ocells fòssils de les Balears. Anuari Ornitològic de les Balears 16, 3-13.

Alcover, J.A., 2003. Les rates pinyades (Mammalia: Chiroptera) fòssils del jaciment paleontològic del Pouàs (St. Antoni de Portmany, Eivissa). Endins 25, 141-154.

Alcover, J.A., 2008. The First Mallorcans: Prehistoric Colonization in the Western Mediterranean. Journal of World Prehistory 21, 19-84.

Alcover, J.A., Bover, P., Escandell, M.J., López-Garí, J.M., Marlasca, R., Ramis, D., 2004. Els superdepredadors de la fauna pleistocènica de Menorca i Formentera. Endins 26, 53-57.

Alcover, J.A., Campillo, X., Macias, M., Sans, A., 1998. Mammal species of the world: additional data on insular mammals. American Museum Novitiates 3248, 1-29.

Alcover, J.A., Florit, F., Mourer-Chauviré, C., Weesie, P.D., 1992. The Avifaunas of the Isolated Mediterranean Islands During the Middle and Upper Pleistocene. Science Series, Natural History Museum of Los Angeles County 36, 273-291.

Alcover, J.A., McMinn, M., 1992. Presència de l'àguila marina Haliaeetus albicilla (Linnaeus 1758) al jaciment espeleologic quaternari d'es Pouàs (Sant Antoni de Portmany, Eivissa). Endins $17-18,81-87$.

Alcover, J.A., McMinn, M., 1994. Vertebrate Predators on Islands. BioScience 44, 12-18.

Alcover, J.A., McMinn, M., Altaba, C.R, 1994. Eivissa: a Pleistocene oceanic-like island in the Mediterranean. National Geographic's Commitee for Research and Exploration 10, 236-238. 
Alcover, J.A., Moyà-SolÀ, S., Pons-MoyÀ, J., 1981. Les Quimeres del Passat. Els Vertebrats fòssils del Plio-Quaternari de les Balears $i$ Pitiüses. Editorial Moll, Palma de Mallorca.

Alcover, J.A., Sans, A., Palmer, M., 1998. The extent of extinctions of mammals onislands. Journal of Biogeography 25(5), 913-918.

Amat, J.A., Obeso, J.R., 1989. Alimentación del cuervo (Corvus corax) en un ambiente marismeño. Ardeola 36(2), 219-224.

Andrews, P., 1990. Owls, Caves and Fossils. The Natural History Museum, London.

Angelici, F.M., Latella, L., Luiselli, L., Riga, F., 1997. The summer diet of the little owl (Athene noctua) on the island of Astipalaia (Dodecanese, Greece). Journal of Raptor Research 31, $280-282$.

Araujo, J., Purroy, F.J., Muñoz-Cobo, J., 1977. Las rapaces y aves marinas del Archipiélago de Cabrera. Naturalia Hispanica 12, 1-94.

Arnau, P., Bover, P., Seguí, B., Alcover, J.A., 2000. Sobre alguns jaciments de Myotragus balearicus Bate 1909 (Artiodactyla, Caprinae) de tafonomia infreqüent. Endins 23, 89-100.

Arvey, M.D., 1951. Phylogeny of the Waxwings and Allied Birds. University of Kansas Publications, Museum of Natural History 3, 473-530.

Ashley, J.F, 1941. A study of the structure of the humerus in the Corvidae. Condor 43, 184-195.

Badal, E., Bernabéu, J., Buxó, R., Dupré, M., Fumanal, M.P., Guillem, P., Martínez, R.,Rodrigo, M.J., Villaverde, V., 1991. Cuaternario litoral de la provincia de Alicante sector Pego-Moraira. Actas de la VIII Reunión Nacional sobre el Cuaternario, 21-78.

Ballmann, P., Adrover, R., 1970. Yacimiento paleontológico de la cueva de Son Bauçà (Mallorca). Acta Geológica Hispánica 5(2), 58-62.

Balouet, J.C., Olson, S.L., 1989. Fossil birds from Late Quaternary deposits in New Caledonia. Smithsonian Contributions to Zoology 469, 1-38.

BAtE, D.M.A., 1914. A gigantic land tortoise from the Pleistocene of Menorca. Geological Magazine D 6(1), 100-107.

Baumel, J.J., ED., 1979. Nomina anatomica avium. An annotated anatomical dictionary of birds. Academic Press, London, New York.

Bedetti, C., Pavia, M., 2013. Early Pleistocene birds from Pirro Nord (Puglia, southern Italy). Palaeontographica Abteilung A, 298, 31-53.

Berger, A.J., 1981. Hawaiian birdlife. Second Edition. University of Hawaii Press, Honolulu, Hawaii. 
Blondel, J., Chessel, D., Frochot, B., 1988. Bird species impoverishment, niche expansion, and density inflation in Mediterranean island habitats. Ecology 69, 1899-1917.

Blondel, J., Frochot, B., 1967. Caractères généraux de l'avifaune corse. Effets de l'insularité et influence de l'homme sur son evolution. Bulletin de la Société des Sciences Naturelles de la Corse 619-620, 63-74.

BocheŃSKI, Z., BocheŃSKI, Z.M., 2008. An Old World hummingbird from the Oligocene: a new fossil from Polish Carpathians. Journal of Ornithology 149, 211-216.

Bock, W.J., 1962. The pneumatic fossa of the humerus in the Passeres. Auk 79, 425-443.

BoESSNECK, J. vON, 1985. Zum Vorkommen des Schreiseeadlers, Haliaeetus vocifer (Daudin, 1800) im alten Ägypten. Spixiana 8, 17-23.

Boev, Z., 2009. Avian Remains from the Late Chalcolithic Settlement near HotnitsaVillage (Veliko Tarnovo Region, CN Bulgaria) Acta Zoologica Bulgarica 61(1), 49-54.

Boev, Z., 2012. Neogene Larks (Aves: Alaudidae (Vigors, 1825)) from Bulgaria. Acta zoologica bulgarica 64(3), 295-318.

Bond, G., Burnside, N.G., Metcalfe, D.J., Scott, D.M., Blamire, J., 2004. The effects of land-use and landscape structure on barn owl (Tyto alba) breeding success in southern England, U.K. Landscape Ecology 20, 555-566.

Bonnot, P., 1928. An outlaw Barn Owl. Condor 30, 320.

Bontzorlos, V.A., Peris, S.J., Vlachos, C.G., Bakaloudis, D.E., 2005. The diet of Barn Owl in the agricultural landscapes of central Greece. Folia Zoologica 54, 99-110.

Bour, R., 1985. Una nova tortuga terrestre del Pleistocè d'Eivissa: la tortuga de la cova de Ca Na Reia. Endins 10-11, 57-62.

Bover, P., Alcover, J.A., 2008. Extinction of the autochthonous small mammals of Mallorca (Gymnesic Islands, Western Mediterranean) and its ecological consequences. Journal of Biogeography 35, 1112-1122.

Bover, P., Quintana, J., Alcover, J.A., 2008. Three islands, three worlds: Paleogeography and evolution of the vertebrate fauna from the Balearic Islands. Quaternary International 182, 135-144.

Bover, P., Valenzuela, A., Guerra, C., Rofes, J., Alcover, J.A., Ginés, J., Fornós, J.J., Cuenca-Bescós, G., Merino, A., 2014. The Cova des Pas de Vallgornera (Llucmajor, Mallorca): a singular deposit bearing an exceptional well preserved Early Pleistocene vertebrate fauna. International Journal of Speleology 43(2),175-192.

Cacho, C., Fumanal, M.P., López, P., López, J.A., Pérez Ripoll, M., Martínez Valle, R.,Uzquiano, P., Arnanz, A., Sánchez Marco, A., Sevilla, P., Morales, A., Roselló, E., Garralda, M.D., García Carillo, M., 1995. El Tossal de la Roca (vall d'Alcalà, Alicante). Reconstrucción paleoambiental y cultura de la transición del Tardiglaciar al Holoceno inicial. Recerques del Museu d'Alcoi 5, 11-101. 
Cassoli, P.F., 1980. L'avifauna del Pleistocene superiore delle Arene Candide (Liguria). Memorie dell'Istituto Italiano di Paleontologia Umana: Nuova Serie 3, 136-234.

ClegG, S.M., OWEns, P.F., 2002. The 'island rule' in birds: medium body size and its ecological explanation. Proceedings of the Royal Society of London Series B-Biological Sciences 269, 1359-1365.

Clements, J.F., 2000. Birds of the World. A Checklist, fifth ed. Pica, Mountfield, Sussex.

CoOper, J.H., 1999. Late Pleistocene Avifaunas of Gibraltar and their Palaeoenvironmental Significance. Ph.D. Thesis, University of London.

Cramp, S., Simmons, K.E.L., 1998. The complete birds of the Western Palearctic on CD-Rom. Oxford University Press CD-Rom, Oxford.

Cugnasse, J.M., Riols, C., 1984. Contribution a la conaissance de l'ecologie de la genette (Genetta genetta) dans quelques départaments du sud de la France. Gibier Faune Sauvage 1, 25-55.

Cuisin, J., 1981. L'identification des crânes de petits passereaux. L'Oiseau et la Revue Française d'Ornithologie 51(1), 17-31.

Darviche, D., Orsini, P., 1982. Critères de différenciation morphologique et biométrique de deux espèces de souris sympatriques: Mus spretus et Mus musculus domesticus. Mammalia 46, 205-217.

Davidson, I., 1989. La economia del final del paleolítico en la España oriental. Serie de trabajos varios-Servicio de Investigación Prehistórica, 85.

Delgado, G., 1993. Variación estacional de la dieta de Tyto alba gracilirostris (Hartert, 1995) en la isla de Alegranza (Lanzarote, Islas Canarias) (Aves: Tytonidae). Vieraea 22, 133-137.

Delgado, G., Carrillo, J., Trujillo, D., 1992. Sobre la presencia y distribución de la lechuza común (Tyto alba Scopoli, 1769) en las islas orientales del Archipiélago Canario. Vieraea 21, $145^{-148 .}$

Delibes, M., Brunet Lecomte, P., Máñez, M., 1984. Datos sobre la alimentación de la lechuza común (Tyto alba), el búho chico (Asio otus) y el mochuelo (Athene noctua) en una misma localidad de Castilla la Vieja. Ardeola 30, 57-63.

Diamond, J.M., 1985. Population processes in island birds: immigration, extinction and fluctuation. International Council for Bird Preservation Technical Publication 3,17-21.

Dickinson, E., Ed., 2003. The Howard and Moore Complete Checklist of the Birds of the World, third ed. Helm, London.

Donázar, J.A., Ceballos, O., 1989. Selective predation by Eagle Owls Bubo bubo on rabbits Oryctolagus cuniculus: age and preferences. Ornis Scandinavica 20, 117-122.

Eastham, A., 1973. Birds from Cueva del Volcán del Faro. Manuscrito depositado en el SIP, Valencia. 
Eastham, A., 1988. The season or the symbol: the evidence of swallows in the Palaeolithic of Western Europe. Archaeozoologia 2, 243-252.

Eastham, A., 1989. Cova Negra and Gorham's Cave: evidence of the place of birds in Mousterian communities. The walking lader, 350-357.

Eastham, A., 2001. Choughs, Man and a shared environment: A study of Chough bones from Upper Pleistocene sites in southwest Europe. In: Animals and Man in the Past. ARC Publicatie 41, Groningen Institute of Archaeology, Groningen, pp. 178-191.

Eastham, A., 2005. Papageno down the ages: A study in fowling methods with particular reference to the Palaeolithic of Western Europe. Munibe 57(1), 369-397.

Ericson, G.P., Tyrberg, T., Kjellberg, A.S., Jonsson, L., Ullén, I., 1997. The Earliest Record of House Sparrows (Passer domesticus) in Northern Europe. Journal of Archaeological Science 24, 183190.

Figueroa, R.A., Rau, J.R., Mayorga, S., Martínez, D.R., Corales, E.S., Mansilla, A., Figueroa, R., 2009. Rodent prey of the Barn Owl Tyto alba and Short-Eared Owl Asio flammeus during winter in agricultural lands of southern Chile. Wildlife Biology 15, 129-136.

Fischer, K., Stephan, B., 1974. Eine Pleistozäne Avifauna von der Gahr Dalam Höhle, Malta. Zeitschrift für Geologische Wissenschaften, Berlin 2, 515-523.

Fleischer, R.C., Olson, S.L., James, H.F., Cooper, A.C., 2000. Identification of the extinct Hawaiian eagle (Haliaeetus) by mtDNA sequence analysis. The Auk,117(4), 1051-1056.

Florit, F., Alcover, J.A., 1987. Els ocells del Pleistocè superior de la Cova Nova (Capdepera, Mallorca). I. El registre. Bolletí de la Societat d'Història Natural de les Balears 31, 7-32.

Florit, F., Alcover, J.A., 1987. Els ocells del Pleistocè superior de la Cova Nova (Capdepera, Mallorca). II. Fauna associada i discussió. Bolletí de la Societat d'Història Natural de les Balears $31,33-44$.

Florit, F., Mourer-Chauviré, C., Alcover, J.A., 1989. Els ocells pleistocènics d'es Pouàs, Eivissa. Nota preliminar. Butlletí de la Institució Catalana d'Història Natural 56, 35-46.

García, D., Arbona, P., 2007. Nuevas localidades de nidificación del Paiño Europeo Hydrobates pelagicus en el Parc Natural de Ses Salines d'Eivissa i Formentera (Islas Pitiüses, Baleares).

Anuari Ornitologic de les Balears 22, 81-83.

García, M., Cervera, F., Rodríguez, A., 2005. Bat predation by Long-eared Owls in the Mediterranean and temperated regions of southern Europe. Journal of Raptor Research 39(4), $445-453$.

García-Gans, F.J., Santana, C., Tornero, J.A., Català, F.J., 2005. Resultats preliminars de la quantificació de la població reproductora d'Ocell de tempesta Hydrobates pelagicus melitensis de l'illot de s'Espartar. Anuari Ornitologic de les Balears 19, 45-49.

Gillespie, R.G., 2007. Oceanic islands: models of diversity. Encyclopedia of biodiversity, 1-13. 
Ginés, A., Ginés J., 1971. Exploraciones en Ibiza. Cavernas 16, 19-26. Badalona.

Gotta, A., Pigozzi, G., 1997. Trophic niche of the Barn Owl and Little Owl in a rice field habitat in Northern Italy. Italian Journal of Zoology 64, 55-59.

GRAYSON, D.K., 2001. The archaeological record of human impacts on animal populations. Journal of World Prehistory 15, 1-68.

Guerra, C., García, D., Alcover, J.A., 2014. Unusual foraging patterns of the barn owl, Tyto alba (Strigiformes: Tytonidae) on small islets from the Pityusic archipelago (Western Mediterranean Sea). Folia Zoologica 63(3), 180-187.

Guerra, C., McMinn, M., Alcover, J.A., 2013. The Upper Pleistocene-Holocene raptorial bird guild from Eivissa Island (Pityusic Archipelago, Western Mediterranean Sea). Geobios 46, 491-502.

Gutiérrez, R., de Juana, E., Lorenzo, J.A., 2012. Lista de las aves de España. Sociedad Española de Ornitología (SEO/BirdLife).

Hamon, J.H., 1964. Osteology and paleontology of the passerine birds of the Reddick, Florida, Pleistocene. Florida Geological Survey, Bulletin 44, 1-210.

HARris, T., 2000. Shrikes and Bush-Shrikes. Helm, London.

Haug, G.H., Tiedemann, R., 1998. Effect of the formation of the Isthmus of Panama on Atlantic Ocean thermohaline circulation. Nature 393(6686), 673-676.

HernánDEZ, F., 1993. Catálogo provisional de los yacimientos con aves del Cuaternario de la península Ibérica. Archaeofauna 2, 231-275.

Hernández, E., Martín, M., Reyes, J.C.R., 1993. Estudio osteológico comparado de dos subespecies de Corvus corax (Aves: Passeriformes). Archaeofauna: International Journal of archaeozoology (2), 181-190.

Herrera, C.M., 1974. Régimen alimenticio de Tyto alba en España sudoccidental. Ardeola 19, $359-394$.

Herrera, C.M., Hiraldo, F., 1976. Food-niche and trophic relationships among European owls. Ornis Scandinavica 7, 29-41.

Herrera, C.M., Jaksic, F.M., 1980. Feeding ecology of the Barn Owl in Central Chile and Southern Spain: a comparative study. Auk 97, 760-767.

Hiraldo, F., Blanco, J.C., Bustamante, J., 1991. Unspecialized exploitation of small carcasses by birds. Bird Study 38(3), 200-207.

Howell, A.B., 1920. Habits of Oceanodroma leucorhoa beali versus O. socorroensis. Condor $22(1), 41-42$.

del Hoyo, J., Elliott, A., Christie, D.A., Eds., 2008. Handbook of the Birds of the World, vol. 13. Lynx Edicions, Barceolona. 
Huntley, B., WeвB, T., 1989. Migration: species response to climatic variations caused by changes in the earth's orbit. Journal of Biogeography 16, 5-19.

Ings, T.C., Montoya, J.M., Bascompte, J., Blüthgen, N., Brown, L., Dormann, C.F., Edwards, F., Figueroa, D., Jacob, U., Ivan Jones, J., Lauridsen, R.B., Ledger, M.E., Lewis, H.M., Olesen, J.M., Frank van Veen, F.J., Warren, P.H.,Woodward, G., 2008. Ecological networks - beyond food webs. Journal of Animal Ecology 78, 1-17.

Isenmann, P., Bouchet, M.A., 1993. L'aire de distribution française et le statut taxonomique de la Pie-grièche mériodonale Lanius elegans meridionalis. Alauda 61, 223-227.

Ivy-Ochs, S., Kerschner, H., Reuther, A., Preusser, F., Heine, K., Maisch, M., Kubik, P. W., SChlÜChter, C., 2008. Chronology of the last glacial cycle in the European Alps. Journal of Quaternary Sciences 23, 559-573.

Jánossy, D. von, 1983. Humeri of Central European smaller Passeriformes. Fragmenta Mineralogica et Paleontologica 11, 85-112.

JÁNOSSY, D. vON, 1985. Wildvögelreste aus archäologischen Grabungen in Ungarn (Neolithicum bis Mittelalter). Fragmenta Mineralogica et Paleontologica 12, 67-103.

Johnson, T.H., Stattersfield, A.J., 1991. A global review of island endemic birds. Ibis 132, 167180.

Johnston, D.W., Hill, J.M., 1987. Prey selection of Common Barn Owls on islands and mainland sites. Journal of Raptor Research 21(1), 3-7.

Juillard, M., Rebetez, M., 1991. Capture d'une famille de Faucon pèlerins, Falco peregrinus, par le Hibou grand-duc, Bubo bubo. Nos Oiseaux 41, 196.

Kessler, E., 2013. Neogene songbirds (Aves, Passeriformes) from Hungary. Hantkeniana 8, 37-149.

Kirch, P.V., 2005. Archaeology and global change: the Holocene record. Annual Revue of Environment and Resources, 30, 409-440.

Kuhbier, H., Alcover, J.A., Guerau d'Arellano Tur, Eds., 1984. Biogeography and Ecology of the Pityusic Islands. Dr W. Junk Publishers, The Hague, Boston, Lancaster.

LAmbrecht, K., 1933. Handbuch der Palaeornithologie, Berlin (Gebründer Borntraeger) 1-1024.

LANGER, G., 1980. Vergleichende Morphologische Untersuchungen an Einzelknochen in Zentraleuropa Vorkommender Mittelgrosse Eulenarten. Ludwig Maximilians Universität, München.

Lefranc, N., Worfolk, T., 1997. Shrikes: A Guide to the Shrikes of the World. Pica Press, Mountfield, Sussex. 
de León, A., Mínguez, E., Harvey, P., Meek, E., Crane, J.E., Furness, R.W., 2006. Factors affecting breeding distribution of Storm Petrels Hydrobates pelagicus in Orkney and Shetland: The main factors are past and present human activities, especially the introduction of rats to islands. Bird Study 53, 64-72.

de León, L., Rodríguez, B., Martín, A., Nogales, M., Alonso, J., Izquierdo, C., 2007. Status, distribution, and diet of Eleonora's Falcon (Falco eleonorae) in the Canary Islands. Journal of Raptor Research 44, 331-336.

Livezey, B., Zusi, R., 2006. Phylogeny of Neornithes. Bulletin of Carnegie Museum of Natural History $37,1-544$.

López-Jurado, C., Ed., 2011. Anuari Ornitològic de les Balears 26. Grup Baleard'Ornitologia i Defensa de la Naturalesa (GOB), Palma de Mallorca.

López-Jurado, C., Ed., 2012. Anuari Ornitològic de les Balears 27. Grup Baleard'Ornitologia i Defensa de la Naturalesa (GOB), Palma de Mallorca.

Louchart, A., 2002. Les oiseaux du Pléistocène de Corse, et de quelques localités sardes-écologie, évolution, biogéographie et extinctions. Documents des Laboratoires de Géologie Lyon 155, 287 pp.

LOUCHART, A., 2004. An extinct large thrush (Aves: Turdidae) from the Late Quaternary of Mediterranean Europe. Neues Jahrbuch für Geologie und Paläontologie, Abhandlungen 233(2), $275^{-296 .}$

LOUCHART, A., 2005. Integrating the fossil record in the study of insular body size evolution: example of owls (Aves, Strigiformes). Monografies de la Societat d'Història Natural de les Balears $12,155^{-174}$.

Louchart, A., 2008. Review of: John R. Stewart (2007). An Evolutionary Study of Some Archaeologically Significant Avian Taxa in the Quaternary of the Western Palaearctic. Oxford, Archaeopress. Journal of Archaeological Science 35, 2666-2667.

Louchart, A., 2011. Aves, in: Harrison, T., Ed., Paleontology and Geology of Laetoli: Human Evolution in Context. Volume 2: Fossil Hominins and the Associated Fauna. Springer, Dordrecht, pp. 505-533.

Louchart, A., Bedetti, C., Pavia, M., 2005. A new species of eagle (Aves: Accipitridae) close to the Steppe Eagle, from the Pleistocene of Corsica and Sardinia, France and Italy. Palaeontographica Abteilung A, Paläozoologie-Stratigraphie 272, 121-148.

Malatesta, A., Suriano, F., 1970. Avifauna pleistocenica di Alghero (Sardegna). Bollettino del Servizio geologico d'Italia 91, 149-158.

Marquiss, M., Воотн, C.J., 1986. The diet of ravens Corvus corax in Orkney. Bird Study 33(3), 190-195.

Martínez, J.A., Zuberogoitia, I., 2004. Habitat preferences and causes of population decline for Barn Owls Tyto alba: a multiscale approach. Ardeola 51(2), 303-317. 
Mason, C.F., MacDonald, S.M., 1995. Corvids feeding on carrion. Bird Study 42(3), 255-256.

McMinn, M., Alcover, J.A., 1992. Els ocells fòssils del Pleistocè superior de la Cova Nova. III. Noves aportacions al registre. Bolletí de la Societat d'Història Natural de les Balears 35, 17-32.

McMinn, M., Palmer, M., Alcover, J.A., 2005. A new species of rail (Aves: Rallidae) from the Upper Pleistocene and Holocene of Ibiza (Pityusic Islands, western Mediterranean). Ibis 147(4), 706-716.

Meiri, S., Raia, P., Phillimore, A.B., 2010. Slaying dragons: limited evidence for unusual body size evolution on islands. Journal of Biogeography 38, 89-100.

Miккоца, H., 1976. Owls killing and killed by other owls and raptors in Europe. British Birds 69, $144-154$.

Mikкola, H., 1983. Owls of Europe. T. and A.D. Poyser, London.

Milne-EdWARdS, A., 1867-71. Recherches anatomiques et paléontologiques pour servir à l'histoire des oiseaux fossiles de la France. Paris.

Moreno, E., 1985. Clave osteológica para la identificación de los Passeriformes ibéricos. I. Aegithalidae, Remizidae, Paridae, Emberizidae, Passeridae, Fringillidae, Alaudidae. Ardeola 32, 295-377.

Moreno, E., 1986. Clave osteológica para la identificación de los Passeriformes ibéricos. II. Hirundinidae, Prunellidae, Sittidae, Certhiidae, Troglodytidae, Cinclidae, Laniidae, Oriolidae, Corvidae, Sturnidae, Motacillidae. Ardeola 33, 69-129.

Moreno, E., 1987. Clave osteológica para la identificación de los Passeriformes ibéricos. III. Muscicapidae. Ardeola 34, 243-273.

Mourer-Chauviré, C., 1975. Les oiseaux du Pléistocène moyen et supérieur de France. Thèse, Université Claude Bernard (Lyon), 1er fascicule 261 pp.

Mourer-Chauviré, C., 1993. The Pleistocene avifaunas of Europe, Archaeofauna 2, 53-66.

Mourer-Chauviré, C., Adrover, R., Pons-Moya, J., 1975. Présence de Grus antigone (L.) dans "l'Avenc de Na Corna" a Majorque (Espagne). Nouveaux Archives du Museum d'Histoire naturelle de Lyon 13, 45-50.

Mourer-Chauviré, C., Moyà-SolÀ, S., Adrover, R., 1977. Les oiseaux des gisements quaternaires de Majorque. Nouvelles archives du Muséum d'histoire naturelle de Lyon 15 (suppl.), 61-64.

Mourer-Chauviré, C., Weesie, P.D.M., 1986. Bubo insularis n.sp., forme endemique insulaire de Gran Duc (Aves, Strigiformes) du Pléistocène de Sardaigne et de Corse. Revue de Paléobiologie 5, 197-205.

MoyÀ-Solà, S., Pons-MoyÀ, J., Alcover, J.A., Agustí, J., 1984. La fauna de vertebrados neógenocuaternaria de Eivissa (Pitiüses). Nota preliminar. Acta Geologica Hispanica 19, 33-35.

Mykytowycz, R., Hesterman, E.R., Purchase, D., 1959. Predation of the Wild Rabbit by the Australian Raven. Emu 59, 41-43. 
Olson, S.L., 1982. The distribution of fused phalanges of the inner toe in the Accipitridae. Bulletin of the British Ornithologists' Club 102, 8-12.

Olson, S.L., 1989. Preliminary systematic notes on some old world passerines. Rivista Italiana Di Ornitologia 59(3-4), 183-195.

Olson, S.L., Hilgartner, W.B., 1982. Fossil and Subfossil Birds from the Bahamas, in: Olson, S.L., Ed., Smithsonian Contributions to Paleobiology 48, 22-56.

Olson, S.L., James, H.F., 1991. Descriptions of thirty-two new species of birds from the Hawaiian Islands: Part l. Non-Passeriformes. Ornithological Monographies American Ornitologists' Union 45, $1-87$.

Olsson, U., Alström, P., Svensson, L., Aliabadian, M., Sundberg, P., 2010. The Lanius excubitor (Aves, Passeriformes) conundrum-Taxonomic dilemma when molecular and non-molecular data tell different stories. Molecular Phylogenetics and Evolution 55, 347-357.

Oro, D., de León, A., Minguez, E., Furness, R.W., 2005. Estimating predation on breeding European storm petrels (Hydrobates pelagicus) by yellow-legged gulls (Larus michahellis). Journal of Zoology 265, 421-429.

Oteni, L.C., 1971. Predator-prey relationships and reproduction of the barn owl in southern Texas. Dissertation (Tech University), Texas.

Отто, С., 1981. Vergleichende Morphologische Untersuchungen an Einzelknochen in Zentraleuropa Vorkommender Mittelgrosse Accipitridae. I. Schädel, Brustbein, Schultergürtel und Vorderextremität. Ludwig Maximilians Universität, München.

DE PAblo, F., 2000. Alimentación de la lechuza común (Tyto alba) en Menorca. Bolletí de la Societat d'Història Natural de les Balears 43, 15-26.

Palmer, M., Pons, G.X., Cambefort, I., Alcover, J.A., 1999. Historical processes and environmental factors as determinants of inter-island differences in endemic faunas: the case of the Balearic Islands. Journal of Biogeography 26, 813-823.

Quintana Cardona, J., Moncunill-Sole, B., 2014. Hypolagus balearicus Quintana, Bover, Alcover, Agusti \& Bailon, 2010 (Mammalia: Leporidae): new data from the Neogene of Eivissa (Balearic Islands, Western Mediterranean). Geodiversitas 36(2), 283-310.

Rand, A.L., 1960. Family Laniidae, in: Mayr, E., Greenway, J.C., JR., Eds., Checklist of the Birds of the World, vol. IX. Museum of Comparative Zoology, Cambridge, MA.

Rando, J.C., 1995. Presencia de restos de Pigargo (Haliaeetus sp.) (Aves: Accipitridae) en yacimientos paleontológicos de Fuerteventura. Vieraea 24, 65-69.

Reumer, J.W.F., 1982. Some remarks on the fossil vertebrates from Menorca, Spain. Proceedings of the Koninklijke Nederlandse Akademie van Wetenschappen Series B 85, 77-87. 
Rolando, A., Laiolo, P., Formica, M., 1997. A comparative analysis of the foraging behaviour of the Chough Pyrrhocorax pyrrhocorax and the Alpine Chough Pyrrhocorax graculus coexisting in the Alps. Ibis 139(3), 461-467.

Ruffino, L., Bourgeois, K., Vidal, E., Deum, C., Paracuellos, M., Escribano, F., Sposimo, P., Baccetti, N., Pascal, M., Oro, D., 2009. Invasive rats and seabirds after 2,000 years of an unwanted coexistence on Mediterranean islands. Biological Invasions 11, 1631-1651.

SÁnchez Marco, A., 1988. Avifauna, in: S. Ripoll López, Ed., La Cueva de Ambrosio (Almería, Spain) y su posición cronoestratigráfica en el Mediterráneo Occidental. British Archaeological Reports, International Series, 462 (I), pp. 143-156.

Sánchez Marco, A., 2004. Avian zoogeographical patterns during the Quaternary in the Mediterranean region and paleoclimatic interpretation. Ardeola 51(1), 91-132.

SÁnchez Marco, A., 2007b. Yacimientos del Cuaternario: descripción, antecedentes y registro aviar. Disponible en: http://avesfosiles.com/Articulos/Yacimientos.html

Sangster, G., Collinson, J.M., Crochet, P.A., Knox, A.G., Parkin, D.T., Votier, S.C., 2012. Taxonomic recommendations for British birds: eighth report. Ibis 154(4),874-883.

Schmidt-Burger, P., 1982. Vergleichende Morphologische Untersuchungen an Einzelknochen in Zentraleuropa Vorkommender Mittelgrosse Accipitridae. II. Becken und Hinterextremität. Ludwig Maximilians Universität, München.

Seguí, B., 1996. Les avifaunes fòssils dels jaciments càrstics del Pliocè, Plistocè i Holocè de les Gimnèsies. Bolletí de la Societat d'Història Natural de les Balears 39, 25-42.

Seguí, B., 1997. Avifauna fòssil del jaciment plistoholocènic de la Cova des Moro (Manacor, Mallorca). Bolletí de la Societat d'Història Natural de les Balears 40, 71-89.

Seguí, B., 1999. Els ocells fóssils de Mallorca i de Menorca. Succesió estratigràfica d'aus en els rebliments càrstics de les Gimnesies. Ph. D. Thesis, Universitat de les Illes Balears, 194 pp.

Seguí, B., Alcover, J.A., 1999. Comparison of paleoecological patterns in insular bird faunas: a case study from the western Mediterranean and Hawaii, in: Olson, S. Ed., Avian Paleontology at the Close of the 2oth Century. Smithsonian Contributions to Paleobiology 89, pp. 67-73.

Seguí, B., Mourer-Chauviré, C., Alcover, J.A., 1997. Upper Pleistocene and Holocene fossil avifauna from Moleta Cave (Mallorca, Balearic Islands). Bolletí de la Societat d'Història Natural de les Balears 40, 223-252.

Serrano, D., 2000. Relationship between raptors and rabbits in the diet of Eagle Owls in Southwestern Europe: competition, removal or food stress? Journal of Raptor Research 34(4), 305-310.

Siverio, F., Palacios, C.J., 2004. Lechuza común Tyto alba gracilirostris, in: Madroño, A., GonzÁlez, C., Atienza, J.C., Eds., Libro rojo de las aves de España. Dirección general para la biodiversidad SEO/BirdLife, Madrid, pp. 286-288.

Snow, D.W., Perrins, C.M., 1998. The Birds of the Western Palaearctic. Oxford University Press. 
Sommer, R., Zoller, H., Kock, D., Böhme, W., Griesau, A., 2005. Feeding of the Barn Owl, Tyto alba with first record of the European free-tailed bat, Tadarida teniotis on the island of Ibiza (Spain, Balearics). Folia Zoologica 54, 364-370.

SondaAr, P.Y., 1977. Insularity and its effects on mammal evolution, in: Hecht, M.K., Goody, P.C., Hecht, B.M., Eds., Major Patterns in Vertebrate Evolution. NATO Advanced Studies Institute Series A, Life Sciences, pp. 671-707.

Sondaar, P.Y., McMinn, M., Seguí, B., Alcover, J.A., 1995. Interès paleontològic dels jaciments càrstics de les Gimnèsies i les Pitiüses. Endins 20/Monografies de la Societat d'Història Natural de les Balears 3, 155-170.

SPEAKMAn, J.R., 1991. The impact of predation by birds in bat populations in the British Isles. Mammal Revue 21(3), 123-142.

Steadman, D.W., 2006. Extinction and Biogeography of Tropical Pacific Birds. The University of Chicago Press, Chicago.

Steadman, D.W., Martin, P.S., 2003. The late Quaternary extinction and future resurrection of birds on Pacific islands. Earth-Science Reviews 61(1), 133-147.

STEWART, J.R., 2007. An evolutionary study of some archaeologically significant avian taxa in the Quaternary of the Western Palaearctic. BAR International Series 1653. Hadrian Books Ltd, Oxford.

TAYLOR, I.R., 1989. The Barn Owl. Shire Publications, Aylesbury.

Tchernov, E., 1962. Paleolithic Avifauna in Palestine. Bulletin of the Research Council of Israel $11,95^{-125}$.

Thomas Casajuana, J.M., Montoriol-Pous, J., 1953. Resultados de una campaña geoespeleológica en la Isla de Ibiza (Baleares). Speleon, Tomo IV, 3-4, 219-256. Oviedo.

TomeK, T., BocheŃski, Z.M., 2000. The comparative osteology of European corvids (Aves: Corvidae), with a key to the identification of their skeletal elements. Publications of the Institute of Systematics and Evolution of Animals, Kraków.

Tortosa, J.E.A., Bonilla, V.V., Ripoll, M.P., Valle, R.M., Calatayud, P.G., 2002. Big game and small prey: Paleolithic and Epipaleolithic Economy from Valencia, (Spain). Journal of Archaeological Method and Theory 9(3), 215-268.

Trias, M., 1982. Noves dades sobre les cavernes Pitïuses. Endins 9, 15-27.

Trias, M., 1983. Espeleologia de les Illes Pitiüses. Estudis Breus 2, 1-58.

Turvey, S.T., Ed., 2009. Holocene extinctions. Oxford University Press.

Tyrberg, T., 1998. Pleistocene Birds of the Palearctic. A Catalogue. Publications of the Nuttall Ornithological Club 27, Cambridge, Massachusetts.

Tyrberg, T., 2008. Pleistocene birds of the Palearctic. Supplement to "Pleistocene birds of the 
Palearctic. A Catalogue". web.telia.com/ u11502098/pleistocene.pdf

UjHeLYI, P., 1992. Identification of the Fringillidae of Europe on the basis of craniometric characteristics. Aquila 99, 99-110.

Van der Geer, A., Lyras, G., De Vos, J., Dermitzakis, M., 2010. Front Matter (pp. i-xi). WileyBlackwell.

Van der Werf, E., Wood, K., Swenson, C., Le Grande, M., Eijzenga, H., Walker, R., 2007. Avifauna of Lehua Islet, Hawaii: Conservation Value and Management Needs 1. Pacific Science 61, 39-52.

VAurie, C., 1959. The birds of the Palearctic Fauna. Order Passeriformes. H.F. and G. Witherby, London.

Velarde, E., Ávila Flores, R., Medellín, R.A., 2007. Endemic and introduced vertebrates in the diet of the Barn Owl (Tyto alba) on two islands in the Gulf of California, Mexico. Southwestern Naturalist 52, 284-290.

Verheyen, R., 1958. Contribution a l'anatomie de base et a la systématique des Alaudidae (Passeriformes). Alauda 26, 1-25.

Vernier, E., 1993. Predazione di Chirotteri da parte del Barbagianni (Tyto alba) in Italia. Hystrix 5, 105-107.

Villalta, J.F., 1964. Datos para un catálogo de las aves fósiles del Cuaternario español. Speleón $15,79-102$.

Villaverde, V., Martínez Valle, R., Guillem, P.M., Badal, E., Zalbidea, L., García, R., 1997. Els nivells Magdalenians de la cova de les Cendres (Teulada, Moraira). Resultats del sondeig del quadre A-17. Aguaits 13/14, 77-115.

Villaverde, V., Menargues, J., García, E.B., Guillerm, P.M., Valle, R.M., García, R., 1999. El Paleotítico superior de la Cova de les Cendres (Teulada-Moraira, Alicante): datos proporcionados por el sondeo efectuado en los cuadros A/B-17. Archivo de Prehistoria Levantina 23, 9-66.

Walker, M., 2001. Excavations at Cueva Negra del Estrecho del Río Quípar and Sima de las Palomas del Cabezo Gordo: two sites in Murcia (south-east Spain) with Neanderthal skeletal remains, Mousterian assemblages and late Middle to early Upper Pleistocene fauna, in: Milliken, S., Cоoк, J., Eds., A Very Remote Period Indeed: Papers on the Palaeolithic presented to Derek Roe. Oxford: Oxbow Books.

WALKer, M., 2003. La Cueva Negra del Estrecho del Quípar en la Encarnación. Caravaca de la Cruz. Campaña de 1996. Memorias de Arqueología 11, 35-44.

Walker, M., Gibert, J., 1998. Two SE Spanish Middle Palaeolithic Sites with Neanderthal Remains: Sima de las Palomas del Cabezo Gordo and Cueva Negra del Estrecho del Río Quípar (Murcia province). Internet Archaeology 5 (http://intarch.ac.uk/journal/issue5/walker_index.html). 
Weesie, P.D.M., 1982. A Pleistocene endemic island form within the genus Athene: Athene cretensis n.sp. (Aves, Strigiformes) from Crete. Proceedings of the Koninklijke Nederlandse Akademie van Wetenschappen. Series B 85, 323-336.

Weesie, P.D.M., 1988. The Quaternary Avifauna of Crete, Greece. Palaeovertebrata 18, 1-94.

Whittaker, R.J., Triantis, K.A., Ladle, R.J., 2008. A general dynamic theory of oceanic island biogeography. Journal of Biogeography 35(6), 977-994.

Willis, K.J., Araujo, M.B., Bennett, K.D., Figueroa-Rangel, B., Froyd, C.A., Myers, N., 2007. How can a knowledge of the past help to conserve the future? Biodiversity conservation and the relevance of long-term ecological studies. Philosophical Transactions of the Royal Society B 362, $175^{-186 .}$

Wing, S.L., Sues, H.D., Potts, R., DiMichele, W.A., Behrensmeyer, A.K., 1992. Evolutionary Paleoecology, in: Behrensmeyer, A.K., Damuth, J.D., DiMichele,W.A., Potts, R., Sues, H.D., WInG, S.L., Eds., Terrestrial Ecosystems through Time. Evolutionary Paleoecology of Terrestrial Plants and Animals. The University of Chicago Press. The Evolution of Terrestrial Ecosystems Consortium, Chicago and London, pp. 1-13.

Winn Jones, R., 2006. Applied Palaeontology. Cambridge University Press.

WółCIK, J.D., 2002. The comparative osteology of the humerus in European thrushes (Aves: Turdus) including a comparison with other similarly sized genera of passerine birds - preliminary results. Acta Zoologica Cracovensia 45, 369-38.

Worthy, T.H., Holdaway, R.N., 2002. The lost world of the moa: prehistoric life of New Zealand. Indiana University Press.

Zelenkov, N.V., Kurochkin, E.N., 2012. First representative Pliocene assemblage of passerine birds in Asia (Northern Mongolia and Russian Transbaikalia). Geobios 45(3), 323-334. 

ANEXO 


\section{LISTADO DE FIGURAS}

Fig. 1 - Número de huesos (cráneos, húmeros y tarsometatarsos) identificados de las diferentes especies de Passeriformes de es Pouàs. Escala logarítmica.

Fig. 2 - Número de huesos (excepto vértebras, costillas, falanges y huesos de las articulaciones) identificados de las diferentes especies de Accipitriformes y Strigiformes de es Pouàs. Escala logarítmica.

Láminas fotográficas de las especies de Passeriformes identificadas en las que se muestran los huesos fósiles y los actuales de las mismas.

Fig. 3 - Alaudidae.

Fig. 4 - Hirundinidae, Motacillidae y Bombycillidae.

Fig. 5 - Prunellidae y Turdidae (I).

Fig. 6 - Turdidae (II).

Fig. 7 - Sylviidae.

Fig. 8 - Muscicapidae, Paridae, Oriolidae y Laniidae.

Fig. 9 - Corvidae (I).

Fig. 10 - Corvidae (II).

Fig. 11 - Corvidae (III).

Fig. 12 - Sturnidae y Passeridae.

Fig. 13 - Fringillidae.

Fig. 14 - Fringillidae (II) y Emberizidae.

Figuras correspondientes a las publicaciones de los apartados 5.2 y 6.2.

Fig 15 - Haliaeetus albicilla.

Fig 16 - Accipitridae.

Fig 17 - Falconidae.

Fig 18 - Strigidae. 


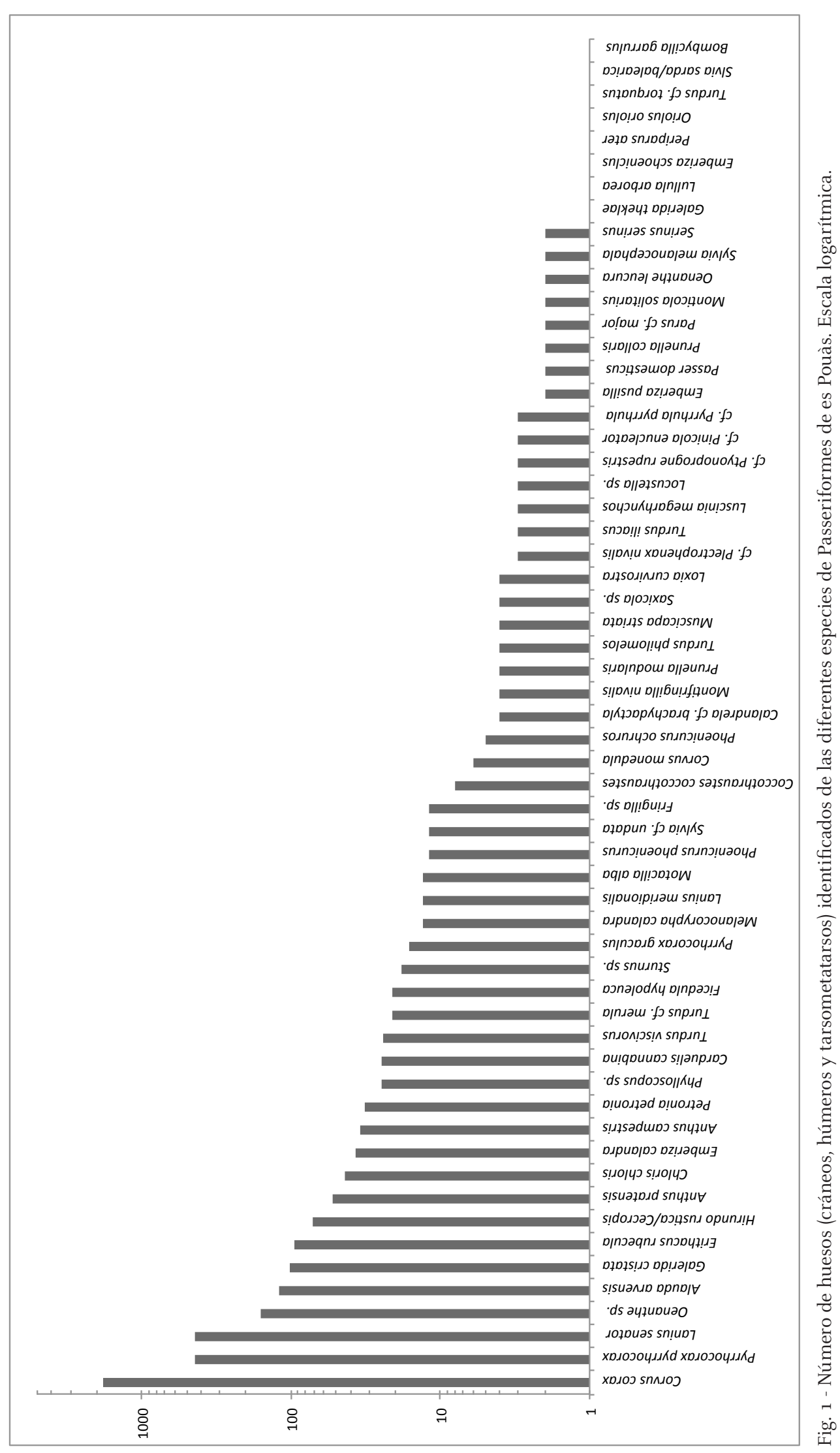




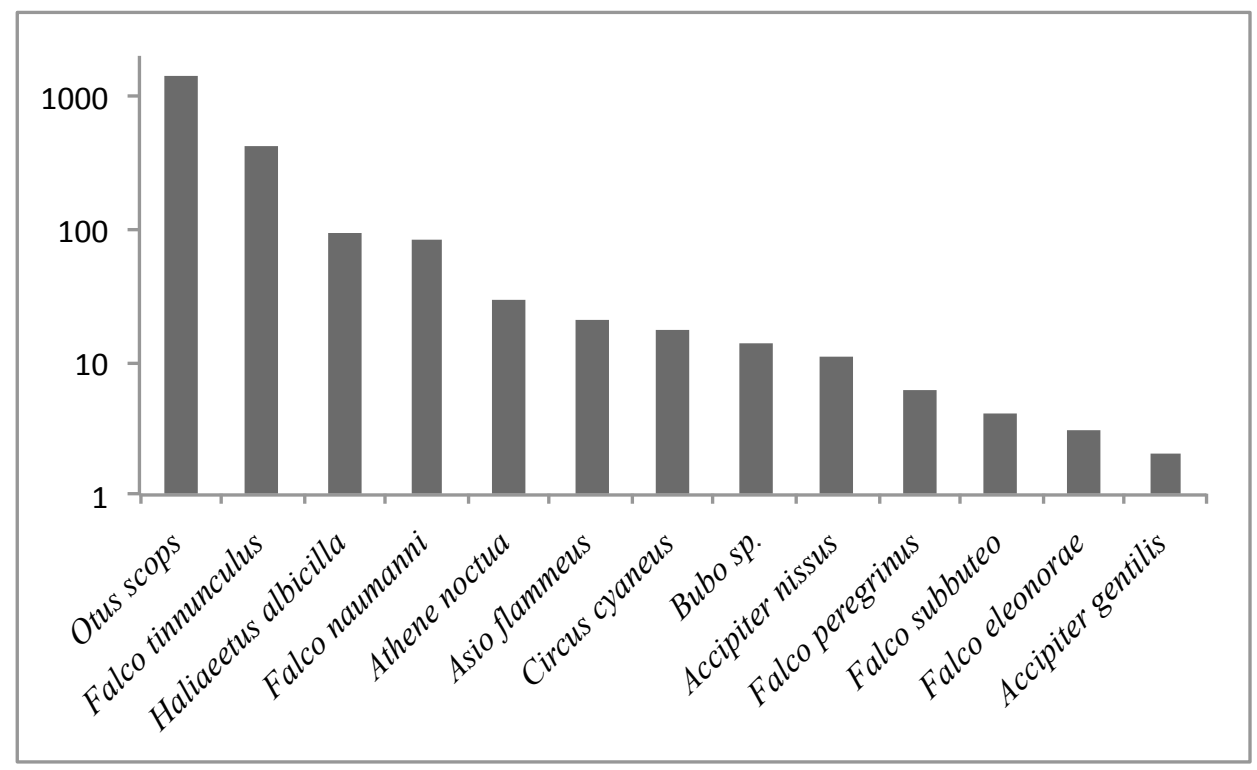

Fig. 2 - Número de huesos (cráneos, húmeros y tarsometatarsos) identificados de las diferentes especies de Falconiformes y Strigiformes de es Pouàs. Escala logarítmica.

Fig. 3 - Alaudidae

Mayúsculas, Alaudidae fósiles de es Pouàs; minúsculas, individuos actuales de comparación.

A, B, b, C, c: Melanocorypha calandra. A: premaxilar, vista dorsal, IMEDEA 29151; B: mandíbula, vista dorsal, IMEDEA 92937; b: mandíbula, vista dorsal, NHMT 5/1952.2.599; C: húmero derecho, vista caudal, IMEDEA 16182; c: húmero derecho, vista caudal, NHMT 5/1952.2.599. D: Calandrella cf. brachydactyla, húmero derecho, vista caudal, IMEDEA 100283. d: Calandrella brachydactyla, húmero derecho, vista caudal, IMEDEA 60113. E, e: Galerida theklae. E: mandíbula, vista dorsal, IMEDEA 102767; e: mandíbula, vista dorsal, IMEDEA 94676. F, f, G, g: Galerida cristata. F: premaxilar, vista dorsal, IMEDEA 102834; f: premaxilar, vista dorsal, IMEDEA 18913; G: mandíbula, vista dorsal, IMEDEA 102932; g: mandíbula, vista dorsal, IMEDEA 18913. H, h, I, i, K, k: Alauda arvensis. H: premaxilar, vista dorsal, IMEDEA 102820; h: premaxilar, vista dorsal, IMEDEA 5161; I: mandíbula, vista dorsal, IMEDEA 5000; i: mandíbula, vista dorsal, IMEDEA 5161; K: húmero derecho, vista caudal, IMEDEA 90682; k: húmero derecho, vista caudal, IMEDEA 191508. J, j: Lullula arborea. J: húmero izquierdo, vista caudal, IMEDEA 82934; j: húmero izquierdo, vista caudal, IMEDEA 830409. Barra de escala: $2 \mathrm{~cm}$. 


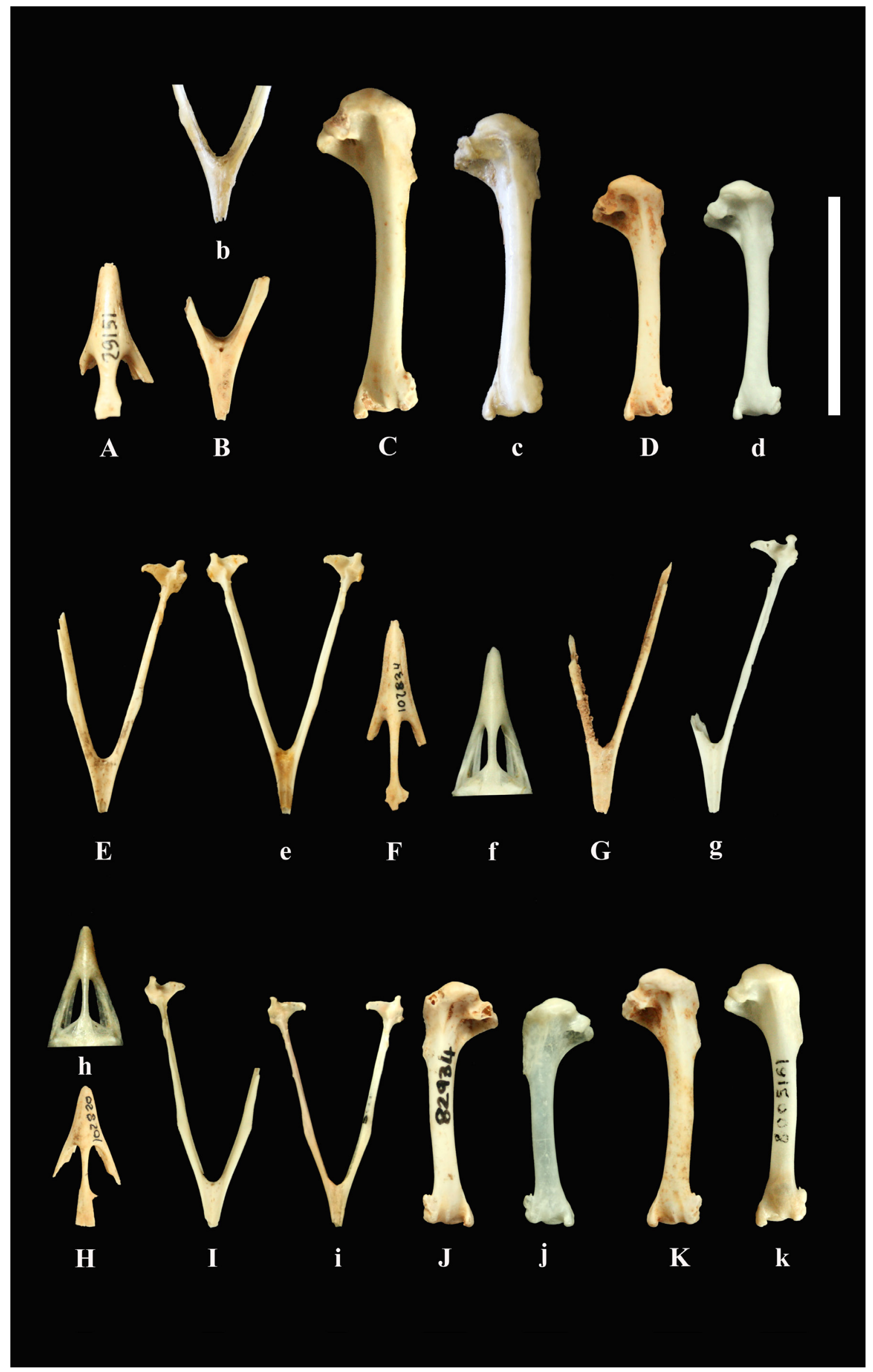


Fig. 4 - Hirundinidae, Motacillidae y Bombycillidae

Mayúsculas, Hirundinidae, Motacillidae y Bombycillidae fósiles de es Pouàs; minúsculas, individuos actuales de comparación.

A, B: cf. Ptyonoprogne rupestris. a, b: Ptyonoprogne rupestris. A: húmero derecho, vista caudal, IMEDEA 92304; a: húmero derecho, vista caudal, IMEDEA 48273; B: tarsometatarso izquierdo, vista dorsal, IMEDEA 28908; b: tarsometatarso izquierdo, vista dorsal, IMEDEA colección sinóptica. C: Hirundo sp., húmero izquierdo, vista caudal, IMEDEA 96379. c: Hirundo rustica, húmero izquierdo, vista caudal, IMEDEA 20746. D, d, E, e, F, f, G, g: Anthus campestris. D: premaxilar, vista dorsal, IMEDEA 93244; d: premaxilar, vista dorsal, IMEDEA 800500; E: mandíbula, vista dorsal, IMEDEA 24745; e: mandíbula, vista dorsal, IMEDEA 800500; F: húmero izquierdo, vista caudal, IMEDEA 100429; f: húmero izquierdo, vista caudal, IMEDEA 38081; G: tarsometatarso izquierdo, vista dorsal, IMEDEA 102483; g: tarsometatarso izquierdo, vista dorsal, IMEDEA 800500; H, h: Anthus pratensis. H: húmero izquierdo, vista caudal, IMEDEA 100398; h: húmero izquierdo, vista caudal, IMEDEA 20428. I, i: Motacilla alba. I: húmero izquierdo, vista caudal, IMEDEA 100385; i: húmero izquierdo, vista caudal, IMEDEA 21966. J, j: Bombycilla garrulus. J: húmero izquierdo, vista caudal, IMEDEA 92500; j: húmero izquierdo, vista caudal, IMEDEA 60135. Barra de escala: $2 \mathrm{~cm}$. 


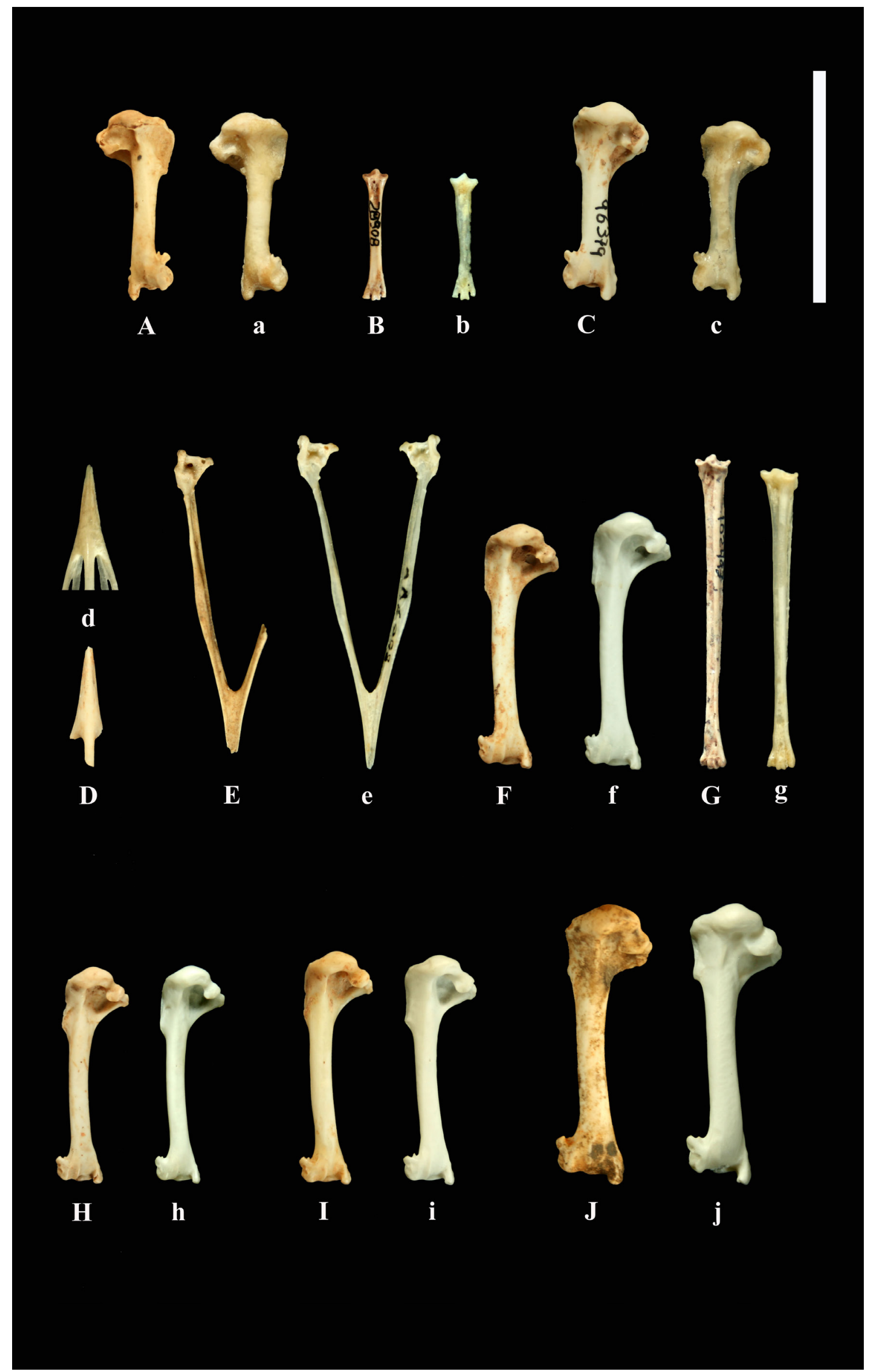


Fig. 5 - Prunellidae y Turdidae (I)

Mayúsculas, Prunellidae y Turdidae fósiles de es Pouàs; minúsculas, individuos actuales de comparación.

A, a, B, b: Prunella modularis. A: mandíbula, vista dorsal, IMEDEA 102939; a: mandíbula, vista dorsal, IMEDEA 79118; B: húmero derecho, vista caudal, IMEDEA 100485; b: húmero derecho, vista caudal, IMEDEA 20733; C, c, D, d: Prunella collaris. C: premaxilar, vista dorsal, IMEDEA 102940; c: premaxilar, vista dorsal, IMEDEA 94033; D: húmero izquierdo, vista caudal, IMEDEA 100483; d: húmero derecho, vista caudal, IMEDEA 94033. E, e, F, f, G, g, H, h: Erithacus rubecula. E: cráneo y premaxilar, vista dorsal, IMEDEA 102549, 28257; e: cráneo, vista dorsal, IMEDEA 20630; F: mandíbula, vista dorsal, IMEDEA 24201; f: mandíbula, vista dorsal, IMEDEA 20630; G: húmero izquierdo, vista caudal, IMEDEA 100576; g: húmero izquierdo, vista caudal, IMEDEA 94124; H: tarsometatarso derecho, vista dorsal, IMEDEA 102518; h: tarsometatarso izquierdo, vista dorsal, IMEDEA 21968. I, i, J, j: Luscinia megarhynchos. I: premaxilar, vista dorsal, IMEDEA 102936; i: premaxilar, vista dorsal, IMEDEA 12591; J: húmero izquierdo, vista caudal, IMEDEA 100525; j: húmero izquierdo, vista caudal, IMEDEA E-8308071. K, k, L, l: Phoenicurus ochruros. K: premaxilar, vista dorsal, IMEDEA 19345; k: premaxilar, vista dorsal, IMEDEA 20877; L: húmero izquierdo, vista caudal, IMEDEA 28218; l: húmero izquierdo, vista caudal, IMEDEA 94156. Barra de escala: $2 \mathrm{~cm}$. 

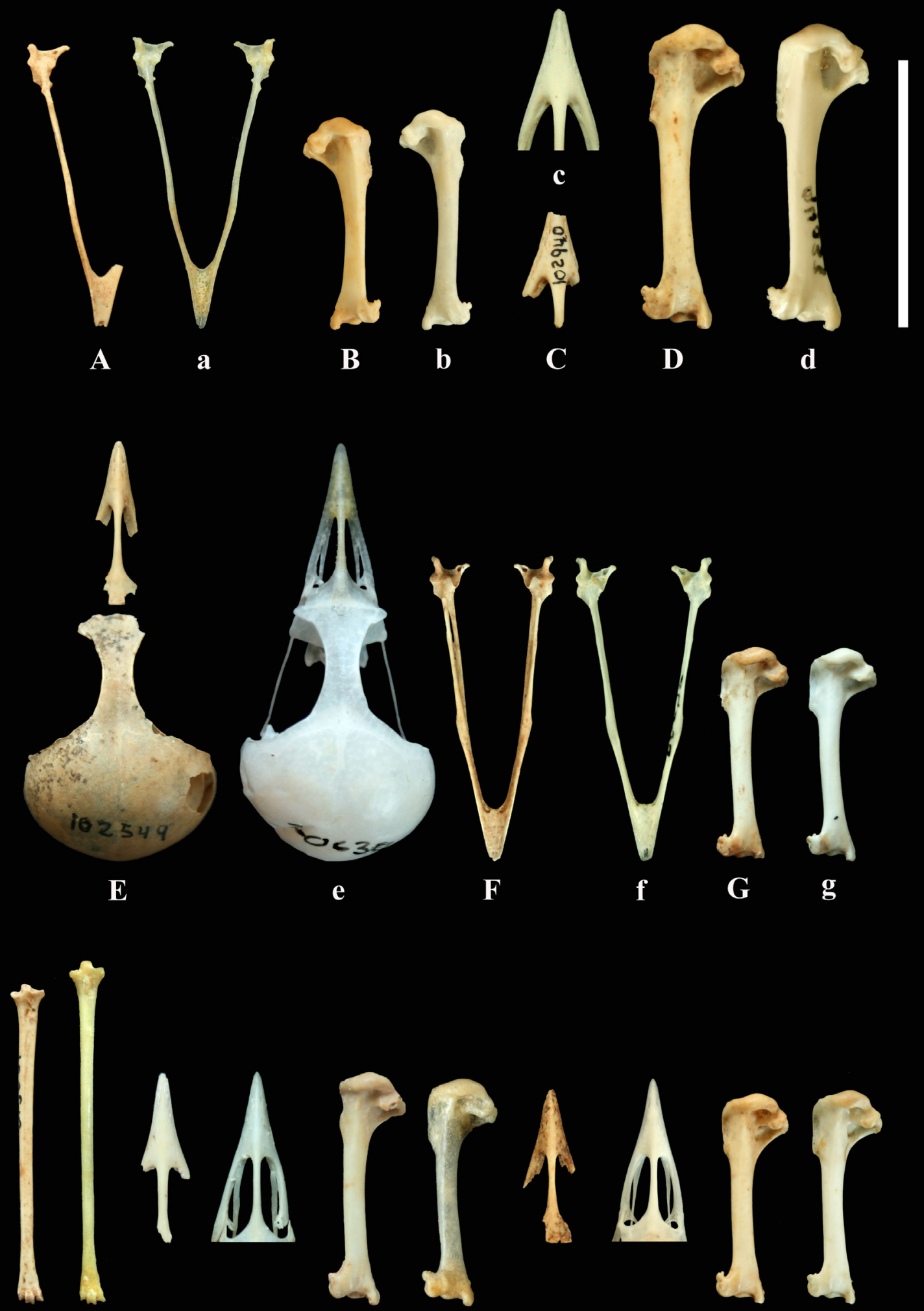

$\begin{array}{llll}\text { H } & \text { h } & \text { I } & \text { i }\end{array}$

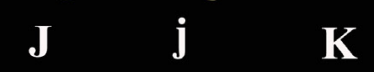

K $\quad$ k

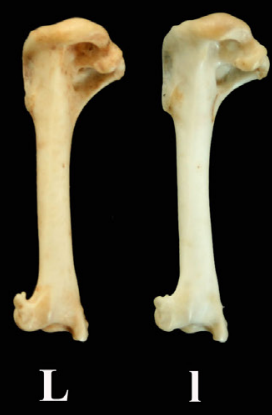


Fig. 6 - TuRdidAe (II)

Mayúsculas, Turdidae fósiles de es Pouàs; minúsculas, individuos actuales de comparación.

A, a, B, b: Phoenicurus phoenicurus. A: premaxilar, vista dorsal, IMEDEA 102934; a: premaxilar, vista dorsal, IMEDEA 48294; B: húmero izquierdo, vista caudal, IMEDEA 92368; b: húmero izquierdo, vista caudal IMEDEA 20877. C: Saxicola sp., húmero derecho, vista caudal, IMEDEA 92414; c: Saxicola torquata húmero derecho, vista caudal, IMEDEA 60104. D, d: Oenanthe leucura. D: húmero derecho, vista caudal, IMEDEA 100592; d: húmero derecho, vista caudal, IMEDEA 8610171. E: Turdus cf. torquatus, premaxilar, vista dorsal, IMEDEA 93238; e: Turdus torquatus, premaxilar, vista dorsal, IMEDEA 12559. F, f: Turdus philomelos. F: premaxilar, vista dorsal, IMEDEA 28419; f: premaxilar, vista dorsal, IMEDEA 12522. G, g: Monticola solitarius. G: húmero izquierdo, vista caudal, IMEDEA 3790; g: húmero izquierdo, vista caudal, IMEDEA 94023. H: Turdus cf. merula, húmero izquierdo, vista caudal, IMEDEA 98338; h: Turdus merula, húmero izquierdo, vista caudal, IMEDEA 20904. I, i: Turdus philomelos. I: mandíbula, vista dorsal, IMEDEA 28418; i: mandíbula, vista dorsal, IMEDEA 22521. J, j, K, k: Turdus iliacus. J: mandíbula, vista dorsal, IMEDEA 102916; j: mandíbula, vista dorsal, IMEDEA 60075; K: tarsometatarso derecho, vista dorsal, IMEDEA 28486; k: tarsometatarso derecho, vista dorsal, IMEDEA 60011. L, l: Turdus viscivorus. L: mandíbula, vista dorsal, IMEDEA 102914; l: mandíbula, vista dorsal, IMEDEA 60072. M, m, N, n: Turdus cf. viscivorus. M: ulna derecha, vista ventral, IMEDEA 100194; m: ulna derecha, vista ventral, IMEDEA 60072; N: húmero izquierdo, vista caudal, IMEDEA 29167; n: húmero izquierdo, vista caudal, IMEDEA 48295. Barra de escala: $2 \mathrm{~cm}$. 


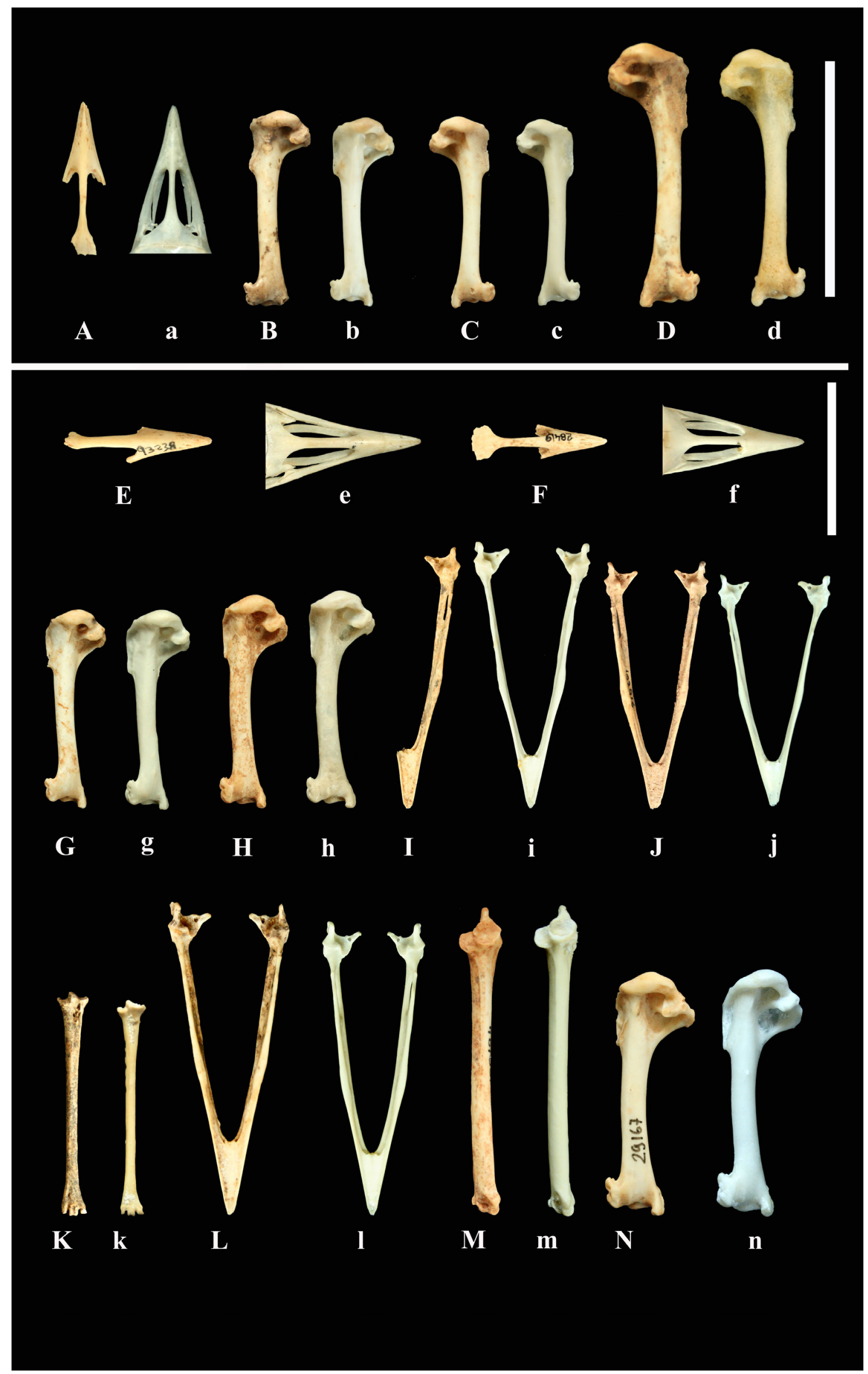


Fig. 7 - SyLVIIDAE

Mayúsculas, Sylviidae fósiles de es Pouàs; minúsculas, individuos actuales de comparación.

A: Locustella sp., húmero derecho, vista caudal, IMEDEA 100675. a: Locustella naevia, húmero derecho, vista caudal, IMEDEA 8409050. B, C: Sylvia sarda/balearica. b, c: Sylvia balearica. B: cráneo, vista dorsal, IMEDEA 29420; b: cráneo, vista dorsal, IMEDEA 21772; C: mandíbula, vista dorsal, IMEDEA 29420; c: mandíbula, vista dorsal, IMEDEA 21772. D, E: Sylvia cf. undata. d, e: Sylvia undata. D: mandíbula, vista dorsal, IMEDEA 102644. d: mandíbula, vista dorsal, IMEDEA 8011272. E: húmero izquierdo, vista caudal, IMEDEA 28224; e: húmero izquierdo, vista caudal, IMEDEA 8011272. F: Phylloscopus sp., húmero derecho, vista caudal, IMEDEA 100672. f: Phylloscopus collybita, húmero derecho, vista caudal, IMEDEA 21923. G, g, H, h: Sylvia melanocephala. G: cráneo, vista dorsal, IMEDEA 24226; g: cráneo, vista dorsal, IMEDEA 12504; H: mandíbula, vista dorsal, IMEDEA 28587; h: mandíbula, vista dorsal, IMEDEA 102504. Barra de escala: $2 \mathrm{~cm}$. 

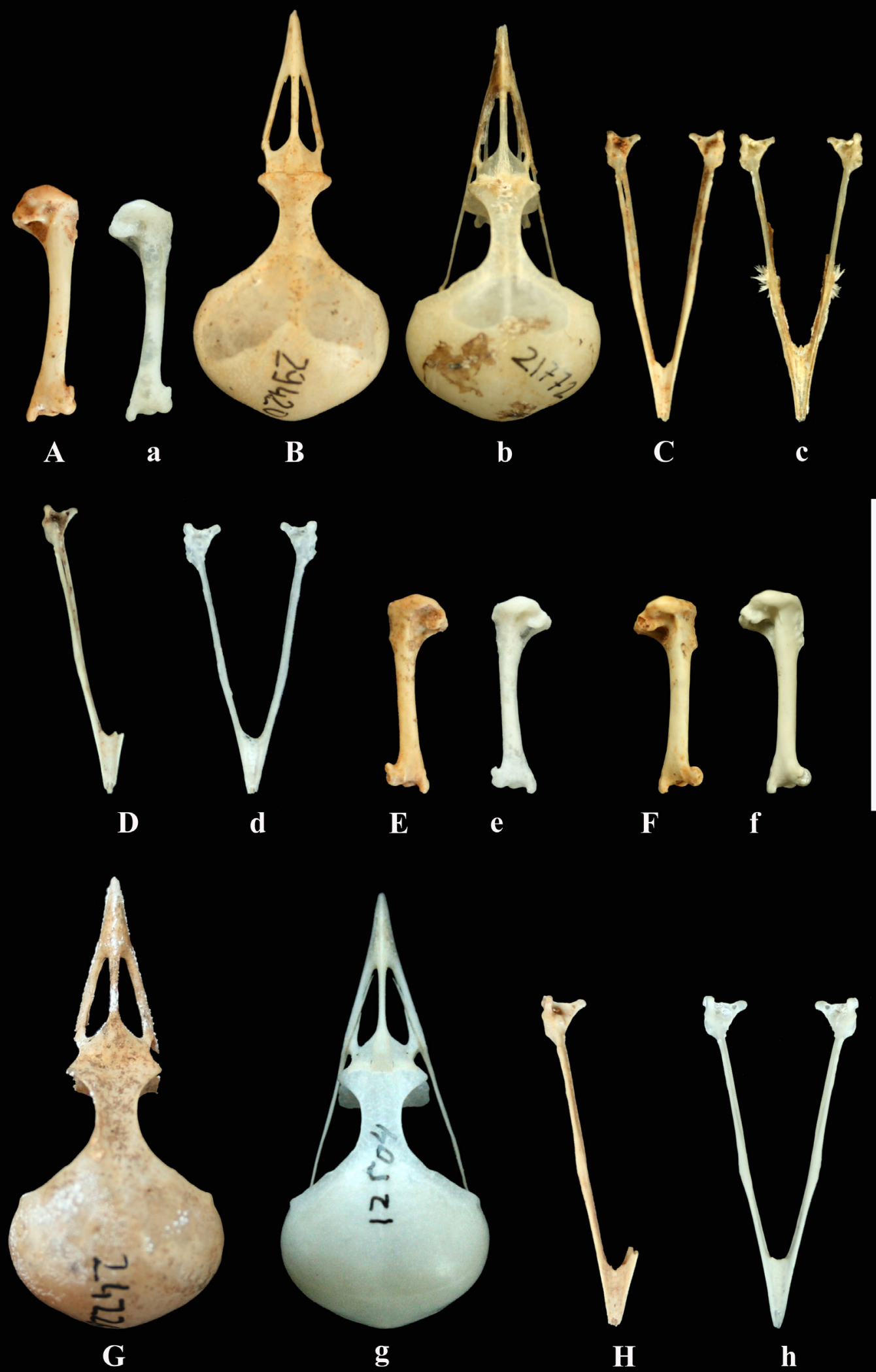


\section{Fig. 8 - Muscicapidae, Paridae, Oriolidae y Laniddae}

Mayúsculas, Muscicapidae, Paridae, Oriolidae y Laniidae fósiles de es Pouàs; minúsculas, individuos actuales de comparación.

A, a: Muscicapa striata. A: húmero izquierdo, vista caudal, IMEDEA 100600; a: húmero izquierdo, vista caudal, IMEDEA 12508. B, b, C, c, D, d, E, e: Ficedula hypoleuca. B: premaxilar, vista dorsal, IMEDEA 93257; b: premaxilar, vista dorsal, IMEDEA 21724; C: mandíbula, vista dorsal, IMEDEA 19346; c: mandíbula, vista dorsal, IMEDEA 21724; D: húmero izquierdo, vista caudal, IMEDEA 100573; d: húmero izquierdo, vista caudal IMEDEA 12544; E: tarsometatarso derecho, vista dorsal, IMEDEA 102526; e: tarsometatarso derecho, vista dorsal, IMEDEA colección sinóptica. F, f: Parus ater. F: húmero izquierdo, vista caudal, IMEDEA 100484; f: húmero izquierdo, vista caudal, IMEDEA 94419. G: Parus cf. major, mandíbula, vista dorsal, IMEDEA 93239. g: Parus major, mandíbula, vista dorsal, IMEDEA 12532. H, h: Oriolus oriolus. H: húmero izquierdo, vista caudal, IMEDEA 19491; h: húmero izquierdo, vista caudal, IMEDEA 94448. I, i, J, j, K, k, L, l: Lanius meridionalis. I: húmero izquierdo, vista caudal, IMEDEA 28643; i: húmero izquierdo, vista caudal, IMEDEA 9942; J: tarsometatarso izquierdo, vista dorsal, IMEDEA 102402; j: tarsometatarso izquierdo, vista dorsal, IMEDEA 9942; K: cráneo, vista dorsal, IMEDEA 24196; k: cráneo, vista dorsal, IMEDEA 94098; L: mandíbula, vista dorsal, IMEDEA 24200; l: mandíbula, vista dorsal, IMEDEA 9942; M, m, N, n, O, o: Lanius senator. M: premaxilar, vista dorsal, IMEDEA 102740; m: premaxilar, vista dorsal, IMEDEA 21925; N: mandíbula, vista dorsal, IMEDEA 19636; n: mandíbula, vista dorsal, IMEDEA 21925; O: húmero izquierdo, vista caudal, IMEDEA 4078; o: húmero izquierdo, vista caudal, IMEDEA 21925. Barra de escala: $2 \mathrm{~cm}$. 

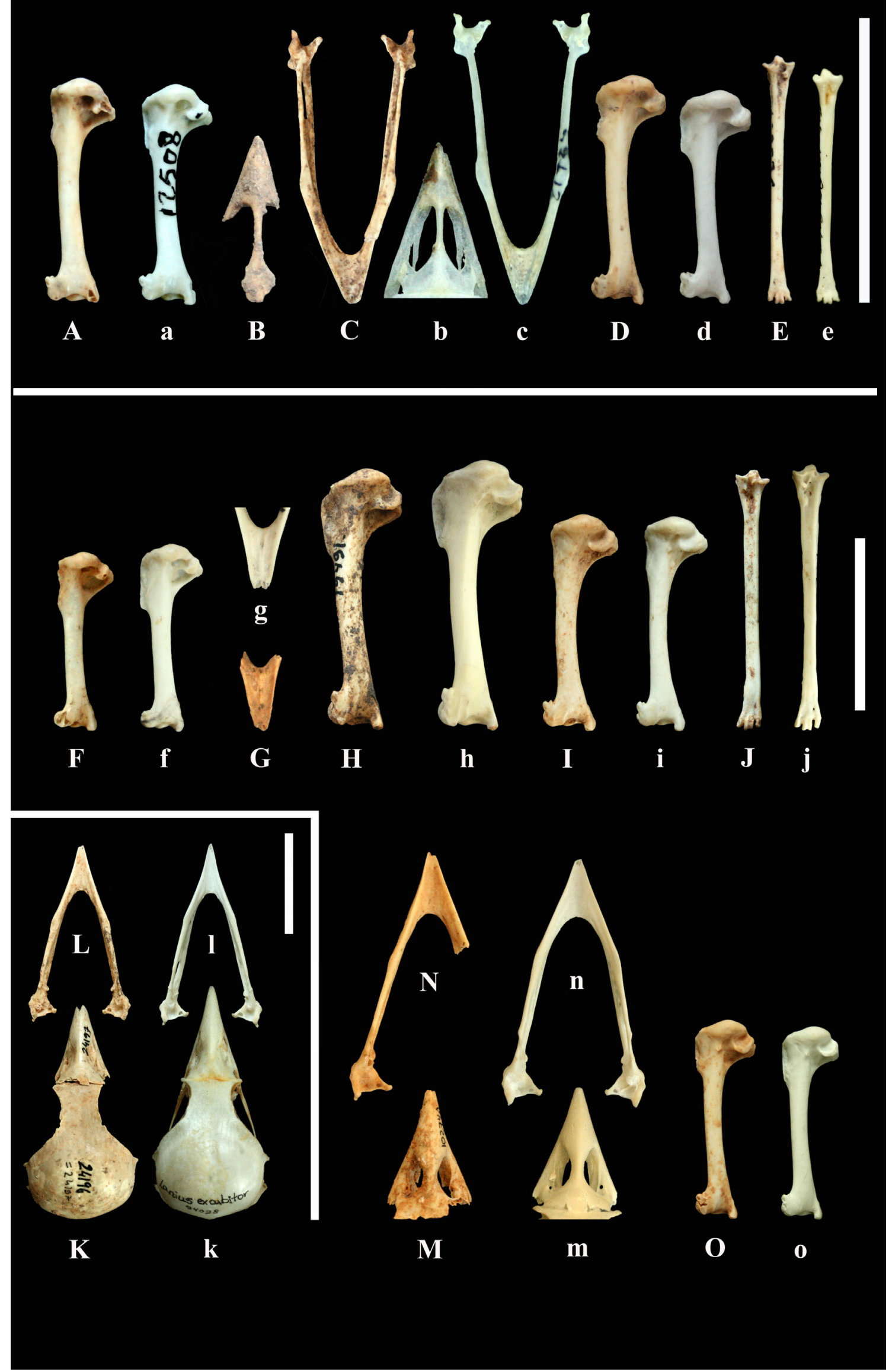
Fig. 9 - CoRvidAe (I)

Mayúsculas, Pyrrhocorax graculus y Pyrrhocorax pyrrhocorax fósiles de es Pouàs; minúsculas, individuos actuales de comparación.

A, a, B, b, C, c: Pyrrhocorax graculus. A: mandíbula, vista dorsal, IMEDEA 95629; a: mandíbula, vista dorsal, IMEDEA 12195; B: húmero izquierdo, vista caudal, IMEDEA 30760; b: húmero izquierdo, vista caudal, IMEDEA 12195; C: tarsometatarso derecho, vista dorsal, IMEDEA 101920; c: tarsometatarso derecho, vista dorsal, IMEDEA 12195. D, d, E, e, F, f, G, g, H, h, I, i, J, j: Pyrrhocorax pyrrhocorax. D: húmero izquierdo, vista caudal, IMEDEA 95669; d: húmero izquierdo, vista caudal, IMEDEA 12194; E: ulna izquierda, vista ventral, IMEDEA 25532; e: ulna derecha, vista ventral, invertida, IMEDEA 392; F: radio derecho, vista ventral, IMEDEA 30122; f: radio izquierdo, vista ventral, invertido, IMEDEA 12194; G: tibiotarso derecho, vista craneal, IMEDEA 33921; g: tibiotarso izquierdo, vista craneal, invertido, IMEDEA 12194; H: carpometacarpo izquierdo vista dorsal, IMEDEA 33944; h: carpometacarpo izquierdo vista dorsal, IMEDEA 12194; I: fémur izquierdo, vista craneal, IMEDEA 101898; i: fémur izquierdo, vista craneal, IMEDEA 392; J: tarsometatarso izquierdo, vista dorsal, IMEDEA 1233; j: tarsometatarso derecho, vista dorsal, invertido, IMEDEA 12194. Barra de escala: $2 \mathrm{~cm}$. 


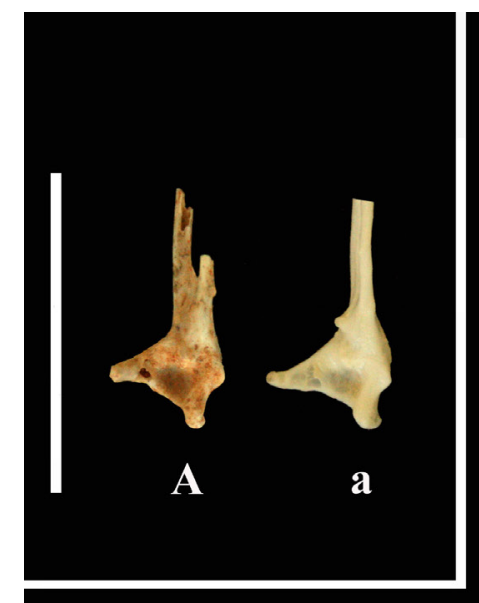

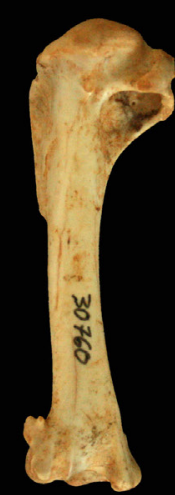

B

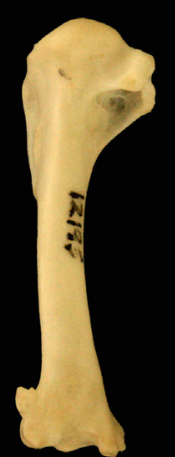

b

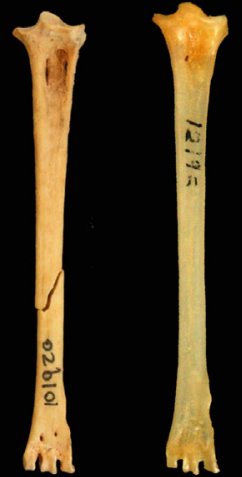

C

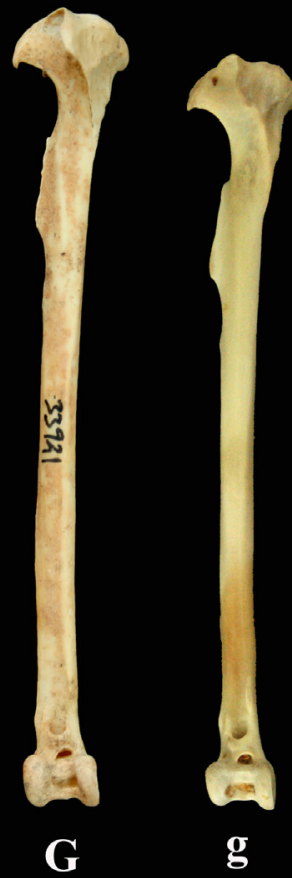

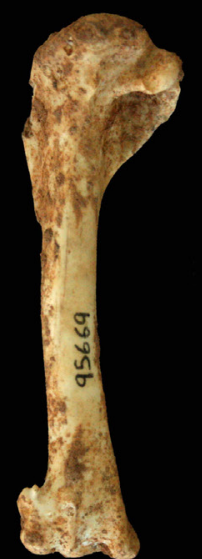

D

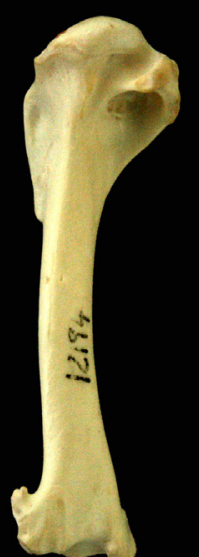

d
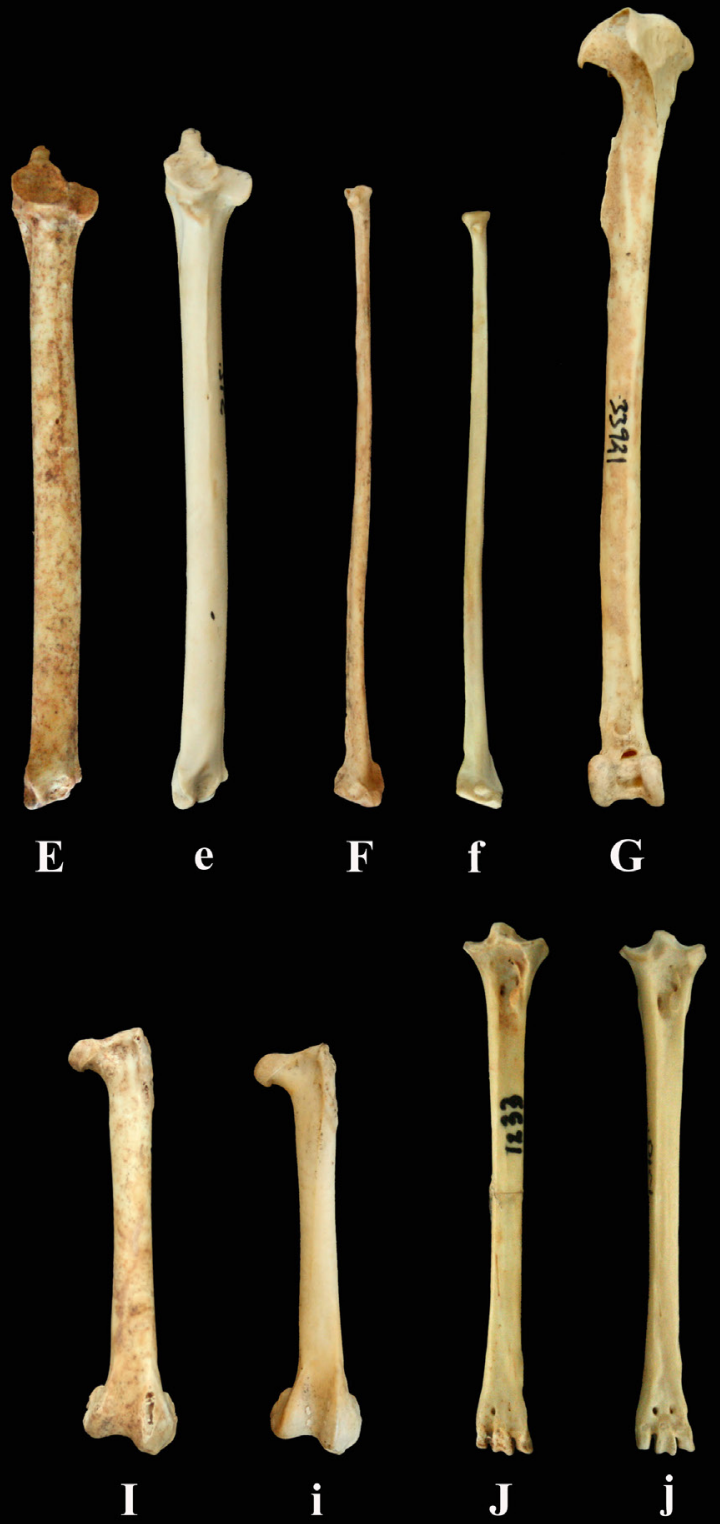
Fig. 10 - CoRvidae (II)

Mayúsculas, Corvidae fósiles de es Pouàs; minúsculas, individuos actuales de comparación.

A, a, B, b, C, c, D, d, E, e: Pyrrhocorax pyrrhocorax. A: cráneo, vista dorsal, IMEDEA 33915; a: cráneo, vista dorsal, IMEDEA 12194; B: mandíbula, vista dorsal, IMEDEA 29710; b: mandíbula, vista dorsal, IMEDEA 12194; C: escápula derecha, vista lateral, IMEDEA 31082; c: escápula derecha, vista lateral, IMEDEA 12194; D: pelvis, vista dorsal, IMEDEA 3032; d: pelvis, vista dorsal, IMEDEA 12194; E: coracoides izquierdo, vista dorsal, IMEDEA 14661; e: coracoides derecho, vista dorsal, invertido, IMEDEA 12194. F, f, G, g, H, h: Corvus monedula. F: mandíbula, vista dorsal, IMEDEA 101963; f: mandíbula, vista dorsal, IMEDEA: 12575; G: húmero derecho, vista caudal, IMEDEA 28003; g: húmero derecho, vista caudal, IMEDEA 12575; H: tarsometatarso derecho, vista dorsal, IMEDEA: 102075; h: tarsometatarso derecho, vista dorsal, IMEDEA 12575. I, i: Corvus corone. I: carpometacarpo derecho vista dorsal, IMEDEA 33952; i: carpometacarpo derecho vista dorsal, IMEDEA 8112132. Barra de escala: $2 \mathrm{~cm}$. 

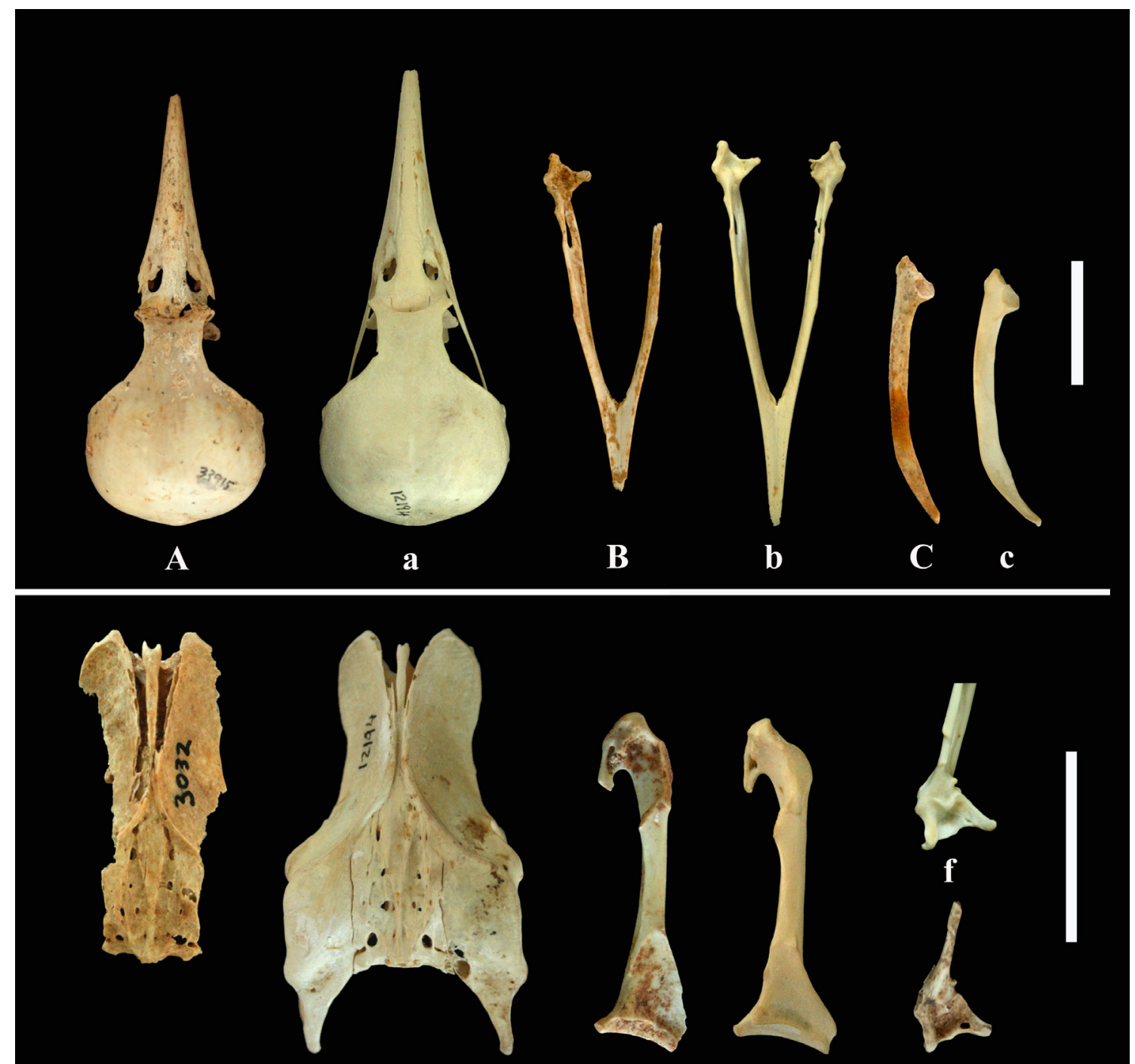

D

d
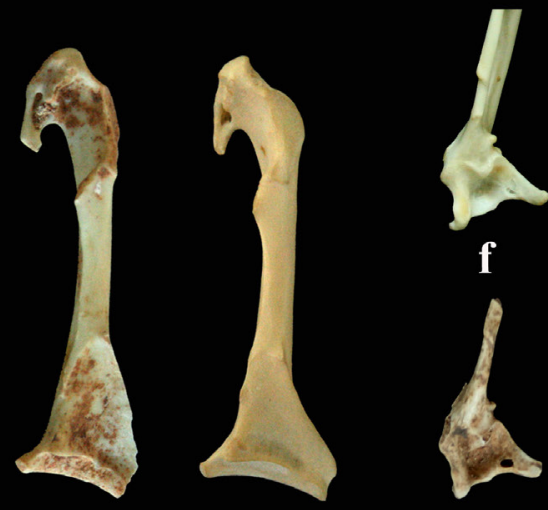

E

e

F

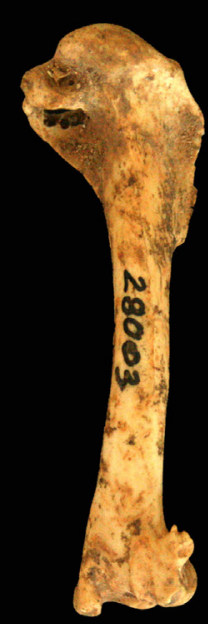

G

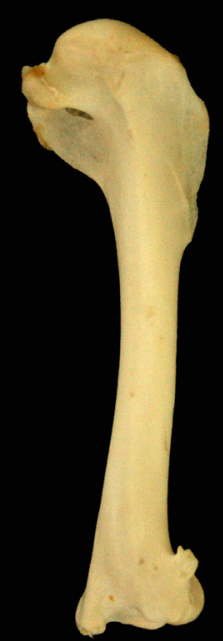

g
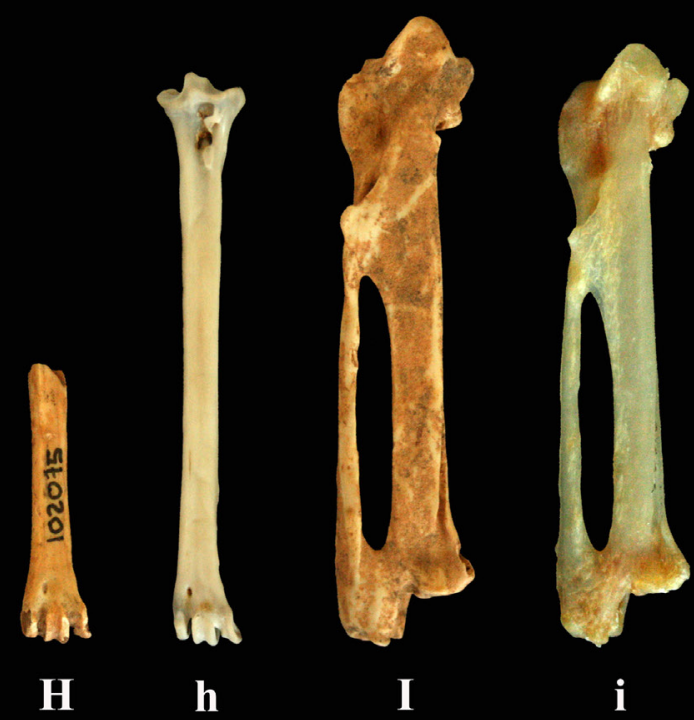
FIG. 11 - CoRvidAe (III)

Mayúsculas, Corvus corax fósiles de es Pouàs; minúsculas, individuos actuales de comparación.

A: cráneo, vista dorsal, IMEDEA 93287. a: cráneo, vista dorsal, IMEDEA 6026. B: mandíbula, vista dorsal, IMEDEA 22668. b: mandíbula, vista dorsal, IMEDEA 6026. C: radio derecho, vista ventral IMEDEA 88851. c: radio derecho, vista ventral, IMEDEA 6026. D: húmero izquierdo, vista caudal, IMEDEA 93537. d: húmero izquierdo, vista caudal, IMEDEA 6026. E: ulna izquierda, vista ventral, IMEDEA 865. e: ulna izquierda, vista ventral, IMEDEA 60043. F: carpometacarpo izquierdo vista dorsal, IMEDEA 22710. f: carpometacarpo derecho, vista dorsal, invertido, IMEDEA 6026. G: fémur izquierdo, vista craneal, IMEDEA 17128. g: fémur derecho, vista craneal, invertido, IMEDEA 6026. H: tibiotarso izquierdo, vista craneal, IMEDEA 17427. h: tibiotarso izquierdo, vista craneal, IMEDEA 6026. I: coracoides izquierdo, vista ventral, IMEDEA 17546. i: coracoides izquierdo, vista ventral, IMEDEA 6026. J: escápula derecha, vista lateral, IMEDEA 31336. j: escápula derecha, vista lateral, IMEDEA 6026. K: fúrcula, vista dorsal, IMEDEA 32557. k: fúrcula, vista dorsal, IMEDEA 6026. l: pelvis, vista dorsal, IMEDEA 17774. L: pelvis, vista dorsal, IMEDEA 6026. M: esternón, vista ventral, IMEDEA 27764. m: esternón, vista ventral, IMEDEA 6026. Barra de escala: $2 \mathrm{~cm}$. 

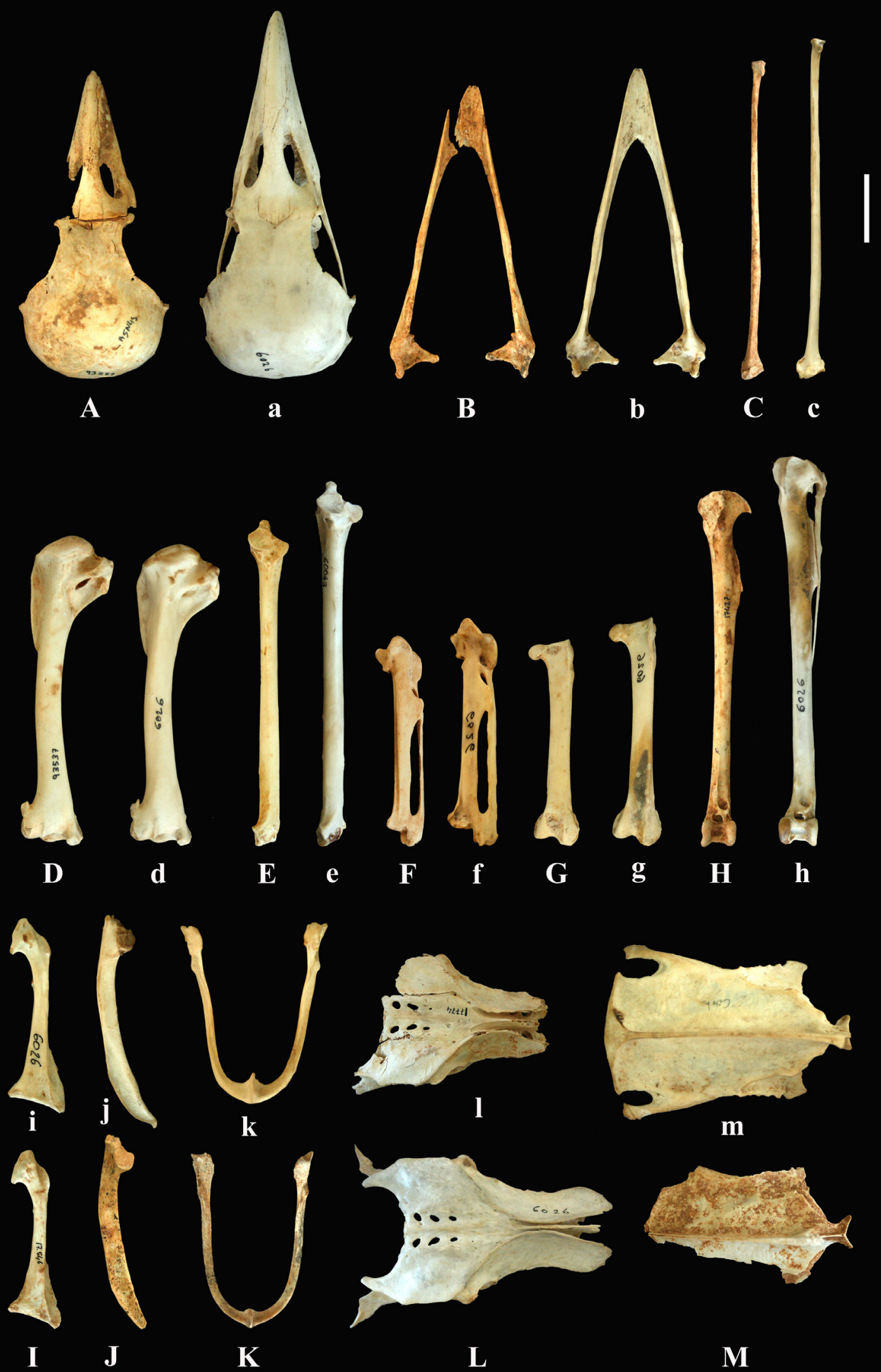
Fig. 12 - StURnidae y PASSERIDAe

Mayúsculas, Sturnidae y Passeridae fósiles de es Pouàs; minúsculas, individuos actuales de comparación.

A, B, C: Sturnus sp. a, b, c: Sturnus vulgaris. A: premaxilar, vista dorsal, IMEDEA 93173; a: premaxilar, vista dorsal, IMEDEA 21710; B: mandíbula, vista dorsal, IMEDEA 102951; b: mandíbula, vista dorsal, IMEDEA 21710; C: húmero derecho, vista caudal, IMEDEA 102468; c: húmero izquierdo, vista caudal, invertido, IMEDEA 11956; D, d, E, e: Passer domesticus. D: húmero derecho, vista caudal, IMEDEA 13697; d: húmero derecho, vista caudal, IMEDEA 12154; E: premaxilar, vista dorsal, IMEDEA 94841; e: premaxilar, vista dorsal, IMEDEA 20933. F, f, G, g: Petronia petronia. F: cráneo, vista dorsal, IMEDEA 34512; f: cráneo, vista dorsal, IMEDEA 18992; G: mandíbula, vista dorsal, IMEDEA 34512; g: mandíbula, vista dorsal, IMEDEA 18992. H, h, I, i: Montifringilla nivalis. H: mandíbula, vista dorsal, IMEDEA 92853; h: mandíbula, vista dorsal, IMEDEA 3821; I: húmero derecho, vista caudal, IMEDEA 27927; i: húmero izquierdo, vista caudal, invertido, IMEDEA 3821. Barra de escala: $2 \mathrm{~cm}$. 


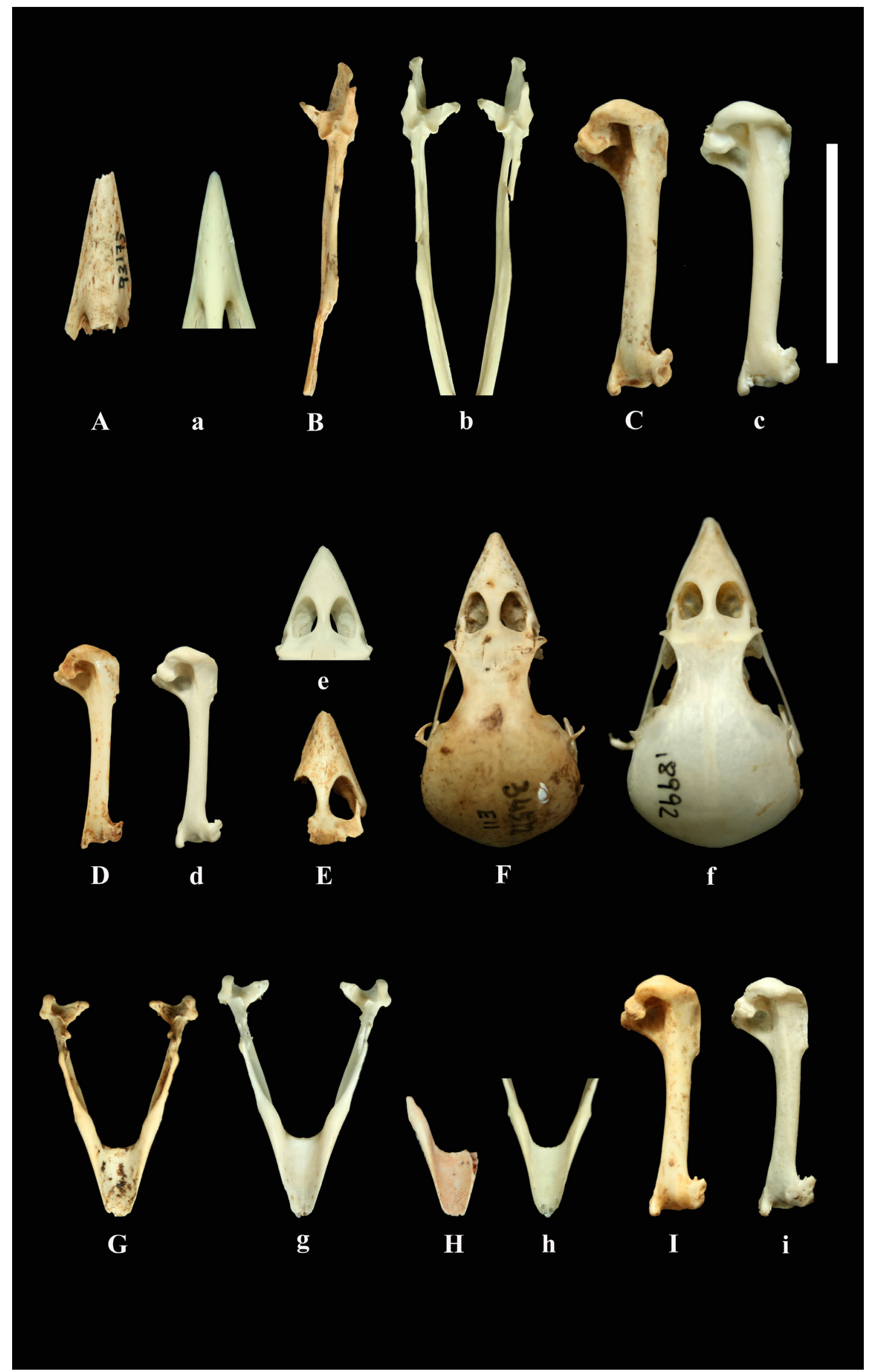


Fig. 13 - FRINGILLIDAE

Mayúsculas, Fringillidae fósiles de es Pouàs; minúsculas, individuos actuales de comparación.

A, B: Fringilla sp. a, b: Fringilla coelebs. A: mandíbula, vista dorsal, IMEDEA 24186; a: mandíbula, vista dorsal, IMEDEA 20814; B: húmero izquierdo, vista caudal, IMEDEA 24479; b: húmero izquierdo, vista caudal, IMEDEA 20814. C, c, D, d: Serinus serinus. C: premaxilar, vista dorsal, IMEDEA 102699; c: premaxilar, vista dorsal, IMEDEA 6020; D: húmero izquierdo, vista caudal, IMEDEA 100510; d: húmero izquierdo, vista caudal, IMEDEA 48278; E, e, F, f, G, g: Carduelis chloris. E: húmero izquierdo, vista caudal, IMEDEA 100497; e: húmero izquierdo, vista caudal, IMEDEA 12512; F: cráneo, vista dorsal, IMEDEA 24846; f: cráneo, vista dorsal, IMEDEA 12512; G: mandíbula, vista dorsal, IMEDEA 92836; g: mandíbula, vista dorsal, IMEDEA 12512; H, h, I, i, J, j: Carduelis cannabina. H: premaxilar, vista dorsal, IMEDEA 94843; h: premaxilar, vista dorsal, IMEDEA 12150; I: mandíbula, vista dorsal, IMEDEA 21990; i: mandíbula, vista dorsal, IMEDEA 12150; J: húmero izquierdo, vista caudal, IMEDEA 100499; j: húmero izquierdo, vista caudal, IMEDEA 12900. K: cf. Pinicola enucleator, húmero izquierdo, vista caudal, IMEDEA 92545. k: Pinicola enucleator, húmero izquierdo, vista caudal, IMEDEA colección sinóptica. L, l: Carduelis cannabina. L: tarsometatarso derecho, vista dorsal, IMEDEA 102536; l: tarsometatarso izquierdo, vista dorsal, invertido, IMEDEA 12150. M, m: Pyrrhula pyrrhula. M: húmero izquierdo, vista caudal, IMEDEA 25234; m: húmero izquierdo, vista caudal, IMEDEA 20755. N, n, O, o: Loxia curvirostra. N: premaxilar, vista dorsal, IMEDEA 102662; n: premaxilar, vista dorsal, IMEDEA 45001; O: mandíbula, vista dorsal, IMEDEA 102700; o: mandíbula, vista dorsal, IMEDEA 45001. Barra de escala: $2 \mathrm{~cm}$. 

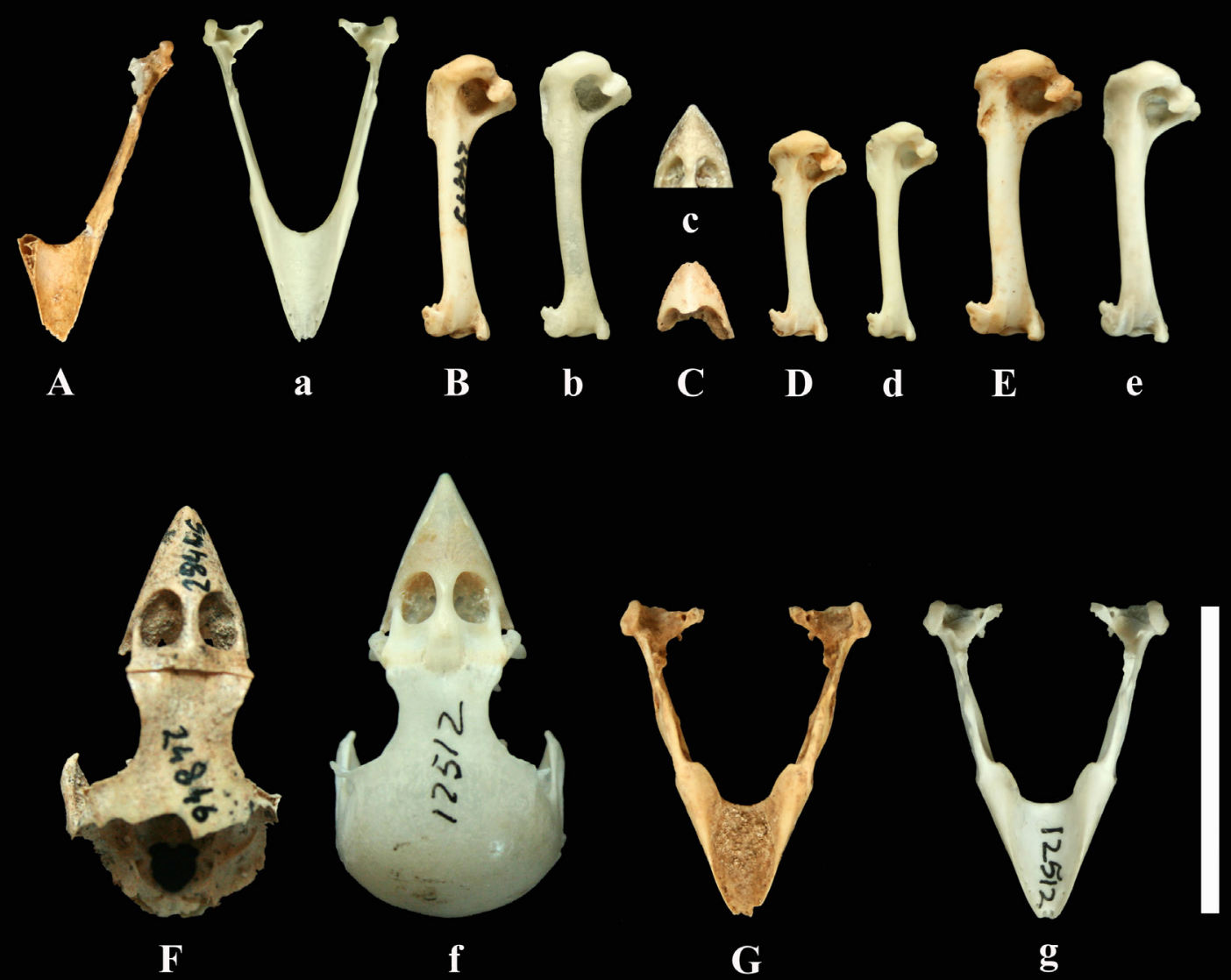

g

10
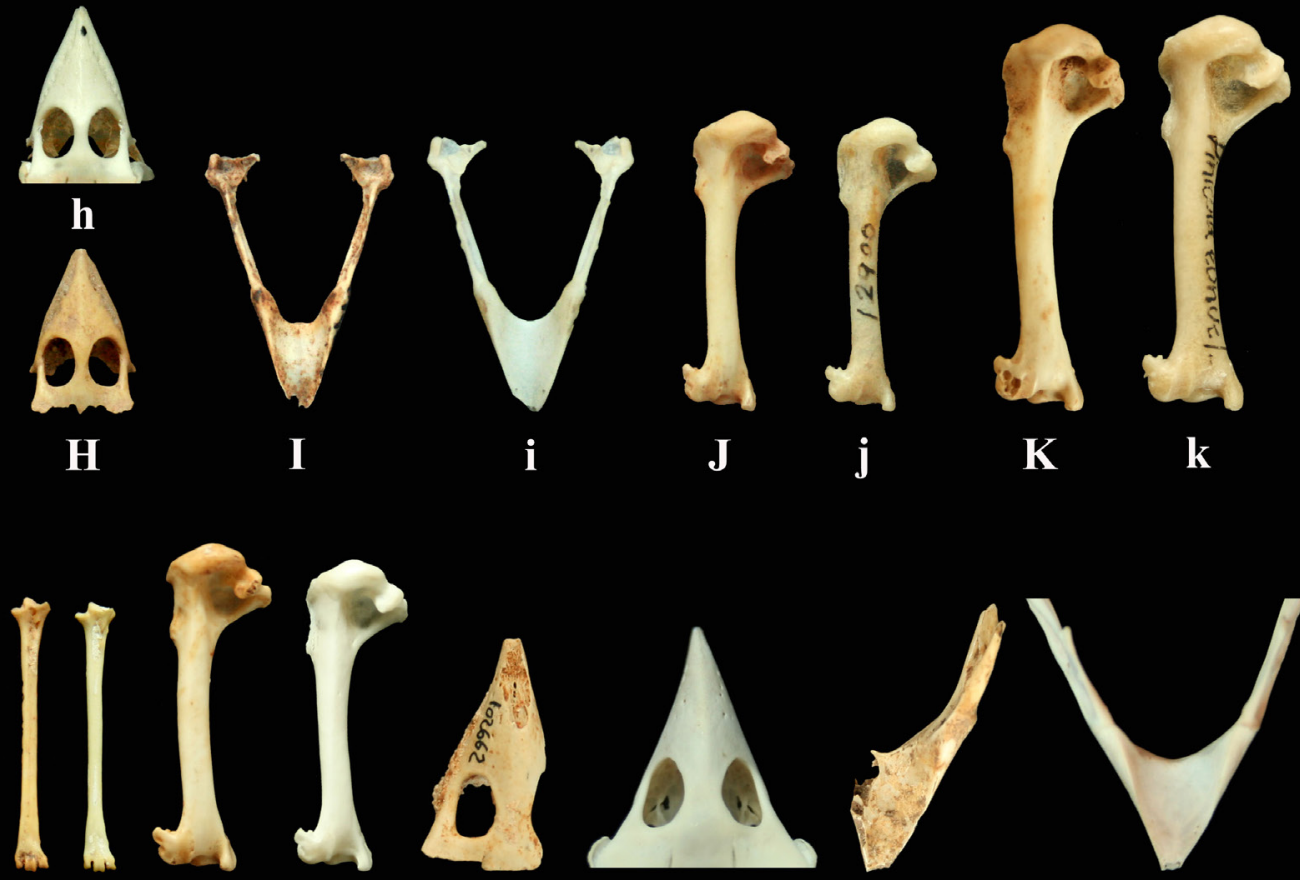

L l M

m

$\mathbf{N}$

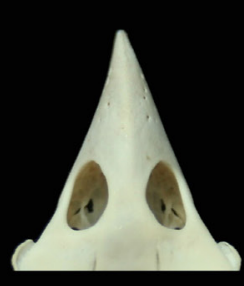

n
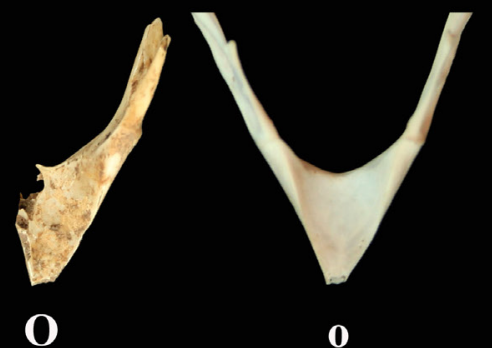

0 
Fig. 14 - Fringillidae (II) y Emberizidae

Mayúsculas, Fringillidae y Emberizidae fósiles de es Pouàs; minúsculas, individuos actuales de comparación.

A, a, B, b, C, c: Coccothrautes coccothrautes. A: premaxilar, vista dorsal, IMEDEA 29427; a: premaxilar, vista dorsal, IMEDEA 20745; B: mandíbula, vista dorsal, IMEDEA 30759; b: mandíbula, vista dorsal, IMEDEA 20745; C: húmero izquierdo, vista caudal, IMEDEA 92505; c: húmero izquierdo, vista caudal, IMEDEA 12473. D: cf. Plectrophenax nivalis, premaxilar, vista dorsal, IMEDEA 102555; d: Plectrophenax nivalis, premaxilar, vista dorsal, colección Skull Site. E, e, F, f: Emberiza pusilla. E: premaxilar, vista dorsal, IMEDEA 92911; e: premaxilar, vista dorsal, IMEDEA 20900; F: húmero derecho, vista caudal, IMEDEA 100470; f: húmero derecho, vista caudal, IMEDEA 20900. G, g: Emberiza schoeniclus. G: mandíbula, vista dorsal, IMEDEA 92890; g: mandíbula, vista dorsal, IMEDEA 20578. H, h, I, i, J, j, K, k: Emberiza calandra. H: premaxilar, vista dorsal, IMEDEA 92897; h: premaxilar, vista dorsal, IMEDEA 12137; I: mandíbula, vista dorsal, IMEDEA 29672; i: mandíbula, vista dorsal, IMEDEA 12040; J: húmero izquierdo, vista caudal, IMEDEA 100466; j: húmero izquierdo, vista caudal, IMEDEA 12537; K: tarsometatarso derecho, vista dorsal, IMEDEA 102530; k: tarsometatarso derecho, vista dorsal, IMEDEA colección sinóptica. Barra de escala: $2 \mathrm{~cm}$. 


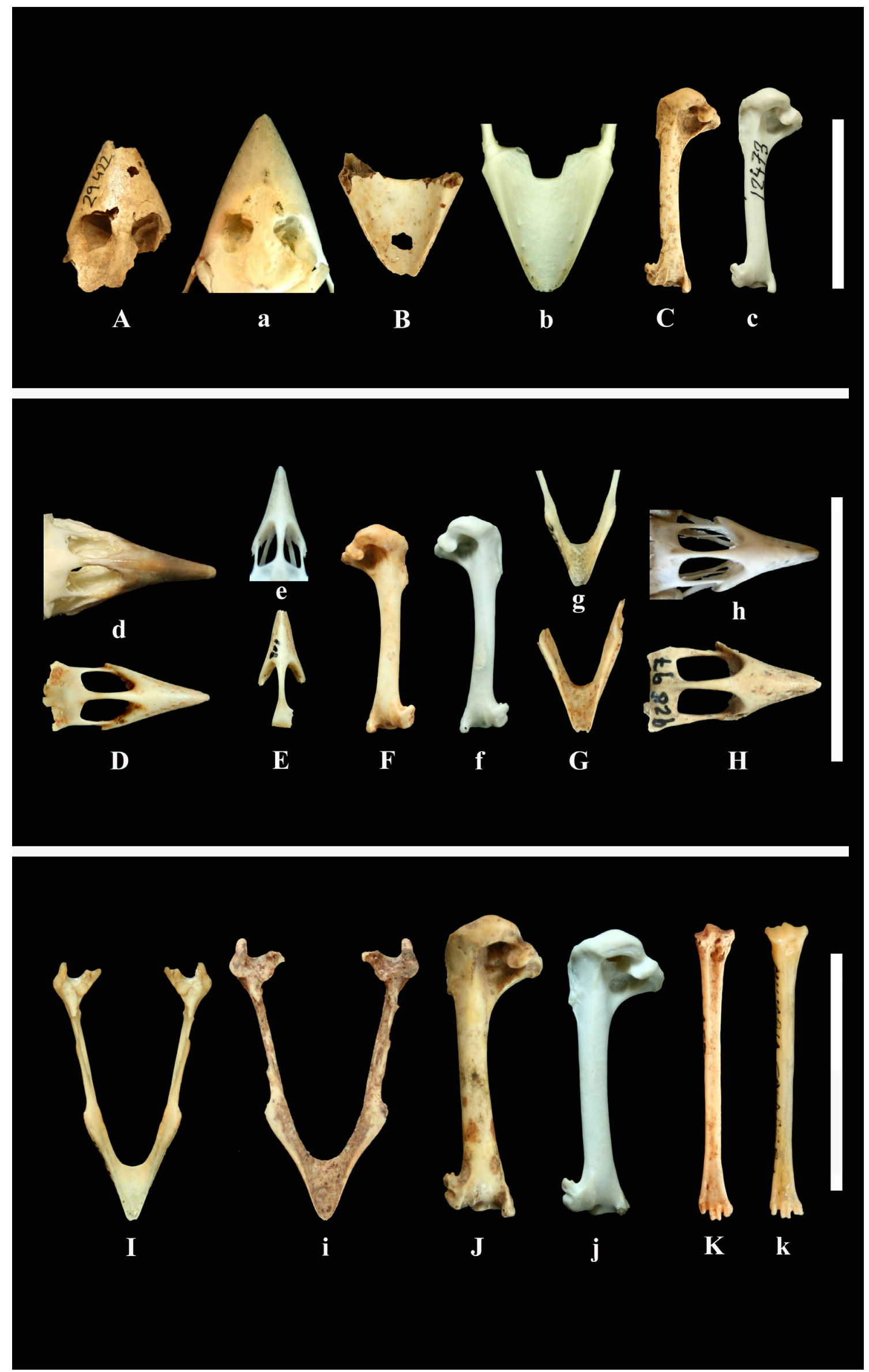




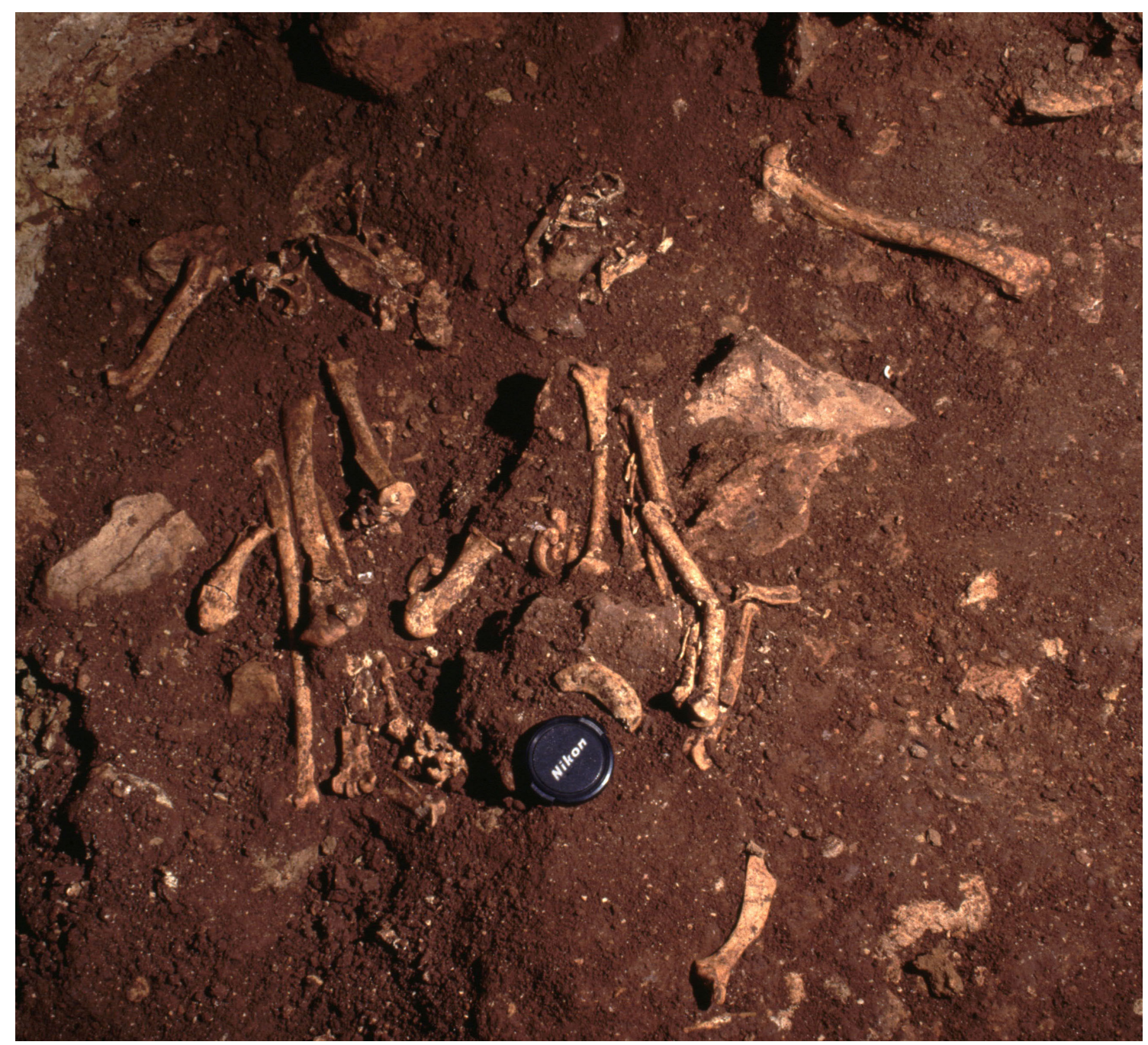

Fig. 15 - Associated bones of Haliaeetus albicilla, es Pouàs, October 1991. 
Fig. 16. ACCIPITRIDAE

Capital letters, fossil Accipitridae from es Pouàs; lowercase letters, recent bones for comparison.

A: Accipiter gentilis, left humerus, cranial view, IMEDEA 29480; a: Accipiter gentilis, left humerus, cranial view, inverted, IMEDEA 9959; B: Accipiter nisus, right ulna, ventral view, IMEDEA 29653; b: Accipiter nisus, right ulna, ventral view, IMEDEA 48261; C: Accipiter nisus, right femur, cranial view, IMEDEA 29656; c: Accipiter nisus, right femur, cranial view, IMEDEA 39403; D: Accipiter nisus, right tarsometatarsus, dorsal view, IMEDEA 29654; d: Accipiter nisus, right tarsometatarsus, dorsal view, inverted, IMEDEA 39403; E: Circus cyaneus, left humerus, cranial view, IMEDEA 29418; e: Circus cyaneus, left humerus, cranial view, inverted, IMEDEA 21735; F: Circus cyaneus, mandible (symphysis), dorsal view, IMEDEA 28592; f: Circus cyaneus, mandible (symphysis), dorsal view, IMEDEA 21735; G: Circus cyaneus, right ulna, ventral view, IMEDEA 17216; g: Circus cyaneus, right ulna, ventral view, inverted, IMEDEA 21735; H: Circus cyaneus, right carpometacarpus, dorsal view, IMEDEA 18944; h: Circus cyaneus, right carpometacarpus, dorsal view, IMEDEA 21735; I: Circus cyaneus, right femur, cranial view, IMEDEA 17131; i: Circus cyaneus, right femur, cranial view, IMEDEA 21735; J: Circus cyaneus, right tibiotarsus, cranial view, IMEDEA 16497; j: Circus cyaneus, right tibiotarsus, cranial view, IMEDEA 21735; K: Circus cyaneus, left tarsometatarsus, dorsal view, IMEDEA 17567; k: Circus cyaneus, left tarsometatarsus, dorsal view, IMEDEA 21735; L: cf. Aquila/Haliaeetus, pedal Phalanx 2 digitus II pedis, plantar view, IMEDEA 96013 ; 1: Aquila chrysaetos, pedal Phalanx 2 digitus II pedis, plantar view, IMEDEA 20500; M: cf. Aquila/Haliaeetus, pedal Phalanx 2 digitus IV pedis, plantar view, IMEDEA 96014; m: Aquila chrysaetos, pedal Phalanx 2 digitus IV pedis, plantar view, IMEDEA 20500. 

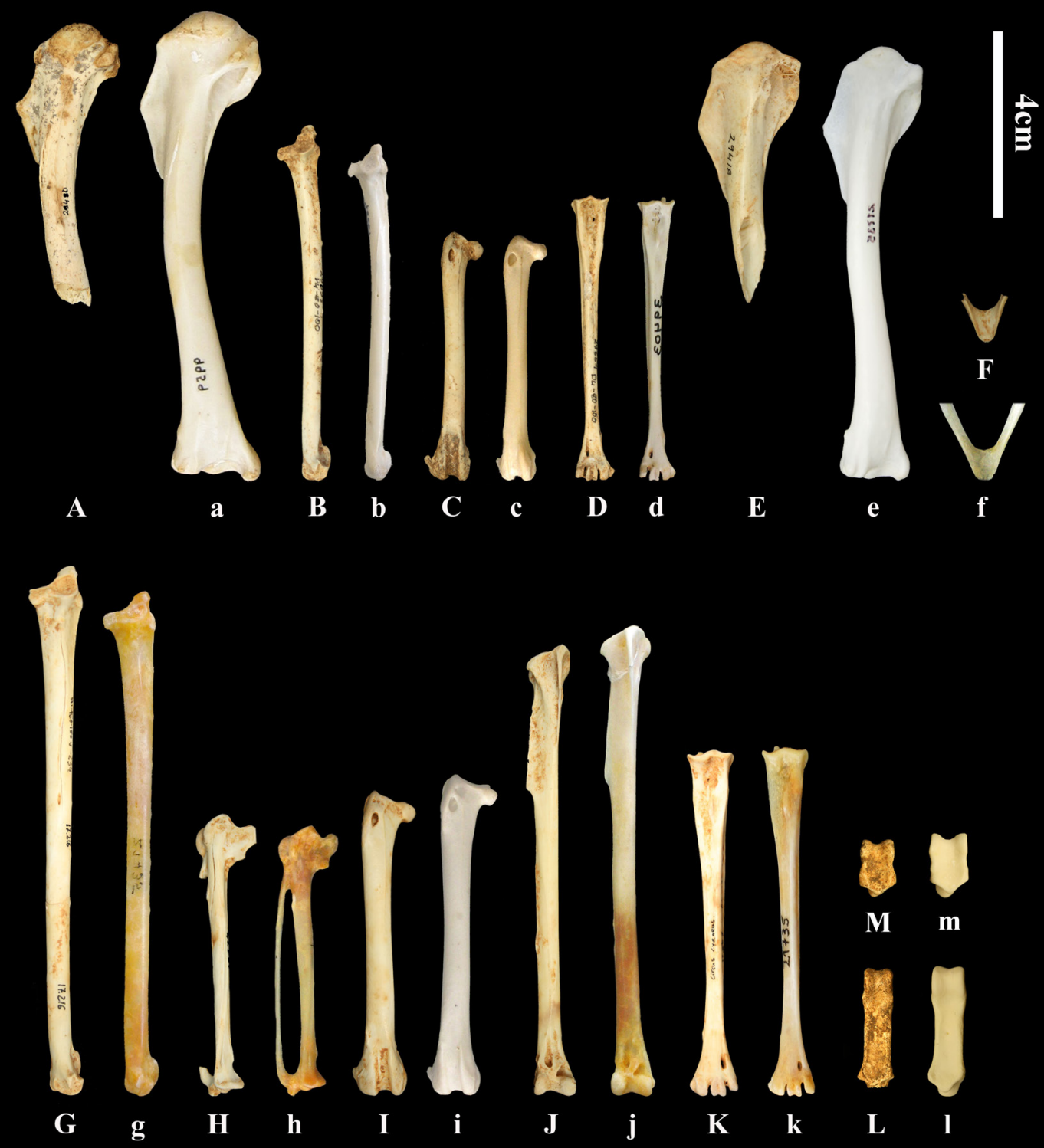
Fig. 17. FALCONIDAE

Capital letters, fossil Falconidae from es Pouàs; lowercase letters, recent bones for comparison.

A: Falco tinunculus, right humerus, cranial view, IMEDEA 28622; a: Falco tinunculus, right humerus, cranial view, IMEDEA 48240; B: Falco tinunculus, left ulna, ventral view, IMEDEA 29470; b: Falco tinunculus, left ulna, ventral view, IMEDEA 2218; C: Falco tinunculus, left femur, cranial view, IMEDEA 28832; c: Falco tinunculus, left femur, cranial view, IMEDEA 21896; D: Falco tinunculus, left tibiotarsus, cranial view, IMEDEA 28840; d: Falco tinunculus, left tibiotarsus, cranial view, IMEDEA 48240; E: Falco tinunculus, left tarsometatarsus, dorsal view, IMEDEA 18076; e: Falco tinunculus, left tarsometatarsus, dorsal view, IMEDEA 21896; F: Falco naumanni, left humerus, cranial view, IMEDEA 90513; f: Falco naumanni, left humerus, cranial view, IMEDEA 21836; G: Falco naumanni, right femur, cranial view, IMEDEA 29353; g: Falco naumanni, right femur, cranial view, IMEDEA 21836; H: Falco naumanni, right tibiotarsus, cranial view, IMEDEA 33648; h: Falco naumanni, right tibiotarsus, cranial view, IMEDEA 21836; I: Falco naumanni, left tarsometatarsus, dorsal view, IMEDEA 25627; i: Falco naumanni, left tarsometatarsus, dorsal view, IMEDEA 21949; J: Falco eleonorae, left tibiotarsus, cranial view, IMEDEA 90290; j: Falco eleonorae, left tibiotarsus, cranial view, IMEDEA 1255; K: Falco subbuteo, left humerus, cranial view, IMEDEA 31761; k: Falco subbuteo, left humerus, cranial view, IMEDEA 12609; L: Falco cf. subbuteo, praemaxilla, dorsal view, IMEDEA 90653; l: Falco subbuteo, praemaxilla, dorsal view, IMEDEA 12609; M1: Falco peregrinus, mandible, dorsal view, IMEDEA 90672; m1: Falco peregrinus, mandible, dorsal view, IMEDEA: 12609; M2: Falco peregrinus, mandible, ventral view, IMEDEA 90672; m2: Falco peregrinus, mandible, ventral view, IMEDEA 12609; N: Falco peregrinus, left coracoid, dorsal view, IMEDEA 19586; n: Falco peregrinus, left coracoid, dorsal view, IMEDEA 1254. 

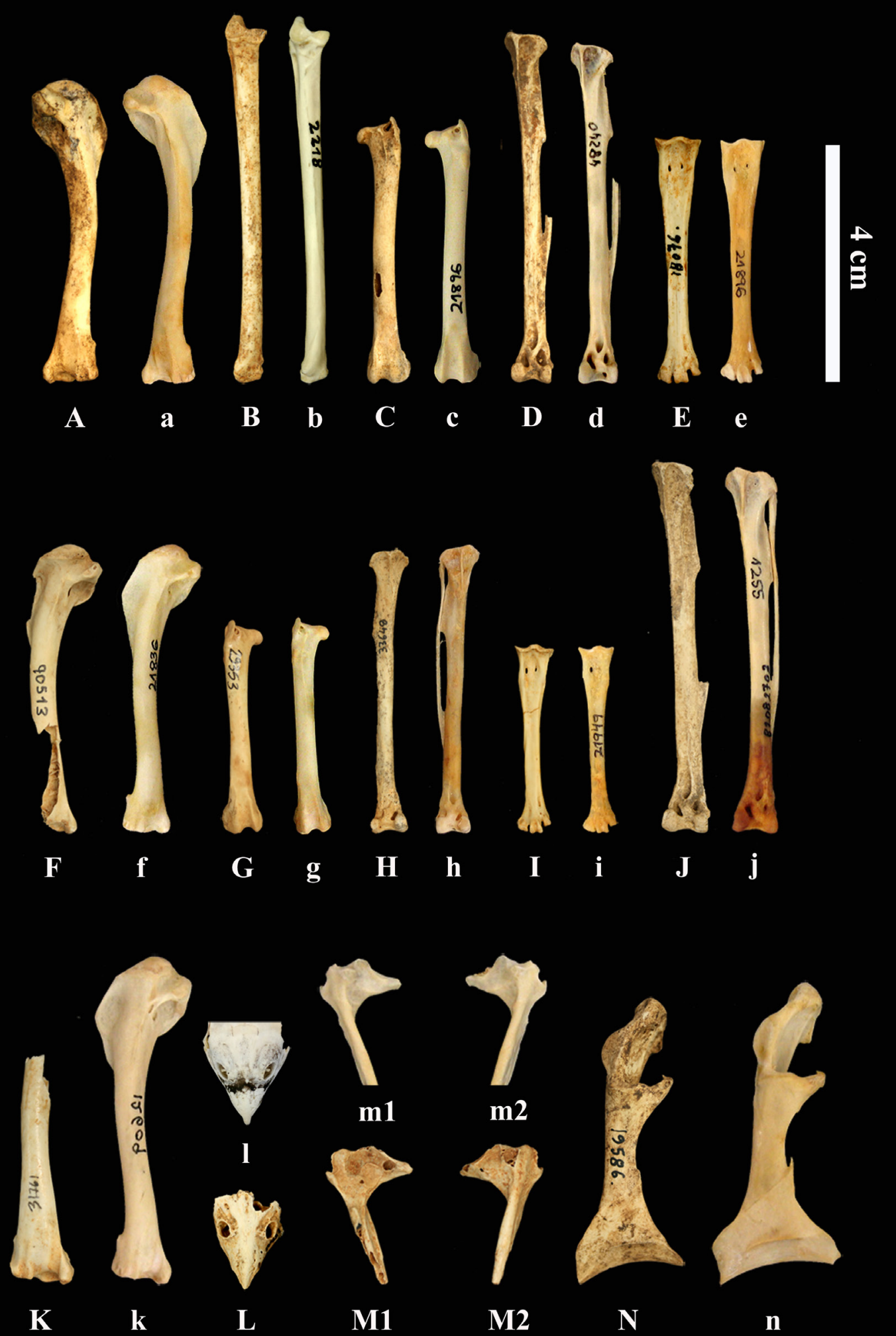
Fig. 18. StRigidae

Capital letters, fossil Strigidae from es Pouàs; lowercase letters, recent bones for comparison.

A: Asio flammeus, left humerus, cranial view, IMEDEA 34530; a: Asio flammeus, left humerus, cranial view, IMEDEA 3997; B: Asio flammeus, right ulna, ventral view, IMEDEA 34535; b: Asio flammeus, right ulna, ventral view, inverted, IMEDEA 20671; C: Asio flammeus, right tibiotarsus, cranial view, IMEDEA 88846; c: Asio flammeus, right tibiotarsus, cranial view, inverted, IMEDEA 3997; D: Asio flammeus, left tarsometatarsus, dorsal view, IMEDEA 90305; d: Asio flammeus, left tarsometatarsus, dorsal view, IMEDEA 3997; E: Athene noctua, left humerus, cranial view, IMEDEA 29439 (proximal fragment) and 25637 (medial and distal fragment); e: Athene noctua, left humerus, cranial view, IMEDEA 21889; F: Athene noctua, right ulna, ventral view, IMEDEA 34529; f: Athene noctua, right ulna, ventral view, IMEDEA 21889; G: Athene noctua, left tarsometatarsus, dorsal view, IMEDEA 27121 (proximal fragment) and IMEDEA 29441 (distal fragment); g: Athene noctua, left tarsometatarsus, dorsal view, IMEDEA 21889; H1: Bubo sp, praemaxilla, lateral view, IMEDEA 29412; h1: Bubo bubo, praemaxilla, lateral view, IMEDEA 12035; H2: Bubo sp, praemaxilla, ventral view, IMEDEA 29412; h2: Bubo bubo, praemaxilla, ventral view, IMEDEA 12035; H3: Bubo sp, praemaxilla, dorsal view, IMEDEA 29412; h3: Bubo bubo, praemaxilla, dorsal view, IMEDEA 12035; I: Otus scops, left humerus, cranial view, IMEDEA 27795; i: Otus scops, left humerus, cranial view, IMEDEA 20298; J: Otus scops, left ulna, ventral view, IMEDEA 31523; j: Otus scops, left ulna, ventral view, IMEDEA 20298; K: Otus scops, left femur, cranial view, IMEDEA 14556; k: Otus scops, left femur, cranial view, IMEDEA 20298; L: Otus scops, right tibiotarsus, cranial view, IMEDEA 16587; l: Otus scops, right tibiotarsus, cranial view, IMEDEA 20298; M: Otus scops, left tarsometatrsus, dorsal view, IMEDEA 30716; m: Otus scops, left tarsometatrsus, dorsal view, inverted, IMEDEA 20298. 

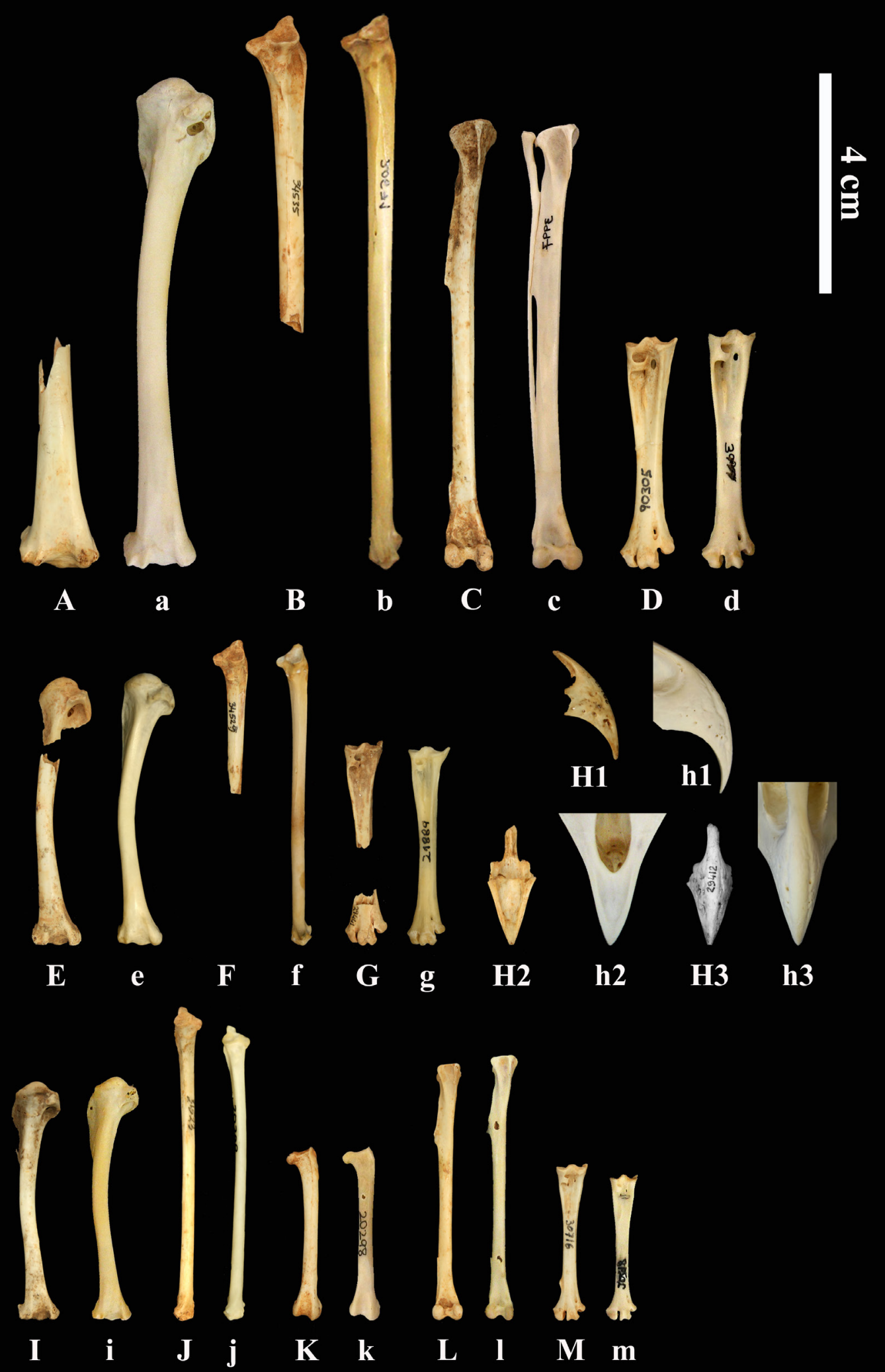


\section{LISTADO DE TABLAS}

Tabla 1- Listado de taxones de aves Passeriformes identificados en es Pouàs.

Biometría de los elementos fósiles y actuales de las especies de Passeriformes identificadas en Es Pouàs. "Actual": ejemplares actuales medidos en este trabajo. "Moreno": ejemplares actuales de las publicaciones de E. Moreno (1985, 1986 y 1987). "Fósil": ejemplares fósiles estudiados en este trabajo.

Tabla 2- Medidas de los cráneos y mandíbulas de Alaudidae.

Tabla 3- Medidas de los húmeros de Alaudidae.

Tabla 4- Medidas de las mandíbulas de Motacillidae.

Tabla 5- Medidas de los húmeros de Motacillidae.

Tabla 6- Medidas de los tarsometatarsos de Motacillidae.

Tabla 7- Medidas de los húmeros de Bombycillidae.

Tabla 8- Medidas de las mandíbulas de Prunellidae.

Tabla 9- Medidas de los húmeros de Prunellidae.

Tabla 10- Medidas de los cráneos y mandíbulas de Turdidae.

Tabla 11- Medidas de los húmeros de Turdidae.

Tabla 12- Medidas de los tarsometatarsos de Turdidae.

Tabla 13- Medidas de los cráneos y mandíbulas de Sylviidae.

Tabla 14- Medidas de los premaxilares y mandíbulas de Muscicapidae.

Tabla 15- Medidas de los húmeros de Muscicapidae.

Tabla 16- Medidas de los tarsometatarsos de Muscicapidae.

Tabla 17- Medidas de los húmeros de Paridae.

Tabla 18- Medidas de los húmeros de Oriolidae.

Tabla 19- Medidas de los cráneos y mandíbulas de Laniidae.

Tabla 20- Medidas de los húmeros de Laniidae.

Tabla 21- Medidas de los tarsometatarsos de Laniidae.

Tabla 22- Medidas de los cráneos y mandíbulas de Corvidae. 
Tabla 23- Medidas de los húmeros de Corvidae.

Tabla 24- Medidas de las ulnas de Corvidae.

Tabla 25- Medidas de los carpometacarpos de Corvidae.

Tabla 26- Medidas de los fémures de Corvidae.

Tabla 27- Medidas de los tibiotarsos de Corvidae.

Tabla 28- Medidas de los tarsometatarsos de Corvidae.

Tabla 29- Medidas de los cráneos y mandíbulas de Passeridae.

Tabla 30- Medidas de los húmeros de Passeridae.

Tabla 31- Medidas de los cráneos y mandíbulas de Fringillidae.

Tabla 32- Medidas de los húmeros de Fringillidae.

Tabla 33- Medidas de los tarsometatarsos de Fringillidae.

Tabla 34- Medidas de los húmeros de Emberizidae.

Tabla 35- Medidas de los tarsometatarsos de Emberizidae.

Tabla 36- Medidas de los huesos principales de Haliaeetus albicilla de Ibiza en comparación con otras poblaciones de la especie.

Resultados del análisis de la varianza y los test no paramétricos de los elementos osteológicos de Corvus corax y Pyrrhocorax pyrrhocorax, comparando los individuos fósiles con los actuales.

Tabla 37- Corvus corax, resultados del ANOVA para los húmeros.

Tabla 38-Corvus corax, resultados del ANOVA para las ulnas.

Tabla 39- Corvus corax, resultados del ANOVA para los carpometacarpos.

Tabla 40-Corvus corax, resultados del ANOVA para los fémures.

Tabla 41- Corvus corax, resultados del ANOVA para los tibiotarsos.

Tabla 42- Corvus corax, resultados del ANOVA para los tarsometatarsos.

Tabla 43-Pyrrhocorax pyrrhocorax, resultados del ANOVA para los húmeros.

Tabla 44-Pyrrhocorax pyrrhocorax, resultados del test no paramétrico para los húmeros. Tabla 45- Pyrrhocorax pyrrhocorax, resultados del ANOVA para los carpometacarpos.

Tabla 46- Pyrrhocorax pyrrhocorax, resultados del test no paramétrico para los carpometacarpos.

Tabla 47- Pyrrhocorax pyrrhocorax, resultados del ANOVA para los fémures.

Tabla 48-Pyrrhocorax pyrrhocorax, resultados del test no paramétrico para los fémures. Tabla 49- Pyrrhocorax pyrrhocorax, resultados del ANOVA para los tibiotarsos.

Tabla 50- Pyrrhocorax pyrrhocorax, resultados del test no paramétrico para los tibiotarsos.

Tabla 51- Pyrrhocorax pyrrhocorax, resultados del ANOVA para los tarsometatarsos.

Tabla 52- Pyrrhocorax pyrrhocorax, resultados del test no paramétrico para los tarsometatarsos.

Tablas correspondientes a las publicaciones de los apartados 5.2 y 6.2.

Tabla 53- Summarized list of material of Falconiformes and Strigiformes from es Pouàs. Tabla 54- Results of the analysis of Tyto alba prey from the study localities. 


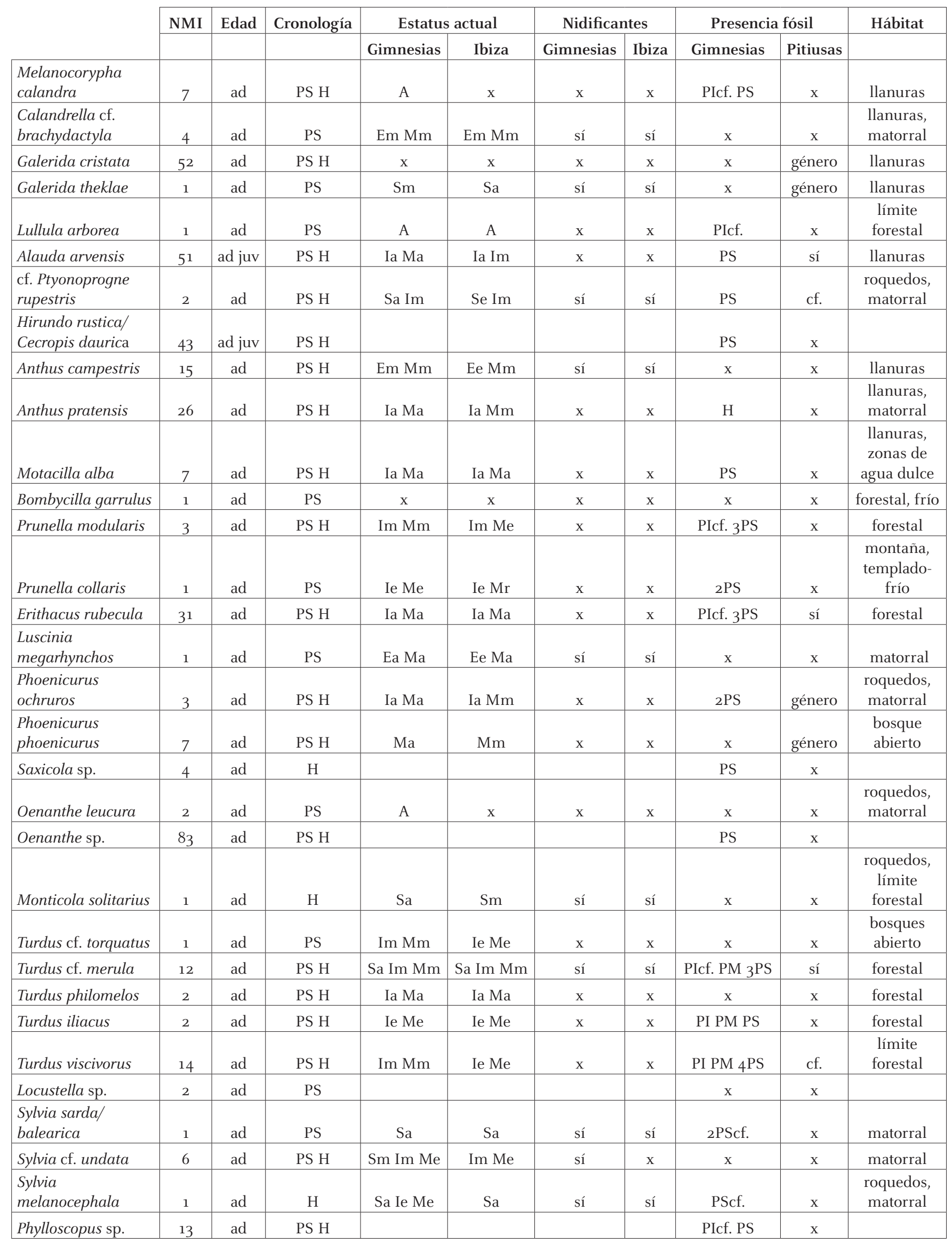




\begin{tabular}{|c|c|c|c|c|c|c|c|c|c|c|}
\hline Muscicapa striata & 3 & $\mathrm{ad}$ & PS H & Ea Ma & Еa Мa & sí & sí & PIcf. & $\mathrm{x}$ & $\begin{array}{l}\text { límite } \\
\text { forestal }\end{array}$ \\
\hline Ficedula hypoleuca & 8 & $\mathrm{ad}$ & PS H & Ma & $\mathrm{Mm}$ & $\mathrm{x}$ & $\mathrm{x}$ & PS & género & $\begin{array}{l}\text { forestal, } \\
\text { montano }\end{array}$ \\
\hline Periparus ater & 1 & $\mathrm{ad}$ & PS & A & A & $\mathrm{x}$ & $\mathrm{x}$ & PIcf. PS & $\mathrm{x}$ & forestal \\
\hline Parus cf. major & 1 & $\mathrm{ad}$ & PS-H & Sa & Sa & sí & sí & PIcf. & $\mathrm{x}$ & $\begin{array}{l}\text { bosque } \\
\text { abierto }\end{array}$ \\
\hline Oriolus oriolus & 1 & $\mathrm{ad}$ & $\mathrm{H}$ & $\mathrm{Me}$ & $\mathrm{Me}$ & $\mathrm{x}$ & $\mathrm{x}$ & $\mathrm{x}$ & $\mathrm{x}$ & forestal \\
\hline Lanius meridionalis & 6 & $\mathrm{ad}$ & PS H & Ir Mr & Ir Mr & $\mathrm{x}$ & $\mathrm{x}$ & PS & sí & $\begin{array}{l}\text { bosque } \\
\text { abierto }\end{array}$ \\
\hline Lanius senator & 215 & ad juv & PS H & Ea Ma & Ea Ma & sí & sí & $\mathrm{x}$ & sí & $\begin{array}{l}\text { bosque } \\
\text { abierto }\end{array}$ \\
\hline $\begin{array}{l}\text { Pyrrhocorax } \\
\text { graculus }\end{array}$ & 8 & ad juv & PS H & A & A & $\mathrm{x}$ & $\mathrm{x}$ & $\mathrm{PM}_{5} \mathrm{PS}$ & sí & $\begin{array}{c}\text { pasto alpino, } \\
\text { roquedos, } \\
\text { frío }\end{array}$ \\
\hline $\begin{array}{l}\text { Pyrrhocorax } \\
\text { pyrrhocorax }\end{array}$ & 88 & ad juv & PS H & Ir & A & $\mathrm{x}$ & $\mathrm{x}$ & PIcf. PM ${ }_{4}$ PS & sí & $\begin{array}{l}\text { roquedos, } \\
\text { llanuras }\end{array}$ \\
\hline Corvus monedula & 2 & $\mathrm{ad}$ & PS H & A & $\mathrm{x}$ & $\mathrm{x}$ & $\mathrm{x}$ & PS & sí & $\begin{array}{c}\text { roquedos, } \\
\text { matorral }\end{array}$ \\
\hline Corvus corone & 1 & $\mathrm{ad}$ & PS & A & A & $\mathrm{x}$ & $\mathrm{x}$ & PS & cf. & $\begin{array}{l}\text { roquedos, } \\
\text { forestal }\end{array}$ \\
\hline Corvus corax & 280 & ad juv & PS H & $\mathrm{Sm}$ & Sr & sí & sí & PS & sí & $\begin{array}{l}\text { bosque } \\
\text { abierto, } \\
\text { roquedos }\end{array}$ \\
\hline Sturnus sp. & 6 & $\mathrm{ad}$ & PS & & & & & PS & $\mathrm{x}$ & \\
\hline Passer domesticus & 1 & $\mathrm{ad}$ & $\mathrm{H}$ & Sa & Sa & sí & sí & PScf. & sí & $\begin{array}{c}\text { bosque } \\
\text { abierto, } \\
\text { áreas } \\
\text { urbanas }\end{array}$ \\
\hline Petronia petronia & 20 & $\mathrm{ad}$ & PS H & Se & $\mathrm{Sm}$ & sí & sí & PS & sí & roquedos \\
\hline $\begin{array}{l}\text { Montifringilla } \\
\text { nivalis }\end{array}$ & 3 & $\mathrm{ad}$ & PS H & Ir & A & $\mathrm{x}$ & $\mathrm{x}$ & ${ }_{3} \mathrm{PS}$ & sí & $\begin{array}{c}\text { alta } \\
\text { montaña, } \\
\text { frío }\end{array}$ \\
\hline Fringilla sp. & 5 & $\mathrm{ad}$ & PS H & & & & & PI PS & sí & \\
\hline Serinus serinus & 2 & $\mathrm{ad}$ & PS H & Sa Ie Me & Sa Ie Me & sí & sí & $\mathrm{x}$ & $\mathrm{x}$ & $\begin{array}{l}\text { límite } \\
\text { forestal }\end{array}$ \\
\hline Chloris chloris & 25 & $\mathrm{ad}$ & PS H & Sa Ie Me & Sa Im & sí & sí & PS & sí & $\begin{array}{l}\text { bosque } \\
\text { abierto, } \\
\text { matorral }\end{array}$ \\
\hline $\begin{array}{l}\text { Carduelis } \\
\text { cannabina }\end{array}$ & 13 & $\mathrm{ad}$ & PS H & Sa Ie Me & Sa & sí & sí & PM & sí & $\begin{array}{l}\text { llanuras, } \\
\text { matorral }\end{array}$ \\
\hline Loxia curvirostra & 2 & $\mathrm{ad}$ & PS H & Sa & Sm & sí & sí & ${ }_{3} \mathrm{PS}$ & $\mathrm{x}$ & forestal \\
\hline $\begin{array}{l}\text { cf. Pinicola } \\
\text { enucleator }\end{array}$ & 2 & $\mathrm{ad}$ & PS & $\mathrm{x}$ & $\mathrm{x}$ & $\mathrm{x}$ & $\mathrm{x}$ & $\mathrm{x}$ & $\mathrm{x}$ & forestal, frío \\
\hline cf. Pyrrhula pyrrhula & 2 & $\mathrm{ad}$ & PS & A & $\mathrm{x}$ & $\mathrm{x}$ & $\mathrm{x}$ & PS & $\mathrm{x}$ & $\begin{array}{l}\text { límite } \\
\text { forestal }\end{array}$ \\
\hline $\begin{array}{l}\text { Coccothraustes } \\
\text { coccothraustes }\end{array}$ & 3 & $\mathrm{ad}$ & PS H & $\operatorname{Im~Me}$ & Ir Mr & $\mathrm{x}$ & $\mathrm{x}$ & PI PM PS & sí & forestal \\
\hline $\begin{array}{l}\text { cf. Plectrophenax } \\
\text { nivalis }\end{array}$ & 3 & $\mathrm{ad}$ & PS & A & $\mathrm{x}$ & $\mathrm{x}$ & $\mathrm{x}$ & $\mathrm{x}$ & $\mathrm{x}$ & $\begin{array}{l}\text { roquedos, } \\
\text { frío }\end{array}$ \\
\hline Emberiza pusilla & 2 & $\mathrm{ad}$ & PS H & A & $\mathrm{x}$ & $\mathrm{x}$ & $\mathrm{x}$ & $\mathrm{x}$ & $\mathrm{x}$ & $\begin{array}{l}\text { bosque } \\
\text { abierto }\end{array}$ \\
\hline $\begin{array}{l}\text { Emberiza } \\
\text { schoeniclus }\end{array}$ & 1 & $\mathrm{ad}$ & PS & A & $\mathrm{x}$ & $\mathrm{x}$ & $\mathrm{x}$ & $\mathrm{x}$ & $\mathrm{x}$ & palustre \\
\hline Emberiza calandra & 14 & $\mathrm{ad}$ & PS H & Sa & $\mathrm{Sm}$ & sí & sí & PScf. & sí & llanuras \\
\hline
\end{tabular}

Tabla 1 - Listado de taxones de aves Passeriformes identificados en es Pouàs. ad: adulto; juv: juvenil; PI: Pleistoceno inferior; PM: Pleistoceno medio; PS: Pleistoceno superior; H: Holoceno. Estatus actual, mayúsculas; A: accidental; E: estival; I: invernante; M: migrante; S: sedentario. Estatus actual, minúsculas; a: abundante; e: escaso; m: moderado; r: raro. 


\begin{tabular}{|c|c|c|c|c|c|c|c|}
\hline \multirow{3}{*}{\multicolumn{2}{|c|}{ Cráneo y mandíbula }} & \multirow{2}{*}{\multicolumn{2}{|c|}{ Fósil }} & \multirow{2}{*}{\multicolumn{2}{|c|}{ Actual }} & \multirow{2}{*}{\multicolumn{2}{|c|}{ Moreno }} \\
\hline & & & & & & & \\
\hline & & LM & $\mathrm{C}$ & LM & $\mathrm{C}$ & LM & $\mathrm{C}$ \\
\hline \multirow{5}{*}{ Melanocorypha calandra } & $\mathrm{n}$ & & 1 & & 1 & & 1 \\
\hline & Media & & 16,1 & & 14,7 & & 15,0 \\
\hline & $\sigma$ & & & & & & \\
\hline & Mín. & & & & & & \\
\hline & Máx. & & & & & & \\
\hline \multirow{5}{*}{ Galerida cristata } & $\mathrm{n}$ & 1 & 2 & 2 & 2 & 2 & 2 \\
\hline & Media & 30,2 & 17,7 & 26,1 & 16,1 & 26,9 & 16,1 \\
\hline & $\sigma$ & & 0,453 & 0,481 & 0,580 & 0,640 & 0,180 \\
\hline & Mín. & & 17,4 & 25,75 & 15,7 & 26,45 & 16 \\
\hline & Máx. & & 18,0 & 26,4 & 16,55 & 27,35 & 16,25 \\
\hline \multirow{5}{*}{ Galerida theklae } & $\mathrm{n}$ & 1 & & 5 & & 2 & \\
\hline & Media & 23,6 & & 24,1 & & 25,2 & \\
\hline & $\sigma$ & & & 0,436 & & 0,810 & \\
\hline & Mín. & & & 23,6 & & 24,6 & \\
\hline & Máx. & & & 24,8 & & 25,75 & \\
\hline \multirow{5}{*}{ Alauda arvensis } & $\mathrm{n}$ & 2 & 7 & 5 & 6 & 3 & 9 \\
\hline & Media & 22,9 & 13,0 & 22,4 & 12,8 & 23,4 & 13,35 \\
\hline & $\sigma$ & 0,905 & 0,720 & 0,779 & 0,207 & 1,109 & 0,240 \\
\hline & Mín. & 22,25 & 12,0 & 21,0 & 12,5 & 22,2 & 13,05 \\
\hline & Máx. & 23,5 & 13,7 & 22,9 & 13,1 & 24,4 & 13,7 \\
\hline
\end{tabular}

Tabla 2- Medidas de los cráneos y mandíbulas de Alaudidae.

\begin{tabular}{|c|c|c|c|c|c|c|c|c|c|}
\hline \multirow{3}{*}{\multicolumn{2}{|c|}{ Húmero }} & \multirow{2}{*}{\multicolumn{4}{|c|}{ Fósil }} & \multirow{2}{*}{\multicolumn{4}{|c|}{ Actual }} \\
\hline & & & & & & & & & \\
\hline & & \multirow{2}{*}{$\begin{array}{l}\mathrm{L} \\
3\end{array}$} & \multirow{2}{*}{$\begin{array}{c}\text { AEP } \\
5 \\
\end{array}$} & \multirow{2}{*}{$\begin{array}{c}\text { APD } \\
3 \\
\end{array}$} & \multirow{2}{*}{$\begin{array}{c}\mathrm{AD} \\
5 \\
\end{array}$} & \multirow{2}{*}{$\begin{array}{l}\mathrm{L} \\
2 \\
\end{array}$} & \multirow[t]{2}{*}{ AEP } & \multirow[t]{2}{*}{ APD } & \multirow[t]{2}{*}{$\mathrm{AD}$} \\
\hline \multirow{5}{*}{$\begin{array}{l}\text { Melanocorypha } \\
\text { calandra }\end{array}$} & $\mathrm{n}$ & & & & & & & & \\
\hline & Media & 30,4 & 9,5 & 6,3 & 2,9 & 27,25 & & & \\
\hline & $\sigma$ & 0,081 & 0,088 & 0,096 & 0,139 & 1,202 & & & \\
\hline & Mín. & 30,3 & 9,4 & 6,2 & 2,8 & 26,4 & & & \\
\hline & Máx. & 30,5 & 9,6 & 6,4 & 3,1 & 28,1 & & & \\
\hline \multirow{5}{*}{ Lullula arborea } & $\mathrm{n}$ & 1 & 1 & 1 & 1 & 1 & 1 & 1 & 1 \\
\hline & Media & 22,8 & 7,3 & 4,9 & 2,3 & 21,2 & 6,6 & 4,7 & 2,1 \\
\hline & $\sigma$ & & & & & & & & \\
\hline & Mín. & & & & & & & & \\
\hline & Máx. & & & & & & & & \\
\hline \multirow{5}{*}{ Alauda arvensis } & $\mathrm{n}$ & 87 & 82 & 83 & 87 & 14 & 6 & 6 & 6 \\
\hline & Media & 25,05 & 7,1 & 4,9 & 2,1 & 24,8 & 7,3 & 4,95 & 2,25 \\
\hline & $\sigma$ & 0,906 & 0,378 & 0,404 & 0,162 & 0,86 & 0,295 & 0,195 & 0,085 \\
\hline & Mín. & 23,1 & 6,3 & 4,4 & 1,9 & 23,5 & 7,0 & 4,7 & 2,2 \\
\hline & Máx. & 27,0 & 8,0 & 7,8 & 2,6 & 26,6 & 7,7 & 5,3 & 2,4 \\
\hline
\end{tabular}

Tabla 3- Medidas de los húmeros de Alaudidae. 


\begin{tabular}{|l|c|c|c|c|}
\cline { 3 - 5 } \multicolumn{2}{c|}{} & \multicolumn{3}{c|}{ LM } \\
\hline \multirow{4}{*}{ Mandíbula } & $\mathrm{n}$ & Fósil & Actual & Moreno \\
\cline { 3 - 6 } Anthus campestris & Media & 26,1 & 28,1 & 1 \\
\cline { 2 - 5 } & $\sigma$ & 0,283 & 0,911 & \\
\cline { 2 - 5 } & Mín. & 25,9 & 26,9 & \\
\cline { 2 - 5 } & Máx. & 26,3 & 29,0 & \\
\hline
\end{tabular}

Tabla 4- Medidas de las mandíbulas de Motacillidae.

\begin{tabular}{|c|c|c|c|c|c|c|c|c|c|}
\hline & & \multicolumn{4}{|c|}{ Fósil } & \multicolumn{4}{|c|}{ Actual } \\
\hline \multicolumn{2}{|l|}{ Húmero } & $\mathrm{L}$ & AEP & APD & AD & $\mathrm{L}$ & AEP & AED & AD \\
\hline \multirow{5}{*}{ Anthus campestris } & $\mathrm{n}$ & 25 & 25 & 25 & 25 & 5 & 5 & 5 & 5 \\
\hline & Media & 21,7 & 6,7 & 4,9 & 2,1 & 22,2 & 6,8 & 5,0 & 2,1 \\
\hline & $\sigma$ & 0,547 & 0,190 & 0,163 & 0,077 & 0,345 & 0,233 & 0,140 & 0,137 \\
\hline & Mín. & 20,6 & 6,25 & 4,6 & 1,9 & 21,8 & 6,5 & 4,75 & 2,0 \\
\hline & Máx. & 22,8 & 7,1 & 5,3 & 2,2 & 22,6 & 7,1 & 5,1 & 2,4 \\
\hline \multirow{5}{*}{ Anthus pratensis } & $\mathrm{n}$ & 47 & 45 & 45 & 47 & 8 & 8 & 8 & 8 \\
\hline & Media & 18,9 & 5,6 & 4,2 & 1,8 & 19,25 & 5,8 & 4,2 & 1,8 \\
\hline & $\sigma$ & 0,487 & 0,151 & 0,115 & 0,064 & 0,517 & 0,290 & 0,234 & 0,130 \\
\hline & Mín. & 17,15 & 5,2 & 3,8 & 1,7 & 18,3 & 5,4 & 3,95 & 1,6 \\
\hline & Máx. & 19,7 & 5,9 & 4,45 & 2,0 & 19,8 & 6,1 & 4,7 & 2,0 \\
\hline \multirow{5}{*}{ Motacilla alba } & $\mathrm{n}$ & 13 & 13 & 13 & 13 & 9 & 9 & 9 & 9 \\
\hline & Media & 20,45 & 6,3 & 4,55 & 2,0 & 19,4 & 6,1 & 4,5 & 1,9 \\
\hline & $\sigma$ & 0,370 & 0,247 & 0,148 & 0,095 & 0,494 & 0,135 & 0,095 & 0,034 \\
\hline & Mín. & 19,8 & 5,8 & 4,2 & 1,8 & 18,5 & 5,9 & 4,3 & 1,8 \\
\hline & Máx. & 21,2 & 6,65 & 4,7 & 2,1 & 20,1 & 6,3 & 4,6 & 1,9 \\
\hline
\end{tabular}

Tabla 5- Medidas de los húmeros de Motacillidae.

\begin{tabular}{|c|c|c|c|c|c|c|c|c|c|}
\hline \multirow{3}{*}{\multicolumn{2}{|c|}{ Tarsometatarso }} & \multirow{2}{*}{\multicolumn{4}{|c|}{ Fósil }} & \multirow{2}{*}{\multicolumn{4}{|c|}{ Actual }} \\
\hline & & & & & & & & & \\
\hline & & $\mathrm{L}$ & AEP & APD & $\mathrm{AD}$ & $\mathrm{L}$ & AEP & AED & $\mathrm{AD}$ \\
\hline \multirow{5}{*}{ Anthus campestris } & $\mathrm{n}$ & 2 & 2 & 2 & 2 & 5 & 5 & 5 & 5 \\
\hline & Media & 26,6 & 3,0 & 2,3 & 1,2 & 26,3 & 3,1 & 2,4 & 1,1 \\
\hline & $\sigma$ & 0,566 & 0,042 & 0,021 & 0,099 & 0,749 & 0,152 & 0,053 & 0,054 \\
\hline & Mín. & 26,2 & 2,95 & 2,3 & 1,1 & 25,6 & 2,9 & 2,3 & 1,0 \\
\hline & Máx. & 27,0 & 3,0 & 2,3 & 1,2 & 27,5 & 3,3 & 2,5 & 1,15 \\
\hline
\end{tabular}

Tabla 6- Medidas de los tarsometatarsos de Motacillidae.

\begin{tabular}{|c|c|c|c|c|c|c|c|c|c|}
\hline \multirow{2}{*}{\multicolumn{2}{|c|}{ Húmero }} & \multicolumn{4}{|c|}{ Fósil } & \multicolumn{4}{|c|}{ Actual } \\
\hline & & L & AEP & APD & AD & $\mathrm{L}$ & AEP & APD & AD \\
\hline \multirow{5}{*}{ Bombycilla garrulus } & $\mathrm{n}$ & 1 & 1 & 1 & 1 & 4 & 4 & 4 & 4 \\
\hline & Media & 24,2 & 7,5 & 6,1 & 2,45 & 23,6 & 7,9 & 5,7 & 2,6 \\
\hline & $\sigma$ & & & & & 0,466 & 0,208 & 0,167 & 0,050 \\
\hline & Mín. & & & & & 23,1 & 7,7 & 5,6 & 2,5 \\
\hline & Máx. & & & & & 24,2 & 8,2 & 6,0 & 2,6 \\
\hline
\end{tabular}

Tabla 7- Medidas de los húmeros de Bombycillidae. 


\begin{tabular}{|l|c|c|c|c|}
\cline { 3 - 5 } \multicolumn{2}{c|}{} & \multicolumn{3}{c|}{ LM } \\
\hline \multirow{4}{*}{ Mandíbula } & $\mathrm{n}$ & Fósil & Actual & Moreno \\
\cline { 2 - 5 } & Media & 21,6 & 21,4 & 8 \\
\cline { 2 - 5 } & $\sigma$ & & 0,499 & 0,558 \\
\cline { 2 - 5 } & Mín. & & 20,7 & 20,8 \\
\cline { 2 - 5 } & Máx. & & 21,9 & 22,25 \\
\hline
\end{tabular}

Tabla 8- Medidas de las mandíbulas de Prunellidae.

\begin{tabular}{|c|c|c|c|c|c|c|c|c|c|}
\hline \multirow{2}{*}{\multicolumn{2}{|c|}{ Húmero }} & \multicolumn{4}{|c|}{ Fósil } & \multicolumn{4}{|c|}{ Actual } \\
\hline & & $\mathrm{L}$ & AEP & APD & AD & $\mathrm{L}$ & AEP & AED & $\mathrm{AD}$ \\
\hline \multirow{5}{*}{ Prunella collaris } & $\mathrm{n}$ & 1 & 1 & 1 & 1 & 1 & 1 & 1 & 1 \\
\hline & Media & 23,0 & 7,3 & 5,5 & 2,3 & 23,1 & 7,0 & 5,4 & 2,2 \\
\hline & $\sigma$ & & & & & & & & \\
\hline & Mín. & & & & & & & & \\
\hline & Máx. & & & & & & & & \\
\hline \multirow{5}{*}{ Prunella modularis } & $\mathrm{n}$ & 3 & 3 & 3 & 3 & 5 & 5 & 4 & 5 \\
\hline & Media & 16,9 & 5,3 & 4,2 & 1,7 & 17,1 & 5,1 & 3,95 & 1,65 \\
\hline & $\sigma$ & 0,840 & 0,182 & 0,146 & 0,087 & 0,348 & 0,204 & 0,217 & 0,048 \\
\hline & Mín. & 16,1 & 5,1 & 4 & 1,6 & 16,75 & 4,8 & 3,7 & 1,6 \\
\hline & Máx. & 17,8 & 5,5 & 4,3 & 1,75 & 17,6 & 5,35 & 4,2 & 1,7 \\
\hline
\end{tabular}

Tabla 9- Medidas de los húmeros de Prunellidae.

\begin{tabular}{|c|c|c|c|c|c|c|c|c|c|c|c|}
\hline & & \multicolumn{4}{|c|}{ Fósil } & \multicolumn{4}{|c|}{ Actual } & \multicolumn{2}{|c|}{ Moreno } \\
\hline \multicolumn{2}{|l|}{ Cráneo y mandíbula } & LM & $\mathrm{C}$ & $\mathrm{Cn}$ & DI & LM & $\mathrm{C}$ & $\mathrm{Cn}$ & DI & LM & $\mathrm{C}$ \\
\hline \multirow{5}{*}{ Erithacus rubecula } & $\mathrm{n}$ & 2 & 3 & & 1 & 33 & 34 & & 32 & 10 & 12 \\
\hline & Media & 22,9 & 12,7 & & 2,4 & 22,5 & 12,8 & & 2,4 & 23,1 & 12,9 \\
\hline & $\sigma$ & 0,495 & 0,095 & & & $0,55^{6}$ & 0,443 & & 0,191 & 0,520 & 0,300 \\
\hline & Mín. & 22,5 & 12,6 & & & 20,8 & 11,9 & & 2,0 & 22,0 & 12,45 \\
\hline & Máx. & 23,2 & 12,8 & & & 23,6 & 13,7 & & 2,8 & 23,85 & 13,4 \\
\hline \multirow{5}{*}{ Phoenicurus ochruros } & $\mathrm{n}$ & & 1 & & & & 10 & & & & 4 \\
\hline & Media & & 12,0 & & & & 13,3 & & & & 13,3 \\
\hline & $\sigma$ & & & & & & 0,438 & & & & 0,063 \\
\hline & Mín. & & & & & & 12,3 & & & & 13,2 \\
\hline & Máx. & & & & & & 13,9 & & & & 13,35 \\
\hline \multirow{5}{*}{ Phoenicurus phoenicurus } & $\mathrm{n}$ & & 1 & 1 & & & 8 & 7 & & & 7 \\
\hline & Media & & 13,3 & 11,55 & & & 13,1 & 11,4 & & & 13,2 \\
\hline & $\sigma$ & & & & & & 0,633 & 0,606 & & & 0,210 \\
\hline & Mín. & & & & & & 12,0 & 10,2 & & & 12,75 \\
\hline & Máx. & & & & & & 14,0 & 12,2 & & & 13,45 \\
\hline \multirow{5}{*}{ Turdus philomelos } & $\mathrm{n}$ & 1 & & 2 & & 12 & & 13 & & 12 & \\
\hline & Media & 34,5 & & 15,25 & & 33,8 & & 17,1 & & 35,3 & \\
\hline & $\sigma$ & & & 1,068 & & 1,219 & & 0,721 & & 1,057 & \\
\hline & Mín. & & & 14,5 & & 31,4 & & 15,7 & & 34,1 & \\
\hline & Máx. & & & 16 & & 35,75 & & 18,1 & & 37,75 & \\
\hline
\end{tabular}

Tabla 10- Medidas de los cráneos y mandíbulas de Turdidae. 


\begin{tabular}{|c|c|c|c|c|c|c|c|c|c|}
\hline \multirow{3}{*}{\multicolumn{2}{|c|}{ Húmero }} & \multirow{2}{*}{\multicolumn{4}{|c|}{ Fósil }} & \multirow{2}{*}{\multicolumn{4}{|c|}{ Actual }} \\
\hline & & & & & & & & & \\
\hline & & \multirow{2}{*}{$\begin{array}{l}\mathrm{L} \\
51\end{array}$} & \multirow{2}{*}{$\begin{array}{c}\text { AEP } \\
47 \\
\end{array}$} & \multirow{2}{*}{$\begin{array}{c}\text { APD } \\
49\end{array}$} & \multirow{2}{*}{$\begin{array}{c}\text { AD } \\
51\end{array}$} & \multirow{2}{*}{$\begin{array}{l}\mathrm{L} \\
33\end{array}$} & \multirow{2}{*}{$\begin{array}{c}\text { AEP } \\
33 \\
\end{array}$} & \multirow{2}{*}{$\begin{array}{c}\text { AED } \\
33 \\
\end{array}$} & \multirow{2}{*}{$\begin{array}{c}\text { AD } \\
33 \\
\end{array}$} \\
\hline \multirow{5}{*}{ Erithacus rubecula } & $\mathrm{n}$ & & & & & & & & \\
\hline & Media & 16,3 & 5,0 & 4,0 & 1,6 & 16,1 & 4,8 & 3,8 & 1,5 \\
\hline & $\sigma$ & 0,356 & 0,168 & 0,159 & 0,061 & 0,622 & 0,315 & 0,180 & 0,079 \\
\hline & Mín. & 15,5 & 4,7 & 3,6 & 1,5 & 13,8 & 3,7 & 3,1 & 1,3 \\
\hline & Máx. & 17,3 & 5,3 & 4,4 & 1,8 & 17,0 & 5,3 & 4,1 & 1,7 \\
\hline \multirow{5}{*}{ Luscinia megarhynchos } & $\mathrm{n}$ & 2 & 2 & 2 & 2 & 6 & 6 & 6 & 6 \\
\hline & Media & 17,6 & 5,4 & 4,0 & 1,7 & 17,1 & 5,2 & 3,9 & 1,6 \\
\hline & $\sigma$ & 0,269 & 0,000 & 0,057 & 0,000 & 0,156 & 0,113 & 0,144 & 0,034 \\
\hline & Mín. & 17,4 & 5,4 & 4,0 & 1,7 & 16,9 & 5,05 & 3,7 & 1,55 \\
\hline & Máx. & 17,8 & 5,4 & 4,05 & 1,7 & 17,3 & 5,4 & 4,1 & 1,65 \\
\hline \multirow{5}{*}{ Phoenicurus ochruros } & $\mathrm{n}$ & 4 & 4 & 4 & 4 & 9 & 9 & 9 & 9 \\
\hline & Media & 16,3 & 5,0 & 3,9 & 1,65 & 17,45 & 5,4 & 4,2 & 1,7 \\
\hline & $\sigma$ & 0,342 & 0,032 & 0,128 & 0,022 & 0,507 & 0,234 & 0,150 & 0,048 \\
\hline & Mín. & 15,8 & 5,0 & 3,8 & 1,6 & 16,8 & 5,2 & 4,0 & 1,6 \\
\hline & Máx. & 16,6 & 5,1 & 4,1 & 1,7 & 18,2 & 5,9 & 4,45 & 1,8 \\
\hline \multirow{5}{*}{ Phoenicurus phoenicurus } & $\mathrm{n}$ & 10 & 10 & 10 & 10 & 8 & 8 & 8 & 8 \\
\hline & Media & 16,0 & 5,1 & 3,95 & 1,55 & 16,2 & 5,1 & 3,9 & 1,6 \\
\hline & $\sigma$ & 0,464 & 0,171 & 0,128 & 0,070 & 0,266 & 0,150 & 0,132 & 0,050 \\
\hline & Mín. & 15,45 & 4,7 & 3,7 & 1,5 & 15,6 & 4,9 & 3,6 & 1,5 \\
\hline & Máx. & 17,0 & 5,3 & 4,15 & 1,7 & 16,4 & 5,3 & 4,1 & 1,7 \\
\hline \multirow{5}{*}{ Oenanthe leucura } & $\mathrm{n}$ & 2 & 2 & 2 & 2 & 2 & 2 & 2 & 2 \\
\hline & Media & 22,4 & 6,7 & 5,2 & 2,1 & 21,75 & 6,4 & 5 & 1,9 \\
\hline & $\sigma$ & 0,198 & 0,021 & 0,049 & 0,021 & 0,410 & 0,113 & 0,141 & 0,021 \\
\hline & Mín. & 22,3 & 6,6 & 5,2 & 2,0 & 21,5 & 6,3 & 4,9 & 1,85 \\
\hline & Máx. & 22,55 & 6,7 & 5,2 & 2,1 & 22,0 & 6,5 & 5,1 & 1,9 \\
\hline \multirow{5}{*}{ Monticola solitarius } & $\mathrm{n}$ & 2 & 2 & 2 & 2 & 3 & 3 & 3 & 3 \\
\hline & Media & 26,2 & 7,8 & 5,8 & 2,5 & 26,4 & 8,0 & 6,0 & 2,5 \\
\hline & $\sigma$ & 0,049 & 0,064 & 0,113 & 0,035 & 0,328 & 0,252 & 0,260 & 0,126 \\
\hline & Mín. & 26,1 & 7,7 & 5,7 & 2,5 & 26,1 & 7,7 & 5,7 & 2,3 \\
\hline & Máx. & 26,2 & 7,8 & 5,85 & 2,5 & 26,7 & 8,9 & 6,2 & 2,6 \\
\hline \multirow{5}{*}{ Turdus viscivorus* } & $\mathrm{n}$ & 18 & 19 & 16 & 19 & 5 & 5 & 5 & 5 \\
\hline & Media & 33,5 & 10,8 & 7,9 & 3,4 & 33,1 & 10,6 & 7,8 & 3,3 \\
\hline & $\sigma$ & 0,414 & 0,344 & 0,343 & 0,176 & 0,795 & 0,457 & 0,222 & 0,106 \\
\hline & Mín. & 33,0 & 10,2 & 7,5 & 3,1 & 32,1 & 10,15 & 7,5 & 3,2 \\
\hline & Máx. & 34,4 & 11,3 & 8,7 & 3,8 & 33,8 & 11,25 & 8,1 & 3,4 \\
\hline
\end{tabular}

Tabla 11- Medidas de los húmeros de Turdidae. *Fósil: Turdus cf. viscivorus.

\begin{tabular}{|c|c|c|c|c|c|c|c|c|c|}
\hline \multirow{2}{*}{\multicolumn{2}{|c|}{ Tarsometatarso }} & \multicolumn{4}{|c|}{ Fósil } & \multicolumn{4}{|c|}{ Actual } \\
\hline & & L & AEP & APD & AD & $\mathrm{L}$ & AEP & AED & AD \\
\hline \multirow{5}{*}{ Erithacus rubecula } & $\mathrm{n}$ & 33 & 32 & 32 & 33 & 31 & 31 & 31 & 31 \\
\hline & Media & 24,9 & 2,6 & 1,9 & 0,9 & 25,5 & 2,6 & 1,9 & 0,9 \\
\hline & $\sigma$ & 0,388 & 0,083 & 0,090 & 0,068 & 0,621 & 0,060 & 0,069 & 0,042 \\
\hline & Mín. & 23,9 & 2,4 & 1,7 & 0,8 & 24,0 & 2,5 & 1,7 & 0,8 \\
\hline & Máx. & 25,5 & 2,8 & 2,1 & 1,1 & 26,8 & 2,7 & 2,05 & 1,0 \\
\hline \multirow{5}{*}{ Turdus iliacus } & $\mathrm{n}$ & 1 & 1 & 1 & 1 & 13 & 13 & 12 & 13 \\
\hline & Media & 29,5 & 4,0 & 3,3 & 1,5 & 29,3 & 3,9 & 3,2 & 1,5 \\
\hline & $\sigma$ & & & & & 0,778 & 0,150 & 0,132 & 0,106 \\
\hline & Mín. & & & & & 28,3 & 3,6 & 3,0 & 1,3 \\
\hline & Máx. & & & & & 30,8 & 4,1 & 3,4 & 1,7 \\
\hline
\end{tabular}

Tabla 12- Medidas de los tarsometatarsos de Turdidae. 


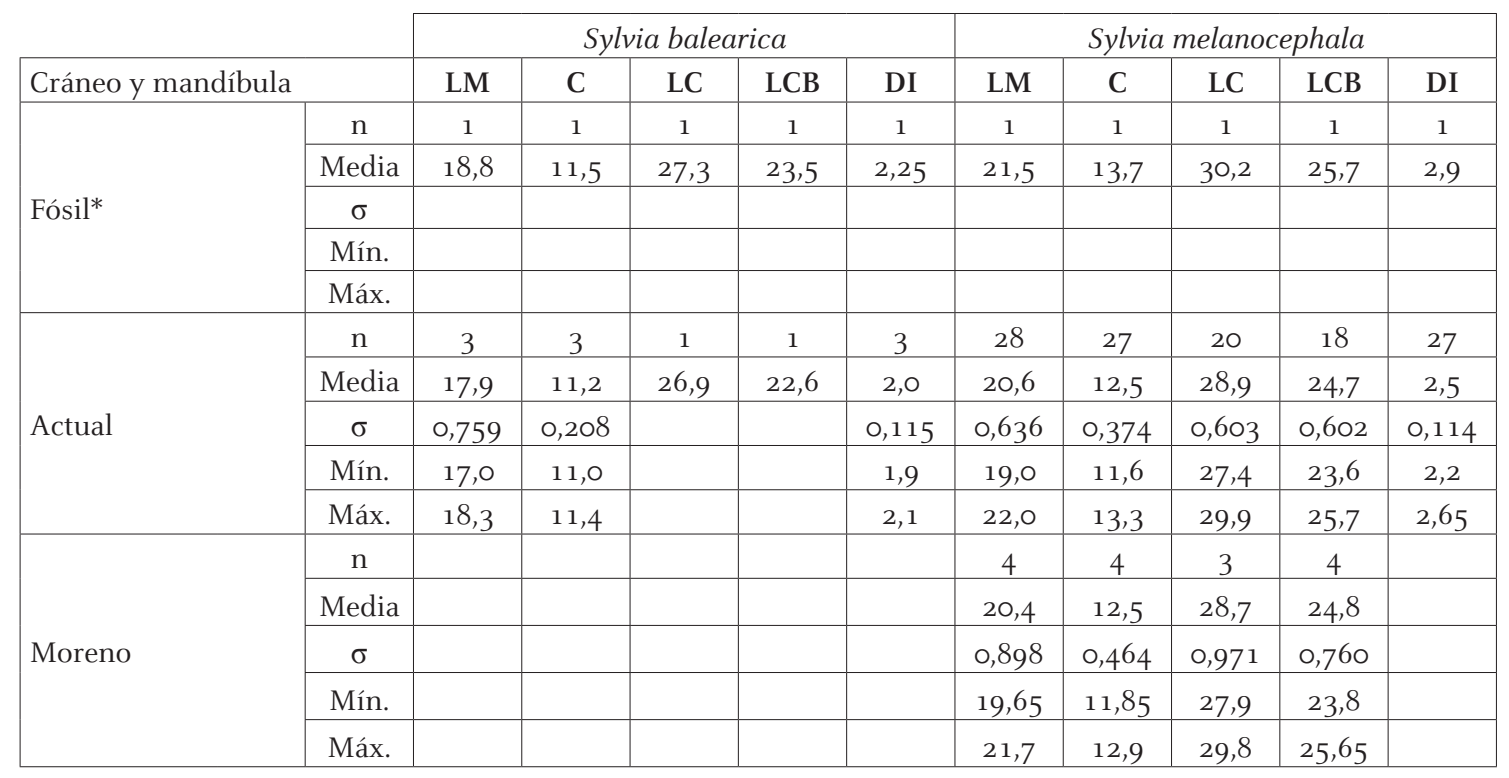

Tabla 13- Medidas de los cráneos y mandíbulas de Silviidae.*Fósil: Sylvia sarda/balearica

\begin{tabular}{|l|c|c|c|c|c|c|c|}
\cline { 3 - 9 } \multicolumn{2}{c|}{} & \multicolumn{2}{c|}{ Fósil } & \multicolumn{2}{c|}{ Actual } & \multicolumn{2}{c|}{ Moreno } \\
\hline \multirow{5}{*}{ Cráneo y mandíbula } & & LM & C & LM & C & LM & C \\
\hline \multirow{3}{*}{ Ficedula hypoleuca } & $\mathrm{n}$ & 3 & 1 & 17 & 16 & 9 & 11 \\
\cline { 2 - 10 } & Media & 19,45 & 11,7 & 20,6 & 12,0 & 20,8 & 12,3 \\
\cline { 2 - 9 } & $\sigma$ & 0,219 & & 0,590 & 0,529 & 0,610 & 0,410 \\
\cline { 2 - 9 } & Mín. & 19,3 & & 19,7 & 11,0 & 20,2 & 11,75 \\
\cline { 2 - 9 } & Máx. & 19,7 & & 21,6 & 12,9 & 21,8 & 13,25 \\
\hline
\end{tabular}

Tabla 14- Medidas de los premaxilares y mandíbulas de Muscicapidae.

\begin{tabular}{|c|c|c|c|c|c|c|c|c|c|}
\hline \multirow{2}{*}{\multicolumn{2}{|c|}{ Húmero }} & \multicolumn{4}{|c|}{ Fósil } & \multicolumn{4}{|c|}{ Actual } \\
\hline & & $\mathrm{L}$ & AEP & APD & AD & $\mathrm{L}$ & AEP & AED & AD \\
\hline \multirow{5}{*}{ Muscicapa striata } & $\mathrm{n}$ & 4 & 4 & 4 & 4 & 3 & 3 & 3 & 3 \\
\hline & Media & 15,7 & 5,0 & 3,85 & 1,6 & 15,6 & 4,9 & 3,9 & 1,55 \\
\hline & $\sigma$ & 0,513 & 0,143 & 0,062 & 0,049 & 0,252 & 0,064 & 0,118 & 0,032 \\
\hline & Mín. & 15,25 & 4,8 & 3,8 & 1,55 & 15,3 & 4,8 & 3,8 & 1,5 \\
\hline & Máx. & 16,3 & 5,1 & 3,9 & 1,7 & 15,8 & 5,0 & 4,0 & 1,6 \\
\hline \multirow{5}{*}{ Ficedula hypoleuca } & $\mathrm{n}$ & 14 & 13 & 14 & 14 & 5 & 5 & 5 & 5 \\
\hline & Media & 15,1 & 4,8 & 3,7 & 1,55 & 15,1 & 4,8 & 3,7 & 1,5 \\
\hline & $\sigma$ & 0,485 & 0,135 & 0,200 & 0,045 & 0,532 & 0,182 & 0,106 & 0,025 \\
\hline & Mín. & 14,5 & 4,6 & 3,5 & 1,5 & 14,35 & 4,6 & 3,6 & 1,5 \\
\hline & Máx. & 16,2 & 5,0 & 4,2 & 1,6 & 15,7 & 5,0 & 3,9 & 1,5 \\
\hline
\end{tabular}

Tabla 15- Medidas de los húmeros de Muscicapidae. 


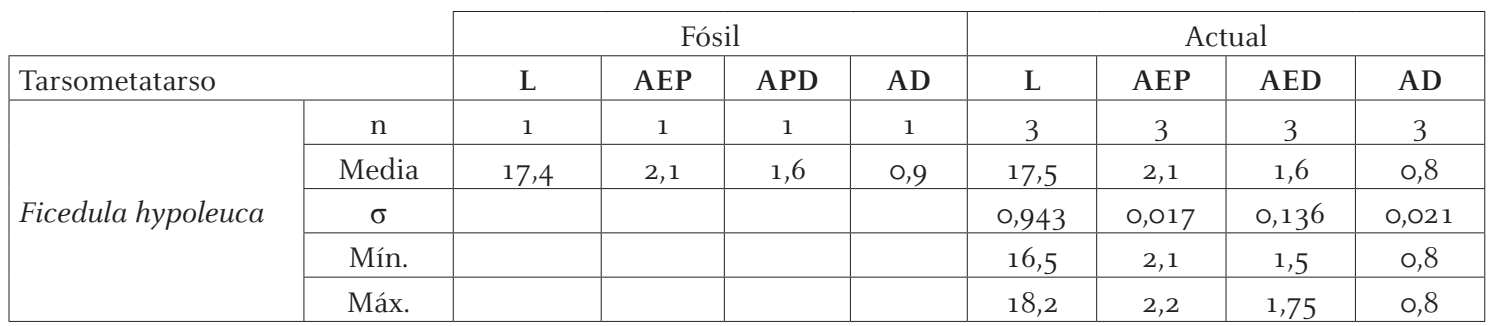

Tabla 16- Medidas de los tarsometatarsos de Muscicapidae.

\begin{tabular}{|c|c|c|c|c|c|c|c|c|c|}
\hline \multirow{2}{*}{ Húmero } & & \multicolumn{4}{|c|}{ Fósil } & \multicolumn{4}{|c|}{ Actual } \\
\hline & & $\mathrm{L}$ & AEP & APD & AD & $\mathrm{L}$ & AEP & APD & $\mathrm{AD}$ \\
\hline \multirow{5}{*}{ Parus ater } & $\mathrm{n}$ & 1 & 1 & 1 & 1 & 2 & 2 & 2 & 2 \\
\hline & Media & 12,75 & 4,1 & 3,1 & 1,4 & 13,25 & 4,05 & 3,3 & 1,4 \\
\hline & $\sigma$ & & & & & 0,064 & 0,049 & 0,177 & 0,092 \\
\hline & Mín. & & & & & 13,2 & 4,0 & 3,2 & 1,3 \\
\hline & Máx. & & & & & 13,3 & 4,1 & 3,4 & 1,4 \\
\hline
\end{tabular}

Tabla 17- Medidas de los húmeros de Paridae.

\begin{tabular}{|c|c|c|c|c|c|c|c|c|c|}
\hline \multirow{3}{*}{\multicolumn{2}{|c|}{ Húmero }} & \multirow{2}{*}{\multicolumn{4}{|c|}{ Fósil }} & \multirow{2}{*}{\multicolumn{4}{|c|}{ Actual }} \\
\hline & & & & & & & & & \\
\hline & & $\mathrm{L}$ & AEP & APD & $\mathrm{AD}$ & $\mathrm{L}$ & AEP & APD & $\mathrm{AD}$ \\
\hline \multirow{5}{*}{ Oriolus oriolus } & $\mathrm{n}$ & 1 & 1 & 1 & 1 & 4 & 4 & 4 & 4 \\
\hline & Media & 30,2 & 8,9 & 7,1 & 3,1 & 30,9 & 9,6 & 7,3 & 3,2 \\
\hline & $\sigma$ & & & & & 0,574 & 0,329 & 0,210 & 0,095 \\
\hline & Mín. & & & & & 30,3 & 9,25 & 7,1 & 3,1 \\
\hline & Máx. & & & & & 31,5 & 10,0 & 7,6 & 3,3 \\
\hline
\end{tabular}

Tabla 18- Medidas de los húmeros de Oriolidae.

\begin{tabular}{|c|c|c|c|c|c|c|c|c|c|}
\hline \multirow{2}{*}{\multicolumn{2}{|c|}{ Cráneo y mandíbula }} & \multicolumn{3}{|c|}{ Fósil } & \multicolumn{3}{|c|}{ Actual } & \multicolumn{2}{|c|}{ Moreno } \\
\hline & & LM & $\mathrm{C}$ & DI & LM & C & DI & LM & $\mathrm{C}$ \\
\hline \multirow{5}{*}{ Lanius meridionalis } & $\mathrm{n}$ & 1 & & 1 & 3 & & 3 & 7 & \\
\hline & Media & 34,4 & & 7,25 & 36,8 & & 7,3 & 38,2 & \\
\hline & $\sigma$ & & & & 0,950 & & 0,635 & 1,08 & \\
\hline & Mín. & & & & 35,8 & & 6,8 & 36,4 & \\
\hline & Máx. & & & & 37,7 & & 8,0 & 39,3 & \\
\hline \multirow{5}{*}{ Lanius senator } & $\mathrm{n}$ & 3 & 11 & & 9 & 9 & & 4 & 4 \\
\hline & Media & 28,9 & 16,8 & & 30,0 & 17,2 & & 28,7 & 16,6 \\
\hline & $\sigma$ & 0,430 & 0,500 & & 0,989 & 0,719 & & 1,210 & 0,370 \\
\hline & Mín. & 28,45 & 16,1 & & 28,6 & 16,0 & & 27,1 & 16,2 \\
\hline & Máx. & 29,3 & 17,5 & & 31,4 & 18,2 & & 30,0 & 17,1 \\
\hline
\end{tabular}

Tabla 19- Medidas de los cráneos y mandíbulas de Laniidae. 


\begin{tabular}{|c|c|c|c|c|c|c|c|c|c|}
\hline \multirow{2}{*}{\multicolumn{2}{|c|}{ Húmero }} & \multicolumn{4}{|c|}{ Fósil } & \multicolumn{4}{|c|}{ Actual } \\
\hline & & $\mathrm{L}$ & AEP & APD & $\mathrm{AD}$ & $\mathrm{L}$ & AEP & AED & $A D$ \\
\hline \multirow{5}{*}{ Lanius meridionalis } & $\mathrm{n}$ & 3 & 3 & 3 & 3 & 2 & 2 & 2 & 2 \\
\hline & Media & 25,55 & 7,6 & 6,4 & 2,5 & 25,1 & 7,3 & 5,9 & 2,3 \\
\hline & $\sigma$ & 0,469 & 0,166 & 0,111 & 0,030 & 0,332 & 0,170 & 0,099 & 0,106 \\
\hline & Mín. & 25,2 & 7,45 & 6,3 & 2,4 & 24,8 & 7,2 & 5,9 & 2,2 \\
\hline & Máx. & 26,1 & 7,8 & 6,5 & 2,5 & 25,3 & 7,45 & 6,0 & 2,3 \\
\hline \multirow{5}{*}{ Lanius senator } & $\mathrm{n}$ & 151 & 143 & 146 & 151 & 9 & 8 & 9 & 9 \\
\hline & Media & 22,7 & 6,6 & 5,1 & 2,0 & 22,5 & 6,45 & 5,0 & 2,0 \\
\hline & $\sigma$ & 0,480 & 0,171 & 0,203 & 0,094 & 0,806 & 0,221 & 0,120 & 0,089 \\
\hline & Mín. & 21,2 & 6,2 & 4,6 & 1,8 & 21,4 & 6,1 & 4,75 & 1,8 \\
\hline & Máx. & 23,7 & 7,0 & 6,3 & 2,35 & 23,5 & 6,8 & 5,15 & 2,2 \\
\hline
\end{tabular}

Tabla 20- Medidas de los húmeros de Laniidae.

\begin{tabular}{|c|c|c|c|c|c|c|c|c|c|}
\hline \multirow{3}{*}{\multicolumn{2}{|c|}{ Tarsometatarso }} & \multirow{2}{*}{\multicolumn{4}{|c|}{ Fósil }} & \multirow{2}{*}{\multicolumn{4}{|c|}{ Actual }} \\
\hline & & & & & & & & & \\
\hline & & \multirow{2}{*}{$\begin{array}{l}\mathrm{L} \\
1\end{array}$} & \multirow{2}{*}{$\begin{array}{c}\text { AEP } \\
1 \\
\end{array}$} & \multirow{2}{*}{$\begin{array}{c}\text { APD } \\
1\end{array}$} & \multirow{2}{*}{$\begin{array}{c}\mathrm{AD} \\
1 \\
\end{array}$} & \multirow{2}{*}{$\begin{array}{l}\mathrm{L} \\
2\end{array}$} & \multirow{2}{*}{$\begin{array}{c}\text { AEP } \\
2 \\
\end{array}$} & \multirow{2}{*}{$\begin{array}{c}\text { AED } \\
2\end{array}$} & \multirow{2}{*}{$\begin{array}{c}\text { AD } \\
2 \\
\end{array}$} \\
\hline \multirow{5}{*}{ Lanius meridionalis } & $\mathrm{n}$ & & & & & & & & \\
\hline & Media & 29,8 & 4,0 & 2,8 & 1,6 & 29,7 & 4,2 & 2,85 & 1,6 \\
\hline & $\sigma$ & & & & & 0,891 & 0,021 & 0,148 & 0,035 \\
\hline & Mín. & & & & & 29,1 & 4,2 & 2,7 & 1,6 \\
\hline & Máx. & & & & & 30,3 & 4,2 & 2,95 & 1,6 \\
\hline \multirow{5}{*}{ Lanius senator } & $\mathrm{n}$ & 9 & 9 & 6 & 9 & 10 & 10 & 10 & 10 \\
\hline & Media & 24,6 & 3,4 & 2,5 & 1,4 & 23,95 & 3,3 & 2,3 & 1,3 \\
\hline & $\sigma$ & 0,394 & 0,085 & 0,073 & 0,075 & 0,713 & 0,136 & 0,110 & 0,089 \\
\hline & Mín. & 23,9 & 3,3 & 2,3 & 1,3 & 22,65 & 3,1 & 2,1 & 1,2 \\
\hline & Máx. & 25,2 & 3,6 & 2,55 & 1,6 & 25,2 & 3,5 & 2,5 & 1,5 \\
\hline
\end{tabular}

Tabla 21- Medidas de los tarsometatarsos de Laniidae.

\begin{tabular}{|c|c|c|c|c|c|c|c|c|c|c|}
\hline \multicolumn{2}{|l|}{ Cráneo y mandíbula } & LM & $\mathrm{C}$ & $\mathrm{C} 2$ & LC & LCB & $\mathrm{LC} 2$ & AM & DI & LS \\
\hline \multirow{5}{*}{$\begin{array}{l}\text { Pyrrhocorax } \\
\text { pyrrhocorax, } \\
\text { fósil }\end{array}$} & $\mathrm{n}$ & 1 & 2 & 6 & 1 & 1 & 3 & 2 & 3 & 10 \\
\hline & Media & 61,6 & 40,9 & 32,8 & 73,5 & 66,0 & 35,9 & 12,5 & 9,8 & 18,4 \\
\hline & $\sigma$ & & 0,424 & 1,689 & & & 0,971 & 0,707 & 0,608 & 1,951 \\
\hline & Mín. & & 40,6 & 31,0 & & & 35,1 & 12,0 & 9,4 & 16,1 \\
\hline & Máx. & & 41,2 & 35,0 & & & 37,0 & 13,0 & 10,5 & 22,6 \\
\hline \multirow{5}{*}{$\begin{array}{l}\text { Pyrrhocorax } \\
\text { pyrrhocorax, } \\
\text { actual }\end{array}$} & $\mathrm{n}$ & 2 & 3 & 3 & 3 & 3 & 3 & 3 & 3 & 2 \\
\hline & Media & 61,7 & 44,0 & 31,5 & 77,7 & 71,0 & 36,0 & 10,1 & 9,6 & 20,2 \\
\hline & $\sigma$ & 2,588 & 2,002 & 1,775 & 3,050 & 3,143 & 0,863 & 0,552 & 1,295 & 2,001 \\
\hline & Mín. & 59,85 & 42,8 & 29,9 & 75,6 & 69,05 & 35,4 & 9,5 & 8,15 & 18,8 \\
\hline & Máx. & 63,5 & 46,3 & 33,4 & 81,2 & 74,6 & 37,0 & 10,5 & 10,5 & 21,6 \\
\hline \multirow{5}{*}{$\begin{array}{l}\text { Pyrrhocorax } \\
\text { pyrrhocorax, Moreno }\end{array}$} & $\mathrm{n}$ & 1 & 1 & & 1 & 1 & & & 1 & \\
\hline & Media & 68,8 & 49,7 & & 83,15 & 77,45 & & & 9,65 & \\
\hline & $\sigma$ & & & & & & & & & \\
\hline & Mín. & & & & & & & & & \\
\hline & Máx. & & & & & & & & & \\
\hline
\end{tabular}




\begin{tabular}{|c|c|c|c|c|c|c|c|c|c|c|}
\hline \multirow{5}{*}{ Corvus corax, fósil } & $\mathrm{n}$ & 4 & 7 & 15 & 2 & 2 & 7 & 7 & 6 & 7 \\
\hline & Media & 82,4 & 57,6 & 31,4 & 104,4 & 94,85 & 46,6 & 16,3 & 18,7 & 18,0 \\
\hline & $\sigma$ & 4,040 & 4,431 & 2,244 & 7,212 & 8,273 & 0,832 & 1,412 & 2,365 & 1,083 \\
\hline & Mín. & 77,0 & 53,1 & 27,3 & 99,3 & 89,0 & 45,5 & 14,3 & 15,7 & 16,0 \\
\hline & Máx. & 86,8 & 63,3 & 35,3 & 109,5 & 100,7 & 47,8 & 18,2 & 22,7 & 19,0 \\
\hline \multirow{5}{*}{ Corvus corax, actual } & $\mathrm{n}$ & 10 & 14 & 15 & 12 & 12 & 13 & 14 & 13 & 10 \\
\hline & Media & 94,1 & 67,8 & 38,8 & 112,3 & 103,0 & 49,4 & 18,45 & 21,9 & 21,7 \\
\hline & $\sigma$ & 3,629 & 2,664 & 2,305 & 4,098 & 4,287 & 1,049 & 0,944 & 1,452 & 1,644 \\
\hline & Mín. & 89,2 & 62,5 & 33,0 & 105,6 & 96,65 & 47,6 & 16,9 & 18,7 & 18,4 \\
\hline & Máx. & 99,75 & 70,8 & 42,0 & 117,3 & 108,1 & 50,9 & 19,7 & 24,0 & 24,5 \\
\hline \multirow{5}{*}{$\begin{array}{l}\text { Corvus corax, } \\
\text { Moreno }\end{array}$} & $\mathrm{n}$ & 4 & 4 & & 4 & 4 & & & 4 & \\
\hline & Media & 97,8 & 70,25 & & 114,5 & 107,2 & & & 22,0 & \\
\hline & $\sigma$ & 4,266 & 2,685 & & 5,037 & 4,472 & & & 1,64 & \\
\hline & Mín. & 93,8 & 68,7 & & 111,15 & 104,25 & & & 19,8 & \\
\hline & Máx. & 103,7 & 74,25 & & 122,0 & 113,75 & & & 23,65 & \\
\hline
\end{tabular}

Tabla 22- Medidas de los cráneos y mandíbulas de Corvidae.

\begin{tabular}{|c|c|c|c|c|c|c|c|c|c|}
\hline \multirow{2}{*}{\multicolumn{2}{|c|}{ Húmero }} & \multicolumn{4}{|c|}{ Fósil } & \multicolumn{4}{|c|}{ Actual } \\
\hline & & $\mathrm{L}$ & AEP & APD & $\mathrm{AD}$ & $\mathrm{L}$ & AEP & AED & $\mathrm{AD}$ \\
\hline \multirow{5}{*}{ Pyrrhocorax graculus } & $\mathrm{n}$ & 7 & 7 & 9 & 8 & 1 & 1 & 1 & 1 \\
\hline & Media & 43,4 & 13,3 & 11,4 & 4,7 & 43,5 & 13,5 & 11,2 & 4,8 \\
\hline & $\sigma$ & 1,949 & 0,424 & 0,528 & 0,248 & & & & \\
\hline & Mín. & 41,6 & 12,8 & 10,45 & 4,4 & & & & \\
\hline & Máx. & 46,6 & 14 & 12,1 & 5,0 & & & & \\
\hline \multirow{5}{*}{ Pyrrhocorax pyrrhocorax } & $\mathrm{n}$ & 32 & 44 & 39 & 36 & 3 & 3 & 3 & 3 \\
\hline & Media & 52,7 & 14,1 & 12,5 & 5,1 & 54,4 & 15,3 & 12,5 & 5,4 \\
\hline & $\sigma$ & 1,858 & 0,484 & 0,512 & 0,265 & 1,312 & 0,815 & 0,416 & 0,332 \\
\hline & Mín. & 49,8 & 13,1 & 11,6 & 4,5 & 53,6 & 14,6 & 12,2 & 5,1 \\
\hline & Máx. & 58,0 & 15,2 & 13,4 & 5,5 & 55,9 & 16,2 & 13,0 & 5,8 \\
\hline \multirow{5}{*}{ Corvus monedula } & $\mathrm{n}$ & 1 & 1 & 2 & 1 & 5 & 5 & 5 & 5 \\
\hline & Media & 47,0 & 13,4 & 10,7 & 4,75 & 47,15 & 13,6 & 10,9 & 4,7 \\
\hline & $\sigma$ & & & 0,085 & & 1,094 & 0,251 & 0,199 & 0,141 \\
\hline & Mín. & & & 10,7 & & 46,2 & 13,3 & 10,7 & 4,5 \\
\hline & Máx. & & & 10,8 & & 48,9 & 13,9 & 11,2 & 4,9 \\
\hline \multirow{5}{*}{ Corvus corax } & $\mathrm{n}$ & 221 & 229 & 332 & 355 & 16 & 16 & 16 & 16 \\
\hline & Media & 82,9 & 21,6 & 17,15 & 7,4 & 90,8 & 24,7 & 19,8 & 8,3 \\
\hline & $\sigma$ & 2,916 & 0,948 & 0,937 & 0,519 & 2,284 & 0,948 & 0,752 & 0,303 \\
\hline & Mín. & 75,7 & 19,4 & 14,9 & 6,0 & 87,95 & 23,5 & 18,5 & 7,9 \\
\hline & Máx. & 91,5 & 25,2 & 27,8 & 10,2 & 94,6 & 26,35 & 21,6 & 9,0 \\
\hline
\end{tabular}

Tabla 23- Medidas de los húmeros de Corvidae. 


\begin{tabular}{|c|c|c|c|c|c|c|c|c|c|}
\hline \multirow{3}{*}{ Ulna } & & \multirow{2}{*}{\multicolumn{4}{|c|}{ Fósil }} & \multirow{2}{*}{\multicolumn{4}{|c|}{ Actual }} \\
\hline & & & & & & & & & \\
\hline & & \multirow[t]{2}{*}{$\mathrm{L}$} & \multirow[t]{2}{*}{ AEP } & \multirow{2}{*}{ APD } & \multirow{2}{*}{$\begin{array}{c}\mathrm{AD} \\
1\end{array}$} & \multirow[t]{2}{*}{$\mathrm{L}$} & \multirow[t]{2}{*}{ AEP } & \multirow{2}{*}{$\begin{array}{c}\text { AED } \\
1\end{array}$} & \multirow{2}{*}{$\begin{array}{c}\mathrm{AD} \\
1 \\
\end{array}$} \\
\hline \multirow{5}{*}{ Pyrrhocorax graculus } & $\mathrm{n}$ & & & & & & & & \\
\hline & Media & & & 7,4 & 4,0 & & & 7,6 & 3,85 \\
\hline & $\sigma$ & & & & & & & & \\
\hline & Mín. & & & & & & & & \\
\hline & Máx. & & & & & & & & \\
\hline \multirow{5}{*}{ Pyrrhocorax pyrrhocorax } & $\mathrm{n}$ & 3 & 6 & 8 & 10 & 2 & 2 & 2 & 2 \\
\hline & Media & 66,6 & 8,6 & 8,0 & 4,0 & 67,4 & 8,9 & 8,0 & 4,3 \\
\hline & $\sigma$ & 2,948 & 0,379 & 0,230 & 0,187 & 0,707 & 0,346 & 0,028 & 0,028 \\
\hline & Mín. & 64,3 & 8,0 & 7,5 & 3,7 & 66,9 & 8,6 & 8,0 & 4,3 \\
\hline & Máx. & 69,9 & 9,0 & 8,2 & 4,4 & 67,9 & 9,1 & 8,0 & 4,3 \\
\hline \multirow{5}{*}{ Corvus corax } & $\mathrm{n}$ & 187 & 275 & 303 & 380 & 10 & 10 & 10 & 10 \\
\hline & Media & 99,6 & 12,25 & 11,5 & 5,3 & 110,8 & 14,0 & 12,8 & 6,3 \\
\hline & $\sigma$ & 3,114 & 0,641 & 0,655 & 0,375 & 2,579 & 0,846 & 0,433 & 0,308 \\
\hline & Mín. & 91,2 & 10,3 & 10,0 & 4,1 & 107,7 & 12,7 & 12,2 & 5,7 \\
\hline & Máx. & 107,1 & 14,1 & 18,8 & 6,5 & 115,2 & 15,05 & 13,5 & 6,6 \\
\hline
\end{tabular}

Tabla 24- Medidas de las ulnas de Corvidae.

\begin{tabular}{|c|c|c|c|c|c|c|c|c|c|}
\hline \multirow{2}{*}{\multicolumn{2}{|c|}{ Carpometacarpo }} & \multicolumn{4}{|c|}{ Fósil } & \multicolumn{4}{|c|}{ Actual } \\
\hline & & $\mathrm{L}$ & AEP & APD & AD & $\mathrm{L}$ & AEP & AED & $\mathrm{AD}$ \\
\hline \multirow{5}{*}{ Pyrrhocorax pyrrhocorax } & $\mathrm{n}$ & 71 & 72 & 72 & 88 & 3 & 3 & 3 & 3 \\
\hline & Media & 37,9 & 8,9 & 8,9 & 3,1 & 40,1 & 9,4 & 9,4 & 3,4 \\
\hline & $\sigma$ & 1,547 & 0,453 & 0,547 & 0,220 & 2,150 & 0,288 & 0,671 & 0,163 \\
\hline & Mín. & 34,4 & 7,5 & 7,6 & 2,5 & 38,6 & 9,1 & 8,9 & 3,2 \\
\hline & Máx. & 41,0 & 9,7 & 9,9 & 3,6 & 42,6 & 9,65 & 10,2 & 3,5 \\
\hline \multirow{5}{*}{ Corvus corone } & $\mathrm{n}$ & 3 & 3 & 3 & 3 & 1 & 1 & 1 & 1 \\
\hline & Media & 48,4 & 11,2 & 10,7 & 3,6 & 49,8 & 11,6 & 11,5 & 4,1 \\
\hline & $\sigma$ & 1,261 & 0,532 & 0,570 & 0,212 & & & & \\
\hline & Mín. & 47,4 & 10,7 & 10,1 & 3,45 & & & & \\
\hline & Máx. & 49,8 & 11,8 & 11,2 & 3,8 & & & & \\
\hline \multirow{5}{*}{ Corvus corax } & $\mathrm{n}$ & 221 & 267 & 222 & 291 & 12 & 12 & 12 & 12 \\
\hline & Media & 60,0 & 13,0 & 12,8 & 4,45 & 67,7 & 14,7 & 14,2 & 5,3 \\
\hline & $\sigma$ & 2,336 & 0,642 & 0,574 & 0,326 & 1,810 & 0,691 & 0,702 & 0,369 \\
\hline & Mín. & 52,4 & 11,3 & 10,7 & 3,6 & 64,1 & 13,8 & 12,6 & 4,6 \\
\hline & Máx. & 66,5 & 14,6 & 14,0 & 5,7 & 70,0 & 15,8 & 15,0 & 5,7 \\
\hline
\end{tabular}

Tabla 25- Medidas de los carpometacarpos de Corvidae.

\begin{tabular}{|c|c|c|c|c|c|c|c|c|c|}
\hline & & \multicolumn{4}{|c|}{ Fósil } & \multicolumn{4}{|c|}{ Actual } \\
\hline \multicolumn{2}{|l|}{ Fémur } & $\mathrm{L}$ & AEP & APD & $\mathrm{AD}$ & $\mathrm{L}$ & AEP & AED & AD \\
\hline \multirow{5}{*}{ Pyrrhocorax pyrrhocorax } & $\mathrm{n}$ & 51 & 60 & 57 & 65 & 3 & 3 & 3 & 3 \\
\hline & Media & 41,05 & 8,4 & 9,1 & 3,7 & 41,55 & 8,8 & 9,3 & 4,0 \\
\hline & $\sigma$ & 1,402 & 0,374 & 0,396 & 0,197 & 0,346 & 0,851 & $0,45^{6}$ & 0,429 \\
\hline & Mín. & 38,2 & 7,3 & 8,3 & 3,4 & 41,3 & 8,3 & 8,8 & 3,6 \\
\hline & Máx. & 43,6 & 9,1 & 9,8 & 4,2 & 41,9 & 9,8 & 9,7 & 4,5 \\
\hline
\end{tabular}




\begin{tabular}{|c|c|c|c|c|c|c|c|c|c|}
\hline & $\mathrm{n}$ & 239 & 282 & 276 & 312 & 12 & 12 & 12 & 12 \\
\cline { 2 - 11 } & Media & 61,0 & 12,6 & 13,0 & 5,45 & 68,3 & 13,8 & 14,5 & 6,1 \\
\cline { 2 - 11 } Corvus corax & $\sigma$ & 2,171 & 0,730 & 0,598 & 0,310 & 1,506 & 0,673 & 0,650 & 0,301 \\
\cline { 2 - 11 } & Mín. & 56,3 & 8,6 & 10,2 & 4,4 & 65,6 & 12,45 & 13,5 & 5,6 \\
\cline { 2 - 10 } & Máx. & 67,4 & 14,1 & 14,3 & 6,4 & 71,5 & 14,7 & 15,5 & 6,7 \\
\hline
\end{tabular}

Tabla 26- Medidas de los fémures de Corvidae.

\begin{tabular}{|c|c|c|c|c|c|c|c|c|c|}
\hline \multirow{3}{*}{\multicolumn{2}{|c|}{ Tibiotarso }} & \multirow{2}{*}{\multicolumn{4}{|c|}{ Fósil }} & \multirow{2}{*}{\multicolumn{4}{|c|}{ Actual }} \\
\hline & & & & & & & & & \\
\hline & & \multirow{2}{*}{$\begin{array}{c}\mathrm{L} \\
18 \\
\end{array}$} & \multirow{2}{*}{$\begin{array}{c}\text { AEP } \\
29 \\
\end{array}$} & \multirow{2}{*}{$\begin{array}{c}\text { APD } \\
42 \\
\end{array}$} & \multirow{2}{*}{$\begin{array}{c}\mathrm{AD} \\
50\end{array}$} & \multirow{2}{*}{$\begin{array}{l}\mathrm{L} \\
3 \\
\end{array}$} & \multirow{2}{*}{$\begin{array}{c}\text { AEP } \\
3 \\
\end{array}$} & \multirow{2}{*}{$\begin{array}{c}\text { AED } \\
3 \\
\end{array}$} & \multirow{2}{*}{$\begin{array}{c}\mathrm{AD} \\
3 \\
\end{array}$} \\
\hline \multirow{5}{*}{ Pyrrhocorax graculus } & $\mathrm{n}$ & & & & & & & & \\
\hline & Media & 74,5 & 8,2 & 6,9 & 3,5 & 78,1 & 8,6 & 7,4 & 3,6 \\
\hline & $\sigma$ & 2,949 & 0,596 & 0,412 & 0,230 & 4,024 & 0,315 & 0,465 & 0,391 \\
\hline & Mín. & 70,6 & 6,7 & 5,9 & 3,0 & 75,7 & 8,3 & 7,1 & 3,4 \\
\hline & Máx. & 79,1 & 9,4 & 7,6 & 4,2 & 82,8 & 8,9 & 7,95 & 4,1 \\
\hline \multirow{5}{*}{ Corvus corax } & $\mathrm{n}$ & 110 & 168 & 219 & 264 & 14 & 14 & 14 & 14 \\
\hline & Media & 103,9 & 11,65 & 10,3 & 5,15 & 117,4 & 13,0 & 12,1 & 6,3 \\
\hline & $\sigma$ & 4,416 & 0,850 & 0,572 & 0,329 & 2,295 & 0,512 & 0,471 & 0,323 \\
\hline & Mín. & 93,9 & 9,8 & 8,9 & 4,4 & 114,0 & 12,1 & 11,45 & 5,7 \\
\hline & Máx. & 112,1 & 14,8 & 12,1 & 6,4 & 120,5 & 13,8 & 13,2 & 6,9 \\
\hline
\end{tabular}

Tabla 27- Medidas de los tibiotarsos de Corvidae.

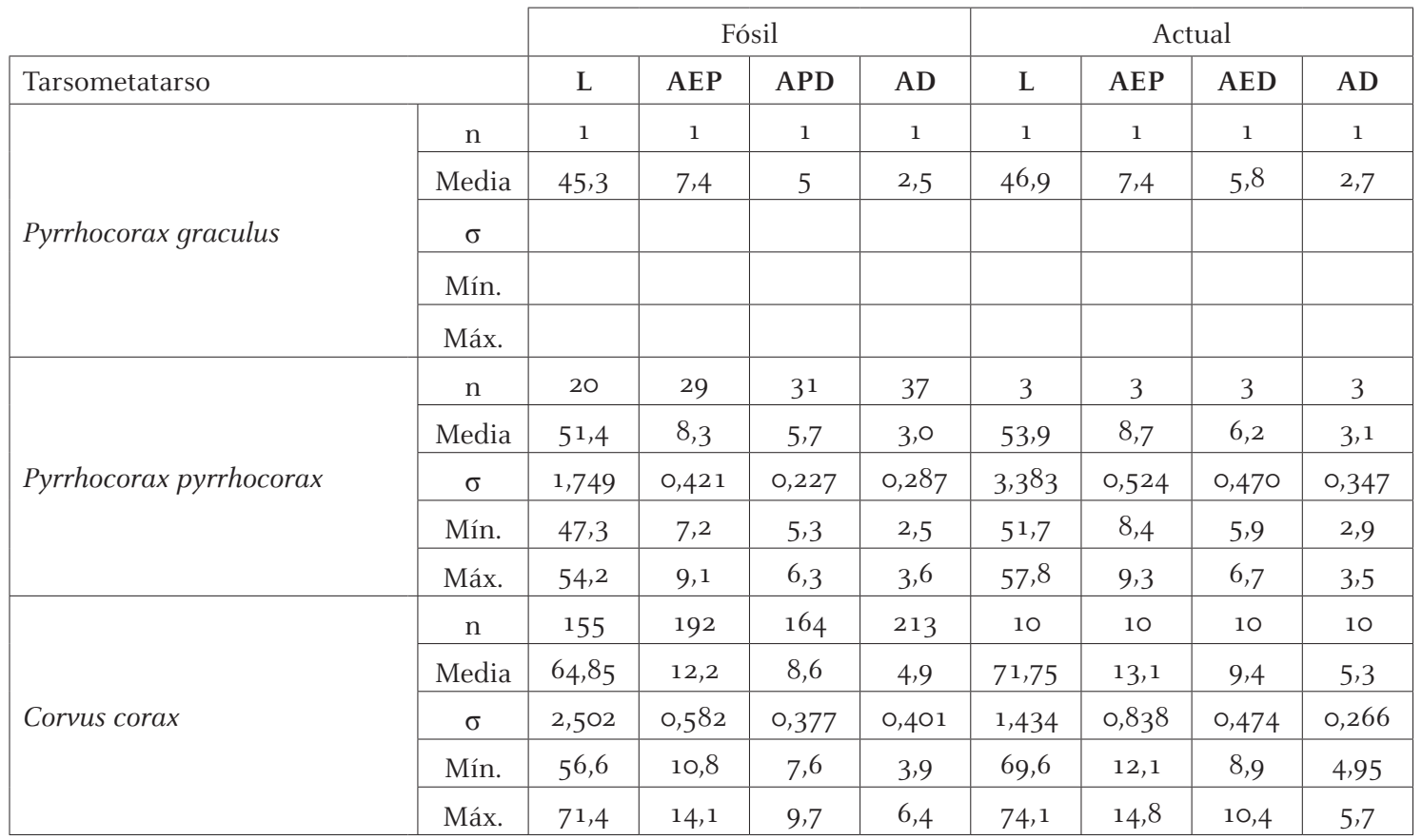

Tabla 28- Medidas de los tarsometatarsos de Corvidae. 


\begin{tabular}{|c|c|c|c|c|c|c|c|}
\hline \multicolumn{2}{|l|}{ Cráneo y mandíbula } & LM & $\mathrm{C}$ & $\mathrm{Cn}$ & LC & LCB & DI \\
\hline \multirow{5}{*}{ Petronia petronia, fósil } & $\mathrm{n}$ & 1 & 5 & 4 & 1 & 1 & 1 \\
\hline & Media & 20,9 & 15,15 & 11,7 & 30 & 25,2 & 5,9 \\
\hline & $\sigma$ & & 1,600 & 0,346 & & & \\
\hline & Mín. & & 13,0 & 11,4 & & & \\
\hline & Máx. & & 16,9 & 12,2 & & & \\
\hline \multirow{5}{*}{ Petronia petronia, actual } & $\mathrm{n}$ & 2 & 2 & 2 & 2 & 2 & 2 \\
\hline & Media & 22,0 & 14,4 & 11,5 & 31,3 & 26,8 & 6,3 \\
\hline & $\sigma$ & 0,403 & 0,417 & 0,255 & 0,035 & 0,325 & 0,530 \\
\hline & Mín. & 21,75 & 14,1 & 11,3 & 31,3 & 26,5 & 5,9 \\
\hline & Máx. & 22,3 & 14,7 & 11,7 & 31,35 & 27,0 & 6,6 \\
\hline \multirow{5}{*}{ Petronia petronia, Moreno } & $\mathrm{n}$ & 5 & 4 & & 4 & 4 & \\
\hline & Media & 23,4 & 15,5 & & 31,8 & 27,3 & \\
\hline & $\sigma$ & 0,867 & 0,970 & & 0,620 & 0,880 & \\
\hline & Mín. & 22,45 & 14,3 & & 31,1 & 26,2 & \\
\hline & Máx. & 24,6 & 16,65 & & 32,5 & 28,2 & \\
\hline
\end{tabular}

Tabla 29- Medidas de los cráneos y mandíbulas de Passeridae.

\begin{tabular}{|c|c|c|c|c|c|c|c|c|c|}
\hline \multirow{2}{*}{\multicolumn{2}{|c|}{ Húmero }} & \multicolumn{4}{|c|}{ Fósil } & \multicolumn{4}{|c|}{ Actual } \\
\hline & & $\mathrm{L}$ & AEP & APD & $\mathrm{AD}$ & $\mathrm{L}$ & AEP & APD & AD \\
\hline \multirow{5}{*}{ Passer domesticus } & $\mathrm{n}$ & 1 & 1 & 1 & 1 & 29 & 29 & 29 & 29 \\
\hline & Media & 18,7 & 6,1 & 3,9 & 1,8 & 18,55 & 6,0 & 4,3 & 1,8 \\
\hline & $\sigma$ & & & & & 0,531 & 0,195 & 0,147 & 0,085 \\
\hline & Mín. & & & & & 17,4 & 5,6 & 3,9 & 1,7 \\
\hline & Máx. & & & & & 19,5 & 6,3 & 4,6 & 2,0 \\
\hline \multirow{5}{*}{ Montifringilla nivalis } & $\mathrm{n}$ & 1 & 1 & 1 & 1 & 4 & 4 & 3 & 4 \\
\hline & Media & 21,9 & 7,1 & 5,4 & 2,2 & 22,5 & 7,5 & 5,65 & 2,3 \\
\hline & $\sigma$ & & & & & 0,496 & 0,109 & 0,056 & 0,019 \\
\hline & Mín. & & & & & 22,0 & 7,4 & 5,6 & 2,3 \\
\hline & Máx. & & & & & 22,9 & 7,6 & 5,7 & 2,3 \\
\hline
\end{tabular}

Tabla 30- Medidas de los húmeros de Passeridae. 


\begin{tabular}{|c|c|c|c|c|c|c|c|c|c|c|c|}
\hline & & \multicolumn{4}{|c|}{ Fósil } & \multicolumn{4}{|c|}{ IMEDEA } & \multicolumn{2}{|c|}{ Moreno } \\
\hline \multicolumn{2}{|l|}{ Cráneo y mandíbula } & LM & $\mathrm{C}$ & $\mathrm{Cn}$ & LCB & LM & $\mathrm{C}$ & Cn & LCB & LM & $\mathrm{C}$ \\
\hline \multirow{5}{*}{ Chloris chloris } & $\mathrm{n}$ & 1 & 6 & 7 & 1 & 27 & 27 & 27 & 11 & 10 & 9 \\
\hline & Media & 21,3 & 14,1 & 11,2 & 24,1 & 21,9 & 14,9 & 11,9 & 25,3 & 21,8 & 14,3 \\
\hline & $\sigma$ & & 0,768 & 0,404 & & 0,617 & 0,484 & 0,489 & 0,825 & 0,45 & 0,51 \\
\hline & Mín. & & 12,8 & 10,7 & & 20,4 & 13,9 & 10,75 & 24,3 & 21,0 & 13,6 \\
\hline & Máx. & & 14,9 & 11,7 & & 23,0 & 15,6 & 12,9 & 27,2 & 22,5 & 15,25 \\
\hline \multirow{5}{*}{ Caduelis cannabina } & $\mathrm{n}$ & 5 & 6 & 2 & & 21 & 21 & 21 & & 10 & 12 \\
\hline & Media & 15,6 & 9,9 & 8,15 & & 16,5 & 10,9 & 9,2 & & 17,1 & 10,6 \\
\hline & $\sigma$ & 0,469 & 0,257 & 0,354 & & 0,444 & 0,513 & 0,325 & & 0,407 & $0,15^{2}$ \\
\hline & Mín. & 15,0 & 9,6 & 7,9 & & 15,4 & 10,3 & 8,6 & & 16,25 & 10,3 \\
\hline & Máx. & 16,3 & 10,3 & 8,4 & & 17,3 & 12,2 & 9,9 & & 17,55 & 10,9 \\
\hline \multirow{5}{*}{ Loxia curvirostra } & $\mathrm{n}$ & & & 1 & & & & 5 & & & \\
\hline & Media & & & 12,9 & & & & 13,8 & & & \\
\hline & $\sigma$ & & & & & & & 0,5145 & & & \\
\hline & Mín. & & & & & & & 13,3 & & & \\
\hline & Máx. & & & & & & & 14,6 & & & \\
\hline
\end{tabular}

Tabla 31- Medidas de los cráneos y mandíbulas de Fringillidae.

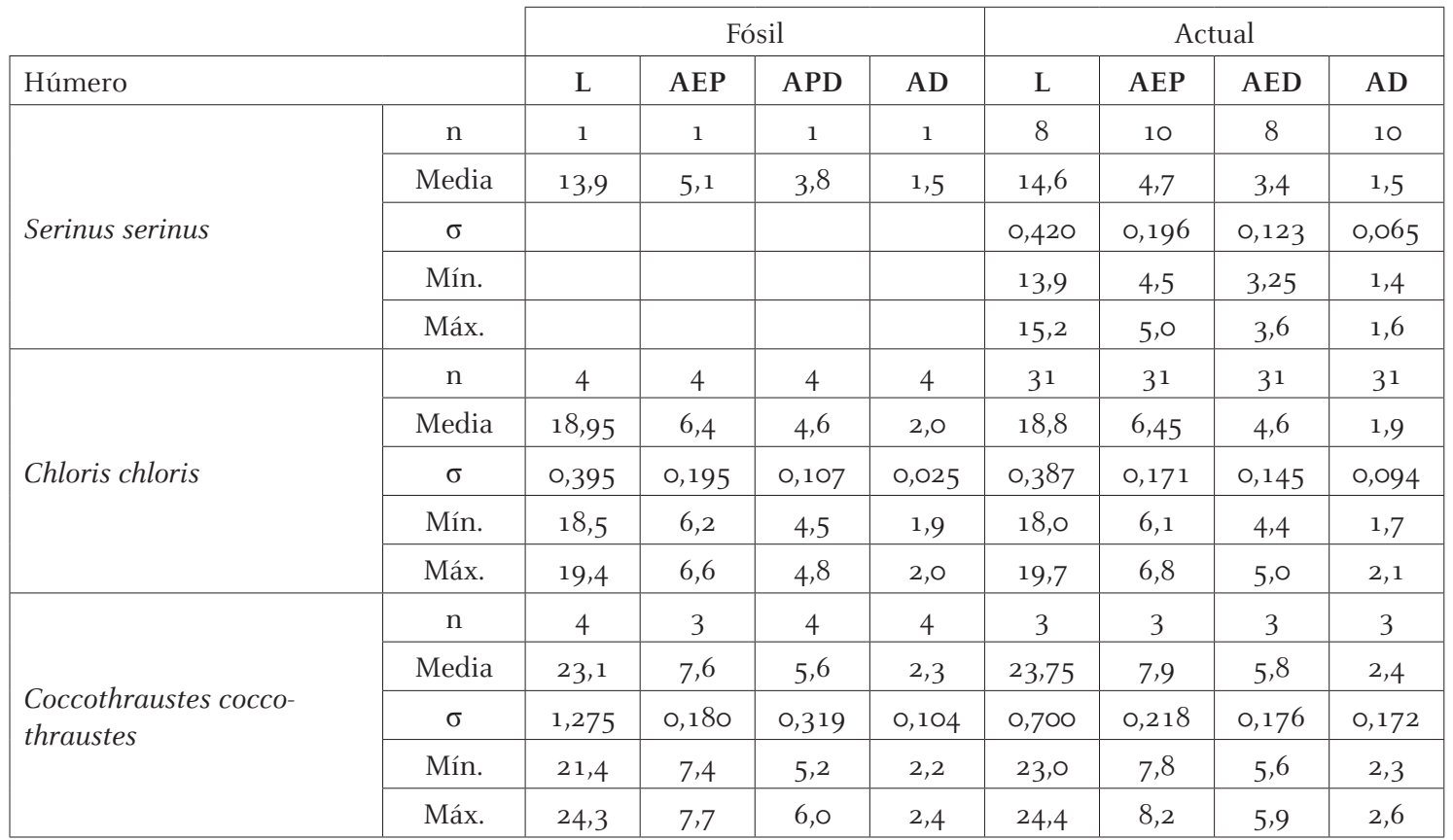

Tabla 32- Medidas de los húmeros de Fringillidae.

\begin{tabular}{|c|c|c|c|c|c|c|c|c|c|}
\hline \multirow{2}{*}{\multicolumn{2}{|c|}{ Tarsometatarso }} & \multicolumn{4}{|c|}{ Fósil } & \multicolumn{4}{|c|}{ Actual } \\
\hline & & $\mathrm{L}$ & AEP & APD & $\mathrm{AD}$ & $\mathrm{L}$ & AEP & AED & $\mathrm{AD}$ \\
\hline \multirow{5}{*}{ Caduelis cannabina } & $\mathrm{n}$ & 4 & 4 & 4 & 4 & 22 & 22 & 22 & 22 \\
\hline & Media & 15,9 & 2,5 & 1,9 & 0,9 & 16,0 & 2,5 & 1,9 & 0,8 \\
\hline & $\sigma$ & 0,457 & 0,116 & 0,058 & 0,040 & 0,526 & 0,076 & 0,091 & 0,046 \\
\hline & Mín. & 15,3 & 2,3 & 1,9 & 0,9 & 14,95 & 2,3 & 1,7 & 0,8 \\
\hline & Máx. & 15,7 & 2,6 & 1,9 & 0,9 & 16,9 & 2,6 & 2,1 & 1,0 \\
\hline
\end{tabular}

Tabla 33- Medidas de los tarsometatarsos de Fringillidae. 


\begin{tabular}{|c|c|c|c|c|c|c|c|c|c|}
\hline \multirow{2}{*}{\multicolumn{2}{|c|}{ Húmero }} & \multicolumn{4}{|c|}{ Fósil } & \multicolumn{4}{|c|}{ Actual } \\
\hline & & $\mathrm{L}$ & AEP & APD & $A D$ & $\mathrm{~L}$ & AEP & APD & $A D$ \\
\hline \multirow{5}{*}{ Emberiza pusilla } & $\mathrm{n}$ & 1 & 1 & 1 & 1 & 1 & 1 & 1 & 1 \\
\hline & Media & 15,95 & 5,2 & 4,0 & 1,6 & 16,6 & 5,2 & 3,7 & 1,6 \\
\hline & $\sigma$ & & & & & & & & \\
\hline & Mín. & & & & & & & & \\
\hline & Máx. & & & & & & & & \\
\hline \multirow{5}{*}{ Emberiza calandra } & $\mathrm{n}$ & 20 & 20 & 20 & 20 & 11 & 11 & 11 & 11 \\
\hline & Media & 23,9 & 7,8 & 5,6 & 2,3 & 23,5 & 7,4 & 5,3 & 2,1 \\
\hline & $\sigma$ & 1,344 & 0,346 & 0,262 & 0,135 & 0,952 & 0,426 & 0,306 & 0,103 \\
\hline & Mín. & 22,2 & 7,25 & 5,25 & 2,0 & 22,1 & 6,7 & 4,9 & 2,0 \\
\hline & Máx. & 26,45 & 8,4 & 6,0 & 2,5 & 24,8 & 8,2 & 5,8 & 2,35 \\
\hline
\end{tabular}

Tabla 34- Medidas de los húmeros de Emberizidae.

\begin{tabular}{|c|c|c|c|c|c|c|c|c|c|}
\hline \multirow{3}{*}{\multicolumn{2}{|c|}{ Tarsometatarso }} & \multirow{2}{*}{\multicolumn{4}{|c|}{ Fósil }} & \multirow{2}{*}{\multicolumn{4}{|c|}{ Actual }} \\
\hline & & & & & & & & & \\
\hline & & $\mathrm{L}$ & AEP & APD & AD & $\mathrm{L}$ & AEP & APD & AD \\
\hline \multirow{5}{*}{ Emberiza calandra } & $\mathrm{n}$ & 2 & 2 & 1 & 2 & 9 & 9 & 9 & 8 \\
\hline & Media & 25,5 & 3,45 & 2,7 & 1,5 & 24,1 & 3,4 & 2,65 & 1,3 \\
\hline & $\sigma$ & 1,188 & 0,233 & & 0,113 & 0,731 & 0,164 & 0,122 & 0,085 \\
\hline & Mín. & 24,6 & 3,3 & & 1,4 & 23,0 & 3,1 & 2,5 & 1,2 \\
\hline & Máx. & 26,3 & 3,6 & & 1,5 & 24,9 & 3,6 & 2,85 & 1,45 \\
\hline
\end{tabular}

Tabla 35- Medidas de los tarsometatarsos de Emberizidae. 


\begin{tabular}{|c|c|c|c|c|}
\hline & $\begin{array}{l}\text { H. albicilla } \\
\text { es Pouàs }\end{array}$ & $\begin{array}{c}\text { H. albicilla } \\
\text { Boessneck } 1985 \\
\lesssim ふ / Q \varnothing\end{array}$ & $\begin{array}{c}\text { H. albicilla } \\
\text { Jánossy } 1984\end{array}$ & $\begin{array}{l}\text { Haliaeetus albicilla } \\
\text { Olson \& James } 1991\end{array}$ \\
\hline LM & $110,5 n=1$ & & & $90,4 n=1$ \\
\hline LH & $246,0 \mathrm{n}=1$ & $\begin{array}{c}208,0-219,0 \mathrm{n}=5221, \mathrm{O}- \\
240,0 \mathrm{n}=4\end{array}$ & $213,0-233,0$ & \\
\hline LU & $281,5 \mathrm{n}=2$ & $\begin{array}{c}240,0-249,0 \mathrm{n}=7259,5^{-} \\
273, \mathrm{O} \mathrm{n}=8\end{array}$ & $240,0-265,0$ & $227,7 \mathrm{n}=1$ \\
\hline LR & $268,5 n=1$ & $\begin{aligned} 229,0-232,0 \mathrm{n} & =2235,5^{-} \\
260,0 \mathrm{n} & =5\end{aligned}$ & & $218,8 n=1$ \\
\hline LCMC & $126,6-130,0 \mathrm{n}=3$ & $\begin{array}{c}111,0-116,5 \mathrm{n}=5118,0- \\
123,8 \mathrm{n}=7\end{array}$ & $110,0-123,0$ & $102,4-106,0 \mathrm{n}=2$ \\
\hline LCO & $89,7-98,3 n=5$ & & & $66,4-68,6 n=2$ \\
\hline LF & $133,0-134,1 \quad n=3$ & $\begin{array}{c}115, \mathrm{O}-122, \mathrm{O} n=5122, \mathrm{O}- \\
135, \mathrm{O} \mathrm{n}=5\end{array}$ & & $112,6-115,8 \mathrm{n}=2$ \\
\hline LTB & $184,0 \mathrm{n}=2$ & $\begin{array}{c}154,0-165,0 \mathrm{n}=5 \quad 165,5^{-} \\
177, \mathrm{O} n=3\end{array}$ & & $154,1 \mathrm{n}=1$ \\
\hline LTMT & $102,7-107,2 \mathrm{n}=3$ & $\begin{array}{c}93,0-99,5 n=7 \\
96,0-106,0 n=8\end{array}$ & $92,0-107,7$ & $90,4-90,6 n=2$ \\
\hline АЕРТМТ & $23,2-25,3 \mathrm{n}=3$ & $\begin{array}{l}19,5-21,5 n=7 \\
22,0-24,0 \mathrm{n}=9\end{array}$ & & $21,4 \mathrm{n}=1$ \\
\hline AEDTMT & $25,9-30,9 n=3$ & $\begin{array}{c}22,2-24,0 \mathrm{n}=7 \\
25,0-27,5 \mathrm{n}=13\end{array}$ & & $24,2 \mathrm{n}=1$ \\
\hline ADTMT & $12,5^{-14,4} \mathrm{n}=3$ & $\begin{array}{l}10,0-10,7 \mathrm{n}=8 \\
10,3-12,0 \mathrm{n}=9\end{array}$ & & $12,4 \mathrm{n}=1$ \\
\hline
\end{tabular}

Tabla 36- Medidas de los huesos principales de Haliaeetus albicilla de Ibiza en comparación con otras poblaciones de la especie (Alcover \& McMinn 1992). LM: longitud mandibular; LH: longitud del húmero; LU: longitud de la ulna; LR: longitud del radio; LCMC: longitud del carpometacarpo; LCO: longitud del coracoides; LF: longitud del fémur; LTB: longitud del tibiotarso; LTMT: longitud del tarsometatarso; AEPTMT: anchura de la epífisis proximal del tarsometatarso; AEDTMT: anchura de la epífisis distal del tarsometatarso; ADTMT: anchura (mínima) de la diáfisis del tarsometatarso. Olson \& James 1991 identificaron los restos de Haliaeetus de Hawái como Haliaeetus sp. Posteriormente, el estudio molecular de estos restos (Fleischer et al. 2000) demostró su atribución a H. albicilla.

\begin{tabular}{|l|c|c|c|c|c|}
\cline { 2 - 6 } \multicolumn{1}{c|}{} & \multicolumn{2}{c|}{$\overline{\mathrm{X}}(\mathrm{N})$} & GL & $\mathrm{F}$ & $\mathrm{P}$ \\
\hline & Fósil & Actual & & & \\
\hline L & $82,59^{ \pm 0,56(17)}$ & $90,84^{ \pm 0,57(16)}$ & 1,31 & 107,3 & $<0,01$ \\
\hline AEP & $21,36 \pm 0,19(15)$ & $24,71 \pm 0,24(16)$ & 1,29 & 120 & $<0,01$ \\
\hline AED & $17,24 \pm 0,15(17)$ & $19,84^{ \pm 0,19(16)}$ & 1,31 & 115,8 & $<0,01$ \\
\hline AD & $7,42 \pm 0,11(17)$ & $8,33^{ \pm 0,07(16)}$ & 1,31 & 46,4 & $<0,01$ \\
\hline IR & $8,98 \pm 0,12(17)$ & $9,17^{ \pm 0,06}(16)$ & 1,31 & 1,8 & 0,188 \\
\hline
\end{tabular}

Tabla 37- Corvus corax, resultados del ANOVA para los húmeros. 


\begin{tabular}{|l|c|c|c|c|c|}
\cline { 2 - 6 } \multicolumn{1}{c|}{} & \multicolumn{2}{c|}{$\overline{\mathrm{X}}(\mathrm{N})$} & GL & $\mathrm{F}$ & $\mathrm{P}$ \\
\hline & Fósil & Actual & & & \\
\hline $\mathrm{L}$ & $100,28 \pm 0,65(29)$ & $110,76 \pm 0,82(10)$ & 1,37 & 74,1 & $<0,01$ \\
\hline AEP & $12,41^{ \pm 0,12(26)}$ & $14,01 \pm 0,27(10)$ & 1,34 & 39,5 & $<0,01$ \\
\hline AED & $11,54^{ \pm 0,1(27)}$ & $12,79 \pm 0,14(10)$ & 1,35 & 46,2 & $<0,01$ \\
\hline AD & $5,35^{ \pm 0,08} 8(29)$ & $6,27 \pm 0,1(10)$ & 1,37 & 42,1 & $<0,01$ \\
\hline IR & $5,34^{ \pm 0,08}(29)$ & $5,66 \pm 0,07(10)$ & 1,37 & 5,6 & $<0,05$ \\
\hline
\end{tabular}

Tabla 38-Corvus corax, resultados del ANOVA para las ulnas.

\begin{tabular}{|l|c|c|c|c|c|}
\cline { 2 - 6 } \multicolumn{1}{c|}{} & \multicolumn{2}{c|}{$\overline{\mathrm{X}}(\mathrm{N})$} & GL & $\mathrm{F}$ & $\mathrm{P}$ \\
\hline & Fósil & Actual & & & \\
\hline L & $60,15^{ \pm 0,32(40)}$ & $67,72 \pm 0,52(12)$ & 1,50 & 132,31 & $<0,01$ \\
\hline AEP & $13,12 \pm 0,09(40)$ & $14,74^{ \pm 0,2(12)}$ & 1,50 & 66,06 & $<0,01$ \\
\hline AED & $12,89 \pm 0,07(32)$ & $14,2 \pm 0,2(12)$ & 1,42 & 57,53 & $<0,01$ \\
\hline AD & $4,44^{ \pm 0,04(40)}$ & $5,3^{ \pm 0,11(12)}$ & 1,50 & 82,31 & $<0,01$ \\
\hline IR & $7,3^{ \pm} \pm 0,07(40)$ & $7,83^{ \pm 0,13(12)}$ & 1,50 & 9,81 & $<0,01$ \\
\hline
\end{tabular}

Tabla 39- Corvus corax, resultados del ANOVA para los carpometacarpos.

\begin{tabular}{|l|c|c|c|c|c|}
\cline { 2 - 6 } \multicolumn{1}{c|}{} & \multicolumn{2}{c|}{$\bar{X}(\mathrm{~N})$} & GL & F & P \\
\hline & Fósil & Actual & & & \\
\hline L & $60,76 \pm 0,27(51)$ & $68,29 \pm 0,43(12)$ & 1,61 & 163,3 & $<0,01$ \\
\hline \multicolumn{1}{|c|}{ AEP } & $12,66 \pm 0,09(51)$ & $13,79 \pm 0,19(12)$ & 1,61 & 30,7 & $<0,01$ \\
\hline AED & $13^{ \pm 0,07(50)}$ & $14,47 \pm 0,19(12)$ & 1,60 & 71,3 & $<0,01$ \\
\hline AD & $5,42 \pm 0,04(49)$ & $6,14 \pm 0,09(12)$ & 1,59 & 72,6 & $<0,01$ \\
\hline IR & $8,92 \pm 0,05(49)$ & $8,99^{ \pm 0,08}(12)$ & 1,59 & 0,3 & 0,576 \\
\hline
\end{tabular}

Tabla 40- Corvus corax, resultados del ANOVA para los fémures.

\begin{tabular}{|l|c|c|c|c|c|}
\cline { 2 - 6 } \multicolumn{1}{c|}{} & \multicolumn{2}{c|}{$\bar{X}(\mathrm{~N})$} & GL & F & P \\
\hline Fósil & Actual & & & \\
\hline AEP & $103,71 \pm 0,89(16)$ & $117,41 \pm 0,61(14)$ & 1,28 & 152,1 & $<0,01$ \\
\hline AED & $11,47 \pm 0,14(15)$ & $13,03^{ \pm 0,14}(14)$ & 1,27 & 65,5 & $<0,01$ \\
\hline AD & $5,07 \pm 0,07(16)$ & $6,3^{ \pm 0,09}(14)$ & 1,28 & 116,5 & $<0,01$ \\
\hline IR & $4,89 \pm 0,06(16)$ & $5,36 \pm 0,06(14)$ & 1,28 & 27,8 & $<0,01$ \\
\hline
\end{tabular}

Tabla 41-Corvus corax, resultados del ANOVA para los tibiotarsos. 


\begin{tabular}{|l|c|c|c|c|c|}
\cline { 2 - 6 } \multicolumn{1}{c|}{} & \multicolumn{2}{c|}{$\overline{\mathrm{X}}(\mathrm{N})$} & GL & $\mathrm{F}$ & $\mathrm{P}$ \\
\hline & Fósil & Actual & & & \\
\hline L & $64,82 \pm 0,44(32)$ & $71,75^{ \pm 0,45(10)}$ & 1,40 & 70,1 & $<0,01$ \\
\hline AEP & $12,29 \pm 0,09(31)$ & $13,10 \pm 0,26(10)$ & 1,39 & 13,6 & $<0,01$ \\
\hline AED & $8,54^{ \pm 0,07(29)}$ & $9,41 \pm 0,15(10)$ & 1,37 & 34,6 & $<0,01$ \\
\hline AD & $4,79^{ \pm 0,07(32)}$ & $5,31 \pm 0,08(10)$ & 1,40 & 14,1 & $<0,01$ \\
\hline IR & $7,4^{ \pm 0,11(32)}$ & $7,4^{ \pm 0,1(10)}$ & 1,40 & 0 & 0,997 \\
\hline
\end{tabular}

Tabla 42- Corvus corax, resultados del ANOVA para los tarsometatarsos.

\begin{tabular}{|l|c|c|c|c|c|}
\cline { 2 - 6 } \multicolumn{1}{c|}{} & \multicolumn{2}{c|}{$\overline{\mathrm{X}}(\mathrm{N})$} & GL & $\mathrm{F}$ & $\mathrm{P}$ \\
\hline & Fósil & Actual & & & \\
\hline L & $52,79^{ \pm 0,64}(7)$ & $54,4^{ \pm 0,75}(3)$ & 1,8 & 2,08 & 0,19 \\
\hline AEP & $14,14^{ \pm 0,25}(7)$ & $15,28 \pm 0,47(3)$ & 1,8 & 5,65 & 0,04 \\
\hline AED & $12,73^{ \pm 0,22}(7)$ & $12,53^{ \pm 0,24}(3)$ & 1,8 & 0,28 & 0,61 \\
\hline AD & $5,15^{ \pm 0,14}(6)$ & $5,4^{ \pm 0,19}(3)$ & 1,7 & 1,1 & 0,33 \\
\hline IR & $9,71 \pm 0,14(6)$ & $9,92 \pm 0,23(3)$ & 1,7 & 0,64 & 0,45 \\
\hline
\end{tabular}

Tabla 43-Pyrrhocorax pyrrhocorax, resultados del ANOVA para los húmeros.

\begin{tabular}{|l|c|c|c|}
\hline & $\begin{array}{c}\text { U de } \\
\text { Mann-Whitney }\end{array}$ & Z & $\begin{array}{c}\text { Sig. asintót. } \\
\text { (bilateral) }\end{array}$ \\
\hline L & 4 & $-1,48$ & 1,14 \\
\hline AEP & 2 & $-1,94$ & 0,05 \\
\hline AED & 8 & $-0,57$ & 0,57 \\
\hline AD & 5 & $-1,05$ & 0,29 \\
\hline IR & 6 & $-0,77$ & 0,44 \\
\hline
\end{tabular}

Tabla 44- Pyrrhocorax pyrrhocorax, resultados del test no paramétrico para los húmeros.

\begin{tabular}{|l|c|c|c|c|c|}
\cline { 2 - 6 } \multicolumn{1}{c|}{} & \multicolumn{2}{c|}{$\overline{\mathrm{X}}(\mathrm{N})$} & GL & $\mathrm{F}$ & $\mathrm{P}$ \\
\hline \multicolumn{1}{c|}{ Fósil } & Actual & & & \\
\hline L & $37,74 \pm 0,26(42)$ & $40,14 \pm 1,24(3)$ & 1,43 & 5,46 & 0,02 \\
\hline AEP & $8,76 \pm 0,08(37)$ & $9,41 \pm 0,17(3)$ & 1,38 & 4,79 & 0,03 \\
\hline AED & $8,8 \pm 0,1(33)$ & $9,41 \pm 0,39(3)$ & 1,34 & 3,13 & 0,09 \\
\hline AD & $3,11 \pm 0,04(42)$ & $3,36 \pm 0,09(3)$ & 1,43 & 3,13 & 0,08 \\
\hline IR & $8,25 \pm 0,09(42)$ & $8,38 \pm 0,13(3)$ & 1,43 & 0,14 & 0,71 \\
\hline
\end{tabular}

Tabla 45- Pyrrhocorax pyrrhocorax, resultados del ANOVA para los carpometacarpos. 


\begin{tabular}{|l|c|c|c|}
\cline { 2 - 4 } \multicolumn{1}{c|}{} & $\begin{array}{c}\text { U de } \\
\text { Mann-Whitney }\end{array}$ & Z & $\begin{array}{c}\text { Sig. asintót. } \\
\text { (bilateral) }\end{array}$ \\
\hline L & 26 & $-1,68$ & 0,09 \\
\hline AEP & 14 & $-2,13$ & 0,03 \\
\hline AED & 26 & $-1,34$ & 0,18 \\
\hline AD & 19 & $-2,02$ & 0,04 \\
\hline IR & 42 & $-0,95$ & 0,34 \\
\hline
\end{tabular}

Tabla 46- Pyrrhocorax pyrrhocorax, resultados del test no paramétrico para los carpometacarpos.

\begin{tabular}{|l|c|c|c|c|c|}
\cline { 2 - 6 } \multicolumn{1}{c|}{} & \multicolumn{2}{c|}{$\overline{\mathrm{X}}(\mathrm{N})$} & GL & $\mathrm{F}$ & $\mathrm{P}$ \\
\hline Fósil & Actual & & & \\
\hline L & $40,96 \pm 0,3(25)$ & $41,55^{ \pm 0,2(3)}$ & 1,26 & 0,44 & 0,51 \\
\hline AEP & $8,23^{ \pm 0,08(25)}$ & $8,81 \pm 0,49(3)$ & 1,26 & 4,24 & 0,05 \\
\hline AED & $9,01 \pm 0,08(25)$ & $9,27 \pm 0,26(3)$ & 1,26 & 1,17 & 0,29 \\
\hline AD & $3,66 \pm 0,03(25)$ & $3,98 \pm 0,25(3)$ & 1,26 & 7,21 & 0,01 \\
\hline IR & $8,95^{ \pm 0,07(25)}$ & $9,59^{ \pm 0}, 6(3)$ & 1,26 & 5,58 & 0,03 \\
\hline
\end{tabular}

Tabla 47- Pyrrhocorax pyrrhocorax, resultados del ANOVA para los fémures.

\begin{tabular}{|l|c|c|c|}
\cline { 2 - 4 } \multicolumn{1}{c|}{} & $\begin{array}{c}\text { U de } \\
\text { Mann-Whitney }\end{array}$ & Z & $\begin{array}{c}\text { Sig. asintót. } \\
\text { (bilateral) }\end{array}$ \\
\hline L & 28 & $-0,71$ & 0,48 \\
\hline AEP & 22 & $-1,15$ & 0,25 \\
\hline AED & 25 & $-0,93$ & 0,35 \\
\hline AD & 15 & $-1,69$ & 0,09 \\
\hline IR & 21 & $-1,23$ & 0,22 \\
\hline
\end{tabular}

Tabla 48- Pyrrhocorax pyrrhocorax, resultados del test no paramétrico para los fémures.

\begin{tabular}{|l|c|c|c|c|c|}
\cline { 2 - 6 } \multicolumn{1}{c|}{} & \multicolumn{2}{c|}{$\bar{X}(\mathrm{~N})$} & GL & F & P \\
\hline & Fósil & Actual & & & \\
\hline L & $72,62 \pm 2,69(5)$ & $78,14 \pm 2,32(3)$ & 1,6 & 1,93 & 0,21 \\
\hline AEP & $9,06 \pm 0,17(5)$ & $8,61 \pm 0,18(3)$ & 1,6 & 2,81 & 0,14 \\
\hline AED & $7,08 \pm 0,2(5)$ & $7,41 \pm 0,27(3)$ & 1,6 & 1,02 & 0,35 \\
\hline AD & $3,42 \pm 0,05(5)$ & $3,64 \pm 0,23(3)$ & 1,6 & 1,58 & 0,25 \\
\hline IR & $4,73^{ \pm 0,19(5)}$ & $4,65^{ \pm 0,15(3)}$ & 1,6 & 0,09 & 0,78 \\
\hline
\end{tabular}

Tabla 49- Pyrrhocorax pyrrhocorax, resultados del ANOVA para los tibiotarsos. 


\begin{tabular}{|l|c|c|c|}
\cline { 2 - 4 } \multicolumn{1}{c|}{} & $\begin{array}{c}\text { U de } \\
\text { Mann-Whitney }\end{array}$ & Z & $\begin{array}{c}\text { Sig. asintót. } \\
\text { (bilateral) }\end{array}$ \\
\hline L & 4 & $-1,04$ & 0,30 \\
\hline AEP & 2 & $-1,65$ & 0,10 \\
\hline AED & 6 & $-0,46$ & 0,65 \\
\hline AD & 6 & $-0,46$ & 0,64 \\
\hline IR & 6 & $-0,45$ & 0,65 \\
\hline
\end{tabular}

Tabla 50- Pyrrhocorax pyrrhocorax, resultados del test no paramétrico para los tibiotarsos.

\begin{tabular}{|l|c|c|c|c|c|}
\cline { 2 - 6 } \multicolumn{1}{c|}{} & \multicolumn{2}{c|}{$\overline{\mathrm{X}}(\mathrm{N})$} & GL & $\mathrm{F}$ & $\mathrm{P}$ \\
\hline & Fósil & Actual & & & \\
\hline L & $50,41 \pm 0,82(7)$ & $53,92 \pm 1,95(3)$ & 1,8 & 4,01 & 0,08 \\
\hline AEP & $8,31 \pm 0,17(7)$ & $8,73^{ \pm 0,3(3)}$ & 1,8 & 1,61 & 0,24 \\
\hline AED & $5,78 \pm 0,09(6)$ & $6,2 \pm 0,27(3)$ & 1,7 & 3,62 & 0,1 \\
\hline AD & $2,77^{ \pm 0,09}(7)$ & $3,09 \pm 0,2(3)$ & 1,8 & 2,87 & 0,13 \\
\hline IR & $5,5^{ \pm 0}, 16(7)$ & $5,72 \pm 0,16(3)$ & 1,8 & 0,63 & 0,45 \\
\hline
\end{tabular}

Tabla 51- Pyrrhocorax pyrrhocorax, resultados del ANOVA para los tarsometatarsos.

\begin{tabular}{|l|c|c|c|}
\cline { 2 - 4 } \multicolumn{1}{c|}{} & $\begin{array}{c}\text { U de } \\
\text { Mann-Whitney }\end{array}$ & Z & $\begin{array}{c}\text { Sig. asintót. } \\
\text { (bilateral) }\end{array}$ \\
\hline L & 4 & $-1,29$ & 0,20 \\
\hline AEP & 6 & $-0,78$ & 0,44 \\
\hline AED & 4 & $-1,05$ & 0,29 \\
\hline AD & 4 & $-1,30$ & 0,19 \\
\hline IR & 6 & $-0,77$ & 0,44 \\
\hline
\end{tabular}

Tabla 52-Pyrrhocorax pyrrhocorax, resultados del test no paramétrico para los tarsometatarsos. 


\begin{tabular}{|c|c|c|c|c|c|c|}
\hline Species & Element & $\mathrm{A}+\mathrm{B}+\mathrm{I}+$ Sectors & $\mathrm{D}_{4}$ & $\mathrm{E} 11+\mathrm{E} 8$ & $\begin{array}{l}\text { Surface+Out of } \\
\text { context }\end{array}$ & Total \\
\hline \multirow{25}{*}{ Haliaeetus albicilla } & Carpometacarpi & 4 & & & & \multirow{25}{*}{219} \\
\hline & Coracoidea & 12 & & & & \\
\hline & Crania & 2 & & & & \\
\hline & Femora & 8 & & & & \\
\hline & Fibulae & 4 & & & & \\
\hline & Pedal phalanges & 38 & & & & \\
\hline & Humeri & 5 & & & & \\
\hline & Mandibles & 6 & & & & \\
\hline & Metacarpus II & 3 & & & & \\
\hline & Metatarsus I & 3 & & & & \\
\hline & Os lacrimale & 1 & & & & \\
\hline & Pelvis & 6 & & & & \\
\hline & Praemaxillae & 1 & & & & \\
\hline & Quadrati & 3 & & & & \\
\hline & Radiale & 3 & & & & \\
\hline & Radii & 7 & & & & \\
\hline & Ribs & 15 & & & & \\
\hline & Scapulae & 6 & & & & \\
\hline & Sternii & 6 & & & & \\
\hline & Tarsometatarsi & 8 & 1 & & & \\
\hline & Tibiotarsi & 4 & & & & \\
\hline & Ulnae & 11 & & & & \\
\hline & Ulnare & 4 & & & & \\
\hline & Vertebrae & 50 & & & & \\
\hline & Alar phalanges & 8 & & & & \\
\hline cf. Aquila/Haliaeetus & Pedal phalanges & 2 & 1 & & & 3 \\
\hline \multirow{10}{*}{ Circus cyaneus } & Carpometacarpi & 2 & & & & \multirow{10}{*}{19} \\
\hline & Femora & 1 & & & & \\
\hline & Pedal phalanges & 2 & & & & \\
\hline & Humeri & 1 & & & & \\
\hline & Mandibles & 3 & 2 & & & \\
\hline & Scapulae & 1 & & & & \\
\hline & Sterni & 1 & & & & \\
\hline & Tarsometatarsi & 2 & & & & \\
\hline & Tibiotarsi & 2 & & & & \\
\hline & Ulnae & 2 & & & & \\
\hline Accipiter gentilis & Humeri & & 1 & & & 1 \\
\hline cf. Accipiter gentilis & Mandibles & 1 & & & & 1 \\
\hline \multirow{7}{*}{ Accipiter nisus } & Coracoidea & 1 & 1 & & & \multirow{7}{*}{11} \\
\hline & Femora & 1 & & & & \\
\hline & Furculae & & 1 & & & \\
\hline & Mandibles & 2 & & & & \\
\hline & Scapulae & 1 & 1 & & & \\
\hline & Tarsometatarsi & & 1 & & & \\
\hline & Ulnae & & 2 & & & \\
\hline
\end{tabular}




\begin{tabular}{|c|c|c|c|c|c|c|}
\hline \multirow{11}{*}{ Falco naumanni } & Carpometacarpi & 8 & 1 & & & \multirow{11}{*}{81} \\
\hline & Crani & 1 & & & & \\
\hline & Femora & 1 & & & & \\
\hline & Humeri & 5 & & 1 & & \\
\hline & Mandibles & 3 & & & & \\
\hline & Praemaxillae & & 1 & & & \\
\hline & Radii & 1 & & & & \\
\hline & Scapulae & 1 & & & & \\
\hline & Tarsometatarsi & 39 & 1 & & & \\
\hline & Tibiotarsi & 13 & & & & \\
\hline & Ulnae & 4 & 1 & & & \\
\hline \multirow{14}{*}{ Falco tinnunculus } & Carpometacarpi & 35 & 5 & & 1 & \multirow{14}{*}{421} \\
\hline & Coracoidea & 28 & 3 & 2 & & \\
\hline & Femora & 29 & 2 & 2 & & \\
\hline & Humeri & 66 & 7 & 4 & & \\
\hline & Mandibles & 20 & 1 & & & \\
\hline & Pelvis & 1 & & & & \\
\hline & Phalanges & 2 & & & & \\
\hline & Praemaxillae & 9 & 1 & & 1 & \\
\hline & Radii & 4 & 2 & & & \\
\hline & Scapulae & 11 & 7 & & & \\
\hline & Synsacri & 3 & & & & \\
\hline & Tarsometatarsi & 66 & 4 & 2 & 2 & \\
\hline & Tibiotarsi & 53 & 5 & 1 & & \\
\hline & Ulnae & 34 & 7 & & 1 & \\
\hline Falco subbuteo & Humeri & 2 & & & & 2 \\
\hline \multirow{2}{*}{ Falco cf. subbuteo } & Mandibles & 1 & & & & \multirow{2}{*}{2} \\
\hline & Praemaxillae & & 1 & & & \\
\hline Falco eleonorae & Tibiotarsi & 3 & & & & 3 \\
\hline \multirow{5}{*}{ Falco peregrinus } & Carpometacarpi & & 1 & & & \multirow{5}{*}{6} \\
\hline & Coracoidea & & 1 & 1 & & \\
\hline & Mandibles & 1 & & & & \\
\hline & Radii & & 1 & & & \\
\hline & Ulnae & 1 & & & & \\
\hline \multirow{10}{*}{ Falco sp } & Carpometacarpi & 5 & & & & \multirow{10}{*}{66} \\
\hline & Coracoidea & 6 & 1 & & & \\
\hline & Femora & 2 & & & & \\
\hline & Humeri & 12 & & & & \\
\hline & Mandibles & 13 & 1 & & & \\
\hline & Praemaxillae & 1 & & & & \\
\hline & Scapulae & 1 & 1 & & & \\
\hline & Tarsometatarsi & 14 & & & 1 & \\
\hline & Tibiotarsi & 1 & & & & \\
\hline & Ulnae & 6 & 1 & & & \\
\hline
\end{tabular}




\begin{tabular}{|c|c|c|c|c|c|c|}
\hline \multirow{9}{*}{$\begin{array}{l}\text { Falco tinnunculus/nauman- } \\
\text { ni }\end{array}$} & Carpometacarpi & 2 & & & & \multirow{9}{*}{30} \\
\hline & Coracoidea & 5 & & & & \\
\hline & Humeri & 1 & & & & \\
\hline & Mandibles & 5 & & & & \\
\hline & Praemaxillae & 1 & & & & \\
\hline & Scapulae & 6 & 2 & & & \\
\hline & Tarsometatarsi & 3 & & & & \\
\hline & Tibiotarsi & 4 & & & & \\
\hline & Ulnae & 1 & & & & \\
\hline \multirow{8}{*}{ Falco tinnunculus/subbuteo } & Carpometacarpi & 1 & & & & \multirow{8}{*}{25} \\
\hline & Crania & 1 & & & & \\
\hline & Coracoidea & 2 & & & & \\
\hline & Femora & 8 & 1 & & & \\
\hline & Humeri & 5 & & & & \\
\hline & Scapulae & 1 & & & & \\
\hline & Tarsometatarsi & 5 & & & & \\
\hline & Tibiotarsi & 1 & & & & \\
\hline \multirow{2}{*}{ Falco tinnunculus/eleonorae } & Tarsometatarsi & 1 & & & & \multirow{2}{*}{2} \\
\hline & Femora & 1 & & & & \\
\hline \multirow{13}{*}{ Otus scops } & Carpometacarpi & 127 & 3 & & & \multirow{13}{*}{1390} \\
\hline & Crania & & 1 & & & \\
\hline & Coracoidea & 181 & 6 & & & \\
\hline & Femora & 32 & 1 & & & \\
\hline & Furculae & & 1 & & & \\
\hline & Humeri & 250 & 12 & & 1 & \\
\hline & Mandibles & 23 & & & & \\
\hline & Praemaxillae & 13 & 2 & & & \\
\hline & Radii & 23 & & & & \\
\hline & Scapulae & 50 & & & & \\
\hline & Tarsometatarsi & 444 & 15 & 1 & 1 & \\
\hline & Tibiotarsi & 127 & 6 & & & \\
\hline & Ulnae & 65 & 5 & & & \\
\hline \multirow{8}{*}{ Athene noctua } & Carpometacarpi & 3 & & & & \multirow{8}{*}{30} \\
\hline & Coracoidea & 4 & & & & \\
\hline & Humeri & 7 & 1 & & & \\
\hline & Mandibles & 2 & & & & \\
\hline & Praemaxillae & 2 & & & & \\
\hline & Tarsometatarsi & 7 & & & & \\
\hline & Tibiotarsi & 3 & & & & \\
\hline & Ulnae & & 1 & & & \\
\hline
\end{tabular}




\begin{tabular}{|c|c|c|c|c|c|c|}
\hline \multirow{10}{*}{ Asio flammeus } & Coracoidea & 2 & & & & \multirow{10}{*}{45} \\
\hline & Femora & 1 & & & & \\
\hline & Pedal phalanges & 24 & & & & \\
\hline & Humeri & 1 & & & & \\
\hline & Mandibles & 1 & & & & \\
\hline & Praemaxillae & 3 & & & & \\
\hline & Sterni & 1 & & & & \\
\hline & Tarsometatarsi & 1 & & & & \\
\hline & Tibiotarsi & 7 & & & & \\
\hline & Ulnae & 4 & & & & \\
\hline \multirow{2}{*}{ Bubo sp } & Pedal phalanges & 14 & & & & \multirow{2}{*}{15} \\
\hline & Praemaxillae & 1 & & & & \\
\hline Asio sp & Mandibles & 2 & & & & 2 \\
\hline \multirow{6}{*}{ Athene/Otus } & Carpometacarpi & 3 & & & & \multirow{6}{*}{20} \\
\hline & Coracoidea & 6 & & & & \\
\hline & Humeri & 8 & & & & \\
\hline & Praemaxillae & 1 & & & & \\
\hline & Radii & 1 & & & & \\
\hline & Ulnae & 1 & & & & \\
\hline Total & & 2248 & 124 & 14 & 8 & 2394 \\
\hline
\end{tabular}

Table 53. Summarized list of material of Falconiformes and Strigiformes from es Pouàs. 


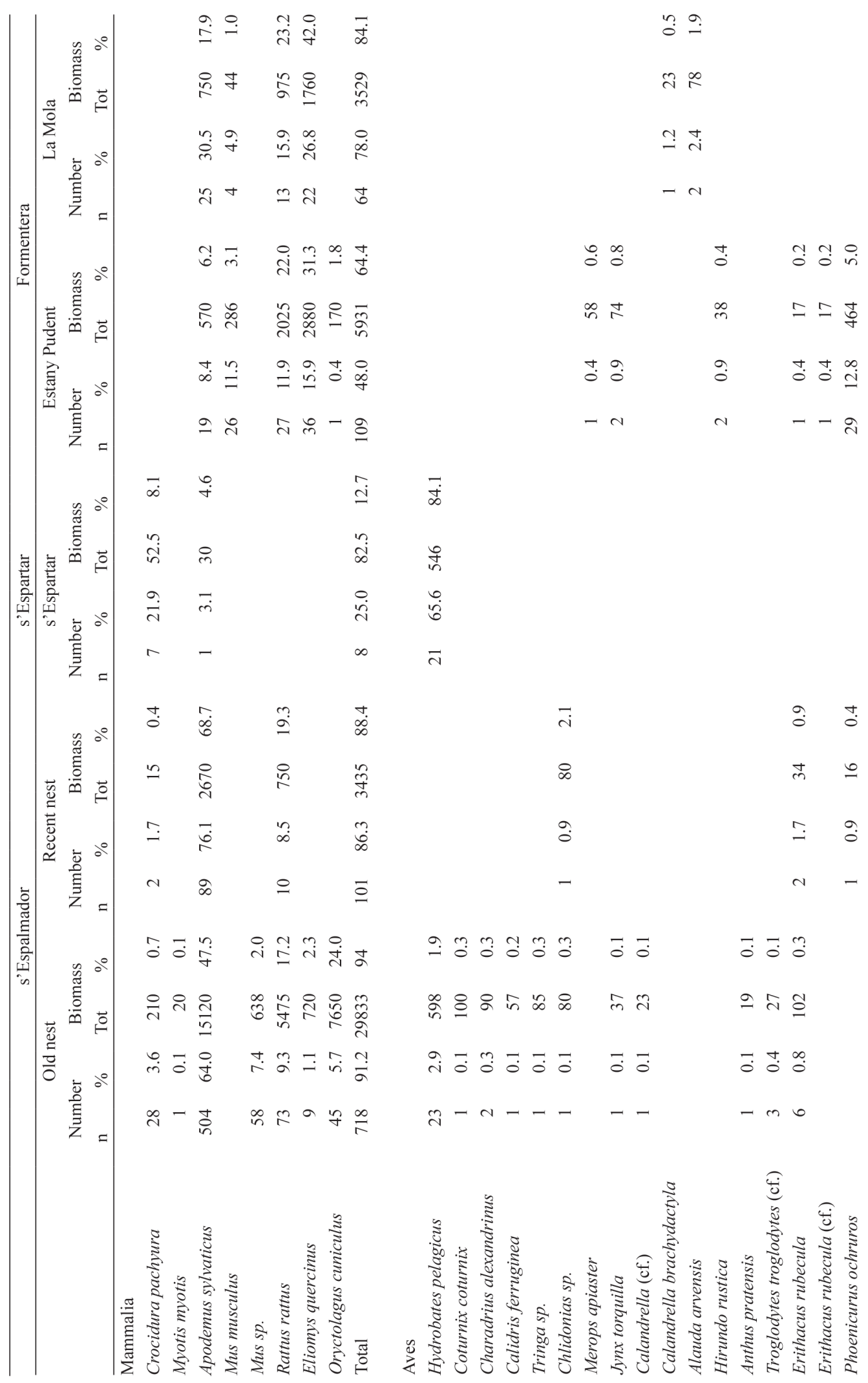

Table 54. Results of the analysis of Tyto alba prey from the study localities. 1) s'Espalmador 1, sediment from old nest (June 2009); 2) s'Espalmador 2, recent nest, pellets (January 2006, April 2007, January 2008); 3) s'Espartar (June 2007); 4) Formentera, quarry close to Estany Pudent (November 2007 and December 2008); 5) Formentera, Torrent des Serverer, La Mola (April 1978). All prey obtained are grouped for each locality. Some birds remain unidentified. An average estimate of the weight of the identified birds was used to calculate the biomass (the effectively consumed biomass must have been smaller, because some of the heavier prey were only partially ingested). Percentages do not add up to 100 because of rounding. 


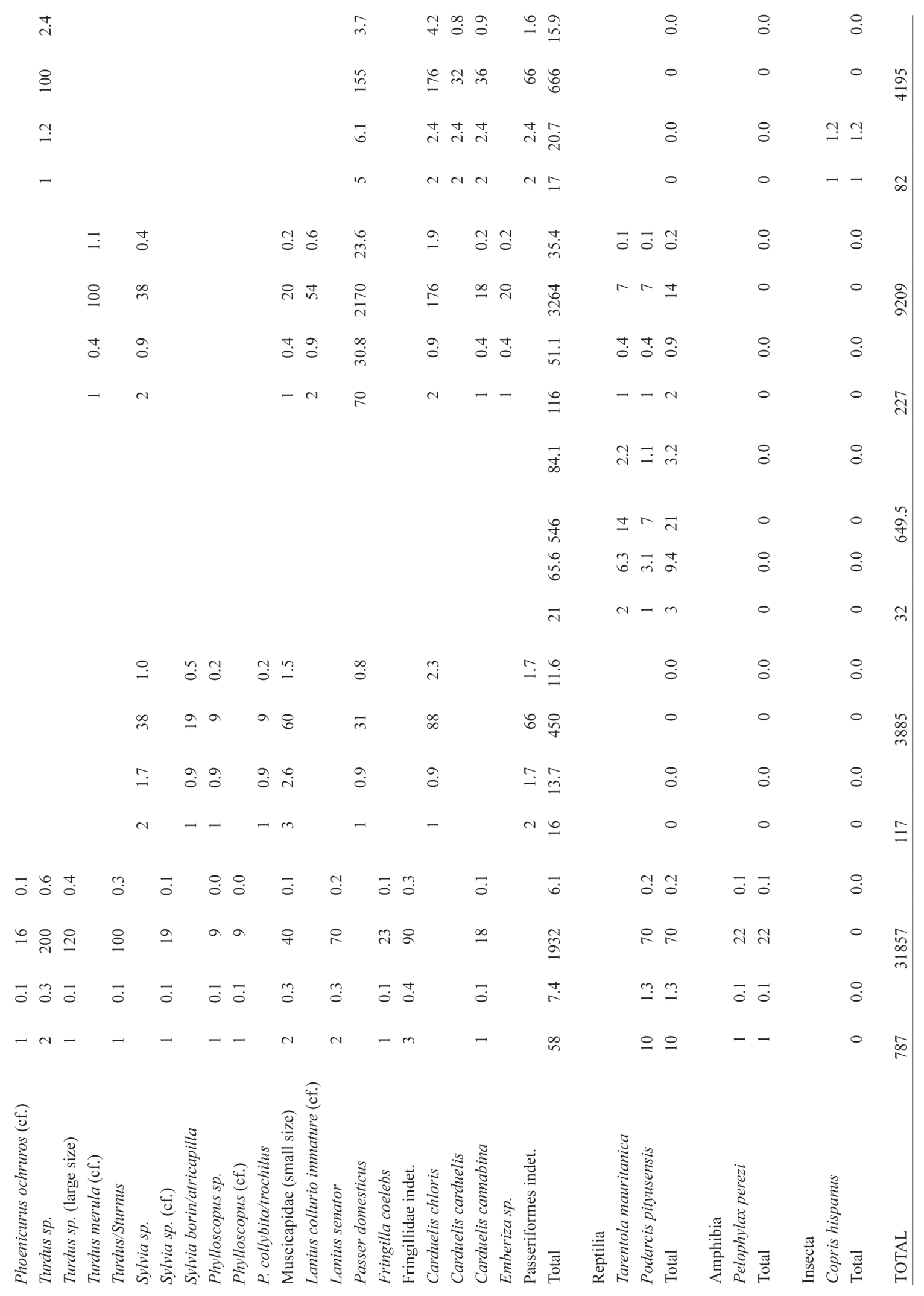





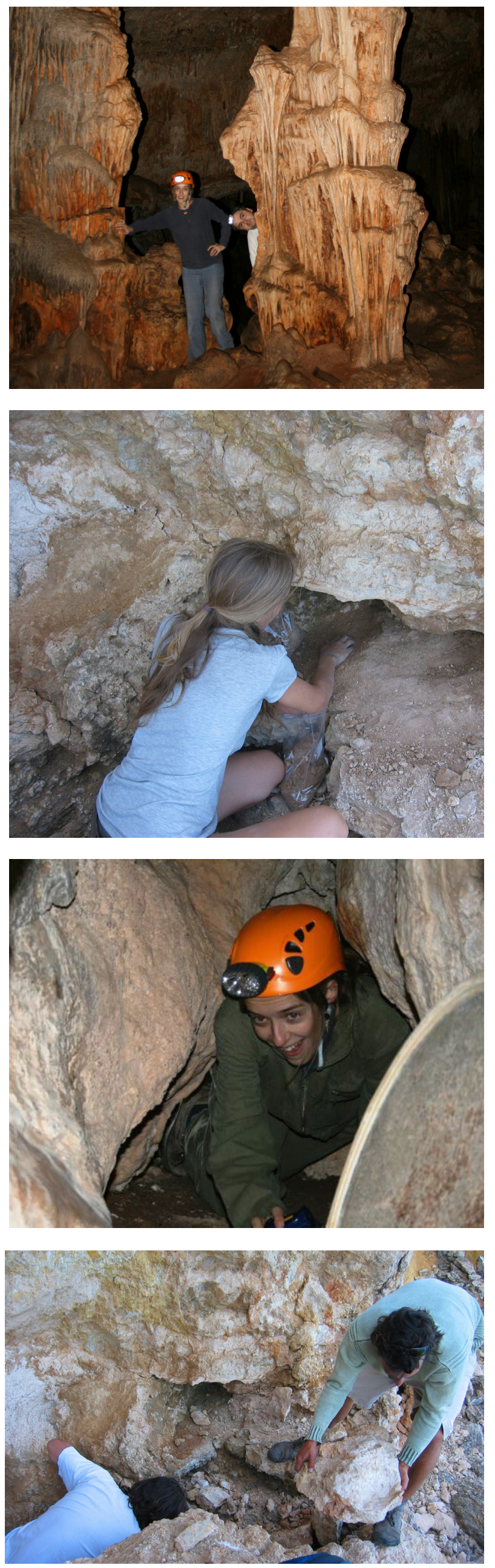
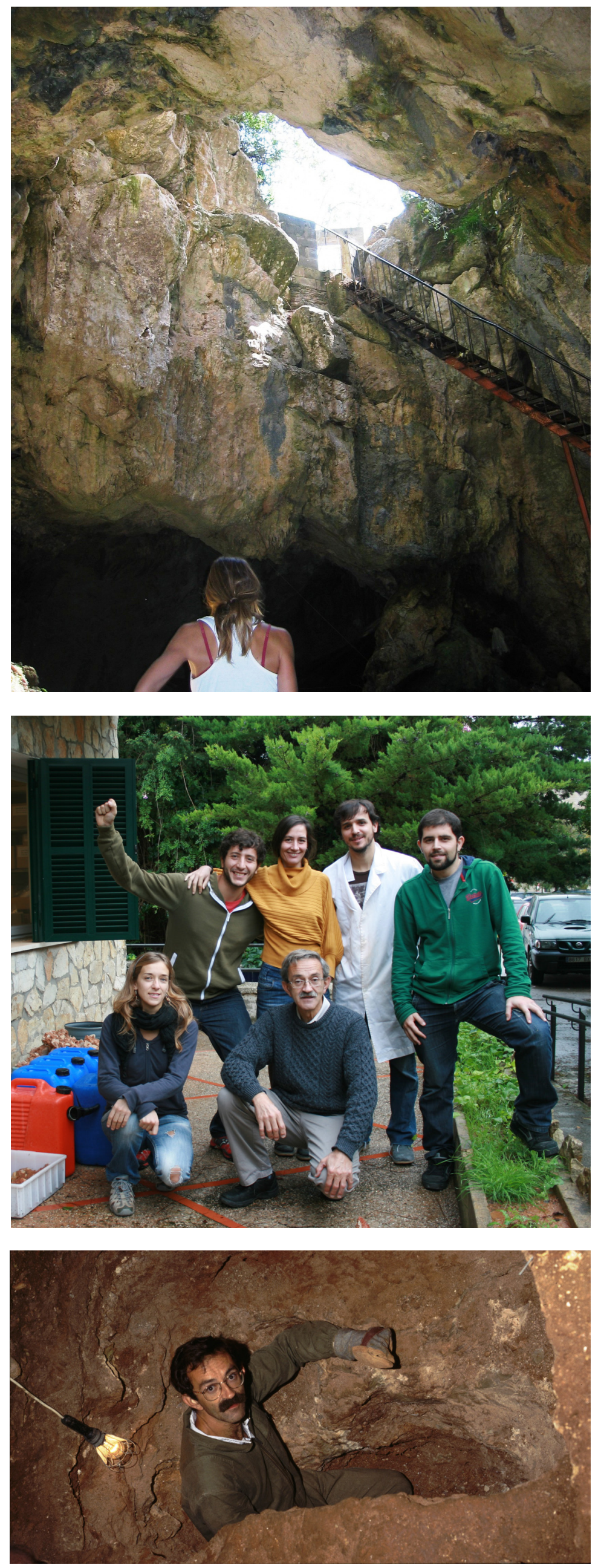

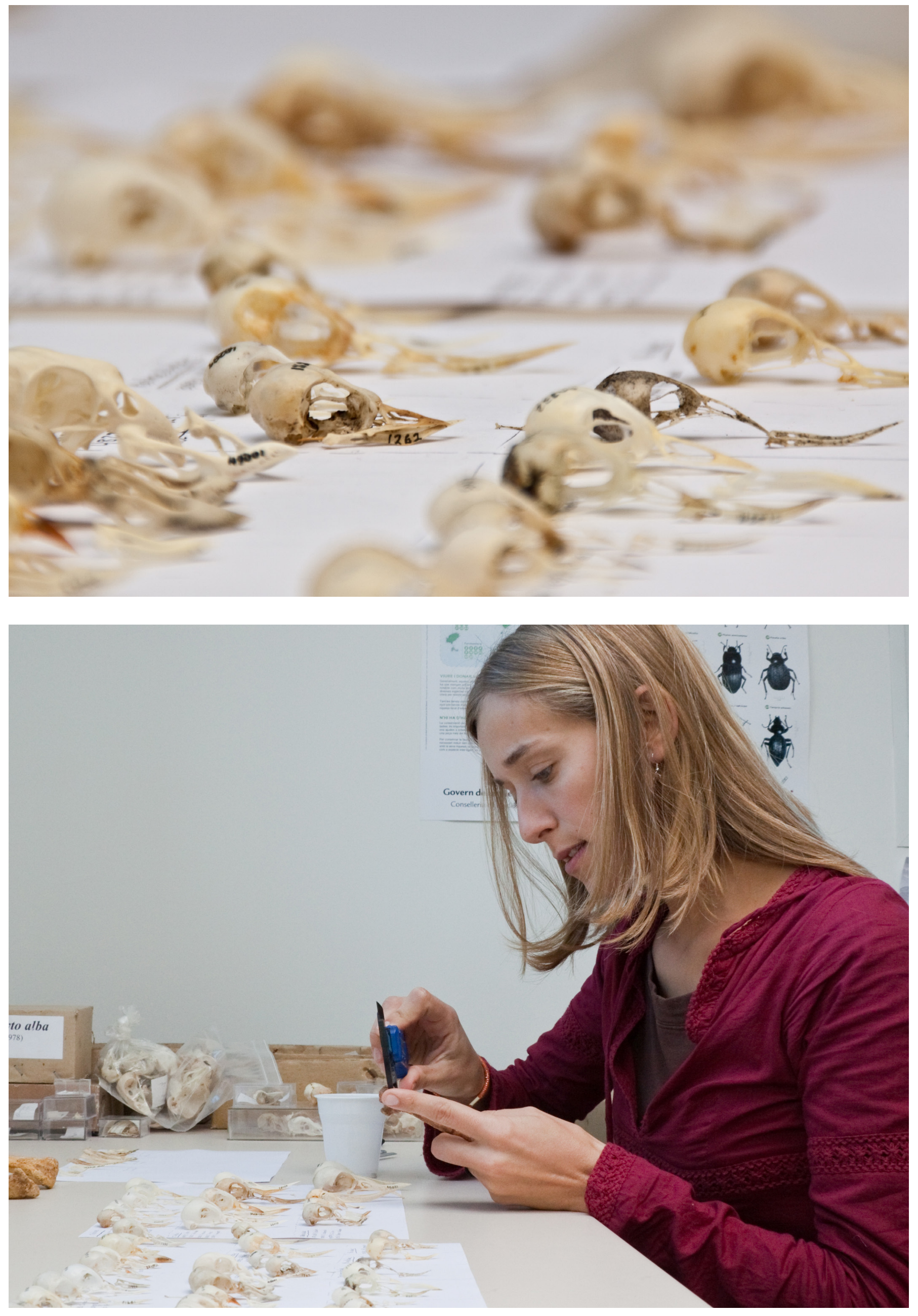
